FIELD METHODS FOR MEASUREMENT OF FLUVIAL SEDIMENT 


\title{
FIELD METHODS FOR MEASUREMENT OF FLUVIAL SEDIMENT
}

\author{
By Thomas K. Edwards and G. Douglas Glysson
}




\title{
DEPARTMENT OF THE INTERIOR DONALD PAUL HODEL, Secretary
}

\author{
U.S. GEOLOGICAL SURVEY \\ Dallas L. Peck, Director
}

For additional information write to:

Chief, Office of Surface Water U.S. Geological Survey 415 National Center 12201 Sunrise Valley Drive Reston, Virginia 22092
Copies of this report can be purchased from:

U.S. Geological Survey, Books and Open-File Reports Box 25425, Federal Center Denver, Colorado 80225 
DISCLAIMER

Reference to trade names, commercial products, manufacturers, or distributors in this manual is for identification purposes only and does not constitute an endorsement or a recommendation for use by the U.S. Geological survey. 


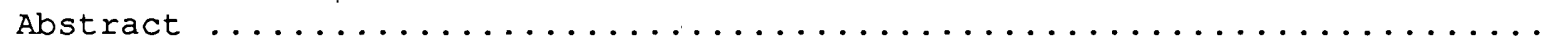

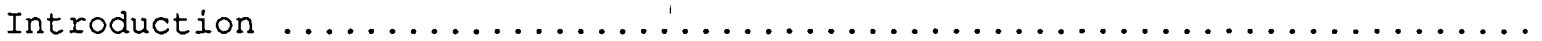

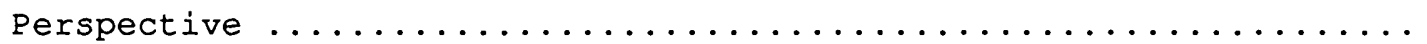

Sediment characteristics, source, and transport $\ldots \ldots \ldots \ldots \ldots \ldots \ldots$

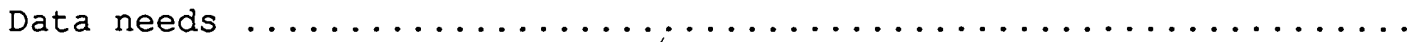

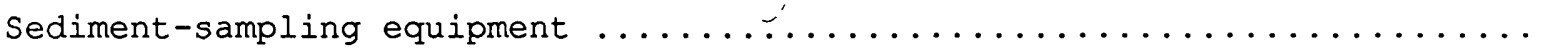

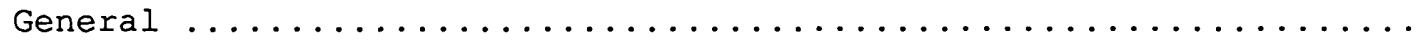

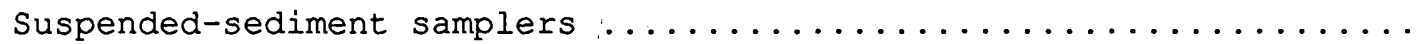

Depth- and point-integrating samplers ...............

Hand-held samplers--USS DH-81, US DH-75, US DH-48,

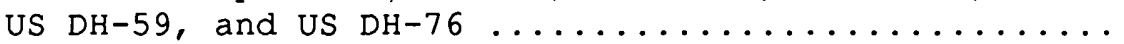

Cable-and-reel samplers--US D-74, US D-77, US P-61,

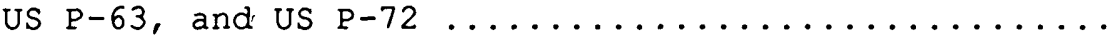

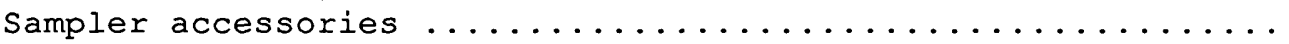

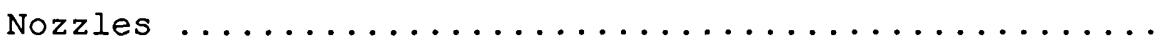

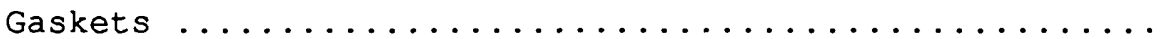

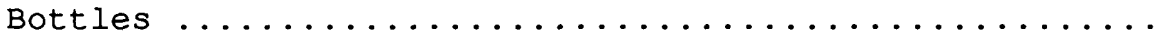

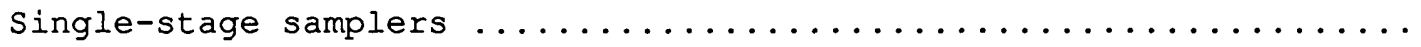

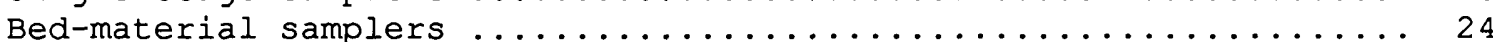

Limitations ............................. 24

Hand-held samplers--US BMH-53, US BMH-60, and US BMH-80 .... 25

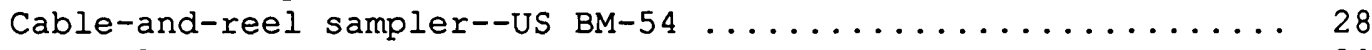

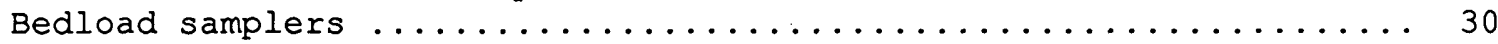

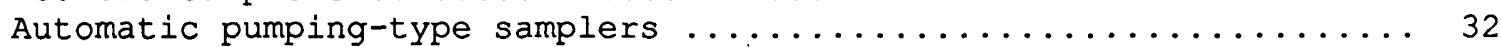

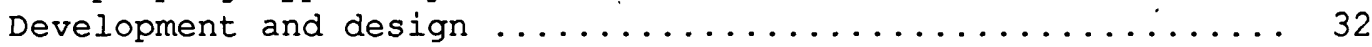

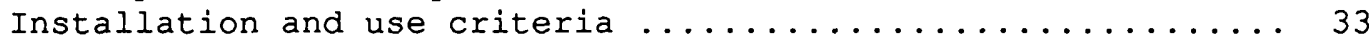

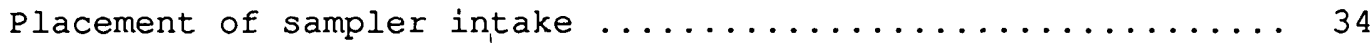

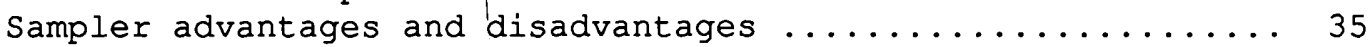

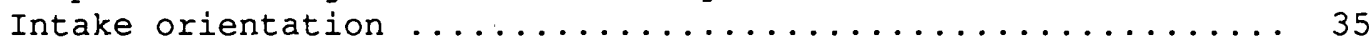

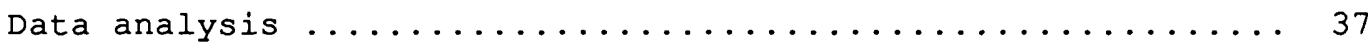

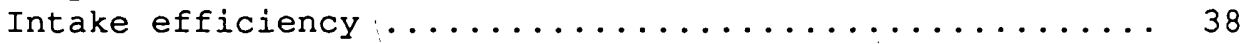

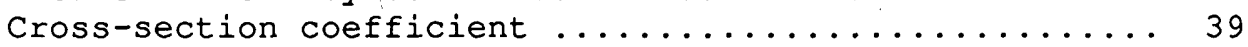

Description of automatic pump-type samplers--US PS-69,

US CS-77, US PS-82, Manning S-4050, and ISCO $1680 \ldots \ldots 39$

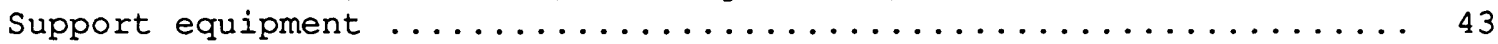

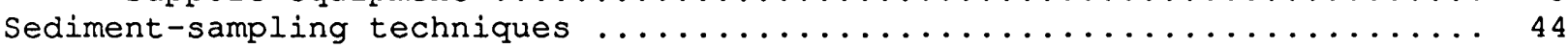

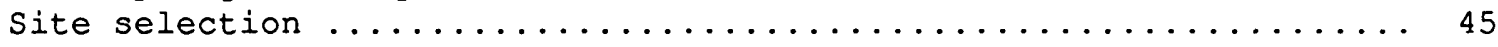

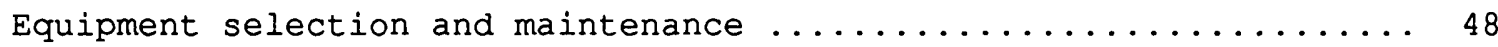

Suspended-sediment sampling methods ..................... 49

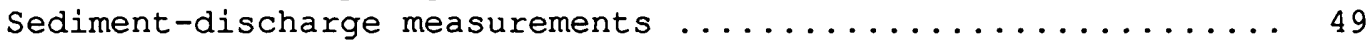

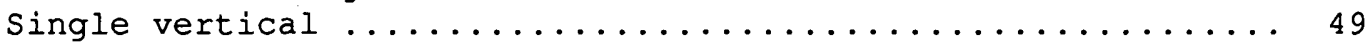

Surface and dip sampling ..................... 53

Multivertical ............................ 54

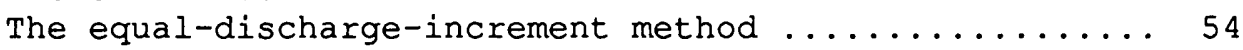

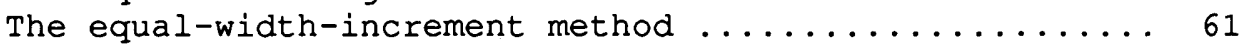

Advantages and disadvantages of the equal-dischargeincrement method and the equal-width-increment

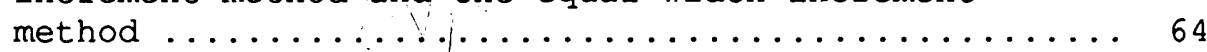

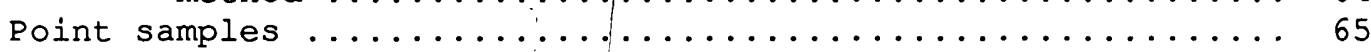

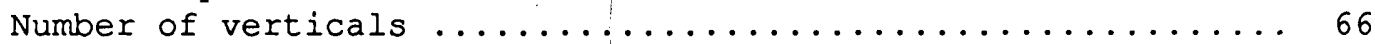

Transit rates for suspended-sediment sampling .......... 67

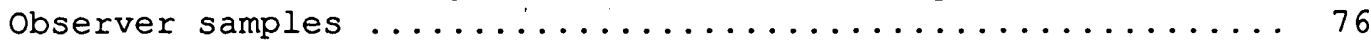


Sediment-sampling techniques (continued)

Suspended-sediment sampling methods (continued)

Sampling frequency, sediment quantity, sample integrity, and

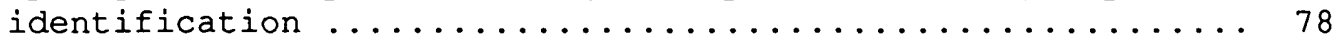

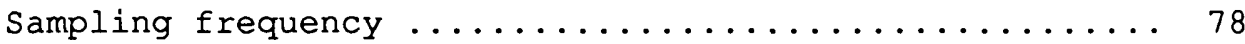

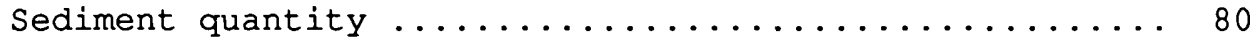

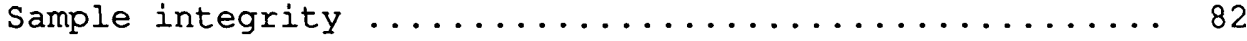

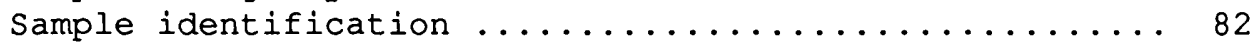

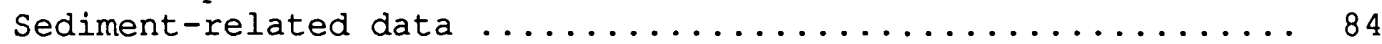

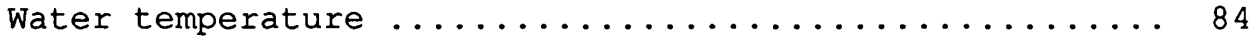

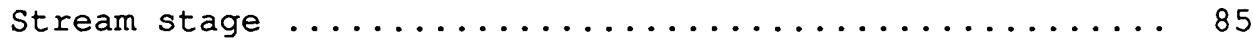

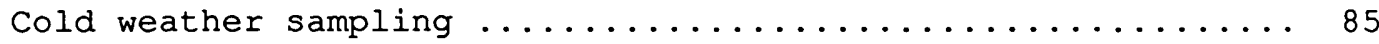

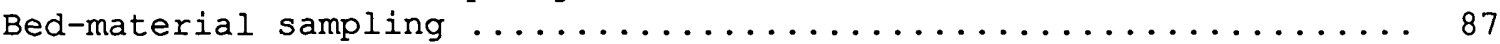

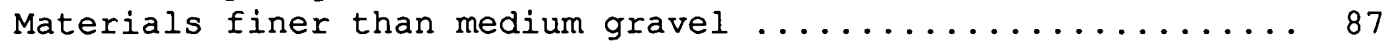

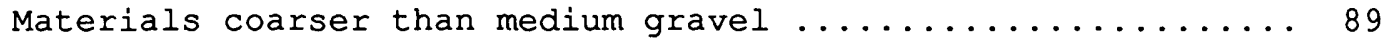

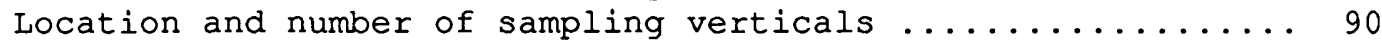

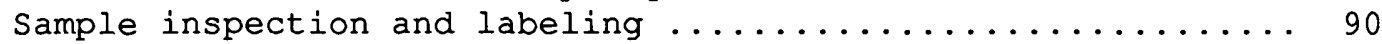

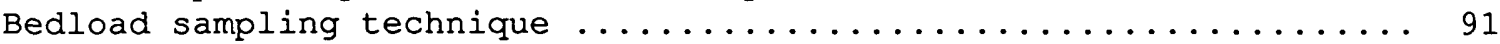

Computation of bedload discharge measurements .......... 103

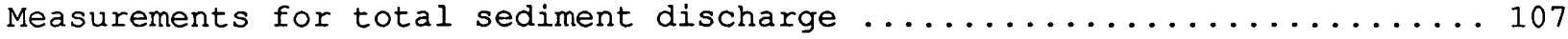

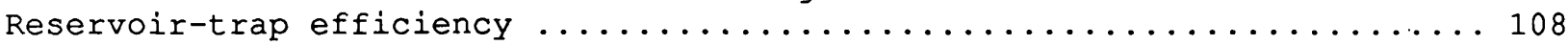

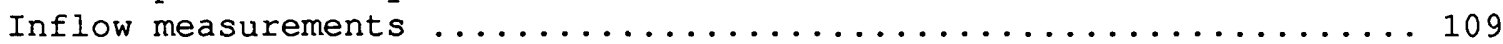

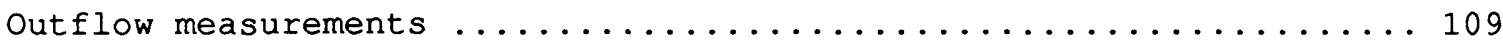

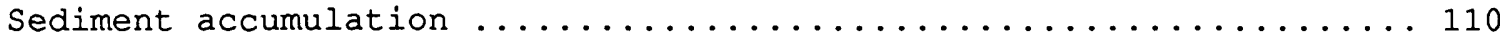

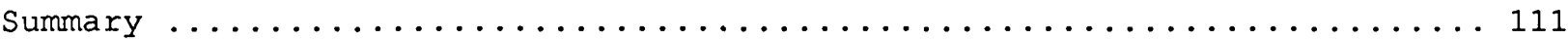

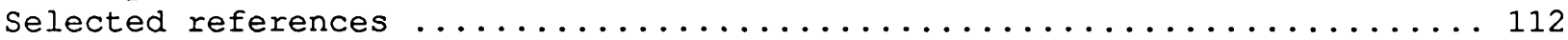

\section{ILLUSTRATIONS}

Figure 1. Diagram showing sampled and unsampled zones in a stream sampling vertical with respect to velocity of flow and sediment concentration ...................... 4

2-10. Photographs showing:

2. US DH-81 suspended-sediment sampler ............... 10

3. US DH-75 ( $P$ and $Q$ ) suspended-sediment samplers with

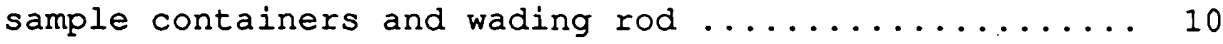

4. US DH-48 suspended-sediment sampler .............. 11

5. US DH-59 suspended-sediment sampler .............. 12

6. US DH-76 suspended-sediment sampler ............. 1 2

7. US D-74 suspended-sediment sampler .............. 13

8. US $\mathrm{D}-77$ suspended-sediment sampler $\ldots \ldots \ldots \ldots \ldots \ldots \ldots \ldots \ldots$

9. US $\mathrm{P}-61$ point-integrating suspended-sediment sampler ... 15

10. US $\mathrm{P}-63$ point-integrating suspended-sediment sampler ... 15

11. Diagram showing relation between intake velocity and sample

concentration for isokinetic and non-isokinetic sample

collection of particles greater than $0.062 \mathrm{~mm} \ldots \ldots \ldots \ldots 17$

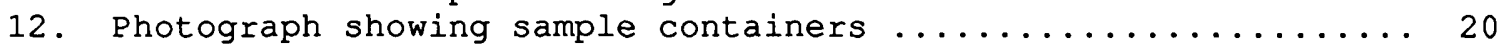

13. Sketch of US U-59 single-stage suspended-sediment sampler ... 21 


\section{ILLUSTRATIONS}

14-19. Photographs showing:

14. US U-73 single-stage suspended-sediment sampler ...... 24

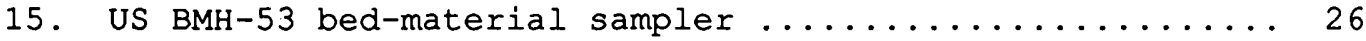

16. US BMH-60 bed-material sampler ................ 26

17a. US BMH-80 rotary-scoop bed-material sampler ......... 27

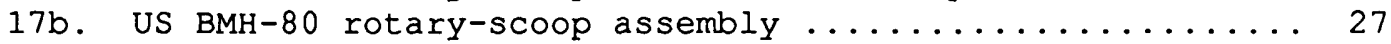

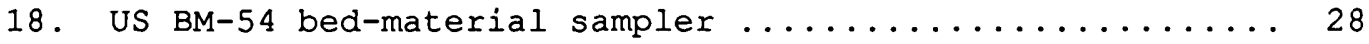

19. Vibra-core sampler prepared for coring ............ 29

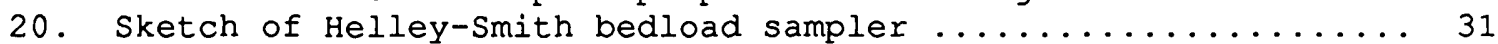

21-22. Diagrams showing:

21. Examples of pumping-sampler intake orientation ...... 36

22. Pumping effect on sediment streamlines within the zone (cone) of influence and velocity changes with distance

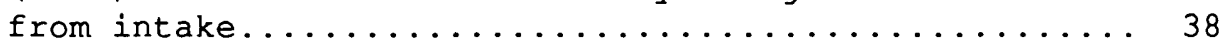

23-25. Photographs showing:

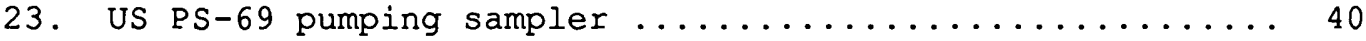

24. US CS-77 (Chickasha) pumping sampler ............ 42

25. US PS-82 pumping sampler .................. 42

26-29. Diagrams showing:

26. Examples of natural and artificially induced streamflow constrictions encountered at sediment-

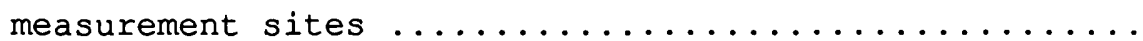

27. Sample bottle showing desired water levels and essential

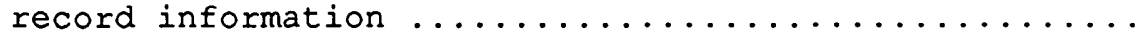

28. Use of point-integrating sampler to depth integrate deep

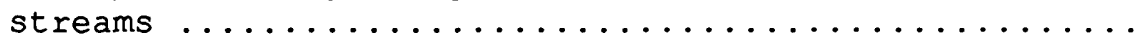

29. Equal-discharge increment--samples collected at the centroids of flow of each increment ............ 55

30. Discharge-measurement notes for Nehalem River near

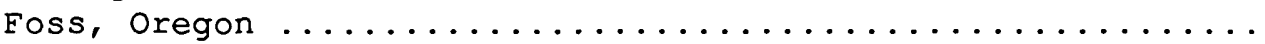

31. Discharge-measurement note sheet used to estimate the equal-discharge-increment centroid locations based on cumulative discharge and far-midpoint stationing ........ 32-34. Plots showing:

32. Cumulative discharge versus stations equal-dischargeincrement centroid determination ...............

33. Three cumulative discharges versus stations equaldischarge-increment centroid determination .........

34. Three cumulative percent of discharges versus stations equal-discharge-increment centroid determination ..... 60

35-37. Diagrams showing:

35: Vertical transit rate relative to sample volume collected at each equal-discharge-increment centroid ........ 60

36. Equal-width-increment sampling technique .......... 62

37. Equal-width-increment vertical transit rate relative to sample volume that is proportional to water discharge

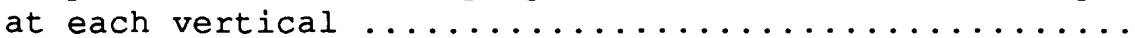

38. Nomograph to determine the number of sampling verticals required to obtain results within an acceptable relative

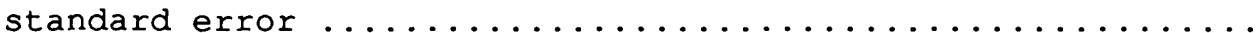


39a-41. Graphs showing:

39a. Ratio of transit rate to mean velocity: transit rate determination for 1/8-inch nozzle and pint bottle ....

39b. Ratio of transit rate to mean velocity: transit rate determination for 3/16-inch nozzle and pint bottle ... 69

39c. Ratio of transit rate to mean velocity: transit rate determination for 1/4-inch nozzle and pint bottle ... 70

40a. Ratio of transit rate to mean velocity: transit rate determination for 1/8-inch nozzle and quart bottle ... 70

40b. Ratio of transit rate to mean velocity: transit rate determination for 3/16-inch nozzle and quart bottle .. 71

40c. Ratio of transit rate to mean velocity: transit rate determination for 1/4-inch nozzle and quart bottle ... 71

41. Ratio of transit rate to mean velocity: transit rate determination for 5/16-inch nozzle and 3-liter

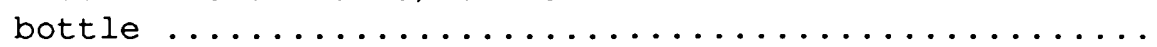

42-43. Diagrams showing:

42. Construction of a transit rate determination graph .....

43. Example of determining transit rate to mean velocity: transit rate determination for 3/16-inch intake nozzle

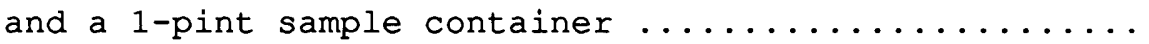

44. Graph showing minimum number of bottles of samples needed to

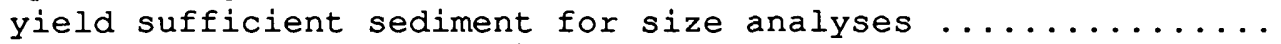

45. Example of inspection sheet for use by field person to record the kinds of measurements made and the stream conditions observed during a visit to a sediment measurement site .....

46-48. Graphs showing:

46. Temporal variation of bedload transport rates for 120 consecutive bedload samples from a stream with

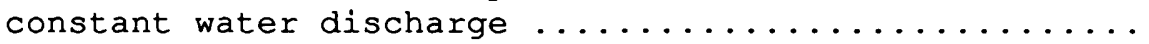

47. Comparison of cumulative probability distributions of bedload transport rates predicted by Einstein and

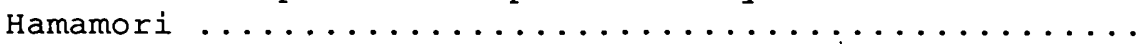

48: Examples of possible distribution of mean bedload

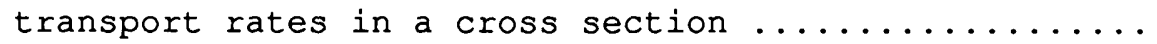

49. Diagram showing zones sampled by suspended-sediment and

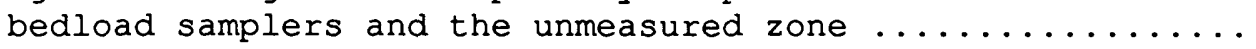

50. Graph showing percent error due to computing total sediment discharge of a size range by summing measured suspendedsediment discharge and discharge measured with a

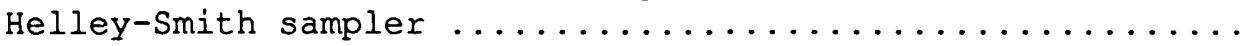

51-53. Diagrams showing:

51. Single equal width increment bedload sampling method ... 98

52. Multiple equal width increment bedload sampling method . 99

53. Unequal width increment bedload sampling method ....... 100

54. Graph showing variation in maximum probable errors with number of sampling traverses at 20 and 4 equally spaced verticals at cross sections with different bedload transport

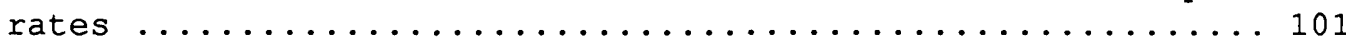


55-57. Diagrams showing

55. Total cross-section method for computing bedload discharge from samples collected with a Helley-Smith

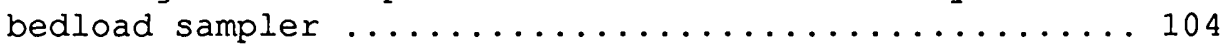

56. Midsection method for computing bedload discharge from samples collected with a Helley-Smith bedload

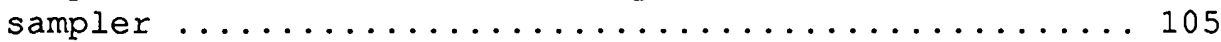

57. Mean-section method for computing bedload discharge from samples collected with a Helley-Smith bedload

TABLES

Page

Table 1. Sampler designations and characteristics .............. 8

2. Automatic pumping-type sampler evaluation ..............4 41

3. The desired quantity of suspended sediment required for

various sediment analyses ................... 80

4. Initial dry unit volume mass $\left(V_{t}\right)$ and $k$ factors for computing

dry unit volume mass of sediment deposits ............. 111 
[For the convenience of readers who prefer to use metric (International System) units rather than the inch-pound units used in this report, values may be converted by using the following factors.]

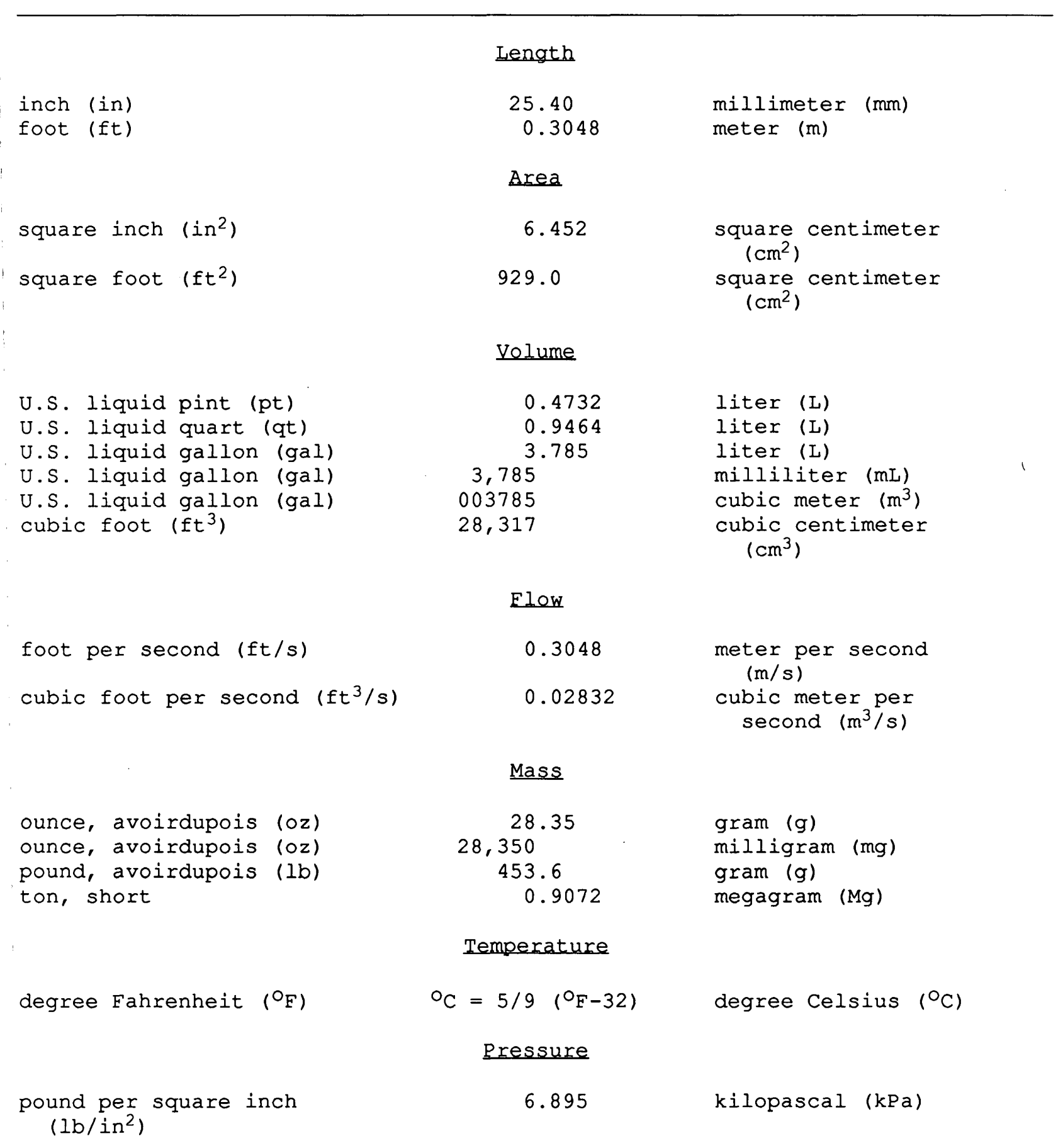


Concentration (Mass/Volume)

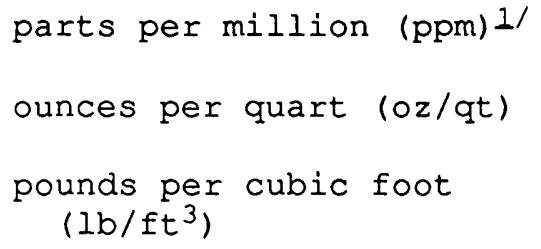

1.0
29,955
16,017

$1 /$ This conversion is true for

$\mathrm{mg} / \mathrm{L}=\mathrm{C}(\mathrm{ppm})=\mathrm{C}\left[\frac{\text { Weight of sediment } \times 10^{6}}{\text { Weight of water-sediment mixture }}\right]$

when the ratio of weight of sediment to weight of water-sediment mixture is between 0 and 8,000 . If this ratio is greater than 8,000 , the investigator is referred to Quality of Water Branch Technical Memorandum No. 72.10, tables 1 and 2, for the correct conversion factor to be used in the formula. 


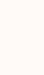

\section{.}

$\therefore-$ .

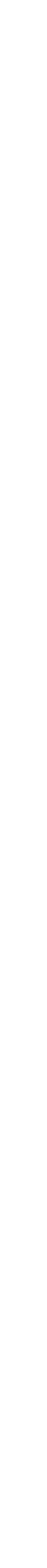


By Thomas K. Edwards and G. Douglas Glysson

\begin{abstract}
This report describes equipment and procedures for collection and measurement of fluvial sediment. The complexity of the hydrologic and physical environments and man's ever-increasing data needs make it essential for those responsible for the collection of sediment data to be aware of basic concepts involved in processes of erosion, transport, deposition of sediment, and equipment, and procedures necessary to representatively sample and measure sediment data.

In addition to an introduction, the report has two major sections. The "Sediment-Sampling Equipment" section encompasses discussions of characteristics and limitations of various models of depth- and point-integrating samplers, single-stage samplers, bed-material samplers, bedload samplers, automatic-pumping samplers, and support equipment. The "Sediment-Sampling Techniques" section includes discussions of representative sampling criteria, characteristics of sampling sites, equipment selection relative to the sampling conditions and needs, depth- and point-integration techniques, surface and dip sampling, determination of transit rates, sampling programs and related data, cold-weather sampling, bed-material and bedload sampling, measuring total sediment discharge, and reservoir sedimentation rates.
\end{abstract}

\title{
INTRODUCTION
}

\section{Perspective}

Knowledge of the erosion, transport, and deposition of sediment relative to land surface, streams, reservoirs, and other bodies of water is important to those involved directly or indirectly in the development and management of water and land resources. It is also becoming more and more important that such development and management be carried out in a manner that yields or conforms to a socially acceptable environment. The need for a clear understanding of hydrogeomorphologic processes associated with sediment makes necessary the measurement of suspended and bed sediments for a wide range of hydrologic environments. The complex phenomena of fluvial sedimentation cause the required measurements and related analyses of sediment data to be relatively expensive in comparison with other kinds of hydrologic data. Accordingly, the purpose of this manual is to help standardize and improve efficiency in the techniques used to obtain sediment data so that the quantity and quality of the data can be maximized for a given investment of labor and resource. Sediment data needs are of practical concern. Some of the general categories include:

1. The evaluation of sediment yield with respect to different natural environmental conditions--geology, soils, climate, runoff, topography, ground cover, and size of drainage area.

2. The evaluation of sediment yield with respect to different kinds of land use. 
3. The time distribution of sediment concentration and transport rate in streams.

4. The evaluation of erosion and deposition in channel systems.

5. The amount and size characteristics of sediment delivered to a body of water.

6. The characteristics of sediment deposits as related to particle size and flow conditions.

7. The relations between sediment chemistry, water quality, and biota.

The scope of these requirements indicates that a wide variety of measurements are needed on streams and other bodies of water, ranging from large river basins to very small tributaries that drain areas, such as parcels of land under urban development.

The equipment and methods discussed in this report for the collection of a suspended-sediment sample are designed to yield a representative sample of the water-sediment mixture. This representative sample may be analyzed for sediment concentration, particle-size distribution, or, if collected with the proper type sampler, any other dissolved, suspended, or total waterquality constituent. Therefore, the equipment and methods described in this report should also be used to collect a representative sample for waterquality analysis. Procedures for the processing of surface-water and bed-material samples for water-quality analysis may be found in the U.S. Geological Survey Techniques of Water-Resources Investigations "Method for Collection of Surface-Water and Bed-Material Samples for Chemical Analysis" (in preparation).

Sediment Characteristics, Source, and Transport

Sediment is fragmental material transported by, suspended in, or deposited by water or air, or accumulated in beds by other natural agents. Sediment particles range in size from large boulders to colloidal-size fragments and vary in shape from rounded to angular. They also vary in mineral composition and specific gravity, the predominant mineral being quart $z$ and the representative specific gravity, 2.65 .

Sediment is derived from any parent material subjected to erosional processes by which particles are detached and transported by gravity, wind, water, or a combination of these agents. When the transporting agent is water, the sediment is termed "fluvial sediment." The Geological survey defines fluvial sediment as fragmentary material that originates mostly from weathering of rocks and is transported by, suspended in, or deposited from water (Federal Interagency Sedimentation Project [F.I.S.P.], 1963b); it includes chemical and biological precipitates and decomposed organic material such as humus.

Erosion by water is classified as either sheet or channel erosion, with no distinct division between the two. Sheet erosion occurs when sediments are removed from a surface in a sheet of relatively uniform thickness by raindrop splash and sheet flow. Sediment-particle movement and the energy of the raindrops compact and partially seal the soil surface, effectively decreasing the infiltration rate and increasing the amount of flow available to erode and transport the sediment. The amount of material removed by sheet erosion 
is a function of surface slope, erodibility, and precipitation intensity and drop size.

Land-surface irregularities inhibit continuous sheet flow over large areas. This inhibition serves to concentrate the flow into small rills or channels and streams, which increase in size as they join together downstream. Within these channels, eroded material from the banks or bed of the stream is contributed to the flow until, in theory, the stream is transporting as much sediment as the energy of the stream will allow. Such channel erosion may be general or local along the stream but is primarily local in nature.

Thus, as streamflow is initiated and propagated by accumulation of sheet flow and small rills into channels and streams, it follows that predominantly fluvial sediment for transport is provided by accumulation of particles dislodged and conveyed by the erosional forces associated with these phases of flow. Some sediment is carried to streams by wind, but direct contribution to the stream channel by this conveyance usually accounts for only a small part of the total fluvial sediments. Aside from bank caving as a result of stream erosion or processes of mass wasting (Thornbury, 1969), gravitational transfer of sediments occurs toward and into streams. Conveyance by gravitational means ranges from slow creep to rapid landslide. Other significant sources of local sediments are glacial-melt outwash, volcanic activity, and mining, earth movement, construction, or additional land-disturbance activities by man.

The stream usually transports sediment by maintaining the finer particles in suspension with turbulent currents and by rolling or skipping the coarser particles along the streambed. Generally, the finer sediments move downstream at about the same velocity as the water, whereas the coarsest sediments may move only occasionally and remain at rest much of the time.

Vertical distributions of suspended-sediment particle sizes may vary among streams and among cross sections within a stream. However, as a general rule the finer particles are uniformly distributed throughout the vertical and the coarser particles are concentrated near the streambed. Occasionally coarse particles may reach the water surface, generally carried by turbulent flow or as a result of dispersive grain stress (Leopold and others, 1964). Thus, with use of the depth- or point-integrating suspended-sediment samplers described here, the sample obtained generally contains a range of particle sizes representative of the suspended-sediment discharge at the sampled vertical. The vertical is divided into two zones, as illustrated by figure 1. This separation is due to the design of the sampler, which limits the effective sampled depth. Sampling the entire depth is not possible because the physical location of the sampler nozzle relative to the bottom of the sampler prevents the nozzle from passing through the zone close to the bed. This portion of the depth is termed the unsampled zone and characteristically carries the higher concentration and coarser particles. The unsampled suspended sediment moving within this zone may or may not account for a large part of the total suspended sediment, depending upon the depth, velocity, and turbulence of the flow through the vertical. The sampled zone is the portion of the vertical through which the sampler traverses during collection, exposing the cross-sectional area of the nozzle to the approaching suspendedsediment particles. The measured sediment discharge is nearly equal to the total sediment discharge if the velocity and turbulence conditions within the sampled vertical overcome the tractive force transporting the bedload in the unmeasured zone and effectively disperse all of the sediment being transported into suspension throughout the total depth. 


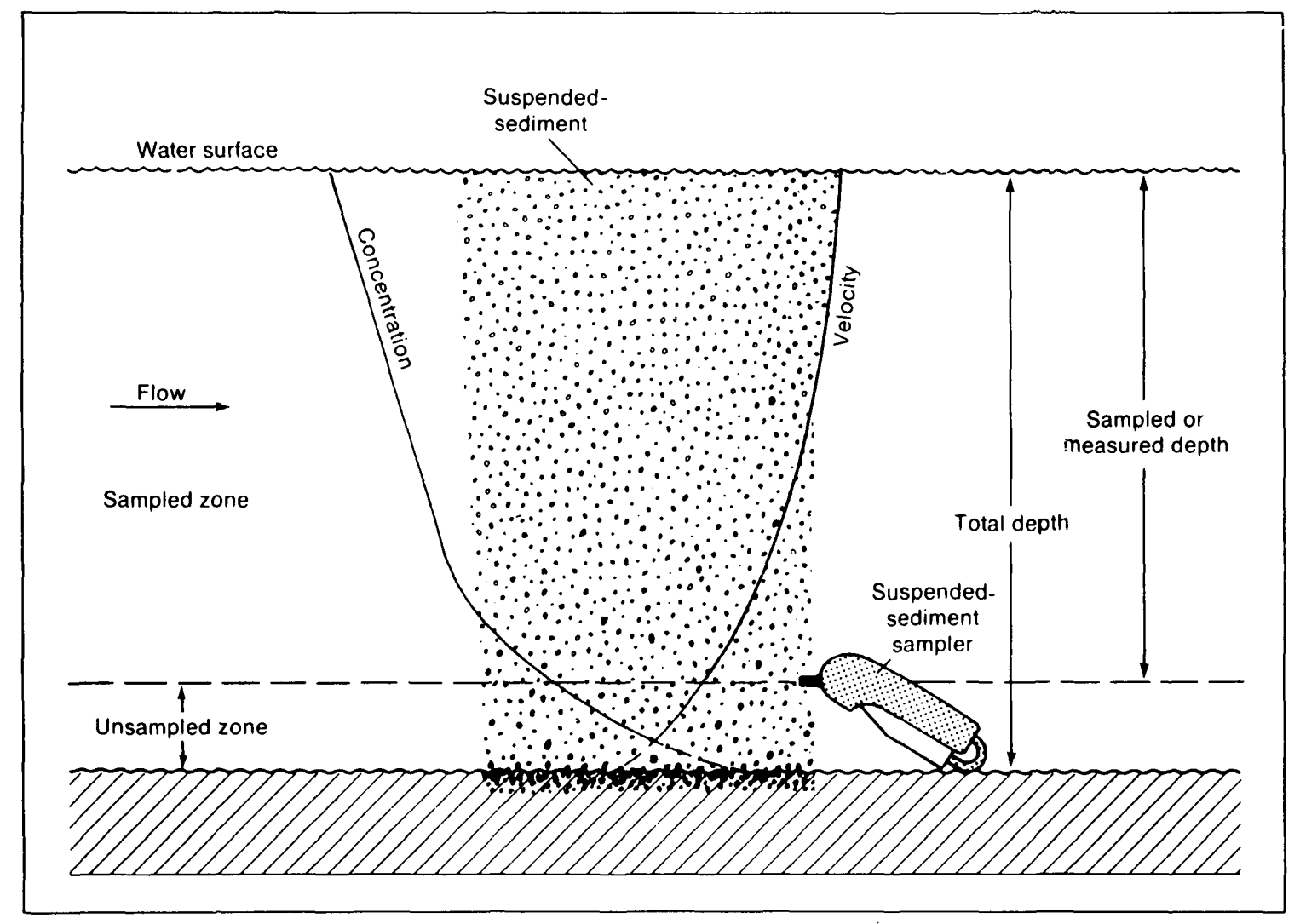

Figure 1.--Sampled and unsampled zones in a stream sampling vertical with respect to velocity of flow and sediment concentration.

The preceding discussion illustrates the complexity of the study of fluvial-sediment transport and some of the many variables involved. The interested reader is directed to more detailed works concerning fluvialsediment concepts and geomorphic processes, such as the contributions by colby (1963); Leopold and others (1964); Guy (1970), and Vanoni (1975). The investigator can also obtain pertinent information on the subject by contacting the F.I.S.P., St. Anthony Falls Hydraulics Lab, Minneapolis, Minnesota.

\section{Data Needs}

No matter how precise the theoretical prediction of sedimentation processes becomes, it is inevitable that man's activities will continue to cause changes in the many variables affecting sediment erosion, transportation, and deposition; thus there will be an increasing need for direct and indirect measurement of fluvial-sediment movement and its characteristics. Because of the rapid advances in technology, it seems of little value to list the many specific kinds of sediment problems and the kinds of sediment data required to solve such problems. However, some general areas of concern may be of interest.

Sediment data are useful in coping with problems and goals related to water utilization. Many industries require sediment-free water in their processes. A knowledge of the amount and characteristics of sediment in the water resource is needed so that the sediment may be removed as economically 
as possible before the water is allowed to enter a distribution system. Information on sediment movement and particle-size characteristics is needed in the design of hydraulic structures such as dams, canals, and irrigation works. Streams and reservoirs that are free of sediment are highly regarded for recreation. Data on sediment movement and particle characteristics are needed to determine and understand how radionuclides, pesticides, and many organic materials are absorbed and concentrated by sediments, thus causing potential health hazards in some streams, estuaries, and water-storage areas. Knowledge concerning the effect of natural and manmade changes in drainage basins on the amount and characteristics of sediment yielded from the drainage basins is useful in helping to predict the stream environment when future basin changes are made. Knowledge about present fluvial-sediment conditions is being used to help establish criteria for water-quality standards and goals.

These data needs require sediment programs that will yield (1) comprehensive information on a national network basis; (2) special information about specific problem areas for water management; and (3) a description and understanding of the relations between water, sediment, and the environment (basic research). The reader is referred to Book 3, Chapter C1, of this series (Guy, 1970, p. 47) for a description of the kinds of sediment records commonly obtained at stream sites. Briefly, the records are of (1) the continuous or daily-record type, where sampling is sufficiently comprehensive to permit computation of daily loads, (2) the partial-record type, where a daily record is obtained for only a part of the year, and (3) the periodic-record type, where samples are taken periodically or intermittently. Usually a series of "reconnaissance" measurements is made prior to implementing any of these three programs. Even after a specific program is started, it is possible that adjustments may be necessary with respect to equipment, sample timing, or even measurement location. Realignment of efforts in this manner can be avoided in many instances by carefully applying design criteria to adequately meet the objectives of the project.

\section{SEDIMENT-SAMPLING EQUIPMENT}

\section{General}

In the early days of fluvial-sediment investigations, each investigator or at least each agency concerned with sediment developed methods and equipment individually as needed. It soon became apparent that consistent data could not be obtained unless equipment, data collection, and analytical methods were standardized. To overcome this difficulty, representatives of several Federal agencies (the Corps of Engineers of the Department of the Army, the Flood Control Coordinating Committee of the Department of Agriculture, the Geological Survey, the Bureau of Reclamation, the office of Indian Affairs of the Department of the Interior, and the Tennessee Valley Authority) met in 1939 to form an Interdepartmental Committee with the expressed purpose of standardizing sediment data-collection equipment, methods, and analytical techniques. The test facility for this work was initially located at the Iowa State University Hydraulic Laboratory in Iowa City, Iowa, and remained there for 9 years. In 1946 the committee became known as the subcommittee on Sedimentation of the Federal Interagency River Basin Committee. In 1948 the committee moved the test facility to its present location at the St. Anthony Falls Hydraulic Laboratory, University of Minnesota in Minneapolis, Minnesota. The Subcommittee reorganized the project in 1956 to its present structure as the F.I.S.P. The project is sponsored by a Technical Committee that is presently (1988) composed of representatives of the Army Corps of Engineers, Geological Survey, Bureau of Reclamation, Agricultural Research Service, 
Tennessee Valley Authority, Federal Highway Administration, and the Bureau of Land Management, working under a formal Guidance Memorandum describing the project's objectives and organization. Presently (1988) the F.I.S.P. is overseen by the Technical Committee of the Subcommittee on Sedimentation of the Interagency Advisory Committee of Water Data.

Since its initiation in 1939, approximately 50 reports dealing with nearly all aspects of measurement and analysis of fluvial sediment movement have been published by F.I.S.P. The intent of this chapter is not to replace the interagency project reports, but to condense and combine their information regarding sediment measurements. Therefore the interested reader should refer to the F.I.S.P. reports listed in the interagency report "Catalog" for further background material and details on the standard samplers. Sampling equipment is available for purchase by any interested investigator from the F.I.S.P. and from the Geological Survey's Hydrologic Instrumentation Facility (HIF) located at Bay St. Louis, Mississippi.

The samplers developed by the F.I.S.P. are designated by the following codes:

- US, United States standard sampler--(In the following discussions, this code will appear in the initial reference but will be dropped from succeeding references to the sampler designations.)

- $D$, depth integrating

- P, point integrating

- $\mathrm{H}$, hand-held by rod or line--(This code is placed after the primary letter designation and is omitted when referring to cable- and reel-suspended samplers.)

- BM, bed material

- BP, battery pack

- U or SS, single stage

- PS or CS, pumping-type sampler

- Year, last 2 digits of the year in which the sampler was developed

Sediment samplers currently available (1988) from F.I.S.P. or HIF include seven depth-integrating suspended-sediment samplers, three point-integrating suspended-sediment samplers, two pumping samplers, four bed-material samplers, and one bedload sampler. In addition, an array of instruments has been developed to fulfill the need for collecting samples during unpredictable high-flow events. One sampler of particular interest for use in the future is a suspended-sediment sampler that utilizes bags as sample containers with a US D-77 sampler to overcome the depth limits of standard samplers due to container size, nozzle diameter, and stream velocity (Szalona, 1982).

\section{Suspended-Sediment Samplers}

The purpose of a suspended-sediment sampler is to obtain a representative sample of the water-sediment mixture moving in the stream in the vicinity of the sampler. The F.I.S.P. committee set up several criteria for the design and construction of suspended-sediment samplers:

1. To allow water to enter the nozzle isokinetically. (In isokinetic sampling, water approaching the nozzle undergoes no change in speed or direction as it enters the orifice.) 
2. To permit the sampler nozzle to reach a point as close to the streambed as physically possible. (This varies from $31 / 2$ to 7 inches, depending on the sampler.)

3. To minimize disturbance to the flow pattern of the stream, especially at the nozzle.

4. To be adaptable to support equipment already in use for streamflow measurement.

5. To be as simple and maintenance free as possible.

6. To accommodate a standard bottle size (that is, 1-pint (473 milliliters [mL]) glass bottle, 1-quart (946 mL) glass, 1-liter (1,000 $\mathrm{mL})$ plastic, 2-liter $(2,000 \mathrm{~mL})$ plastic, or 3-liter $(3,000 \mathrm{~mL})$ plastic, as listed in table 1).

When a suspended-sediment sampler is submerged with the nozzle pointing directly into the flow, a part of the streamflow enters the sampler container through the nozzle as air in the container exhausts under the combined effect of three forces:

1. the positive dynamic head at the nozzle entrance, due to the flow;

2. a negative head at the end of the air-exhaust tube, due to flow separation; and

3. a positive pressure due to a difference in elevation between the nozzle entrance and the air-exhaust tube.

When the sample in the container reaches the level of the air-exhaust, the flow rate drops and circulation of the streamflow in through the nozzle and out through the air-exhaust tube occurs. Because the velocity of the water flowing through the bottle is less than the stream velocity, the coarser particles settle out, causing the concentration of coarse particles in the bottle to gradually increase.

\section{Depth- and Point-Integrating Samplers}

A depth-integrating sampler is designed to isokinetically and continuously accumulate a representative sample from a stream vertical while transiting the vertical at a uniform rate (F.I.S.P., 1952, p. 22). The simple depth-integrating sampler collects and accumulates a velocity or dischargeweighted sample as it is lowered to the bottom of the stream and raised back to the surface.

The point-integrating sampler, on the other hand, uses an electrically activated valve, enabling the operator to isokinetically sample points or portions of a given vertical. For stream cross sections less than 30 feet deep, the full depth can be traversed in one direction at a time by opening the valve and depth integrating either from surface to bottom or vice versa. Stream cross sections deeper than 30 feet can be integrated in segments of 30 feet or less by collecting "integrated-sample pairs" consisting of a downward integration and a corresponding upward integration in separate containers. 


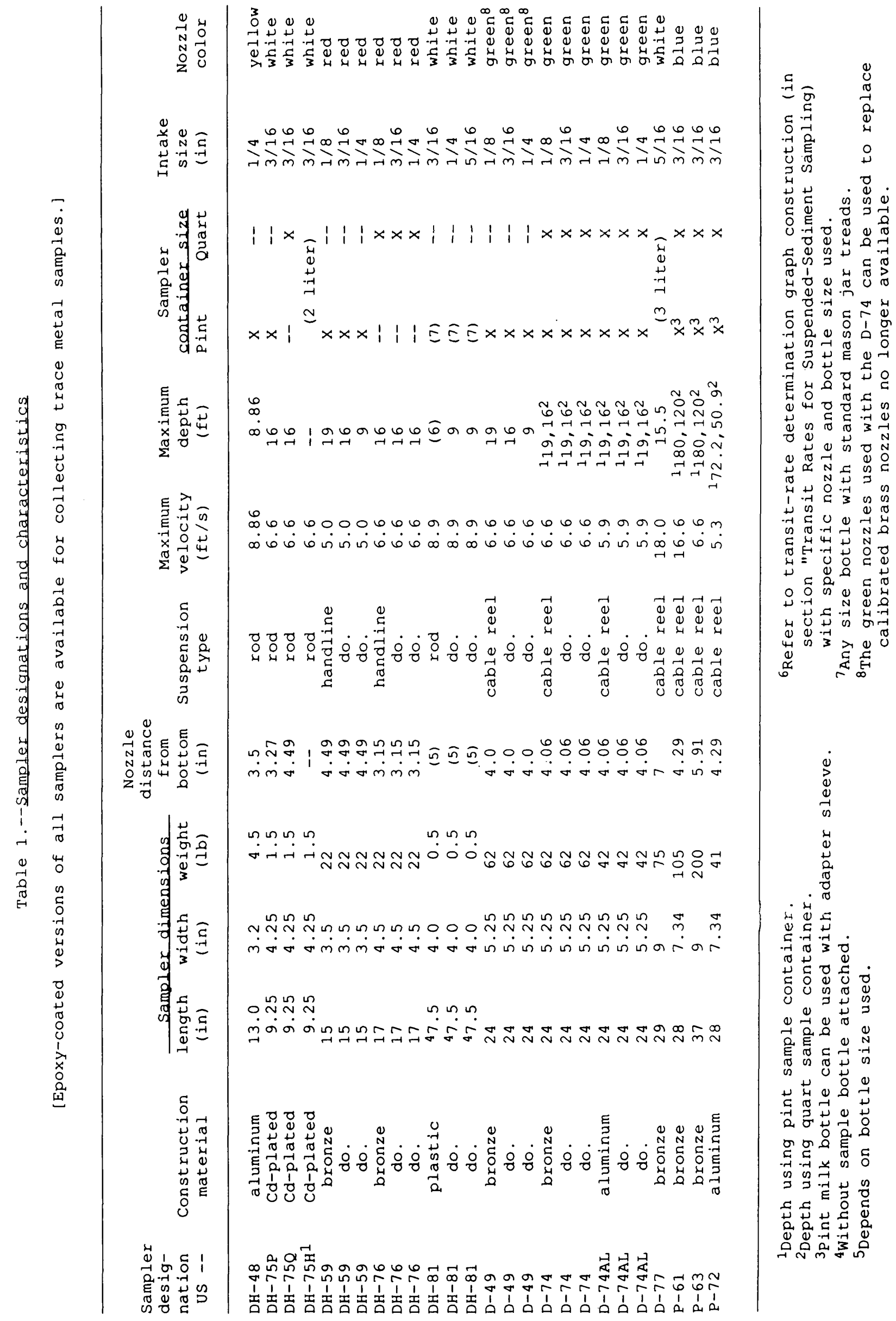


To eliminate confusion and more adequately differentiate between depthand point-integrating samplers, a direct reference to Interagency Report 14 (F.I.S.P., 1963b, P. 60) is presented here to describe the characteristics of the point-integrating samplers which make them useful in conditions beyond the limits of the simpler depth-integrating samplers.

Point-integrating samplers are more versatile than the simpler depth-integrating types. They can be used to collect a suspendedsediment sample representing the mean sediment concentration at any point from the surface of a stream to within a few inches of the bed, as well as to integrate over a range in depth. These samplers were designed for depth integration of streams too deep (or too swift) to be sampled in a continuous round-trip integration. When depth integrating, sampling can begin at any depth and proceed either upward or downward from that initial point through a maximum vertical distance of 30 feet.

A point-integrating sampler uses a 3/16-inch nozzle oriented parallel to the streamflow with the cross-sectional area exposed to approaching particles. The air is exhausted from the sample container and directed downstream away from the nozzle area as the sample enters. The intake and exhaust passages are controlled by a valve that can be activated on demand. When the valve is activated (opened to the sampling position), the sampling procedure is identical to that used for depth-integrating samplers. The increased effective depth to which a point-integrating sampler can be used, as compared to the maximum sampling depth to which a depth-integrating sampler is limited, is made possible by a pressure-equalizing chamber (diving-bell principle) enclosed in the sampler body. This chamber equalizes the air pressure in the sample container with the external hydrostatic head near the intake nozzle at all depths to alleviate the inrush of sample water, which would otherwise occur when the intake and air exhaust are opened at depth.

Hand-held samplers--US DH-81, US DH-75, US DH-48, US DH-59, and US DH-76

Where streams are wadable or access can be obtained from a low bridge span or cableway, a choice of five lightweight samplers can be used to obtain suspended-sediment samples via a wading rod or handine.

The "DH-81" (fig. 2) is a new sampler, constructed of polyprophylene plastic; the nozzle, head, and collar are all autoclavable. This construction enables the samplex to be used for collection of depth-integrated samples for bacterial analysis. The DH-81 can be used with 1/8-, 3/16-, or 1/4-inch nozzles and is suspended from a rod. Any bottle having standard mason jar threads can be used with this sampler. Obviously the height of the unmeasured zone will vary depending on the size of bottle used. The DH-81 should be useful for sampling during cold weather because the plastic sampler head and nozzle attach directly to the bottle, eliminating a metal body (which would more rapidly conduct heat away from the nozzle, air exhaust, and bottle and create a more severe sampler-freezeup condition).

The "DH-75" (fig. 3) weighs 0.9 pound (lb) and is available in two versions, the "DH-75P" and "DH-75Q," which accept plastic containers of pint and quart volumes respectively. The sampler consists of a cadmium-plated sheet-steel body 9-1/4 inches long, excluding the nozzle and sample container, with a retainer piece and shock cord assembly to hold the sample container against a cast silicone stopper through which the 3/16-inch nozzle and $180^{\circ}$ air-exhaust tube pass to the mouth of the bottle. The DH-75 was developed as 


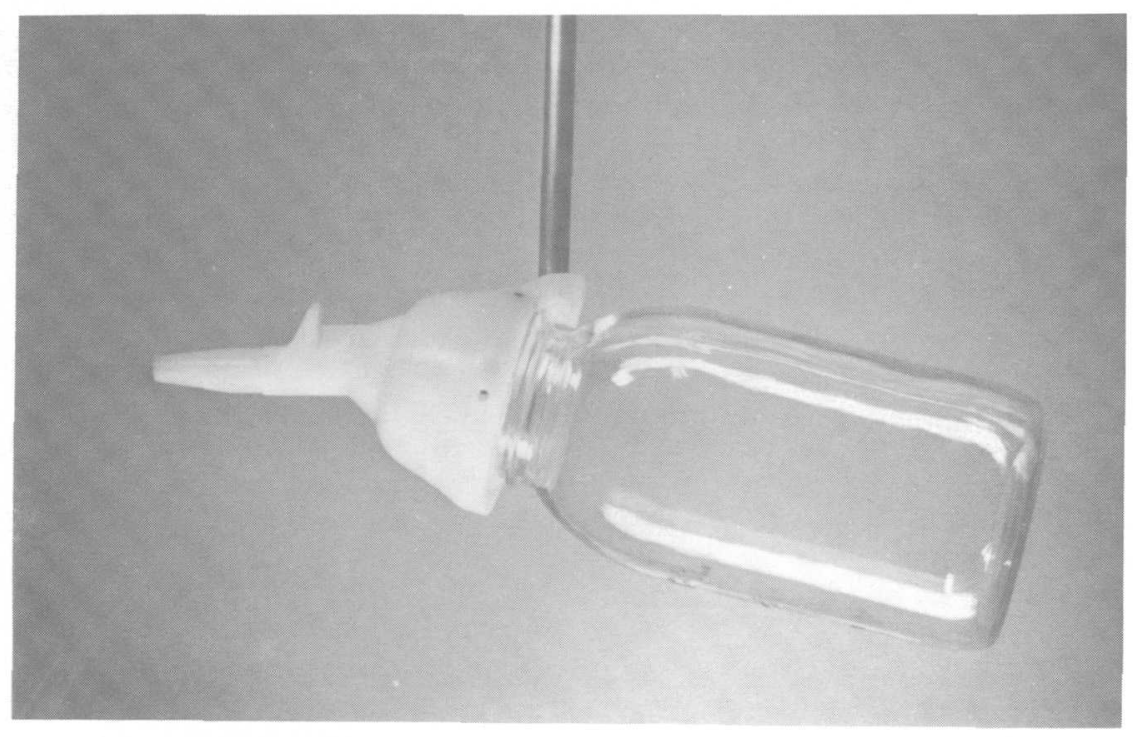

Figure 2.--US DH-81 suspended-sediment sampler.

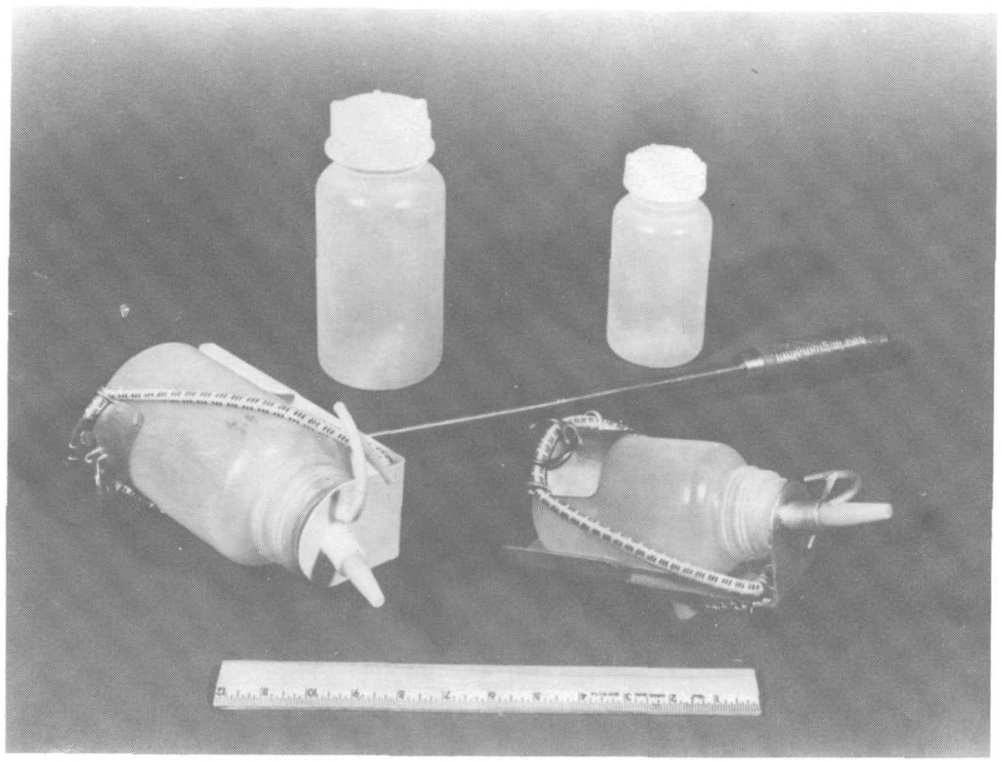

Figure 3.--US DH-75 ( $\mathrm{P}$ and $\mathrm{Q}$ ) suspended-sediment samplers with sample containers and wading rod.

a freeze-resistant sampler but can be used in wadable cross sections as a general purpose depth-integrating suspended-sediment sampler.

The "DH-48" sampler (fig. 4) features a streamlined aluminum casting 13 inches long that partly encloses the sample container. The container, usually a round pint glass milk bottle, is sealed against a gasket recessed in the head cavity of the sampler by a hand-operated spring-tensioned pull-rod assembly at the tail of the sampler. A modified version of this sampler is 
available to accommodate square pint bottles also. The sample enters the container through the intake nozzle as the air from the container is displaced and exhausted downstream through the air exhaust. The sampler, including container, weighs $4 \mathrm{l} / 2 \mathrm{lb}$ and can sample to within $31 / 2$ inches of the streambed. This instrument is calibrated with an intake nozzle $1 / 4$ inch in diameter but may be used with a 3/16-inch nozzle in high flow velocities situations (F.I.S.P., 1963b, p. 57-60).

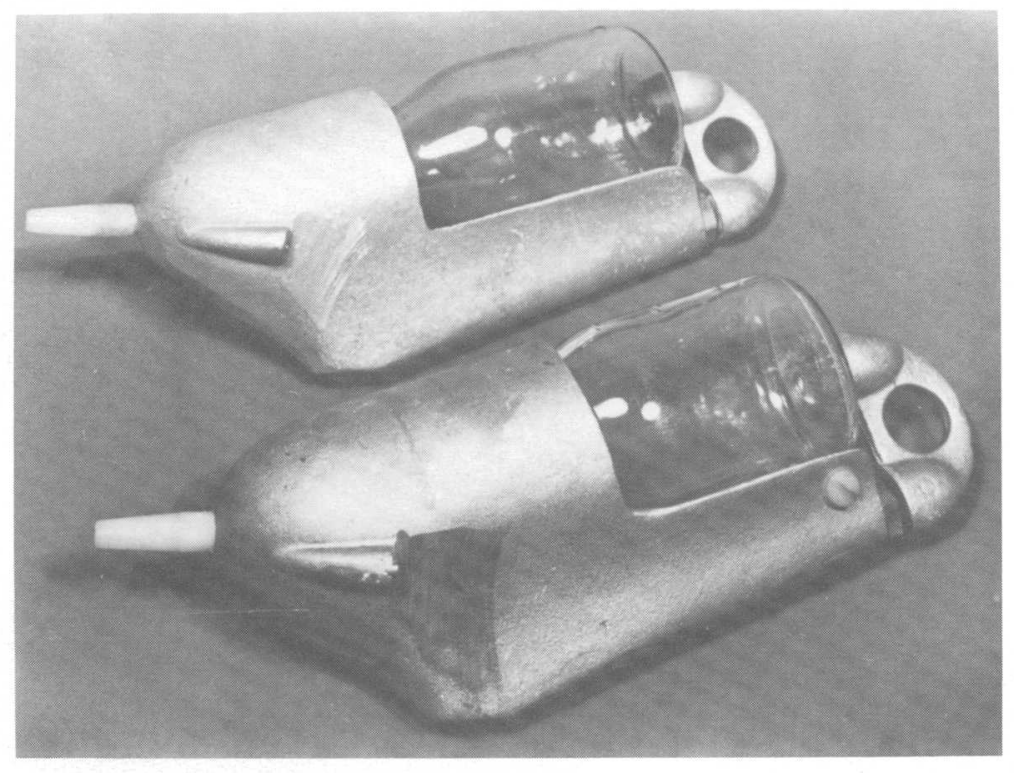

Figure 4.--US DH-48 suspended-sediment sampler.

Two lightweight (24 and $25 \mathrm{lb}$ ) handline samplers, designated "DH-59" and "DH-76" (figs. 5 and 6), are designed for use in shallow, unwadable streams with flow velocities up to 5 feet per second (ft/s). These samplers feature streamlined bronze castings 15 and 17 inches in length for the DH-59 and DH-76 respectively. The DH-59 accommodates a round pint sample bottle, while the DH-76, a more recent version of the sampler, is designed to take a quart container. The tail assembly extends below the body of the casting to assure sampler alignment parallel to the flow direction with the intake nozzle entrance oriented upstream. Intake nozzles of 1/8-inch, 3/16-inch, and 1/4inch diameters are calibrated for use with these samplers and may be interchanged as necessary when varying flow conditions are encountered from stream to stream. Suspended sediment can be collected to within $41 / 2$ inches of the streambed with the DH-59, while the DH-76 can sample to within about 4 inches from the bottom.

These lightweight hand samplers are the most commonly used for sediment sampling during normal flow in small- and perhaps intermediate-sized streams. Because they are small, light, durable, and adaptable, they are preferred by hired observers and field people on routine or reconnaissance measurement trips. At many locations, a heavier sampler will be needed only for high-flow periods. It is often desirable, however, to require the observer to use a heavier sampler installed at a fixed location. The small size of the hand samplers also enables the person taking a sample in cold weather to warm the sampler readily if water freezes in the nozzle or air exhaust. 


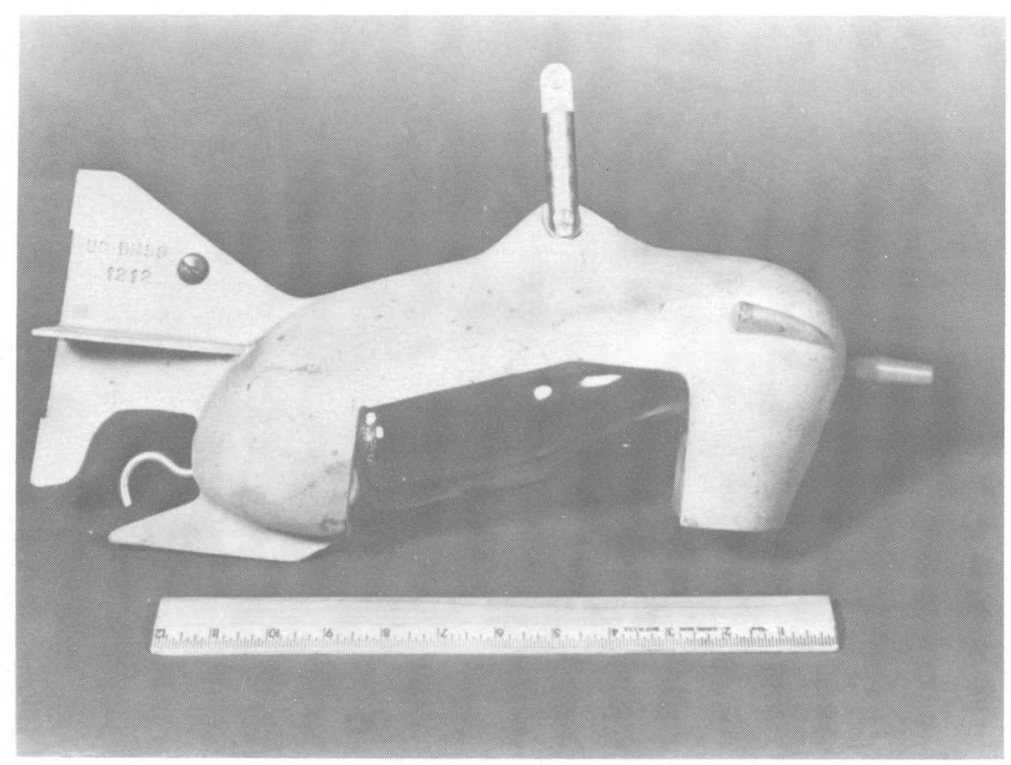

Figure 5.--US DH-59 suspended-sediment sampler.

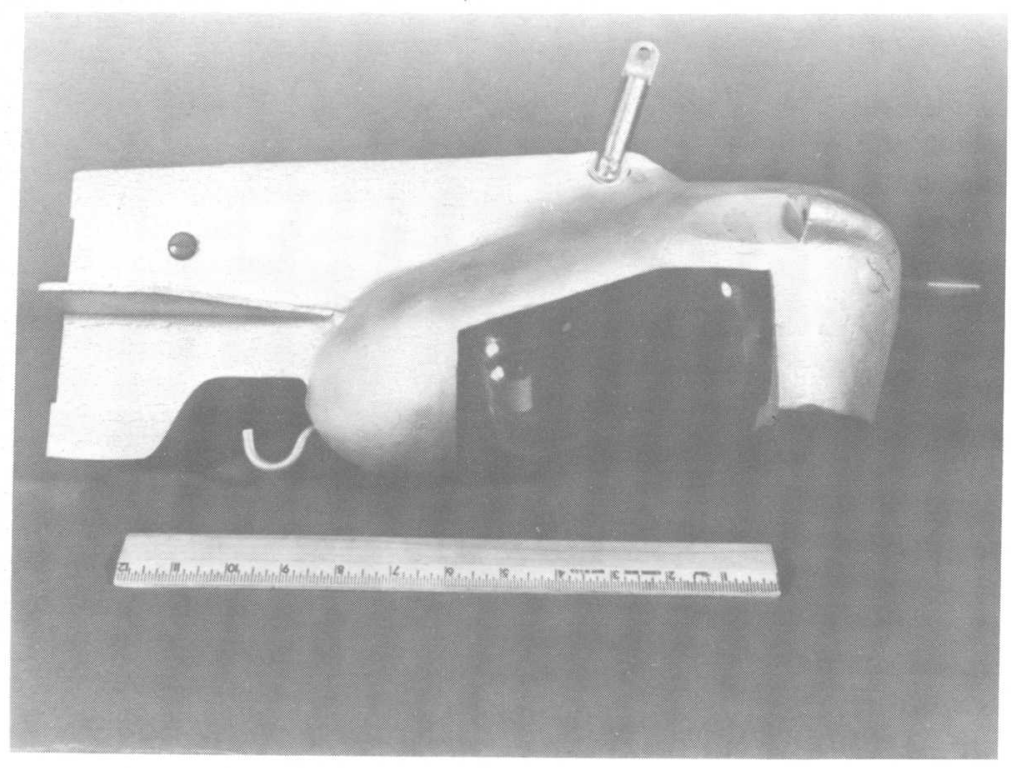

Figure 6.--US DH-76 suspended-sediment sampler.

Cable-and-reel samplers--US D-74, US D-77, US P-61, US P-63, and US P-72

When streams cannot be waded, but are shallower than about 15 feet, depth-integrating samplers designated "D-74" and "D-77" can be used to obtain suspended-sediment samples. Forerunners of these samplers were the "US D-43" and "US D-49" samplers, both of which are no longer manufactured. These latter two are only mentioned here because many of these earlier designed instruments are still used at some locations. Sampling techniques for using the older samplers are identical to those presented later in this text relative to operation of the newer D-74 and D-77 samplers. 
The D-74 (fig. 7) is a 62-1b sampler (approximately 40 lb for the aluminum version) designed to be suspended from a bridge crane or cableway by means of a standard hanger bar and cable-and-reel system. This sampler replaces the earlier D-49 which replaced the D-43 for general use. The D-74 has a streamlined cast bronze (or aluminum) body 24 inches long that completely encloses the sample container. This sampler accommodates a round quart bottle, or, with addition of an adapter sleeve, a standard pint bottle may be used. The sampler head is hinged at the bottom and swings downward to provide access to the sample-container chamber. In this manner, sample containers can be changed during the normal sampling routine. The body includes tail vanes which serve to align the sampler and the intake nozzle with the flow. Intake nozzles of 1/8-inch, 3/16-inch, and 1/4-inch diameters are available for use with the sampler and can be interchanged as varying flow conditions dictate. The sample container fills as a filament of water passes through the intake nozzle and displaces air from the container. The air is expelled in the downstream direction through an air-exhaust port in the side of the sampler hear. The intake nozzle can be lowered to within about 4 inches of the streambed during sampling (approximately $41 / 3$ inches for the aluminum version).

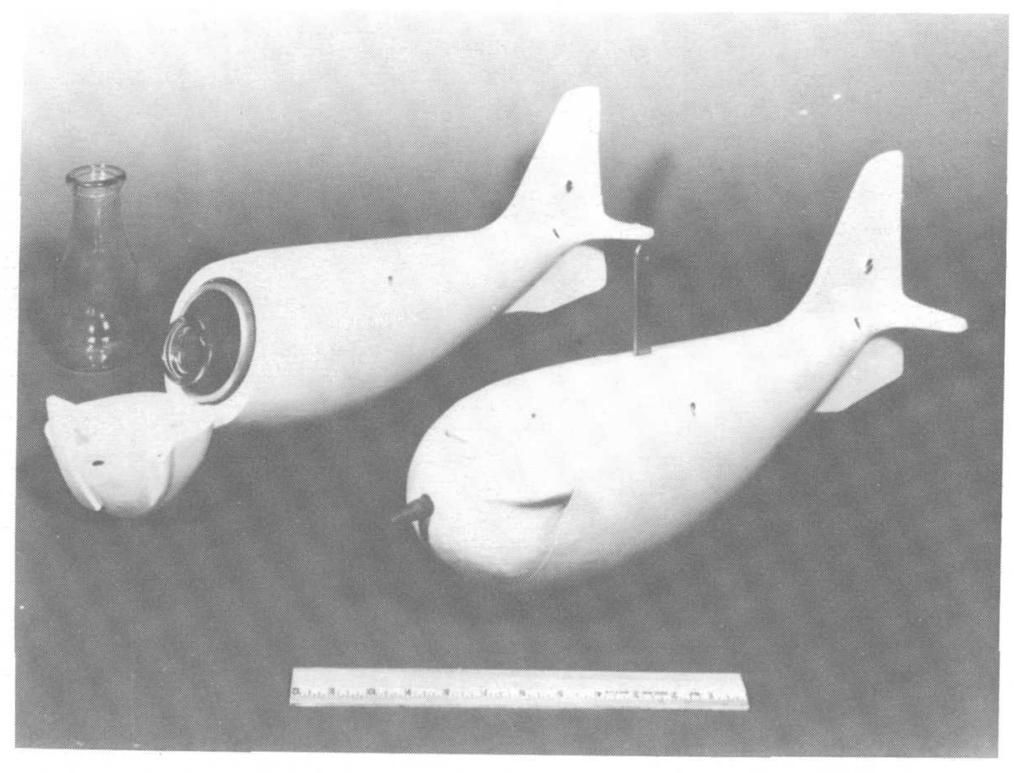

Figure 7.--US D-74 suspended-sediment sampler.

The D-77 is a dramatically different design (fig. 8) as compared to the design configuration of the D-74 and its predecessors. The sampler is 29 inches long and weighs $75 \mathrm{lb}$; it has a bronze casting attached to a tail cone with four sheet-metal vanes welded in place to provide a means of orienting the intake nozzle into the flow. The casting is structured to accommodate a 3-liter autoclavable sample container that slides into the sample container chamber and is held in place by means of a spring clip on the bottom of the chamber. This sampler is constructed without a head assembly to cover the mouth of the container and facilitate attachment of the intake nozzle. Instead, a cap, nozzle, and air-exhaust assembly, constructed. of autoclavable plastic, is screwed on to the mouth of the sample container, which is entirely exposed at the front of the sampler. This configuration was purposely chosen to allow collection of a large volume $(2,700 \mathrm{~mL})$, depth-integrated biological or chemical sample at near- or below-freezing temperatures. A single intake 
nozzle size (5/16-inch diameter) is used with this sampler. The distance between the nozzle and sampler bottom is 7 inches.

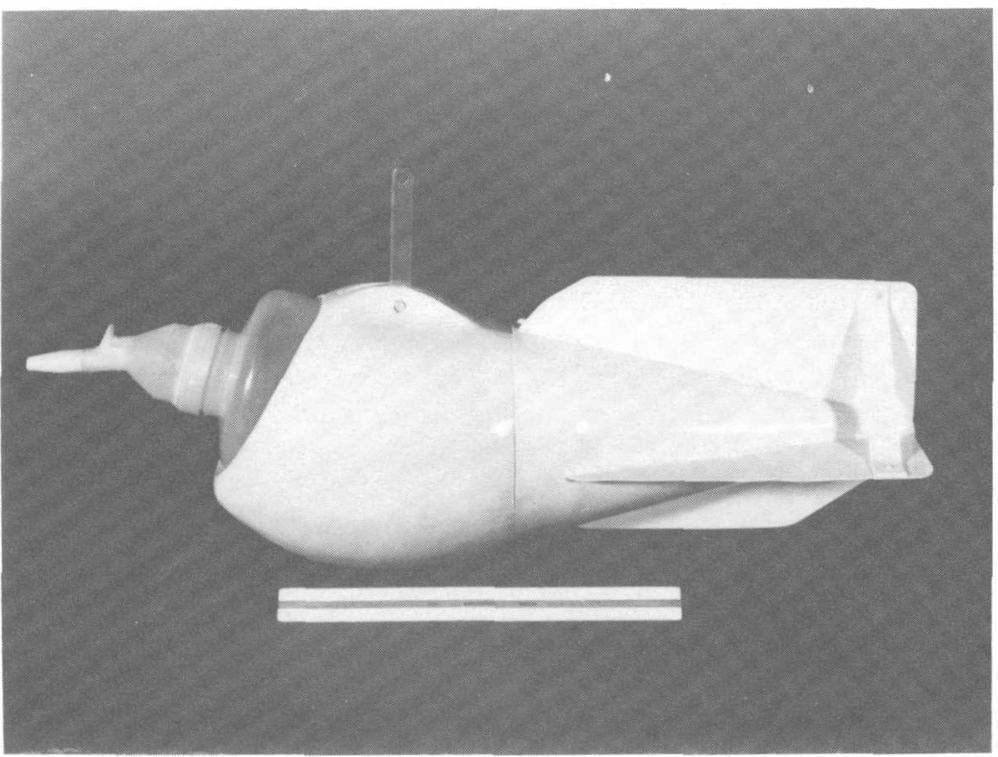

Figure 8.--US D-77 suspended-sediment sampler.

A version of the D-77 sampler is being developed to eliminate the depthrange limit dictated by sample container size, nozzle size, and stream velocity (Szalona, 1982). This version, commonly referred to as a "bag sampler," incorporates a sample bag inside a special rigid container. In addition, a valve assembly may be attached to the face of the sampler to allow the sampler to operate as a point-integrating sampler. Information about this sampler can be obtained from F.I.S.P.

Point-integrating samplers currently manufactured and widely used are the P-61, P-63, and P-72. Forerunners of these samplers were the P-46 and P-50 samplers, which are no longer manufactured but are mentioned here as several of these instruments are still used. The sampling techniques used for obtaining a sample with these older samplers are the same as for the newer samplers. The primary differences among these old and new versions are valve mechanisms and cost. The new versions have a simpler valve and are less expensive.

The 105-1b p-61 (fig. 9) can be used for depth integration as well as for point integration to a maximum stream depth of 180 feet. The sampler valve for the P-61 has two positions. When the solenoid is not energized, the valve is in the nonsampling position, in which the intake and air-exhaust passages are closed, the air chamber in the body is connected to the cavity in the sampler head, and the head cavity is connected through the valve to the sample container. When the solenoid is energized, the valve is in the sampling position, in which the intake and air exhaust are open and the connection from the sample container to the head cavity is closed. A P-61 sampler that has been modified to accommodate a quart bottle is illustrated in figure 9. When the ordinary pint bottle is used, the cylindrical adapter must be inserted into the bottle cavity. The maximum sampling depth is about 120 feet when the quart container is used. 


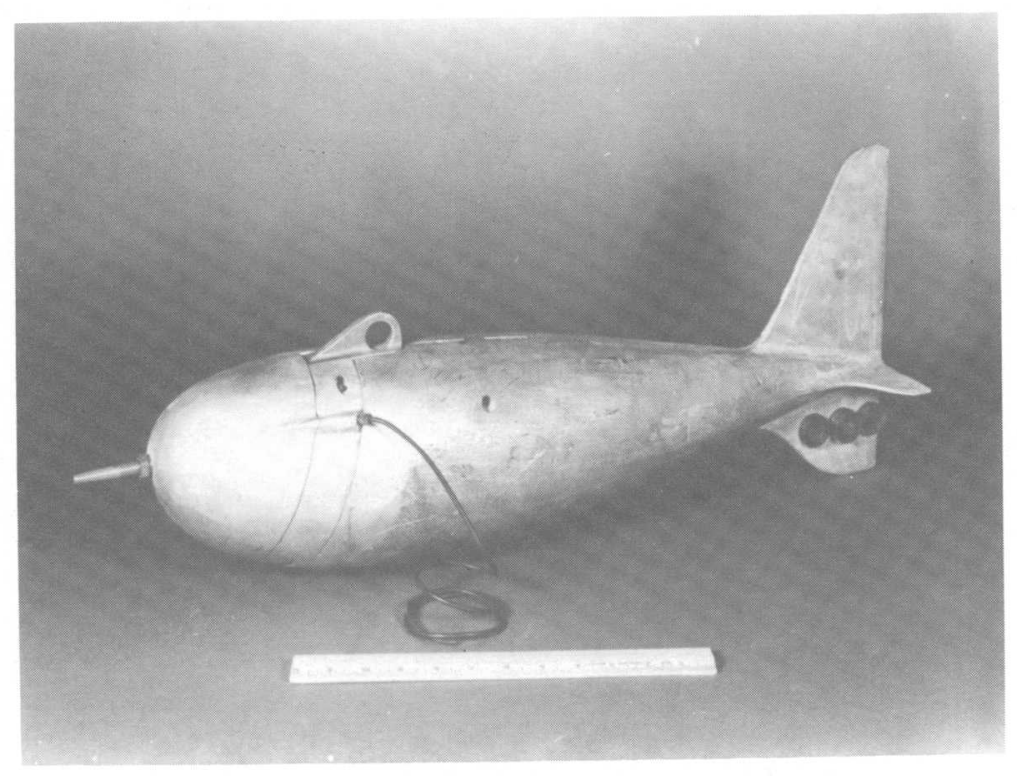

Figure 9.--US P-61 point-integrating suspended-
sediment sampler.

The P-63 (fig. 10) is a 200-lb point-integrating suspended-sediment sampler and is better adapted to high velocities. The solenoid head is basically the same as that on the P-61. The P-63 differs from the P-61 mainly in size and weight. The $\mathrm{P}-63$ is cast bronze, 34 inches long, and has the capacity for a quart-sized round bottle. An adapter is furnished so that a round pint-sized bottle can be used. The maximum sampling depth is the same as for the P-61, about 180 feet with a pint sample container and about 120 feet with a quart container.

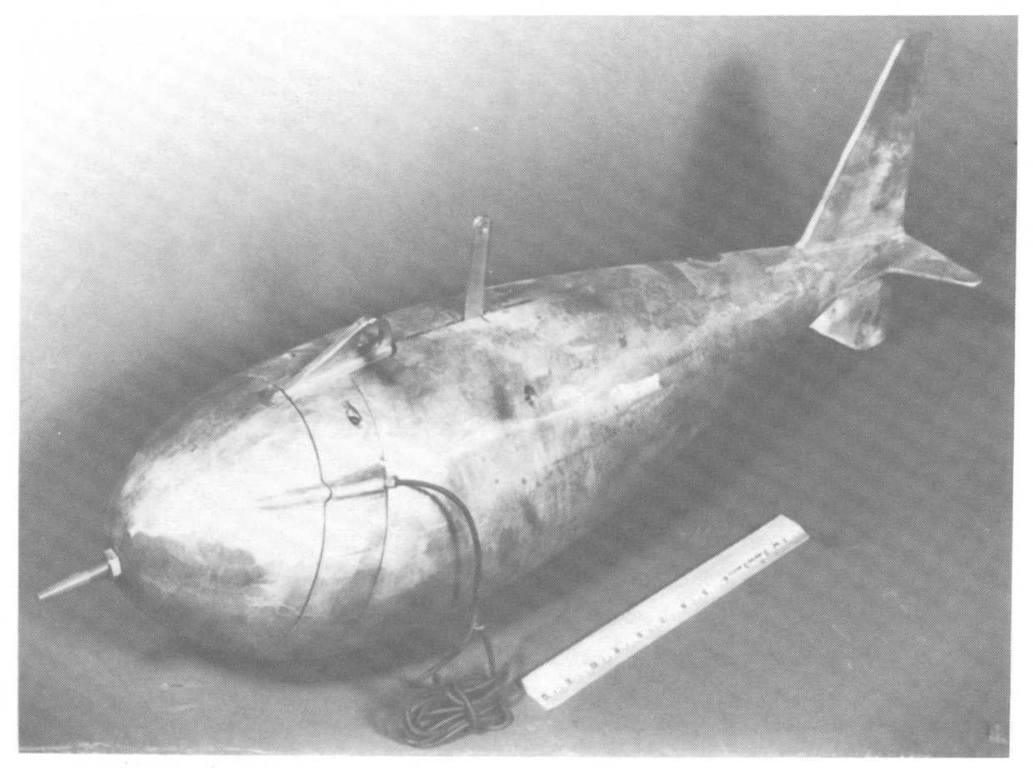

Figure 10.--US $\mathrm{P}-63$ point-integrating suspendedsediment sampler. 
The 41-1b $P-72$ is a light-weight version of the $P-61$. It features a streamlined cast-aluminum shell rather than the bronze used to construct the P-61. The outward appearance of the P-72, the 3/16-inch intake nozzle, the solenoid head, and the accommodation for pint-and quart-sized containers are similar to the P-61. However, the listed maximum stream velocity at which the $\mathrm{P}-72$ is recommended for use is $5.3 \mathrm{ft} / \mathrm{s}$, as opposed to $6.6 \mathrm{ft} / \mathrm{s}$ for the $\mathrm{p}-61$, and the depth limit to which this sampler should be used is about 72 feet using the pint container and 51 feet with the quart container. These depths are less than half of the maximum usable depths for the P-61 with the same container sizes.

All the point samplers are designed for suspension with a steel cable having an insulated inner conductor core. By pressing a switch located at the operator's station, the operating current may be supplied through the cable to the solenoid in the sampler head by storage batteries connected in series to produce 24 to 48 volts. If the suspension cable is longer than 100 feet, a higher voltage may be desirable. The US BP-76 battery pack has been designed as a portable power source for activating the $\mathrm{P}-61, \mathrm{P}-63$, and $\mathrm{P}-72$ samplers and is available from the F.I.S.P. and HIF.

Because of the complex nature of point-integrating samplers, the user may find it necessary to seek additional information given in the interagency reports (F.I.S.P., 1952, 1963b, and 1966).

\author{
Sampler Accessories
}

\title{
Nozzles
}

Each suspended-sediment sampler is equipped with a set of nozzles specifically designed for the particular sampler. These nozzles are cut and shaped externally and internally to ensure that the velocity of water after entering the nozzle is within 8 percent of the ambient stream velocity when the stream velocity is greater than $1 \mathrm{ft} / \mathrm{s}$. It has been found that a deviation in intake velocity from the stream velocity at the sampling point causes an error in the sediment concentration of the sample, especially for sandsized particles. For example, a plus 10-percent error in sediment concentration is likely for particles of sediment 0.45 millimeter (mm) in diameter when the intake velocity is 0.75 of the stream velocity (F.I.S.P., 1941, p. 38-41). The relation between intake-velocity deviation and errors in concentration resulting from collecting a sample enriched or deficient in sand-size particles $(>0.062 \mathrm{~mm})$ is illustrated by figure 11. When sand-size particles are entrained in the flow, the intake velocity within the sampler nozzle must be equal to the ambient stream velocity (isokinetic), in order to collect a sample representative of the mean discharge-weighted sediment concentration (fig. 11a). The resulting sediment concentration of the sample will be equal to the average discharge-weighted sediment concentration of the approaching flow. However, when the velocity in the nozzle is less than the stream velocity (nonisokinetic, fig. 11b), some water that should flow into the nozzle now curves to the side and flows around it. Inertia resists the curving flow and forces the approaching particles to follow straight-line paths into the nozzle. This combination of curved and straight-line movement increases the concentration of coarse particles in the sample. As a result, the sediment concentration in the sample is greater than the concentration in the approaching flow. Likewise, when the velocity in the nozzle is greater than the stream velocity (nonisokinetic, fig. 11c), some water that should flow past the nozzle curves to the side and flows into it. Again, inertia resists the curving flow and forces the particles to follow straight-line paths and flow 

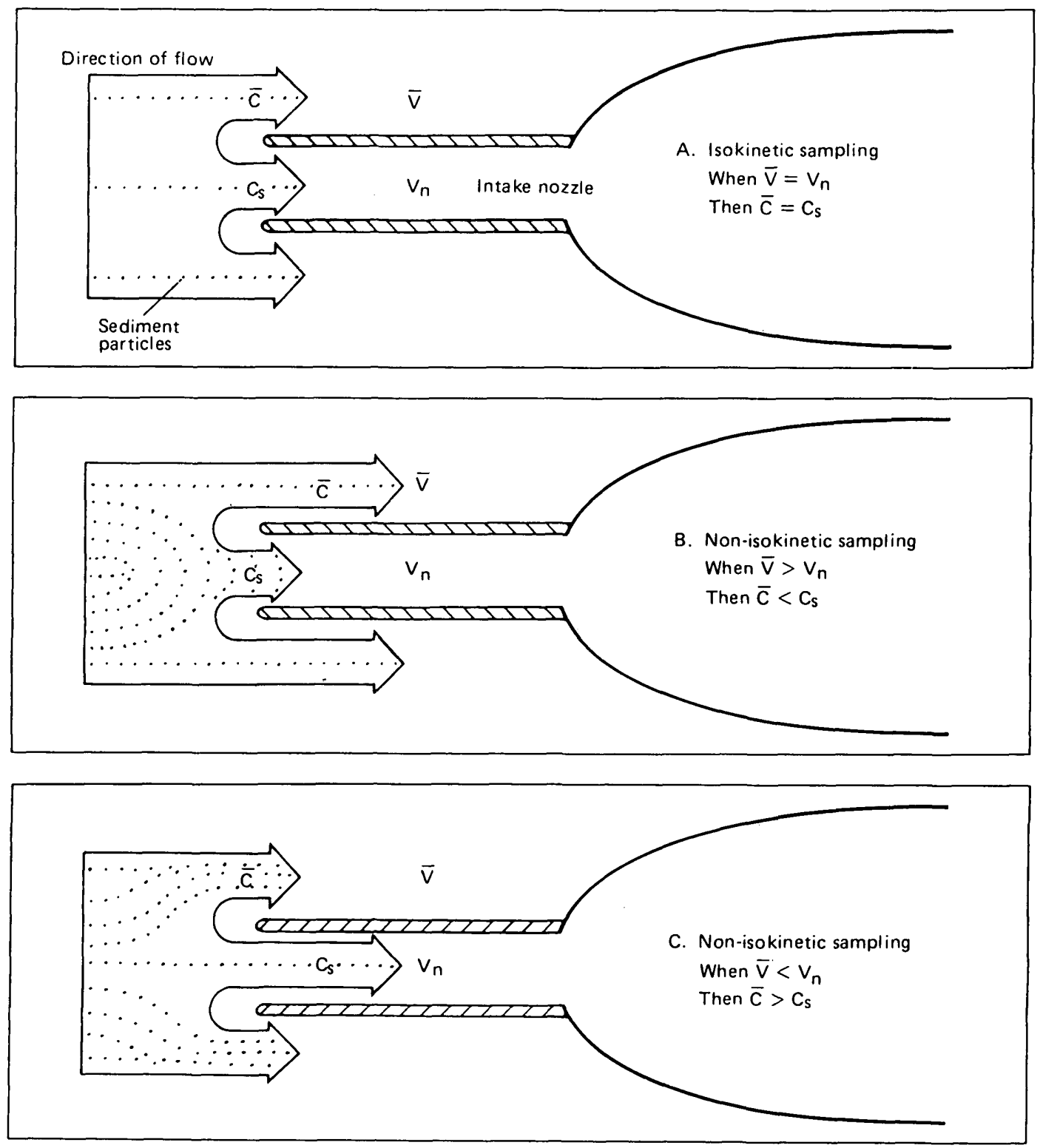

Figure 11.--Relation between intake velocity and sample concentration for isokinetic and nonisokinetic sample collection of particles $>0.062 \mathrm{~mm}$. When $\overline{\mathrm{V}}=$ mean stream velocity, Vn=velocity in the sampler nozzle, $\bar{C}=$ mean sediment concentration in the stream, and $\mathrm{Cs}=$ sample sediment concentration.

past the nozzle. The result of this combination of curved and straight-line movement is a decrease in the sample concentration relative to the concentration of the approaching flow.

Because in general. each sampler nozzle is designed for a particular series of samplers, it must be emphasized that a nozzle for one series of samplers should not be used in another series of samplers. However, there are two exceptions to this rule: the same nozzle can be used in the P-61, P-63, 
and P-72 series, and a nozzle can be interchanged between the D-49 and D-74. To ensure against incorrectly matching samplers and nozzles, all nozzles are color coded to specific sampler designs (table 1).

The reasons for the differences between the nozzles of different series are that (1) the length of flow paths for water and air are different, resulting in differences of flow resistance; and (2) the differential heads between the nozzle entrance and the air exhaust are different. Thus, interchanging nozzles among samplers of various series results generally in an incorrect intake velocity and thus incorrect sediment concentration and particle-size distribution in the sample. Therefore, when a nozzle is bent or broken, be certain to use a correct replacement nozzle.

If extra nozzles are needed for a sampler, they can be ordered from the F.I.S.P. at the address in the latest interagency report. The order must indicate the sampler series. If the exhaust tubes, tail fins, or any other part of a sampler are damaged, the entire sampler should be sent to the F.I.S.P. for repair and recalibration.

Three nozzle diameters--1/4-, 3/16-, and 1/8-inch--are available for use with all depth-integrating samplers, except for the DH-48, DH-75, D-77, and the point-integrating samplers. The D-77 sampler is the only depth-integrating sampler which uses a 5/16-inch nozzle. Although a nozzle may physically fit a sampler, the match may not be correct. For example, it is possible, but incorrect, to interchange any one of the 1/4-, 3/16-, or 1/8-inch nozzles listed in table 1 among the depth-integrating or point-integrating samplers. For instance, it is possible but incorrect to put DH-48 nozzles in DH-59 samplers. One exception is the D-77, which will not accept any nozzle other than the correct one. To help prevent the incorrect interchange of colorcoded nozzles among samplers, new samplers ordered from F.I.S.P. are delivered with a color coded plastic screw in the tail vane assembly, which indicates the correct color of nozzle to be used with the sampler (for example, DH-59 has a red screw and uses a red nozzle).

The reason for different size nozzles is that stream velocities and depths occur that will cause the sample bottle to overfill for a specific transit rate when using the largest nozzle. More specifically, for depthintegrating samplers with a pint bottle, the maximum theoretical sampling depths for round-trip integration are about 9, 16, and 19 feet for the 1/4-, 3/16-, and 1/8-inch nozzles, respectively. Therefore, to reduce the quantity of sample entering the bottle at depths approaching 19 feet, use a smaller bore nozzle. For a given situation, the largest nozzle should be used to reduce the chance of excluding large sand particles may be in suspension. Possible errors caused by using too small a nozzle are usually minor when dealing with fine material $(>0.062 \mathrm{~mm})$ but tend to increase in importance with increasing particle size. Small nozzles also are more likely than large ones to plug with organic material, sediment, and ice particles. This means that problems with nozzles can exist even when sampling streams transporting mostly fine material.

Point-integrating samplers are supplied only with a 3/16-inch nozzle to match the opening through the valve mechanism.

\section{Gaskets}

Of equal importance to using the correct nozzle in the instrument is the necessity for using the proper gasket to seal the bottle mouth sufficiently. 
Gaskets for this purpose are made of a sponge-like neoprene that deteriorates somewhat with use and time. When samples are being collected for water quality, such as for trace metal analysis, the gasket should be made of silicone rubber to avoid biasing the sample chemistry.

To check the gasket for adequate seal, insert a bottle in the proper position in the sampler; then block the air-exhaust port and force air into the sampler nozzle. CAUTION: A field person should never force air into the sampler by placing the mouth directly in contact with the nozzle--due to the possibility of questionable water quality at the site or the likelihood of receiving an electrical shock (if a brass nozzle is in use) upon activating the solenoid of a point-integrating sampler when opening the intake. A safe procedure to perform this check would be to block the air exhaust with a finger and place a short length of clean plastic or rubber tubing snugly over the nozzle and then apply air pressure by blowing into the tubing to force air through the nozzle. If air escapes around the bottle mouth, replace the gasket. If the problem persists, check the spring that pushes the bottle against the gasket. Each sampler series uses a different size or shape of gasket; therefore, it is necessary to have spares for each series in use. Appropriate gaskets may be obtained from the F.I.S.P. (address can be obtained from the latest interagency report). Gaskets in the " $P$ " series samplers may also be tested by lowering the sampler, with sample bottle in place, into the stream without opening the solenoid. After a minute or so, raise the sampler to the surface and inspect the sample bottle. If the gasket is sealing properly, less than a few milliliters of water should be present in the bottle.

\section{Bottles}

Depth- and point-integrating samplers accommodate different bottle sizes and types (fig. 12). Many field people still use pint glass milk bottles, which have been used for many years and can be adapted to every sampler series with the exception of the $\mathrm{DH}-81$ and $\mathrm{D}-77$. Quart-sized glass mayonnaise bottles (Owens-Illinois \#6762) are increasing in general use, as versions of all samplers except the $\mathrm{DH}-48$ and $\mathrm{D}-77$ use this size sample container. The D77 sampler holds a 3-liter plastic autoclavable bottle with standard mason jar threads (Nalge 2115-3000); the DH-81 holds any bottle with standard mason jar threads; and the DH-75 holds a plastic bottle (Bel-Art \#F-10906, 1,000 cubic centimeter $\left.\left[\mathrm{cm}^{3}\right]\right)$ and a variety of other quart/liter bottles. Ideally, each type of glass bottle should have an etched surface to provide a labeling area to accommodate a record of pertinent information concerning each sample. Hydrofluoric acid has been used for this purpose, but care must be exercised when handling and storing this substance. In the past commercial etching agents have been available for general use. However, the authors do not know of any such agent that is available at this time. This etched labeling surface should easily accept medium-soft blue or black pencil markings of sufficient durability to withstand handling and yet be easily removed during cleaning. Plastic bottles also require an area for labeling. However, this is less of a problem as a grease pencil or other marker that is not readily soluble in water, but which can be removed using a solvent, can be used to write on the side of the bottle.

The practice of using plain bottles with attached tags or marked caps for recording purposes should be avoided whenever possible. These labeling areas are generally small and provide little writing space. Additionally, the use of these labeling devices can result in tags being torn off during transport or in bottles being mislabeled by interchanging caps. 

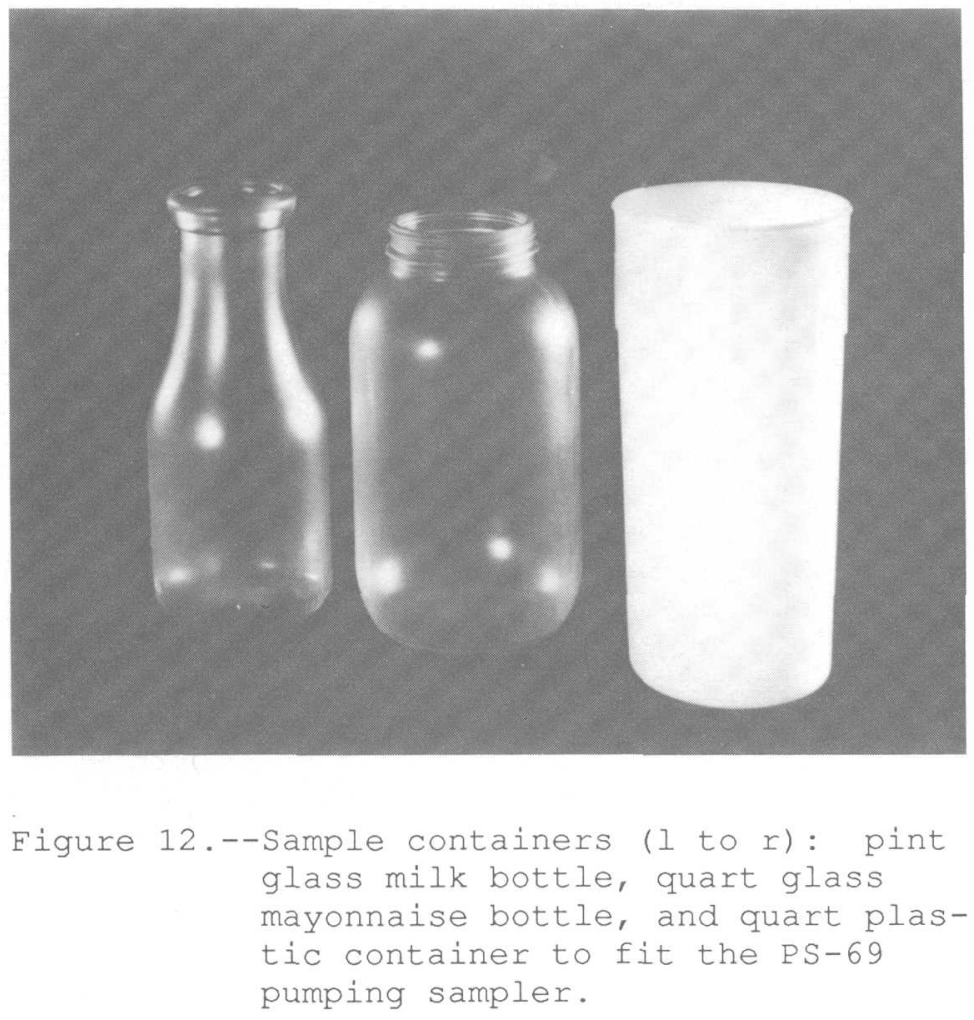
glass milk bottle, quart glass mayonnaise bottle, and quart plastic container to fit the PS-69 pumping sampler.

Plastic bottles are increasing in use throughout the water Resources Division of the Geological Survey, as several samplers have been designed to use plastic sample containers (the DH-75 series, the DH-81 and D-77 samplers). compared to glass, these bottles are lightweight, strong, and easy to etch.

During depth integration, a collapsible bottle or bag would be the ideal arrangement to eliminate the problem of depth limitation due to the size of the sample container. A version of the D-77 depth-integrating sampler is being developed incorporating this collapsible bottle/sample bag concept as previously discussed.

Bottles are usually stored and transported in wire, wooden, fiberboard, or plastic cases holding 12 to 30 bottles each. In the field a small bottle carrier, which holds 6, 8, or 10 bottles, is more convenient, eliminates the need to handle the heavier 12- to 30-bottle cases while making a measurement, and provides a neat, convenient, and relatively safe place to set the bottles. When making wading measurements, both hands can be free to operate the sampler if the bottle carrier is suspended from the shoulder with a strap or rope.

\section{Single-stage samplers}

The single-stage samplers, US U-59, also designated US SS-59 (fig. 13), and US U-73, were designed and tested by the F.I.S.P. to meet the needs for instruments useful in obtaining sediment data on streams where remoteness of site location and rapid changes in stage make it impractical to use a conventional depth-integrating sampler. As noted in the U.S. Interagency Report "Catalog" (F.I.S.P., 1981a, P. 46-55): 
The U-59 (SS-59) consists of a pint bottle or other sample container, a 3/16-inch inside diameter air exhaust, and 3/16-inch or 1/4-inch inside diameter intake constructed of copper tubing. Each tube is bent to an appropriate shape and inserted through a stopper sized to fit and seal the mouth of the sample container. There are two general types of this sampler, one with a vertical intake and the other with a horizontal intake. The horizontalintake type is further divided into three versions, each distinguished from the others by the height of the intake and airexhaust tubes. Under some conditions either type could be used but the two are not always interchangeable.

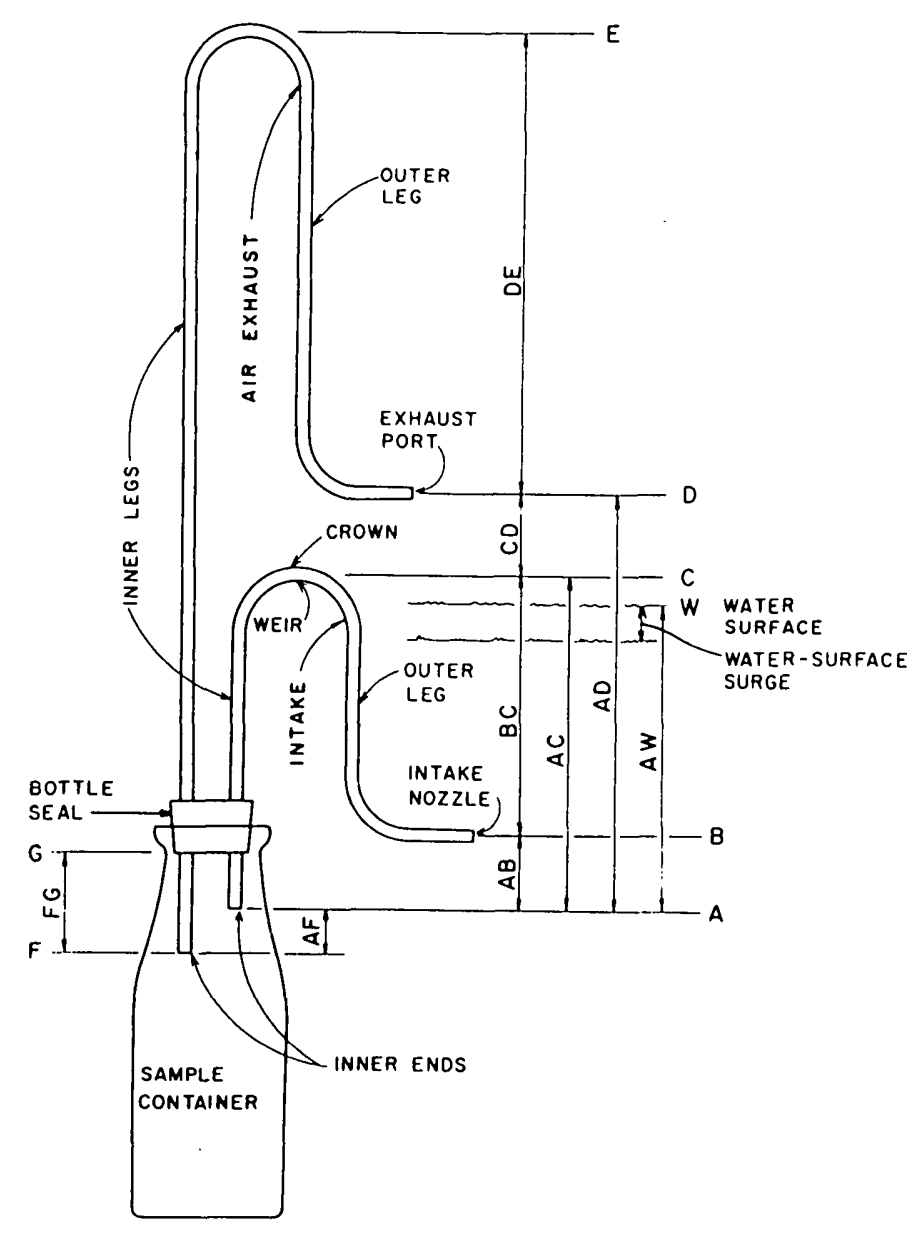

Figure 13.--US U-59 single-stage suspendedsediment sampler.

The vertical-intake sampler is used to sample streams carrying sediments finer than $0.062 \mathrm{~mm}$. The vertical-intake sampler has the advantage of somewhat less tendency to fouling by debris and deposits of sediment in the intake nozzle than does the horizontal type of intake. Conversely, the horizontalintake sampler should be used to sample streams carrying a considerable amount of sediment coarser than $0.062 \mathrm{~mm}$. 
The basic sampling operation of the instrument when velocities and turbulences are small is described by F.I.S.P. (1961, p. 17):

When the stream surface rises to the elevation of the intake nozzle, the water-sediment mixture enters; and as the water surface continues to rise in the stream, it also rises in the intake. (The general elevation and dimensions are expressed without regard to the inside diameter of the tube or without distinction between the weir and the crown of the siphon.) When the water-surface elevation $W$ reaches $C$, flow starts over the weir of the siphon, primes the siphon, and begins to fill the sample bottle under the head AC. Filling continues until the sample rises to $F$ in the bottle, and water is forced up the air exhaust to the elevation $w$. Actually the momentum of flow in the tubes causes a momentary rise above $\mathrm{W}$ in the air exhaust. Water drains out of the inner leg of the intake. When the stream rises to $D$, air is trapped in the air exhaust. As long as sufficient air remains in the tubes, no flow can pass through to alter the original sample unless a differential head that exceeds the height of invert is built up. (If the legs of an invert are not symmetrical, the inverts have different effective air-trap heights, resisting flow into and out of the bottle.) For conditions without significant surge and velocity effects at the intake nozzle or exhaust port, the heights $\mathrm{BC}$ and $\mathrm{DE}$ may be small.

If, after the normal time of sampling, the depth of submergence over the sample bottle increases, the air in the bottle is compressed and a small additional sample enters the bottle. This additional sample will enter through the tube having the smallest height of invert. Under variable submergence the entrance of water will compress the air in the bottle on rising stages, and some expanding air will escape on falling stages; thus the quantity of air in the bottle becomes less and less, and the water rises in the bottle.

The sampling operation just described is somewhat idealistic because in reality the operation is affected by the flow velocity and turbulence, which alter the effective pressure at the nozzle entrance.

The U-59 has many limitations with respect to good sampling objectives. It must be considered a type of point sampler because it samples a single point in the stream at whatever stage the intake nozzle is positioned before a flow event occurs. Its primary purpose is to collect a sample automatically, and it is used at stations on flashy streams or other locations where extreme difficulty is encountered in trying to reach a station to manually collect samples. Besides being automatic, it is inexpensive; a "battery" of them can be used to obtain a sample at several elevations or times during the rising hydrograph. However, despite these seemingly important advantages, the U-59 has many limitations. Following are the most important:

1. Samples are collected at or near the stream surface, so that, in the analysis of the data, theoretical adjustments for vertical distribution of sediment concentration or size are necessary.

2. Samples are usually obtained near the edge of the stream or near a pier or abutment; therefore, theoretical adjustments for lateral variations in sediment distribution are required. 
3. Even though several combinations of size, shape, and orientation of intake and air-exhaust tubes are available, the installed system may not result in intake ratios sufficiently close to unity to sample sands accurately for a specific runoff event.

4. Covers or other protection from trash, drift, and vandalism often create unnatural flow lines at the point of sampling.

5. Water from condensation may accumulate in the sample container prior to sampling.

6. Sometimes the sediment content of the sample changes during subse quent submergence.

7. The device is not adapted to sampling on falling stages or on secondary rises.

8. No specific sampler design is best for all stream conditions.

9. The time and gage height at which a sample was taken may be uncertain.

10. Under high velocities, circulation of flow into the intake nozzle and out the air exhaust can occur. This will increase the concentration of coarse material in the sample and can make the sample concentra tion several orders of magnitude higher than stream concentration.

To cover a wide range of operating conditions, four "standard" models of the U-59 are available. The many specific details of these are further described in F.I.S.P. (1961).

Before a bank of the U-59 samplers can be designed and installed, it is necessary to have some knowledge of the seasonal stage characteristics of the stream, so that several samples can be obtained for a given storm event and throughout the season. The stream stage and flow-velocity characteristics not only affect the design with respect to the vertical spacing of the samplers but also the support necessary for the bank of samplers.

The U-73 (fig. 14) is a more sophisticated single-stage sampling device. The sampler's design configuration solves several of the problems characteristic of the U-59. Specifically this sampler (1) can be used to sample either a rising or falling stage, (2) has no problem of condensation in the sample container before the spring-loaded stoppers are tripped, and (3) features an exterior design that allows for a degree of protection from trash or drift without additional covers or deflection shields. Aside from these few advantages, the U-73 has the same limitations and should be used under the same conditions as the U-59.

The investigator using either the U-59 or U-73 may find protective measures necessary to avoid blockage of intakes or air exhausts due to nesting insects. In freezing climates precaution may be warranted against samplecontainer breakage due to expansion of a freezing sample. Samples for waterquality analysis can be collected using the U-73-TM version of the U-73. However, do not use insecticides or antifreeze solutions if samples are to be analyzed for water quality, as these will obviously contaminate the sample. 


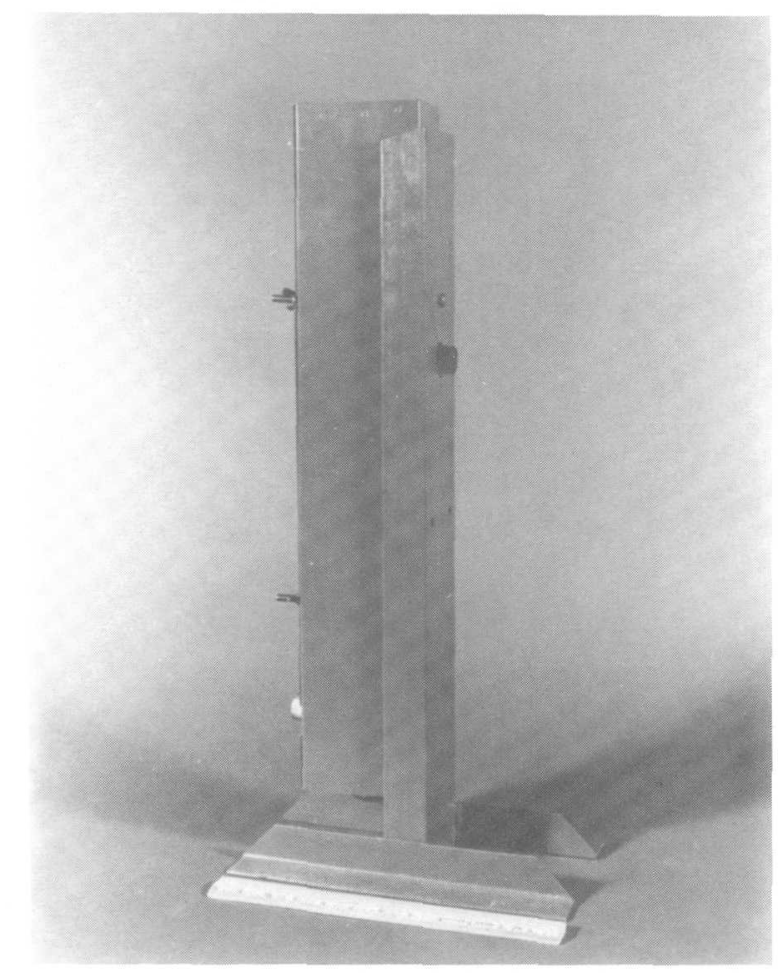
Figure 14.--US U-73 single-stage suspended-sediment sampler.

\section{Bed-Material Samplers}

\section{Limitations}

To properly sample bed material for interpretation, it is first necessary to establish what constitutes bed material and understand its relation to transported load, especially to bedload. Bedload is best defined as sediment that moves by sliding, rolling, or bouncing along on or near the streambed (Hubbell, 1964; Leopold and others, 1964; and Emmett, 1980a). Bed material, on the other hand, is best defined in the office of Water Data coordination National Handbook (1978, Chapter 3, p. 3-5), which describes bed material as "the sediment mixture of which the bed is composed." In alluvial streams bedmaterial particles are likely to be moved at any moment or during some future flow conditions. From the perspective of Leopold and others, 1964, the streambed is composed of two elements, distinguished one from the other by particle size and their reaction to stream velocity. The first element consists of particles frequently transported as part of the suspended load or bedload, but considered as bed material when at rest. The second element consists of particles and aggregates of particles which compose definite structures on the streambed and reside there indefinitely or at least for long periods of time. The size fractions comprising the second element may only be moved by the most extreme flow events during which streambed erosion and scour occurs.

The samplers described in this section are physically limited to those capable of collecting bed-material samples consisting of particles finer than about 30 or $40 \mathrm{~mm}$ in diameter. In reality, however, bed-material samplers cannot representatively sample particles much larger than $16 \mathrm{~mm}$. As noted in the description of individual samplers, there may also be limitations with respect to some very fine sediments for some of the samplers. This limits 
bed-material sampling to essentially those sediments comprising the first element of bed material or fine material that might be transported in suspension or as bedload at higher flows. The collection and analysis of material larger than coarse gravel is more difficult and costly because other techniques are required to avoid handling heavy samples with larger and more expensive equipment. Due to this difficulty in collecting large particle sizes, little information regarding bed-material size distribution is available for streams having gravel, cobble, and boulder beds. Therefore, much of the equipment for measurement of large bed material is of an experimental nature; standard equipment for sampling large particles is not available. However, the interested investigator is directed to several references on direct and indirect methods of sampling and analysis of coarse bed materials and is encouraged to contact Chief, office of Surface Water, or the F.I.S.P. for information (Lane and Carlson, 1953; Kellerhals, 1967; and Wolman, 1954).

\section{Hand-Held Samplers--US BMH-53, US BMH-60, and US BMH-80}

Three types of instruments for hand sampling of bed material finer than medium gravel have been developed for general use. The BMH-53 (fig. 15) is designed to sample bed material in wadable streams. The instrument is 46 inches long and is made of corrosion-resistant materials. The sample container is a stainless steel thin-walled cylinder 2 inches in diameter and 8 inches long with a tight-fitting brass piston. The piston is held in position by a rod which passes through the handle to the opposite end. The piston creates a partial vacuum above the material being sampled. This vacuum aids in overcoming the frictional resistance required to force the sampler into the bed. When sampling fine-grained material, this partial vacuum also aids in retaining the shallow core in the cylinder when the sampler is removed from the bed. The piston then serves to remove the sample from the cylinder by forcing it downward toward the bottom of the cylinder. In soft cohesive beds this technique generally provides shallow cores with a minimum of distortion, from which sediment variations with depth and subsamples can be obtained.

(See F.I.S.P., 1963b and 1966, for more detailed information.) A new version of this sampler, being developed by the F.I.S.P., incorporates a "core catcher" mechanism in the cylinder to retain samples containing a high percentage of sand.

The bed material of some wadable streams or lakes can be sampled with the US BMH-60 (fig. 16). This handline sampler is about 22 inches long, is made of cast aluminum, and weighs $30 \mathrm{lb}$. Because of its light weight, it is useful only in streams of moderate depths and velocities. The bed material must be moderately firm and contain little or no gravel.

The sampler mechanism of the US BMH-60 consists of a scoop or bucket driven by a constant-torque spring that rotates the bucket from front to back. The scoop, when activated by release of tension on the hanger rod, can penetrate into the bed about 1.7 inches and can hold approximately $175 \mathrm{~cm}^{3}$ of material. The scoop is aided in penetration of the bed by extra weight in the sampler nose. To cock the bucket into an open position for sampling (that is, retract it into the body), the sampler must first be supported by the handline; then the bucket can be rotated (back to front) with an allen wrench to an open cocked position.

The hanger rod to which the handline is attached is grooved so that a safety yoke can be placed in position to maintain tension on the hanger rod assembly. Caution: At no time should the hand or fingers be placed in the bucket opening, as the bucket may accidentally close with sufficient force to 


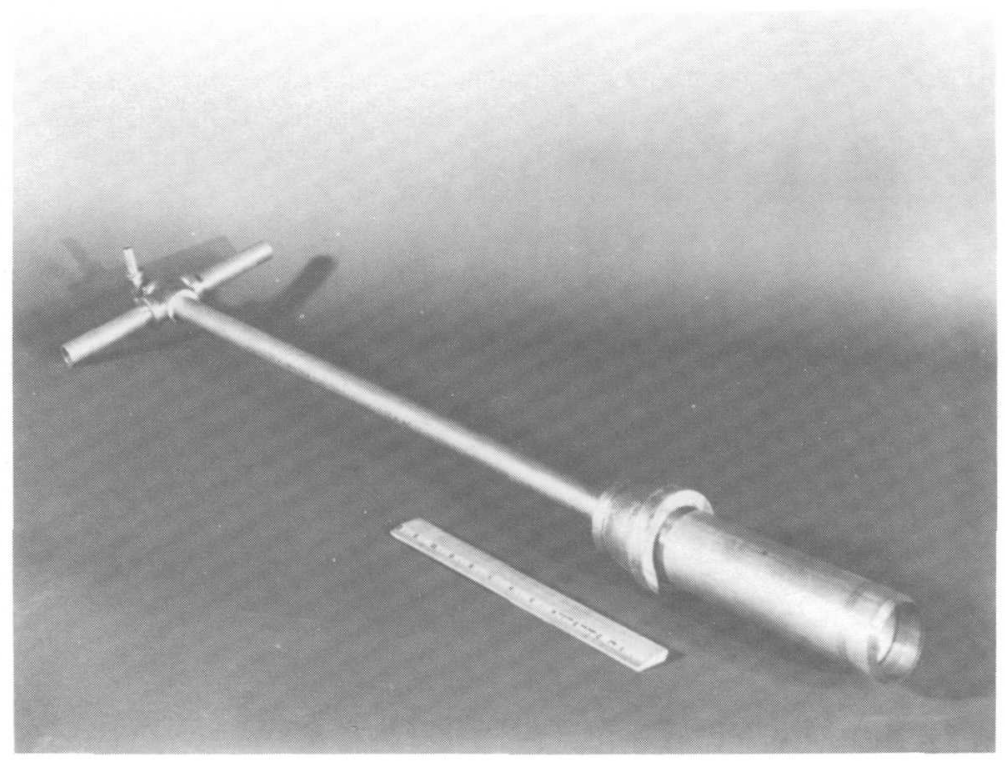

Figure 15.--US BMH-53 bed-material sampler.

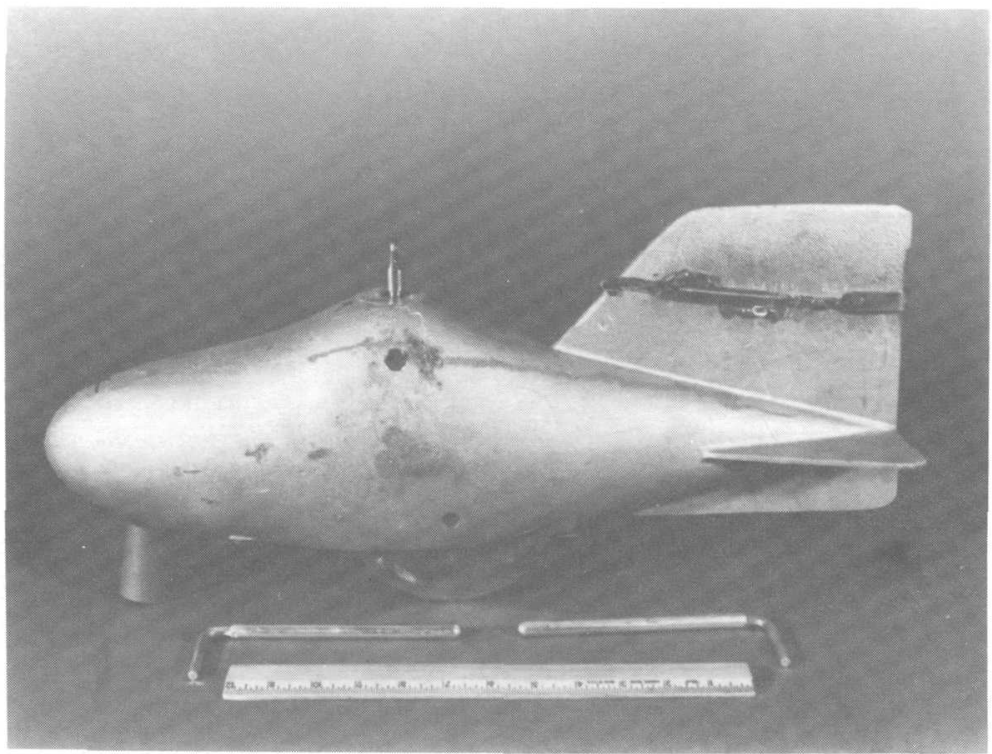

Figure 16.--US BMH-60 bed-material sampler.

cause permanent injury! A piece of wood or a brush can be used to remove any material adhering to the inside of the sample bucket. (See F.I.S.P., 1963b and 1966, for more detailed information.)

After the safety yoke is removed, the bucket closes when tension on the handline is released, which occurs as the sampler strikes the streambed. A gasket on the closure plate prevents sampled material from being contaminated or being washed from the bucket.

The newest of the bed-material hand-sampling instruments available for general use is designated $\mathrm{BMH}-80$ (fig. 17). This sampler is 56 inches in 
total length and is used to sample the bed of wadable streams. The sampling mechanism is a semi-cylindrical bucket, resembling the BMH-60 bucket assembly, which is operated by positioning the lever on the handle to open or close the bucket. When the bucket is closed and a sample volume of approximately 175 $\mathrm{cm}^{3}$ of bed material is captured, the closure is sufficiently sealed to prevent erosion of the sample while the instrument is lifted through the water column.

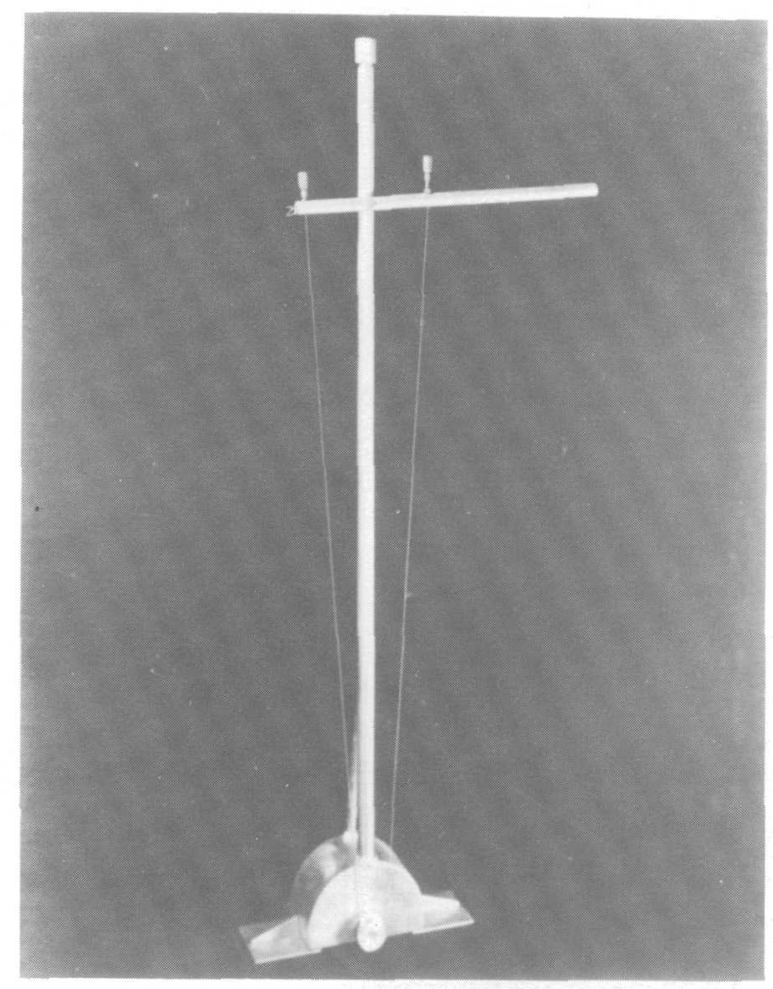
Figure 17a.--US BMH-80 rotary-scoop bed-material sampler (approximately 5 feet tall).

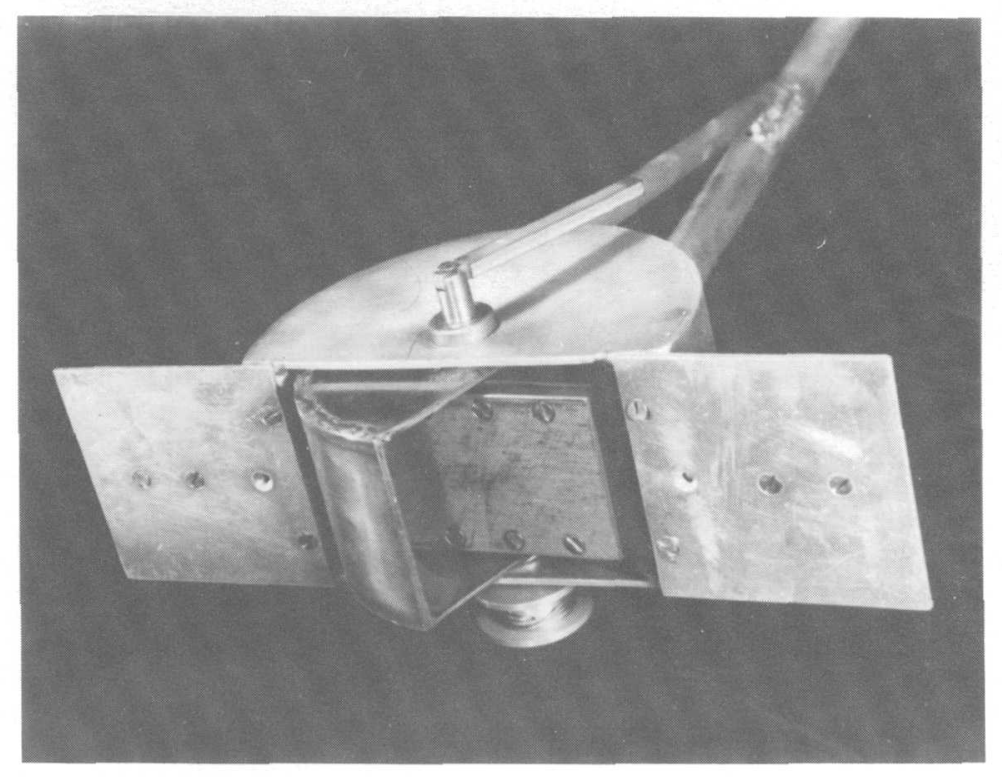

Figure 17b.--US BMH-80 rotary-scoop assembly (approximately 12 inches long). 
An additional handline sampler, used successfully for bed-material chemistry sampling on the Willamette and Columbia Rivers in Oregon, is the Ponar sampler. This is a clam-shell type sampler, consisting of two quarter-cylinder sections hinged together at the top. The sampler, which is constructed of galvanized or stainless steel, weighs about 25 lb and can be suspended on a handline. The jaws of the instrument are held in the open position by a system of solid-notched bars and by the downward force created by the weight of the sampler on the suspension line. Gravity provides the necessary force for bottom penetration during sampling. The solid-notched bars holding the sampler jaws open are released when the downward force of the sampler's weight is released from the suspension line as the sampler strikes the bed. The sampler then closes as an upward force is applied to lift the sampler with the captured sediment. This sampler is particularly effective where bottom sediments consist of unconsolidated fines with no armoring present. Under these conditions bottom penetration is 6 to 8 inches, resulting in a sample volume range of $8,000 \mathrm{~cm}^{3}$ to $10,000 \mathrm{~cm}^{3}$ of material. Some protection against erosion of the captured sediment is provided by an overlapping lip on the bottom and sides. However, a watertight seal does not exist, so care must be exercised when raising the sampler to the surface.

\section{Cable-and-Reel Sampler--US BM-54}

The 100-1b cable-and-reel suspended BM-54 sampler (fig. 18) can be used for sampling bed material of streams and lakes of any reasonable depth, except for streams with extremely high velocities. The body of the BM-54 is cast steel. Its physical configuration is similar to the cast aluminum BMH-60, 22 inches long and with tail vanes. Its operation is also similar to the BMH-60 in that it takes a sample when tension on the cable is released as the sampler touches the bed. The sampling mechanism externally looks similar to that of the BMH-60, but its operation is somewhat different.

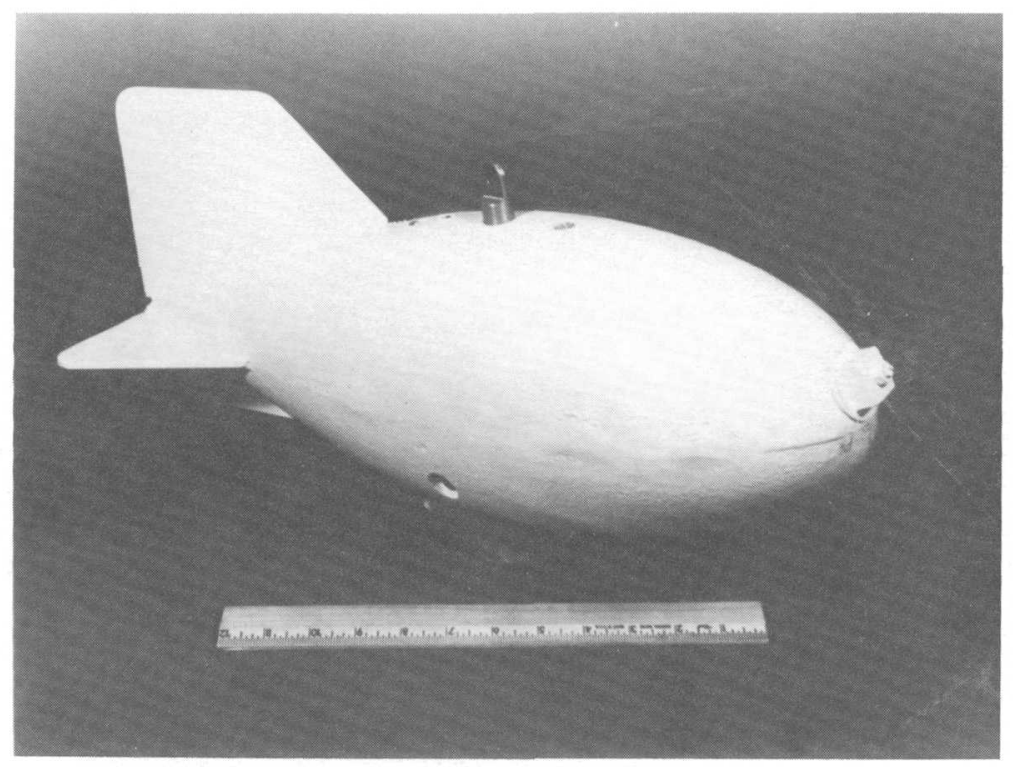

Figure 18.--US BM-54 bed-material sampler. 
The driving force of the bucket comes not from a constant-torque spring, but rather from a conventional coil-type spring. The tension on the spring is adjusted by the nut-and-bolt assembly protruding from the front of the sampler. The spring is powerful enough to obtain a sample from a bed of very compacted sand. It is suggested that the tension on the spring be released during extended periods of idleness even though the bucket is closed. Maximum tension need be used only when the streambed is very firm. Unlike the BMH-60 the spring and cable assembly rotates the bucket from the back to the front of the sampler. The trapped sample is kept from washing out by a rubber gasket. (See F.I.S.P., 1963b, 1964, and 1966, for more complete description and details.)

BM-54 samplers obtained after 1956 are equipped with a safety mechanism similar to the safety yoke used on the BMH-60. This safety bar can be rotated over the cutting edge of the sample bucket when cocked into the open position. The bar keeps the bucket open when in the safety position, even if there is no tension on the hanger bar. As with the BMH-60, the cable tension on the catch mechanism holds the bucket open while the sampler is lowered. Safety bars can be obtained from F.I.S.P. and should be installed on any unit which does not have one. Again, personnel operating these samplers are cautioned to please keep one's hands away from the bucket cavity even if a safety bar is in use. The power of the bucket is demonstrated by the fact that upon release it has been observed to lift the 100-lb sampler from a hard surface.

A bed-material sampler incorporating the heavy streamlined body of the P-61 sampler and the spring driven bucket of the BM-54 is being developed (John Skinner, F.I.S.P., oral commun., 1984). This sampler, designated the BM-84, is intended for use in large, swift rivers.

Prych and Hubbell (1966) developed a core sampler for use in deep flowing water in studies of the Columbia River estuary. This cable-suspended sampler (fig. 19) is used to collect a 1 7/8-inch diameter by 6-foot long core

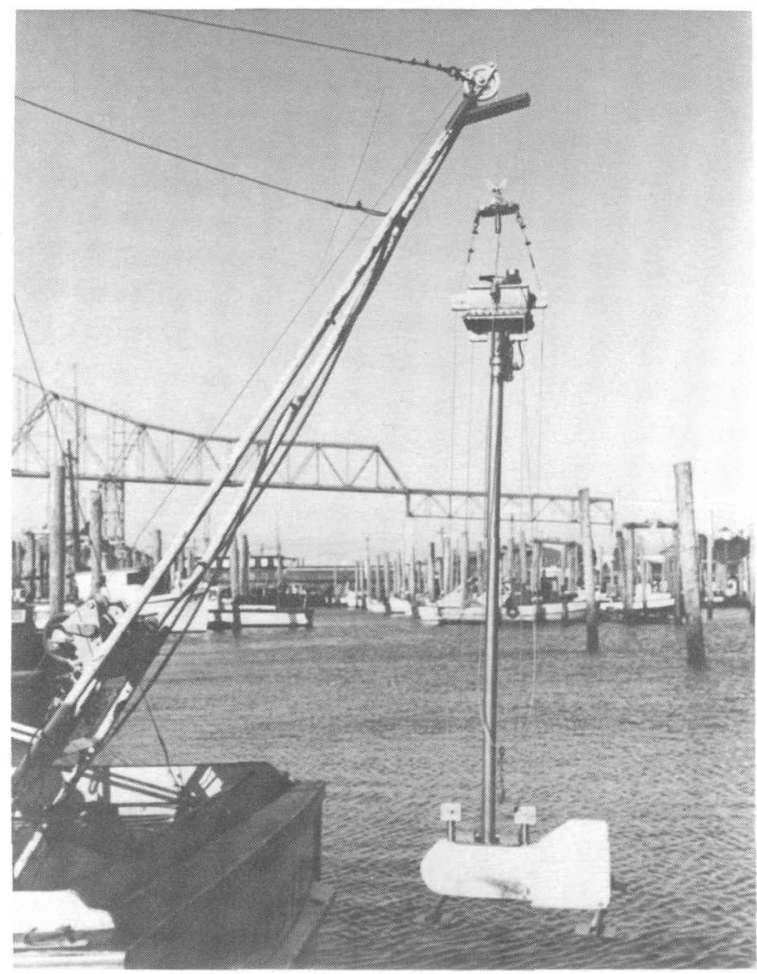

Figure 19.--Vibra-core sampler prepared for coring (core barrel approximately 5 feet long). From Prych and Hubbell, 1966, plate 1. 
by means of the combined action of vibration, suction, and an axial force derived through cables connected to a 250-lb streamlined stabilizing weight that rests on the streambed.

Smaller estuaries along the oregon coast and other places have been successfully sampled using a "Gravity Corer" available from Benthos, Inc. This sampler is allowed to plunge to the bottom where, under the force of the gravitational pull on the sampler coupled with the momentum of its 250-1b total weight, it can penetrate up to 5 feet deep in soft bed material. However, much less penetration can be expected if the bed material consists of sand or gravel. The sampler is retrieved from the bed using a cable-reel boom assembly. The 2 5/8-inch diameter by 5-foot-long core is retained in a core liner held in place by a core catcher at the bottom and protected against sample-washout by a watertight valve at the top. The length of core and depth of penetration depends upon the degree of hardness of the bed being sampled.

other slightly more crude devices have been used with some success to sample bed material and thus deserve mention here. The two most notable of these devices are: (1) the pipe dredge, which is lowered to the streambed and dragged a short distance to collect a sample; and (2) the "can on a stick" sampler, consisting of a rod with a scoop connected to the end, which can be used in wadable streams by lowering it to the streambed and scooping bed material from the bottom.

Bedload Samplers

At this time the reader should note the difference between bedload and unmeasured sediment load. Remember from the bed-material section that bedload is the sediment that moves by sliding, rolling, or bouncing along on or very near the streambed. Unsampled sediment is comprised of bedload particles and particles in suspension in the flow below the sampling zone of the suspendedsediment samplers (fig. 1).

Bedload is difficult to measure for several reasons. Any device placed on or near the bed may disturb the flow and rate of bedload movement. More importantly, the bedload transport rate and the velocity of water close to the bed vary considerably with respect to both space and time. Therefore, any sample obtained at a given point may not be representative of the mean transport rate for a reasonable interval of time because the bed particles move intermittently at a mean velocity much less than that of the water. Bedload discharge is not determined in the same manner as suspended-sediment loads, that is, by use of concentration and water-discharge data. Thus, a bedload sampler must be able to representatively sample, directly or indirectly, the mass or volume of particles moving along the bed through a given width in a specified period of time.

Prior to 1940 most bedload was measured using some type of directcollecting sampler. Bedload samplers developed during this era can be grouped into four categories: (1) box or basket, (2) pan or tray, (3) pressure difference, and (4) slot or pit samplers (Hubbell, 1964). Essentially, box or basket samplers consist of a heavy open-front box or basket apparatus, which is lowered to the streambed and positioned to allow collection of bedload particles as they migrate downstream. The basket type, displaying various sampling efficiencies, has been used preferentially over box types. pan or tray samplers consist of an entrance ramp leading to a slotted or partitioned box. These samplers also have varying sampling efficiencies. Pressure-difference samplers are designed to create a pressure drop at the sampler's exit and thus 
maintain entrance velocities approximately equal to the ambient stream velocity. Sampling efficiencies may be higher with this type of sampler than with others, and the deposition of sediments at the sampler entrance, inherent with basket or tray samplers, is eliminated. The best known early pressure-difference sampler is probably the Arnhem or Dutch sampler, after which the present day Helley-Smith bedload sampler is designed. Ideally, the best measurement of bedload would occur when all of the bedload moving through a given width during a specific time period was measured. The category of samplers that most closely meets this ideal is the slot or pit sampler. This type of sampler has efficiencies close to 100 percent. The slot openings of these pits are 100- to 200-grain diameters wide to ensure the high sampling efficiency. However, samples collected in the pits are removed only with great difficulty or by use of an elaborate conveyor device. A variation of this technique, consisting of a collection trough accessed by a series of hydraulically operated gates, extends from bank to bank at a site on the East Fork River, near Pinedale, Wyoming (Emmett, 1980a). Sediment trapped in the trough during sampling is removed by means of a continuous conveyor belt, which carries the sample to a weighing station on the stream bank.

The original Helley-Smith bedload sampler, introduced in 1971, was a variation of the Arnhem pressure-difference sampler. This sampler consists of an expanding nozzle, sample bag, and frame (fig. 20). The sampler design enables collection of particle sizes less than $76 \mathrm{~mm}$ at mean velocities to 9.8 $\mathrm{ft} / \mathrm{s}$. The sampler has a 3 -inch by 3 -inch square entrance nozzle, an area ratio (ratio of nozzle exit are to entrance area) of 3.22, and a 295-squareinch polyester mesh sample bag that is 18 inches long with mesh openings, usually either 0.2 or $0.25 \mathrm{~mm}$, attached to the rear of the nozzle assembly with a rubber "O" ring. The total weight of the original sampler design is 66 lb, requiring the use of a cable-reel suspension system. However, a lighter version incorporating a wading rod assembly is also available. Heavier versions weighing 99, 165, and $550 \mathrm{lb}$ (used on the Amazon River) have been used by Geological Survey personnel (Emmett, 1980b). A scaled-up version of the sampler having a 6 -inch by 6 -inch square entrance has been used to sample streams with large particle sizes.

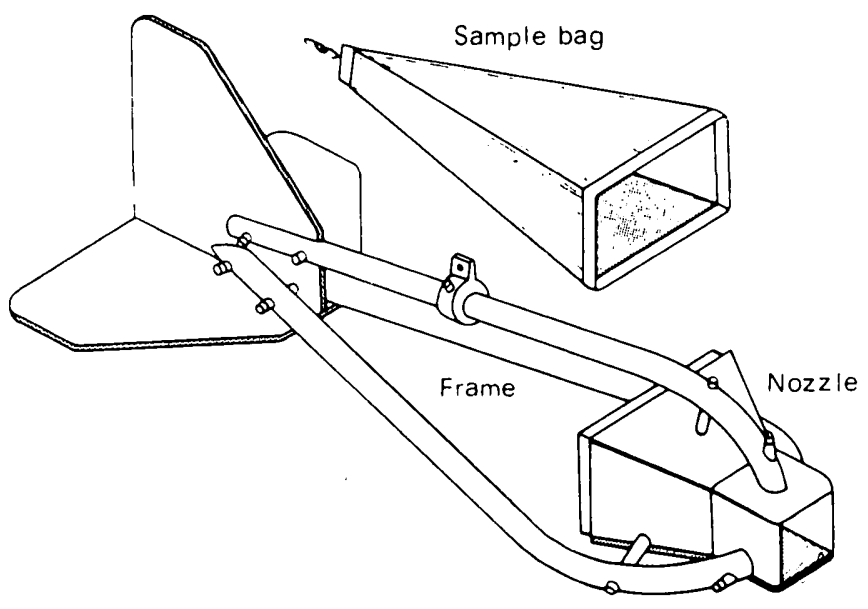

Figure 20.--Helley-Smith bedload sampler. From Emmett, 1980, p. 2 
The standard 3-inch by 3-inch sampler has been calibrated in two different laboratory studies and in an extensive field study. Jobson's laboratory study (Helley-Smith, 1971) indicated an average sampling efficiency of about 160 percent. Emmett (1980a) concluded from his field study that the overall sampling efficiency was close to 100 percent. A recent laboratory investigation (Hubbell and others, 1985) of varying bed materials and a range of transport rates indicates that the sampling efficiency of the standard 3-inch by 3-inch sampler varies with particle size and transport rate, displaying an approximate efficiency of 150 percent for sand and small gravel and close to 100 percent for coarse gravel. The standard 6-inch by 6-inch sampler had generally higher efficiencies. Tests of a Helley-Smith type sampler, which has a 3-inch by 3-inch nozzle with less expansion than the standard nozzle (an area ratio of 1.40 ), resulted in fairly constant efficiencies close to 100 percent for all transport rates and particle sizes. In May 1985 the 1.40 nozzle was approved by the Technical Committee on Sediment as a provisional standard nozzle for use by U.S. Federal Agencies. However, until this new sampler with the 1.40-area-ratio nozzle is tested further and becomes available for use, the original Helley-Smith sampler should be used.

\section{Automatic Pumping-Type Samplers}

\section{Development and Design}

Some sediment studies require frequent collection of suspended sediment at a site. Site location, flow conditions, frequency of collection, and operational costs frequently make collection of sediment data by manual methods impractical. For these reasons F.I.S.P. and Geological survey personnel have developed and evaluated several models of automatic pumping-type samplers. The US PS-69 sampler is probably the best known of these samplers to be designed, tested, and used by water Resources Division personnel of the Geological Survey. Recently, the US CS-77 (designed and tested by the Agricultural Research Service in Durant, Oklahoma) and the US PS-82 (F.I.S.P.) have been made available for general use. A number of automatic pumping-type samplers also have been designed by and are available through commercial sources. Two such samplers are the Manning S-4050 and the ISCO 1680 .

Automatic pumping-type samplers generally consist of (1) a pump to draw a suspended-sediment sample from the streamflow and, in some cases, to provide a back-flush to clear the sampler plumbing before or after each sampling cycle; (2) a sample container unit to hold sample bottles in position for filling; (3) a sample distribution system to divert a pumped sample to the correct bottle; (4) an activation system that starts and stops the sampling cycle, either at some regular time interval or in response to a rise or fall in streamflow (gage height); and (5) an intake system through which samples are drawn from a point in the sampled cross section. Ideally, this combination of components should be designed to meet the 17 optimum criteria as set forth by Curtis and Onions (written commun., 1982):

1. Stream velocity and sampler-intake velocity should be equal to allow for isokinetic sample collection if the intake is aligned with the approaching flow.

2. A suspended-sediment sample should be delivered from stream to sample container without a change in sediment concentration and particle-size distribution. 
3. Cross contamination of sample caused by sediment carry-over in the system between sample-collection periods should be prevented.

4. The sampler should be capable of sediment collection when concentra tions approach 50,000 milligrams per liter $(\mathrm{mg} / \mathrm{L})$ and particle diameters reach $0.250 \mathrm{~mm}$.

5. Sample-container volumes should be at least $350 \mathrm{~mL}$.

6. The intake inside diameter should be $3 / 8$ or $3 / 4$ inch, depending upon the size of the sampler used.

7. The mean velocity within the sampler plumbing should be great enough to ensure turbulent flow (Reynolds number greater than 4,000).

8. The sampler should be capable of vertical pumping lifts to 35 feet from intake to sample container.

9. The sampler should be capable of collecting a reasonable number of samples, dependent upon the purpose of sample collection and the flow conditions.

10. Some provision should be made for protection against freezing, evaporation, and dust contamination.

11. The sample-container unit should be constructed to facilitate removal and transport as a unit.

12. The sampling cycle should be initiated in response to a timing device or stage change.

13. The capability of recording the sample collection date and time should exist.

14. The provision for operation using DC battery power or 110-volt AC power should exist.

15. The weight of the entire sampler or any one of its principal compo nents should not exceed $100 \mathrm{lb}$.

16. The maximum dimensions of the entire sampler or any one of its com ponents should not exceed 35 inches in width or 79 inches in height.

17. The required floor area for the fully assembled sampler should not exceed 9 square feet ( 3 feet by 3 feet).

\section{Installation and Use Criteria}

The decision to use a pumping sampler for collection of sediment samples is usually based on both physical and fiscal criteria. These are real considerations; yet it should be understood that automatic-pumping samplers can be as labor intensive and costly as the manual sediment-data collection they were designed to supplement. Installation of an automatic-pumping sampler requires intensive planning before installation, including careful selection of the sampler-site location and detailed background data, to ensure the collection of useful pumped sample data. 
Before installation of an automatic pumping-type sampler, many of the problems associated with installing stream-gaging equipment must be dealt with. In addition, much data concerning the sediment-transport characteristics at the proposed sampling site must be obtained and evaluated prior to emplacement of the sampler and location of the intake within the streamflow. Logistically, the sample site must be evaluated as to ease of access, availability of electrical power, location of a bridge or cable-way relative to the site, normal range of ambient air temperatures inherent with local weather conditions, and the availability of a local observer to collect periodic reference samples. The sediment-transport characteristics should include detailed information on the distribution of concentrations and particle sizes throughout the sampled cross section over a range of discharges.

\section{Placement of Sampler Intake}

The primary concept to consider when placing a sampler intake in the streamflow at a sample cross section is that only one point in the flow is being sampled. Therefore, to yield reliable and representative data, the intake should be placed at the point where the concentration approximates the mean sediment concentration for the cross section across the full range of flows. This idealistic concept has great merit, but the mean cross-section concentration almost never exists at the same point under varying streamflow conditions. It is even less likely that specific guidelines for locating an intake under given stream conditions at one stage would produce the same intake location relative to the flow conditions at a different stage. These guidelines would have even less transfer value from cross section to cross section and stream to stream. For these reasons, some very generalized guidelines presented by Curtis and Onions (written commun., 1982) are outlined here and should be considered on a case-by-case basis when placing a sampler intake in the streamflow at any given cross section.

1. Select a stable cross section of reasonably uniform depth and width to maximize the stability of the relation between sediment concen tration at a point and the mean sediment concentration in the cross section. This guideline is of primary importance in the decision to use a pumping sampler in a given situation; if a reasonably stable relation between the sample-point concentration and mean crosssection concentration cannot be attained by the following outlined steps, the sampler should not be installed and an alternate location considered.

2. Consider only the depth that would be sampled using a standard US, manually operated sediment sampler excluding the unsampled zone as data from a manual sampler will be used to calibrate the pumping sampler.

3. Determine, if possible, the depth of the point of mean sediment con centration in each vertical for each size class of particles finer than $0.250 \mathrm{~mm}$ from a series of carefully collected, point-integrated samples.

4. Determine, if possible, the mean depth of occurrence of the mean sediment concentration in each vertical for all particles finer than $0.250 \mathrm{~mm}$. 
5. Use the mean depth of occurrence of the mean sediment concentration in the cross section as a reference depth for placement of the intake.

6. Adjust the depth location of the intake to avoid interference by dune migration or contamination by bed material.

7. Adjust the depth location of the intake to assure submergence at all times.

8. Locate the intake laterally in the flow at a distance far enough from the bank to eliminate any possible bank effects.

9. Place the intake in a zone of high velocity and turbulence to improve sediment distribution by mixing, reduce possible deposition on or near the intake, and provide for rapid removal of any parti cles disturbed during the purge cycle.

Because of the generalized nature of these guidelines, it will often be impossible to satisfy them all when placing a pumping sampler intake into naturally occurring streamflows. The investigator is encouraged, however, to try to satisfy these guidelines or, at the very least, to satisfy as many as possible and to minimize the effects of those not satisfied.

\section{Sampler Advantages and Disadvantages}

Automatic pumping-type samplers are very useful for collecting suspendedsediment samples during periods of rapid stage changes caused by storm-runoff events and in reducing the manpower necessary to carry out intensive sedimentcollection programs (F.I.S.P., 1981b). However, it should be noted that pumping samplers quite often require more man-hours and cost more to operate than a conventional, observer sampled type of station. Pumping samplers, because of their mechanical complexity, power requirements, and limited sample capacity, quite often require more frequent site visits by the field personnel than would be required at the conventional observer station. In addition, problems associated with collecting high-flow, cross-section samples are still present.

In streams with significant eamounts of suspended-sand loads, the problems associated with using a pumping sampler are so great that two records may have to be calculated, one for the silt-clay size fraction load and one for the sand size fraction load. This requires that most of the samples collected with the pumping sampler, as well as the samples collected manually, be subjected to a full particle-size analysis. Extensive lab work of this type increases the cost of analysis and computation of the sediment-discharge record. Another disadvantage is that the pumping lift for most samplers is relatively small and may be less than the normal fluctuations in stage at some sites. This is especially true on western rivers, where stage ranges may exceed 50 feet, making it necessary to locate the pump outside of the sampler's shelter in order to maintain a manageable pumping lift.

\section{Intake Orientation}

The orientation of the pumping-sampler intake nozzle can drastically affect sampling efficiency. There are five ways in which an intake could be oriented to the flow (fig. 21): (A) normal and pointing directly upstream 


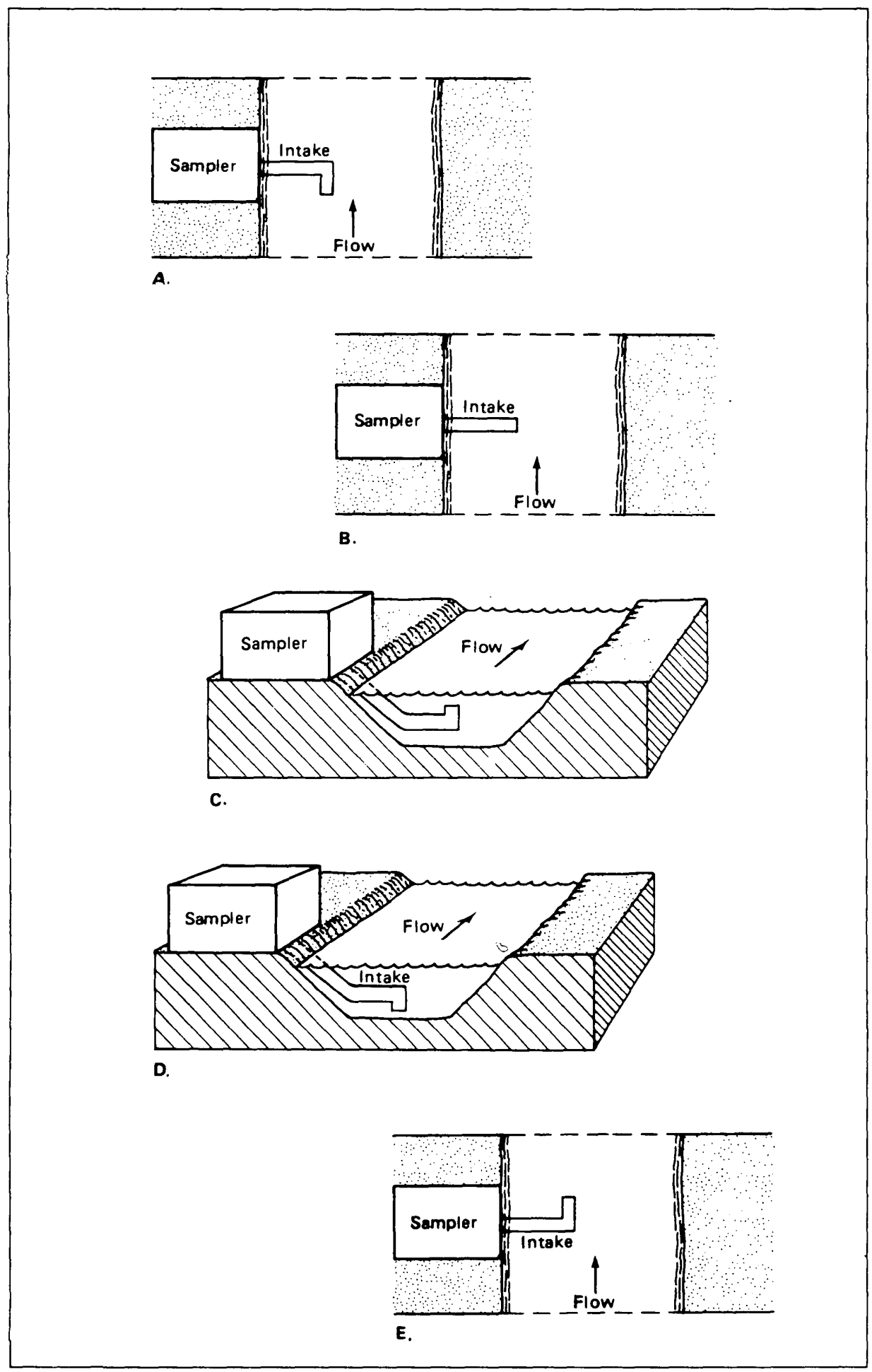

Figure 21.--Examples of pumping-sampler intake orientations. 
(fig. 2la), (B) normal and horizontal to flow (fig. 21b), (C) normal and vertical with the orifice up (fig. 21C), (D) normal and vertical with the orifice down (fig. 21d), and (E) normal and pointing directly downstream (fig. 21e). Of these five possible orientations, A, C, and D should be avoided because of high sampling errors and trash collection problems. Orientation $B$, with the nozzle positioned normal and horizontal to the flow, is the most common alternative used. The major problem with this orientation is that sand-size particles may not be adequately sampled (see the following section on pumped-sample data analysis). Orientation $E$, pointing directly downstream, appears to have an advantage over orientation B (Winterstein and stefan, 1983). When the intake is pointing downstream, a small eddy is formed at the intake, which envelops the sand particles and thus allows the sampler to collect a more representative sample of the coarse load.

\section{Data Analysis}

A major concern when evaluating sediment data collected by automatic pumping-type samplers is the relation between the data and the "true" mean suspended-sediment concentration in transport at the time of sample collection. In order to determine this relation, concentrations determined from the pumping sampler must be compared with the corresponding concentrations determined from a complete depth-integrated cross-section sample over the full range of flow. This relation is then used to adjust the pumped sample data.

It must be remembered that samples collected by pumping samplers are taken from a single point in the flow. Although attempts are made to ensure that cross-sectional mean sediment concentrations are obtained, in reality this rarely happens. However, if a stable relation between the concentration at the sample point and the mean concentration in the cross section exists, the sample can be considered as representative as possible. In addition, pumping samplers do not collect samples isokinetically (as do standard US depth- or point-integrating samplers), due to the pumping rate and the orientation of the intake orifice. Not sampling isokinetically introduces concentration errors, particularly for particles $>0.062 \mathrm{~mm}$.

Pumping samplers rely on pump speed to create a velocity in the intake tube greater than the settling velocity of particles in suspension. This higher velocity is necessary to deliver the sample to the sample container without reducing the concentration of coarser particles by depositing them within the sampler's plumbing. The pumping action at the intake orifice bends the streamlines of sediment-laden flow as a sample is drawn into the intake and as particles are propelled through the sampler to the sample container. This force acts on particles carried past the orifice with varying results, dependent upon particle size and velocity (F.I.S.P., Report 5, 1941). That is, the pumping force attempts to pull particles laterally from their streamlines and accelerate them in the direction of the intake. At low stream velocities, when only fine silts and clays are being transported, this is not a problem. However, as stream velocity increases and particles larger than $0.062 \mathrm{~mm}$ begin to move in suspension, the pumping force must overcome the momentum of these particles, due to their mass and acceleration in the downstream direction, in order for a representative sample to be obtained. This decrease in efficiency can result in a biased sample since fewer and fewer large particles are drawn into the intake as the perimeter of the zone of pumping influence is approached (fig. 22). From figure 22 it is apparent that only those sediment particles passing directly in front of the intake, a short distance away, are greatly affected and subject to capture. It should also be realized that the zone (cone) of influence is an idealized concept and pumping 


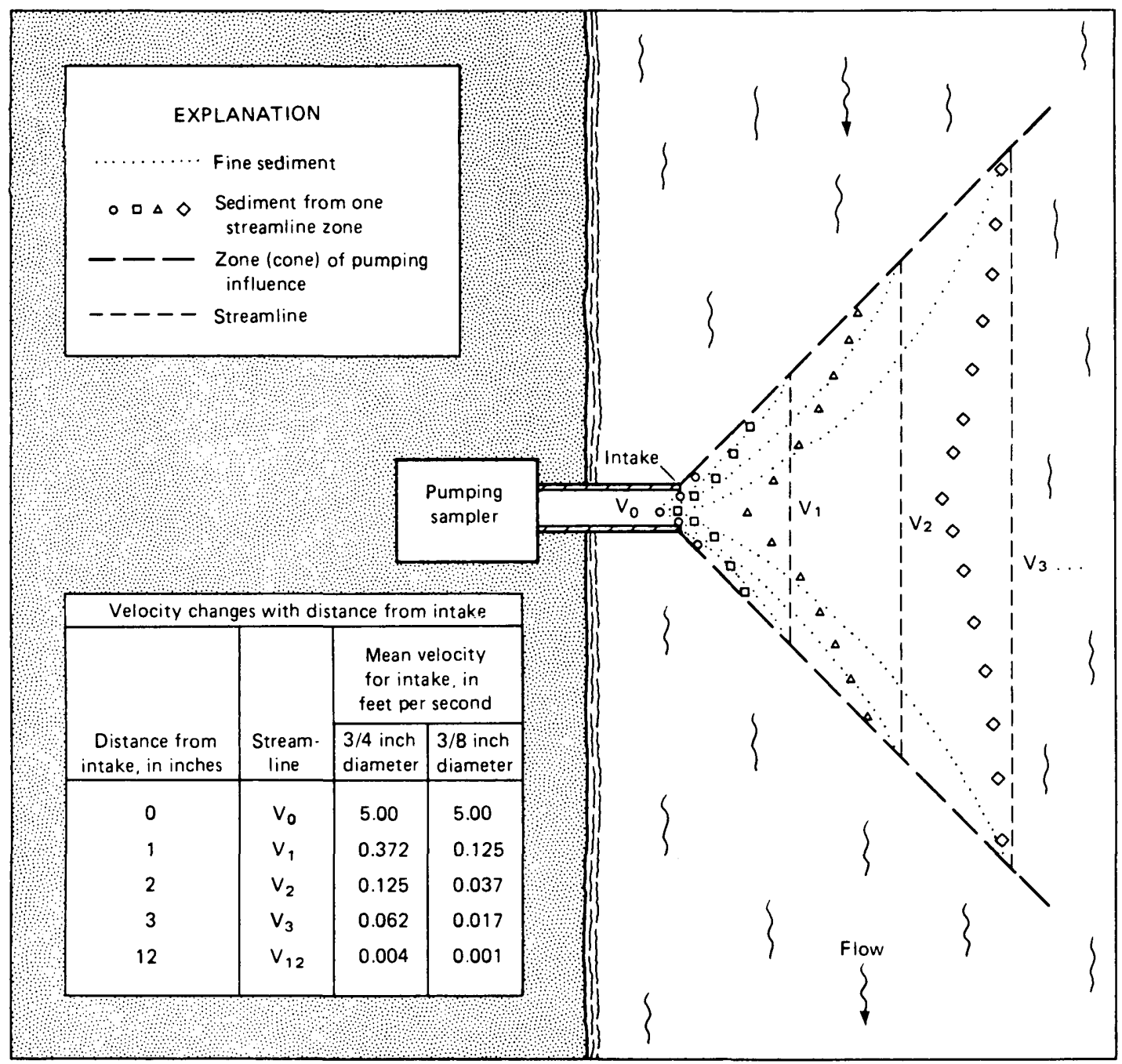

Figure 22.--Pumping effect on sediment streamlines within the zone (cone) of influence and velocity changes with distance from intake. From F.I.S.P., 1966, and Curtis and Onions, written commun., 1982 .

influence is much greater on sediments approaching the intake from upstream than on those sediments that have passed to the downstream side. As mentioned previously, this problem may be relieved somewhat by orienting the intake directly downstream.

\section{Intake efficiency}

To facilitate accurate interpretation of data collected by automatic pumping-type samplers, some comparison between sediment concentration of the pumped sample $\left(C_{p}\right)$ and mean sediment concentration of the streamflow $\left(C_{S}\right)$ must be made. This comparison is made in terms of intake efficiency, which is the ratio of the pumped-sample sediment concentration to the mean concentration of the stream at the intake sampling point (F.I.S.P., Report T, 1966), or 


$$
\frac{C_{p}}{C_{S}}(100)=\text { intake efficiency. }
$$

In reality this relation is based on comparison of the pumped sample to sediment concentration of a point sample collected as close to the intake sampling point as possible, using a standard US depth-or point-integrating sampler.

Intake efficiencies should be determined for pumping samplers as soon as possible after installation-related sediment disturbances have stabilized. Additional efficiency values should be established over a broad range of flow conditions to determine actual effects of variations in particle sizes at a given sample site. These data can then be used to evaluate the sediment concentration of pumped samples and check their credibility.

\section{cross-section coefficient}

Determining the degree of efficiency with which a pumping sampler obtains a representative sample is one step in the interpretation of suspended-sediment concentration data. These data should be further assessed relative to the cross-sectional mean suspended-sediment concentration. A coefficient should be determined based on how well the pumping sampler's data represents the crosssectional mean, and this coefficient should be applied to the pumping sampler data.

From previous discussion it should be evident that sediment samples taken at a single point of flow within a cross section seldom, if ever, represent the mean sediment concentration. Therefore, cross-section coefficients must be determined to relate pumped-sample sediment concentration to the mean sediment concentration in the cross section. Because no theoretical relation exists between these parameters, an empirical comparison must be made between concentrations obtained from pumped samples and concentrations obtained from depthintegrated, cross-sectional samples collected at the same time. Obviously, it is impossible to collect an entire cross-sectional sample in the length of time it takes to cycle the pumping sampler to collect a single sample. Therefore, it is recommended that a sample collected with the pumping sampler be taken immediately before and after the cross-section sample. This procedure will help bracket any changes in concentration that might occur during the time period necessary to collect the cross-section sample. If it is suspected that the concentration is changing rapidly during the collection of the crosssection sample, try to collect one or more samples with the pumping sampler during the time that the cross- section sample is being collected. This data will help in the development of the cross-section coefficient. Collection and comparison of these check samples should be repeated during each station visit, as well as during rising and falling stages, and at peak flows for all seasonal periods (snowmelt runoff, thunderstorms, etc.). A more detailed discussion on development of cross-section coefficients is available to the interested reader in Guy (1970) and Porterfield (1972).

$$
\begin{gathered}
\text { Description of Automatic Pump-Type Samplers--US PS-69, US CS-77, } \\
\text { US PS-82, Manning S-4050, and ISCO 1680 }
\end{gathered}
$$

The US PS-69 pumping sampler (fig. 23) is a time- or stage-activated, electrically-driven, suspended-sediment sampler capable of collecting up to 72 samples at volumes to $1,000 \mathrm{~mL}$. Standard pumping lifts are to 17 feet vertically, but repositioning the pump or using multiple pumps in series can increase lift capabilities for extreme situations. This sampler must be 


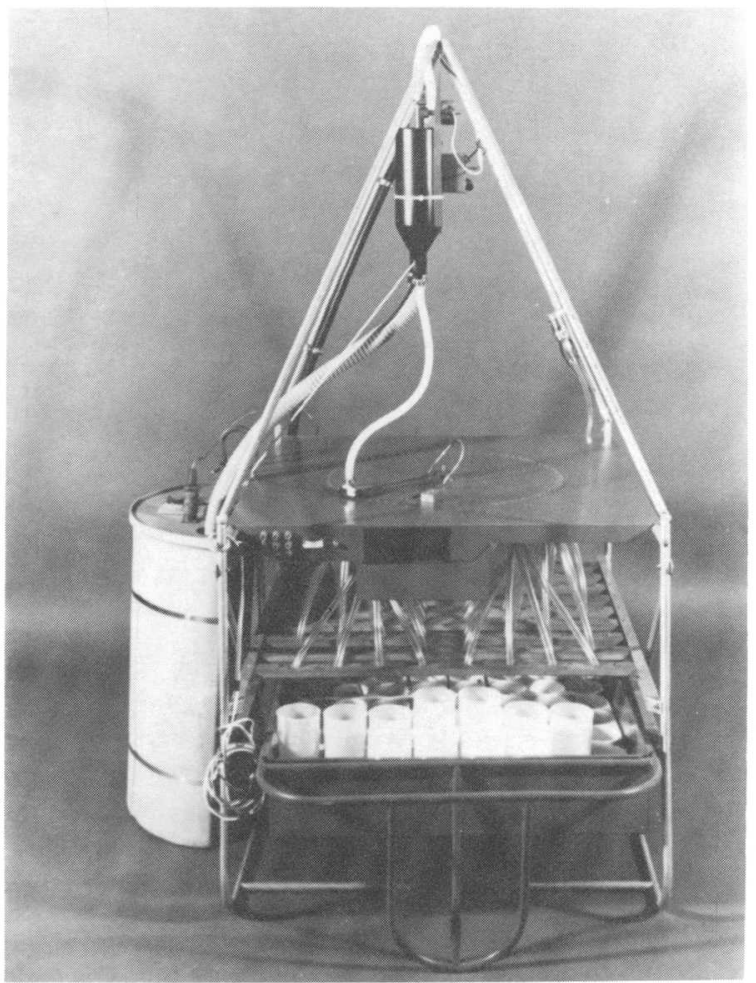

Figure 23.--US PS-69 pumping sampler.

placed in a shelter and protected against inclement weather and temperature extremes.

Particle sizes sampled range to 0.250 millimeters with some decrease in sampling efficiency for the larger particles. Sediment concentrations to $160,000 \mathrm{mg} / \mathrm{L}$ have been sampled by Geological Survey personnel in New Mexico using an air driven pump with the PS-69 (John Skinner, F.I.S.P., written commun., 1985); extremely high concentrations have also been sampled in the vicinity of the Mount St. Helens volcano in Washington.

The PS-69 was evaluated by Curtis and Onions (written commun., 1982) by comparing the sampler's attributes to the 17 criteria previously listed. Results of this comparison are included in table 2.

The US CS-77, or Chickasha, sediment sampler (fig. 24) was designed and developed by the Agricultural Research Service, Durant, Oklahoma, and is available from F.I.S.P. This sampler was fashioned after an earlier design (US XPS-62, developed by F.I.S.P.) but has not been widely used by Geological Survey personnel.

Like the PS-69, this sampler is time- or stage-activated to facilitate sampling on a predetermined schedule as well as during runoff events. Sampling times are recorded during the sampling procedure as part of the standard sampler's design of operation in lieu of add-on modules and recording devices common to other samplers discussed here.

Pumping lift attained by the standard CS -77 sampler configuration is 16 vertical feet; however, relocation of the pump unit to a lower elevation will establish a pull-push sequence, enabling greater sample lifts. 
Table 2.--Automatic pumping-type sampler evaluation

$[\mathrm{A}=$ US PS $-69 ; \mathrm{B}=$ US CS $-77 ; \mathrm{C}=\mathrm{US} \mathrm{PS}-82 ; \mathrm{D}=$ Manning $\mathrm{S}-4050 ; \mathrm{E}=$ ISCO 1680$]$

Evaluation criteria

Samplers meeting

criteria

1. Sample collection isokinetic

2. Sediment concentration constant stream to sample container

3. Cross contamination prevented

4. Collects concentrations to $50,000 \mathrm{mg}^{\mathrm{L}} \mathrm{L}$ and particles to $0.25 \mathrm{~mm}$

5. Sample volume $\geq 350 \mathrm{mI}$

6. Intake diameter $3 / 4$ inch

7. Turbulent flow $(R=4,000)$ within sampler

8. Vertical pumping lift $\geq 35$ feet

9. Capable of collecting an adequate number of samples to accomplish the purpose of sampling

10. Sampler protected against freezing, evaporation, and dust

11. Sample container tray removable single unit

12. Sampling cycle activated by timer or stage change

13. Capable of recording sampling date and time

14. AC or DC power capability

15. Sampler or principle components $\leq 100 \mathrm{lb}$

16. Sampler dimensions $\leq 35$ inches by 79 inches

17. Required floor space $\leq 9 \mathrm{ft}^{2}$ ( 3 feet by 3 feet)

$A^{2}, B^{1}, C^{1}, D$
$A, B, C, D$
$A^{2}, B^{1}, 2, C^{2}, D^{2}, E^{1}$
$A^{3}, B^{3}, C^{3}, D^{3}, E^{3}$
$A$
$A^{3}, B^{1}, C^{2}, D^{3}, E^{3}$
$A^{1}, B^{1}, C^{1}$
$A^{3}, B^{3}, C^{3}, D, E$
$A^{1}, B^{1}, C, D^{1}, E^{1}$
$A^{2} D^{2} E$
$A, B, C, D^{1} E^{1}$
$A^{1}, B^{1} C^{1} D^{1}, E^{1}$
$A^{1}, B^{1}, C^{1}, D^{1}, E^{1}$
$A^{1}, B^{1}, C^{3}, D^{3}, E^{3}$
$A^{1}, B^{1}, C^{3}, D^{3}, E^{3}$
$C^{3}, D^{3}, E^{3}$

${ }^{1}$ Sampler requires modification to meet criteria.

2 Sampler shows a reduction in capacity with particle sizes $>0.250 \mathrm{~mm}$.

${ }^{3}$ Sampler exceeds criteria.

Further modification is necessary to improve the sampling efficiency for high-concentration flows carrying greater than 10 percent sand-sized material. Additional information regarding this sampler may be obtained from the evaluation in table 2 and by contacting personnel at the' F.I.S.P.

The US PS-82 automatic pumping-type sampler (fig. 25) is the most recent design available from F.I.S.P. It was made available in March 1984 and has yet to be widely used under field conditions. Information from Szalona and Beverage (1983) describes the PS-82 as a lightweight, portable pumping sampler, driven by 12-volt battery power, which is used to sample streamflows transporting particles ranging to fine sand size. These samplers weigh 35 lb and can be housed under a 55-gallon:oil drum. An evaluation of this sampler is included in table 2. For more specific information concerning the technical aspects of this sampler and its availability, the interested reader should contact the F.I.S.P. 


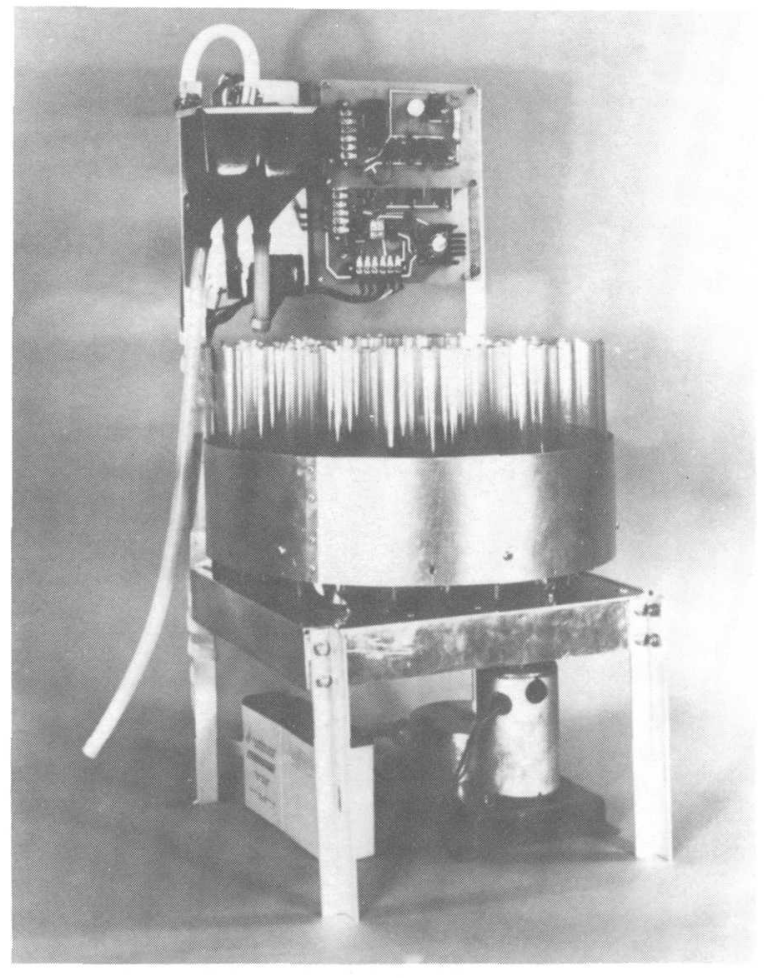

Figure 24.--US CS-77 (Chickasha) pumping sampler.

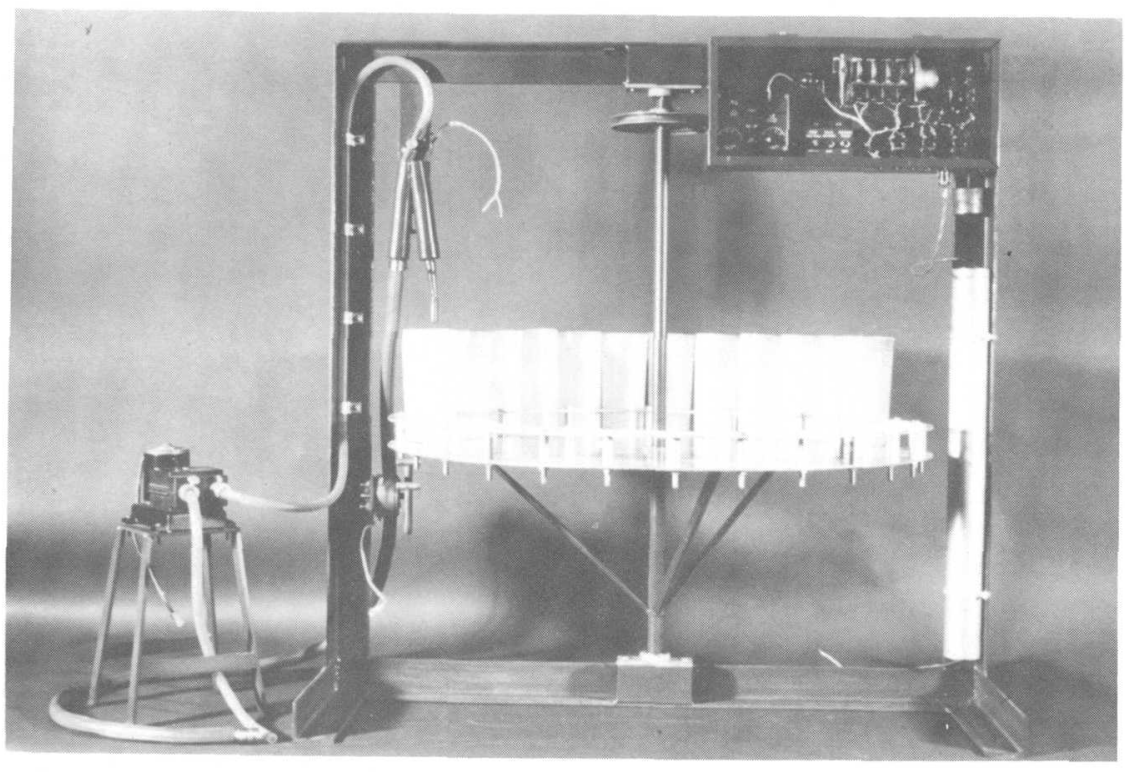

Figure 25.--US PS-82 pumping sampler.

The aforementioned samplers were developed by Federal agencies concerned with the collection of suspended-sediment data in a timely, cost-effective manner and are available to the interested investigator from the F.I.S.P. at St. Anthony Falls Hydraulic Laboratory, Hennepin Island and Third Avenue, S.E., Minneapolis, Minnesota 55414. 
The following discussion is a description of the Manning S-4050 and ISCO 1680 automatic pumping-type samplers, which are not available through F.I.S.P. but may be obtained from the individual manufacturers. These samplers are described because they represent the types of samplers that are commonly available from commercial sources and used by the Water Resources Division of the Geological Survey.

The Manning S-4050 portable sampler, available through Manning Environmental Corp., was originally designed as a lightweight unit for sampling sewage. Modifications to this sampler have rendered it useful as a suspendedsediment sampler.

The sampler features a time- or stage-activated electric compressor, which purges the sample intake using the pressure side and draws a sample through the intake using the suction side to create a vacuum in the line allowing atmospheric pressure to push the sample up to a maximum of 22 feet during the sampling mode. Particle suspension within the sampler is maintained by swirling action of the sample as it passes through the measuring chamber to the sample container.

Evaluation of this sampler in the same manner used for the previously discussed samplers indicates that this instrument is well suited to conditions where extreme pumping lifts are not necessary. Results of this evaluation are included in table 2 .

The ISCO 1680 with super-speed pump is available through Instrument Specialties Co. Like the Manning sampler, this instrument was originally developed as a sewage or waste-water sampler. Normally, waste water, for which this sampler was developed, does not carry significant amounts of sediment. Therefore, representation of particle distribution was not a considered criteria during its design and testing stages. The sampler features an electrically driven peristaltic pump, which is activated on a predetermined schedule by an internal timer or in response to stage change. The intake tube is purged before and after each pumping period by automatic reversal of the pump.

The ISCO sampler demonstrates two major shortfalls regarding sediment collection: (1) continuity of sediment concentration from stream to sample container is not maintained efficiently, and (2) a possibility of cross contamination exists from sample to sample as a result of residue remaining in the system after the purge cycle. These problems can be minimized by the installation of a high output pump, available as an option with recent models. A sampler evaluation is included in table 2 .

\section{Support Equipment}

Sediment-sampling equipment has been designed by F.I.S.P. to facilitate the use of existing support equipment normally used in stream-gaging procedures. This compatibility enables the field person to readily use equipment permanently installed at a site and, in many cases, reduces the amount of equipment required to be transported to the sampling location. Support equipment is generally necessary for the proper operation of the heavier versions of sediment samplers. Wading rods must be ordered separately for those versions designated as hand samplers, or the necessary suspension can be easily attained by constructing handlines from nylon line and steel cable of sufficient strength to prevent equipment loss yet small enough in diameter to minimize drag at high flow. In general, support equipment consists of steel 
cable, hanger bars, reels, and cranes. However, specific conditions at a site in many cases dictate modifications to these pieces of equipment to improve the response to sampling conditions and ease of handling.

Sediment investigations are performed under a wide variety of field conditions, including inclement weather, darkness, or catastrophic flow events. Under these conditions the work is inherently dangerous, increasing the need for regular maintenance and careful use of equipment to improve the safety margin and shorten the sampling time period during which field personnel are exposed to unsafe conditions.

Modifications of support equipment necessary to facilitate the handling of samplers and improve safety are encouraged. Investigators are cautioned against alterations that might adversely affect sample collection, either by disturbing the streamflow in the cross section or by changing the sedimenttrapping characteristics of the sampler. To ensure sample integrity, Regional and Office of Surface Water specialists should be consulted before any modifications of this type are made.

Commonly used support items include C-type hanger bars; type-A, B, and E reels; and portable cranes with 2-, 3-, and 4-wheel bases. The C-type hanger bars can be shortened to eliminate awkward and hazardous handling. Type-A reels can be used to suspend light- to medium-weight samplers and have been widely used at permanent single-vertical observer sites. Type-B and $E$ reels are typically used with medium and heavy samplers. The type-B reel can be used manually or with an available power unit, allowing the sampler to be lowered by releasing the brake mechanism and letting it slip until the sampler reaches the water surface, then integrating the sampled vertical as usual and raising the sampler, either manually or by activating the DC-powered motor to drive the reel. The type-E reel is a DC-powered reel which lends itself more readily to permanent installations where heavy sampling equipment is required. Cranes are used to provide a mechanical advantage over hand-line or bridgeboard suspended equipment for more effective maneuvering of a sampler. The 2, 3-, and 4-wheel base cranes are useful when sampling from a bridge deck; however, safety precautions should be taken to warn approaching traffic and to avoid blocking the roadway. Boom assemblies are also used in some instances, such as with truck- and boat-mounted installations.

Reels, cranes, and powered hoists can be purchased from the HIF. The HIF also can provide information on the availability, installation requirements, and operation of this equipment. Some additional information may also be obtained from the report "Discharge Measurements at Gaging Stations" (Buchanan and Somers, 1969).

\section{SEDIMENT-SAMPLING TECHNIQUES}

The sediment-sampling method and frequency of collection are dictated by the hydrologic and sediment characteristics of the stream, the required accuracy of the data, the funds available, and the proposed use of those data collected. When sampling sediment moving through a stream cross section, emphasis should be placed on the collection of a statistically representative population of the sediment particles in transit. To acquire a representative sample, one must first obtain a sample that adequately defines the concentration of particles over the full depth of the sampled vertical. Secondly, a sufficient number of verticals must be sampled to adequately define the horizontal variation in the cross section. 
The type of sampler used to collect the sample, the method of depthintegration, the site at which the samples are collected, and the number of verticals needed depend on the flow conditions at the time of sample collection, characteristics of the sediment being transported, the accuracy required of the data, and the objectives of the program for which the samples are being collected.

The purpose of this section is to discuss site selection; equipment selection and maintenance; depth integration; sediment-discharge measurements; point integration; surface and dip sampling; transit rates; sample frequency, quantity, integrity, and identification; sediment-related data; cold weather sampling; bed-material sampling; bedload sampling; total sediment discharge; and reservoir sedimentation. This section then deals with the decisions to be made and the instructions necessary to obtain the quantity and quality of samples required for computation and compilation of the desired sediment records.

\section{Site Selection}

The selection procedure for establishing a sampling location should emphasize the quest for a "stream-data site." A stream-data site is best defined as a cross section displaying relatively stable hydrologic characteristics and uniform depths over a wide range of stream discharges, from which representative water-quality and sediment data can be obtained and related to a stage-discharge rating for the site. This is a rather idealized concept as the perfect site is rare at best. Therefore, it is necessary to note the limitations of the most suitable site available and build a program to minimize the disadvantages and maximize the advantages. Most often sampling sites are located at or near existing gage sites, which may not always be well suited to water-quality and sediment-data collection. For this reason future sites selected for stream gaging should be carefully assessed for suitability as a water-quality and sediment-sampling site.

As indicated, the site should be at or near a gaging station because of the obvious relation of sediment movement to the flow of the stream. If the sediment-measuring site is more than a few hundred feet from the water-stage recorder or at a site other than where the water-discharge measurement is made, it may be desirable to install a simple nonrecording stage indicator at the site so that a correlation of the flow conditions between the sediment and the distant water-measuring sites can be developed. The obvious difficulties with inflow between the sites from small tributaries should also be avoided where possible.

Sites that may be affected by backwater conditions should be avoided whenever possible. Backwater affects both the stage-discharge and velocitydischarge relation at the site. Therefore, a given discharge may have varying stage and mean stream velocity and thus have varying sediment-transport rates. If a site is affected by backwater, samples will have to be collected more frequently; and the cost in both man-hours and money will be significantly higher than for more "normal" sites.

A sediment-measuring site downstream from the confluence of two streams may also require extra sediment measurements. The downstream site may be adequate for water-discharge measurement but could present problems if used as a sediment-measuring site due to incomplete mixing of the flows from the tributaries. Therefore it might be desirable to move far enough downstream to ensure adequate mixing of the tributary flows. As indicated in Book 3, 
Chapter C1, "Fluvial Sediment Concepts" (Guy, 1970, p. 24), the distance downstream from a confluence for complete mixing depends on the stream velocity, depth, and mixing width. If the flow at a sediment-measuring site is not mixed, extra samples will be required on a continuing basis because the relative flow quantity and sediment concentration from the two tributaries will change with time.

Aside from the confluence or tributary problem, the type of cross section for flow both in the channel and on the floodplain may affect the ease with which data can be obtained and the quality of the samples. The ratio of suspended load to total load and its variation with time can be greatly affected by the width-depth ratio, especially for sand-bed streams. For sites where the data are expected to be correlated with channel properties and the landforms of the region, a normal or average section should be used. When a fixed-routine sampling installation is used, a measuring section at a bend may provide a more stable thalweg and hence a more uniform adjustment coefficient with respect to time than one at a crossover. Sites in areas of active bank erosion should be avoided if possible.

As a result of economic necessity, most sediment-measuring sites are located at highway bridges. These bridges are often constructed so that they restrict the flow width or may be located at a section where the channel is naturally restricted in width. Figure 26 (Culbertson and others, 1967) illustrates the conditions at several kinds of natural and artificially induced flow constrictions. As expected, the sand-bed type of stream causes the most serious flow problems with respect to scour in the vicinity of such constrictions. Even if the bridge abutments do not interfere with the natural width of the stream, the bridge may be supported by several midstream piers that can interfere with the streamflow lines and thereby reduce the effective crosssectional area. As indicated in figure $26 \mathrm{~F}$, midstream piers can catch debris and thereby interfere with effective sediment sampling.

Because sediment samples must be obtained more frequently during floods, it is imperative that a site be selected where obtaining data during times of flooding is feasible. That is, particular attention should be given to the ease of access to the water-stage recorder and to a usable bridge or cable during a flood. Because of the need to collect samples frequently during floods, many of which occur at night, sites accessible only by poorly maintained back roads or trails should be avoided. Sometimes the choice of a sediment-measuring site must also be determined by the availability of a suitable observer to collect the routine samples.

In choosing a sediment-measurement site, it should be emphasized that samples need to be collected at the same cross-section location throughout the period of record. Different sampling cross sections can be used, if absolutely necessary, during the low-water wading stage and the higher stages requiring the use of a bridge or cableway. However, although the total sediment transported through the different cross sections is probably equal at a given flow stage, the percentage of that total load represented by suspendedsediment load may be drastically different from one cross section to the other, due to differences in hydraulic and sediment-transport characteristics. When data computations are performed, therefore, these differences must be considered, as the data may not be compatible and the usefulness of the data in answering the objectives of the sampling program could be threatened. Sites where highway or channel realignment or other construction is anticipated during the period of record should be avoided. Good photographs of proposed or selected sediment-measuring sites are necessary to help document such features as channel alignment, water-surface conditions at various stages, 


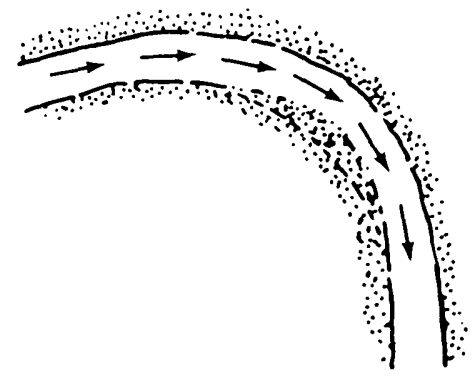

A. Natural constriction of channel at bend

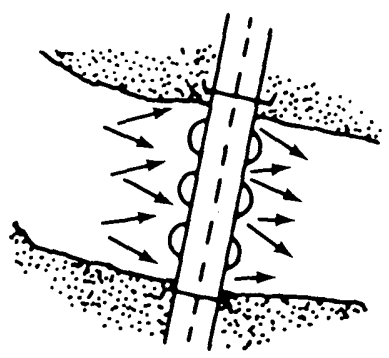

C. Constriction of channel by massive piers

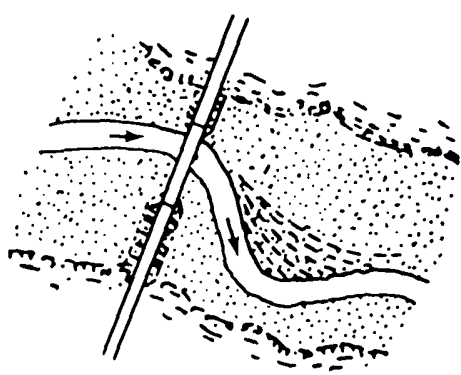

E. Constriction of flood plain by embankments

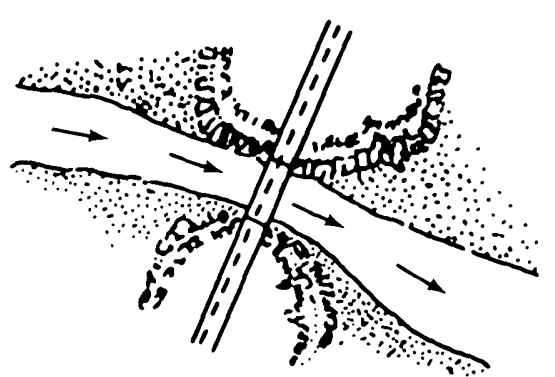

B. Natural constriction of channel by persistant bedrock

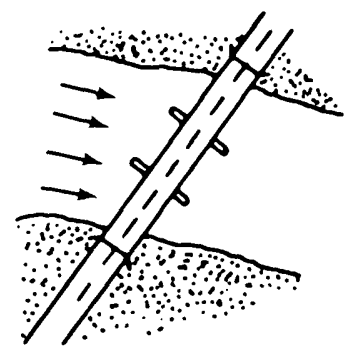

D. Effective constriction of channel by long skewed piers

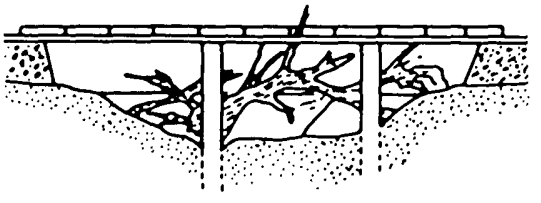

F. Constriction of flow by accumulation of debris

\section{Figure 26.--Examples of natural and artificially induced streamflow constrictions encountered at sediment-measurement sites.}

composition of bed and bank material (at low flow), and natural or manmade features which could affect the water-discharge and (or) sediment-discharge relations. Such pictures and extensive field notes are particularly useful when deciding on alternatives among sites and in later consideration of environmental changes at the site(s). 
Before departing on a field trip where sediment data are to be collected, a field person should assemble and check all equipment needed to collect the best samples and related measurements. For example, if data are needed for total-load computation, equipment is needed for water-discharge measurement, suspended-sediment sampling, bedload sampling, and (or) bedmaterial sampling. If suspended-sediment concentration and particle-size profiles are required, point samplers and water-discharge-measuring equipment will be needed. Some of the special equipment used only at one location may be stored in the station gage house, with the observer, or in special storage shelters or boxes. However, a sampler or some support equipment could be damaged or stolen without the observer noticing or reporting the loss. Hence, it is necessary for field personnel to carry repair equipment, spare parts (including nozzles and gaskets), and perhaps even an extra sampler.

The streamflow conditions and sampling structures (bridge, cableway, or other) determine more specifically which sampler or samplers should be used at a station. Stream depth determines whether hand samplers, such as the DH-48 or the BMH-53, or cable-suspended samplers, such as the D-74 or the P-61, should be used. Depths over 15 feet will require the use of point samplers as depth-integrating samplers to avoid overfilling or using too fast a transit rate. Stream velocity as well as depth are factors in determining whether or not a stream can be waded. A general rule is that when the product of depth in feet and velocity in feet per second equals 10 or greater, a stream's wadability is questionable. Application of this rule will vary considerably among field persons according to an individual's stature and the condition of the streambed. That is, if footing is good on the streambed, a heavier field person with a stocky build will generally wade more easily when a stream depth-velocity product approaching 10 exists, than will a lighter, thinner person.

The depth-velocity product also affects the action of each sampler. The larger this product, the heavier and more stable the sampler must be to collect a good sample. At a new station or for inexperienced persons, considerable trial and error may be necessary to determine which sampler is best for a given stream condition.

All sampler nozzles, gaskets, and air exhausts, as well as the other necessary equipment, should be checked regularly and replaced or serviced if necessary. Sampler nozzles in particular should be checked to ensure that they are placed in the appropriate instrument or series. See the guidelines presented in table 1 to determine whether the nozzle is correct. The correct size of nozzle to use for a given situation must often be determined by trial. As mentioned in the previous section, it is best to use the largest nozzle possible that will permit depth integration without overfilling the sample bottle or exceeding the maximum transit rate (about. 0.4 the mean velocity in the sampled vertical for most samplers with pint containers).

If a sample bottle does not fill in the expected time, the nozzle or air-exhaust passages may be partly blocked. The flow system can be checked, as described in the section titled Gaskets, by sliding a length of clean rubber or plastic tubing over the nozzle and blowing through the nozzle with a bottle in the sampler. This procedure should be performed carefully, avoiding direct contact with the nozzle, thus eliminating the possibility of ingesting any pollutant which might exist on the sampler. When air pressure is applied in this manner, circulation will occur freely through the nozzle, sample container, and out the air exhaust. Obstructions can be cleared by removing and 
cleaning the nozzle and (or) air exhaust using a flexible piece of multistrand wire. This procedure should be adequate for most airway obstruction problems. However, if blockage results from accumulation of ice or from damage to the sampler, a heat source must be used to melt the ice or the sampler must be sent to the F.I.S.P. or HIF repair facility. Point samplers can be checked using the same technique if the valve mechanism is placed in the sampling position while air is forced into the nozzle and through the air exhaust.

All support equipment required for sampling, such as cranes, waders, taglines, power sources, and current meters, should be examined periodically and as used, to ensure an effective and safe working condition. For example, be certain that the supporting cable to the sampler or current meter is fastened securely in the connector; if worn or frayed places are noted, the cable should be replaced. Power equipment used with the heavier samplers and point samplers needs a periodic operational check and battery charge. Point samplers should be checked immediately before use to determine, among other things, if the valve is opening and closing properly. By exercising such precautions, the field person will avoid unnecessary exposure to traffic on the bridge and will avoid lost sampling time should repairs and adjustments be required.

Maintenance of samplers and support equipment will be facilitated if a file of instructions for assembly, operation, and maintenance of equipment can be accumulated in the field office. Such a file could include F.I.S.P. reports as well as other pertinent information available from F.I.S.P. and HIF.

\section{Suspended-Sediment Sampling Methods}

\section{Sediment-Discharge Measurements}

The usual purpose of sediment sampling is to determine the instantaneous mean discharge-weighted suspended-sediment concentration at a cross section. Such concentrations are combined with water discharge to compute the measured suspended-sediment discharge. A mean discharge-weighted suspended-sediment concentration for the entire cross section is desired for this purpose and for the development of coefficients to adjust observer and automatic pumping-type sampler data.

Ideally, the best procedure for sampling any stream to determine the sediment discharge would be to collect the entire flow of the stream over a given time period, remove the water, and weigh the sediment. Obviously this method is a physical impossibility in the majority of instances. Instead, the sediment concentration of the flow is determined by (1) collecting depth-integrated suspended-sediment samples that define the mean discharge-weighted concentration in the sample vertical, and (2) collecting sufficient verticals to define the mean discharge-weighted concentration in the cross section.

\section{Single Vertical}

The objective of collecting a single vertical sample is to obtain a sample that represents the mean discharge-weighted suspended-sediment concentration in the vertical being sampled at the time the sample was collected. The method used to do this depends on the flow conditions and particle size of the suspended sediment being transported. These conditions can be generalized to four types of situations: (1) low velocity ( $\mathrm{V}<2.0 \mathrm{ft} / \mathrm{s}$ ) when little or no sand is being transported in suspension; (2) high velocity $(2.0<\mathrm{V}<12.0 \mathrm{ft} / \mathrm{s})$ 
when depths are less than 15 feet, (3) high velocity $(2.0<\mathrm{V}<12.0 \mathrm{ft} / \mathrm{s})$ when depths are greater than 15 feet, and (4) very high velocities (V>12.0 ft/s).

In the first case, the velocity is low enough that no sand is being transported as suspended sediment. The distribution of sediment (silt and clay) is relatively uniform from the stream surface to bed (Guy, 1970, p. 15). The sampling error for this case, when only sediment particles $<0.062 \mathrm{~mm}$ are in suspension, is small, even with intake velocities somewhat higher or lower than the ambient mean stream velocities. Therefore, it is not as important to collect the sample isokinetically with fines in suspension as it is when particles $>0.062 \mathrm{~mm}$ are in suspension. In shallow streams a sample may be collected by submerging an open-mouthed bottle into the stream by hand. The mouth should be pointed upstream and the bottle held at approximately a $45^{\circ}$ angle from the streambed. The bottle should be filled by moving it from the surface to the streambed and back. Care should be taken to avoid touching the mouth of the bottle to the streambed. An unsampled zone of about 3 inches should be maintained in order to obtain samples that are compatible with depth-integrated samples collected at higher velocities.

If the stream is not wadable, a weighted-bottle type sampler may be used. Remember that these samples are not discharge-weighted samples and that, if possible, their analytical results should be verified by or compared to data obtained using a standard sampler and sampling technique.

In the second case, when $2.0<\mathrm{V}<12.0 \mathrm{ft} / \mathrm{s}$ and the depth is less than 15 feet, the standard depth-integrating samplers, such as DH-48, DH-75, DH-59, $\mathrm{D}-49$, D-77, and D-74, may be used. The method of sample collection is basically the same for all these samplers, whether used while wading or from a bridge or cableway. Insert a clean sample bottle into the sampler and check to see that there are no obstructions in the nozzle or air-exhaust tube. Then lower the sampler to the water surface so that the nozzle is above the water and the lower tail vane or back of the sampler is in the water for proper upstream-downstream orientation. After orientation of the sampler, depth integration is accomplished by traversing the full depth and returning to the surface with the sampler at a constant transit rate.

When the bottom of the sampler touches the streambed, immediately reverse the sampler direction and raise the sampler to clear the surface of the flow at a constant transit rate. The transit rate used in raising the sampler need not be the same as the one used in lowering, but both rates must be constant in order to obtain a velocity- or discharge-weighted sample. The rates should be such that the bottle fills to near its optimum level (approximately 3 inches below the top or 350 to $420 \mathrm{~mL}$ for the pint bottle, or 2 inches below the top or 650 to $800 \mathrm{~mL}$ for the quart bottle).

For streams that transport heavy loads of sand, and perhaps for some other streams, at least two complete depth integrations of the sample vertical should be made as close together in time as possible--one bottle for each integration. Each bottle then constitutes a sample and can be analyzed separately or, for the purposes of computing the sediment record, two or more bottles can be averaged whereby they are called a set. This set is then a sample in time with respect to the record. Sample analyses from two or more individual bottles for a given observation are useful for checking sediment variations among bottles--an obvious advantage in the event the sediment concentration in one bottle is quite different from the concentration in the other bottles for the same observation. Immediately after collection, every bottle or sample should be inspected visually by swirling the water in the bottle and observing the quantity of sand particles collected at the bottom. 
If there is an unusually large quantity or a difference in the quantity of sands between bottles, another sample from the same vertical should be taken immediately. The sample suspected of having too much sand should be discarded. If it is saved, an explanation such as "too much sand" should be clearly written on the bottle. If by chance a bottle is overfilled or if a spurt of water is seen coming out of the nozzle when the sample is raised past the water surface, the sample should be discarded. A clean bottle should be used to resample the vertical.

To help avoid the problem of striking the nozzle into a dune or settling the sampler too deeply into a soft bed, it is recommended that a slow downward integration be used followed by a more rapid upward integration. Because most of the sand is transported near the bed, it is essential that the transit direction of the sampler be immediately reversed as the sampler touches the. bed.

Pertinent information as shown in figure 27 must be available with each bottle for use in the laboratory and in compiling the record. Most Districts of the Geological Survey provide bottles with an etched area on which a medium-soft lead (blue or black) or wax pencil can be used. Other Districts use plain bottles and attach tags for recording the required information. The required information may be recorded on the bottle cap if there are no other alternatives, but this should be avoided because of the small writing space and because of the possibility of putting the cap on the wrong bottle. Paper caps should not be used because they do not form as good a seal as do the plastic caps and may allow evaporation of the sample.

In the third case, the depth-integrating samplers cannot be used because the depth exceeds the maximum allowable depth for these samplers. In this case, one of the point-integrating or bag-type samplers must be used. Because the bag sampler is still new and sufficient field data have not been collected to verify its sampling efficiency, Water Resources Division personnel who wish to use it must contact the Chief, office of Surface Water, and must set up a comparability sampling system to verify the sampler's efficiency under their specific conditions. The technique for collection of a sample using the bagtype sampler is similar to that used with the depth-integrating samplers.

The point samplers may be used to collect depth-integrated samples in verticals where the depth is greater than 15 feet. For streams with depths between 15 and 30 feet, the procedure is as follows:

1. Insert a clean bottle in the sampler and close the sampler head.

2. Lower the sampler to the streambed keeping the solenoid closed and note the depth to the bed.

3. Start raising the sampler to the surface using a constant transit rate. Open the solenoid at the same time the sampler begins the upward transit.

4. Keep the solenoid open until after the sampler has cleared the water surface. Close the solenoid.

5. Remove the bottle containing the sample, check the volume of the sample, and mark the appropriate information on the bottle. (If the sample volume exceeds allowable limits, discard the sample and repeat depth integration at a slightly higher transit rate.) 


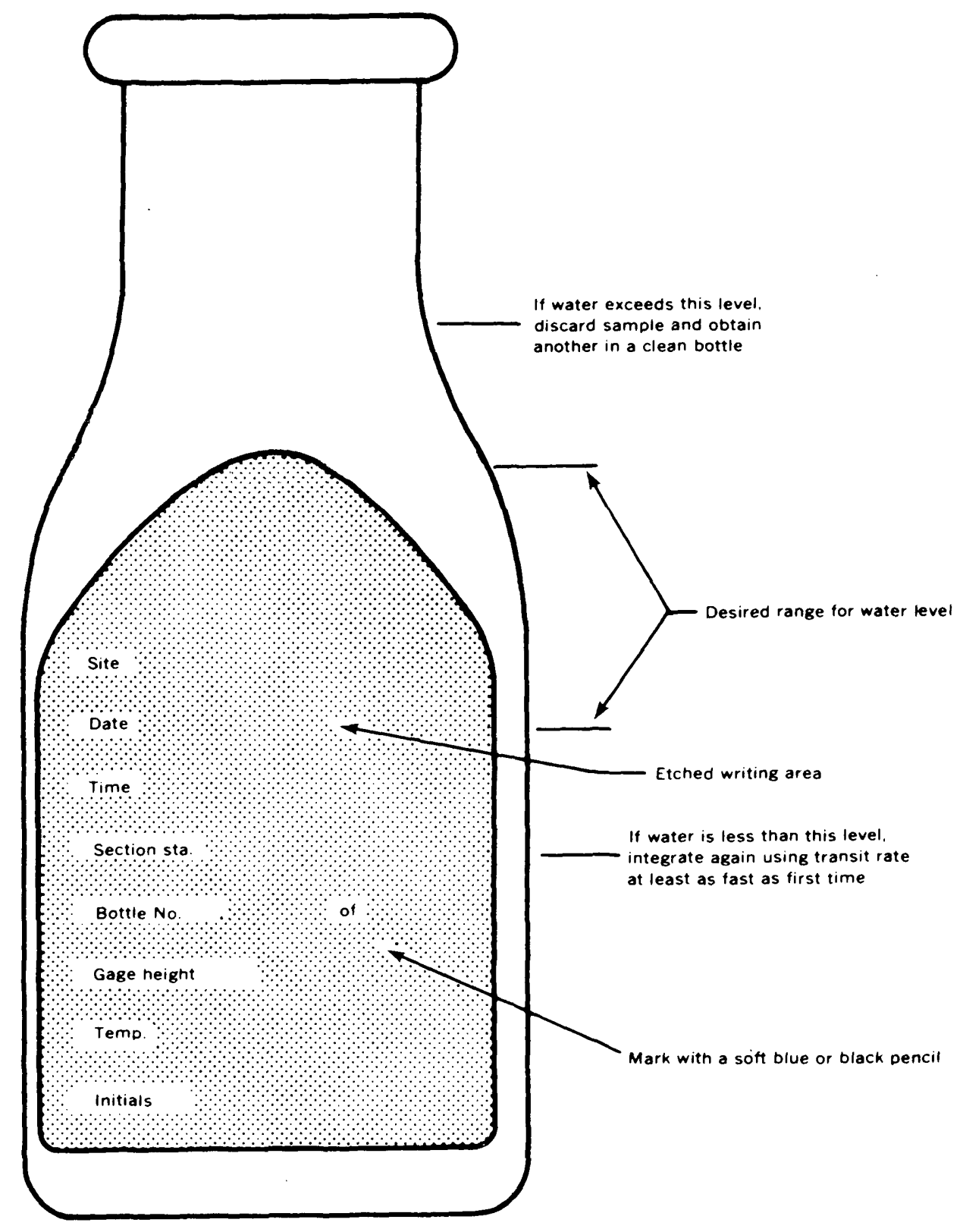

Figure 27.--Sample bottle showing desired water levels and essential record information.

6. Insert another clean bottle into the sampler, and close the sampler head.

7. Lower the sampler until the lower tail vane is touching the water allowing the sampler to align itself with the flow.

8. Open the solenoid and lower the sampler at a constant transit rate until the sampler touches the bed. 
9. Close the solenoid the instant the sampler touches the bed. (By noting the depth to the streambed in step 2 above, the operator will know when the sampler is approaching the bed.)

The transit rate used when collecting the sample in the upward direction need not be the same as that used in the downward direction. If the stream depth is greater than 30 feet, the process is similar, except that the upward and downward integrations are broken into segments no greater than 30 feet. Figure 28 illustrates the procedure for sampling a stream with a depth of 60 feet. Note the transit rate used in the upward direction $\left(T R_{1}\right.$ and $\left.T R_{2}\right)$ is not equal to the transit rate in the downward direction $\left(T R_{3}\right.$ and $\left.T R_{4}\right)$ but $T R_{1}=T R_{2}$ and $T R_{3}=T R_{4}$. Samples collected by this technique may be composited in the laboratory for each vertical and a single mean concentration is computed for the vertical. In addition to the usual information (fig. 27), the label on each bottle should indicate the segment or range of depth sampled and whether it was taken on a descending or ascending trip.

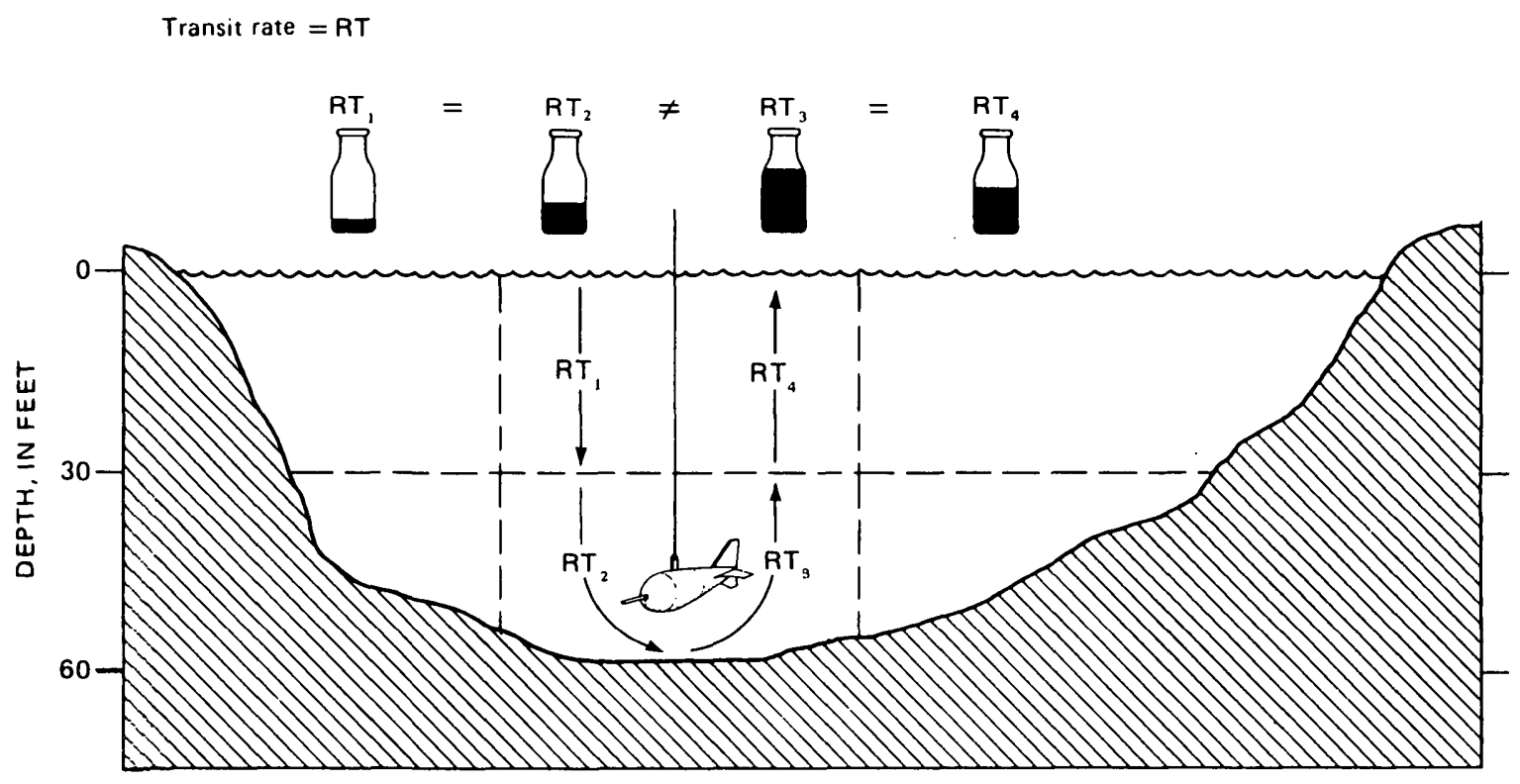

Eigure 28.--Use of point-integrating sampler to depth integrate deep streams.

Samples must be obtained at a given vertical for both the downward and upward directions. Tests in the Colorado River, United States (F.I.S.P., 1951, p. 34), have shown an increase in the intake ratio of about 4 percent when descending versus a decrease in the intake ratio of about 4 percent on ascent. These differences may affect sample concentrations at some sites.

\section{Surface and Dip Sampling}

In the fourth case, circumstances are often such that surface or dip sampling is necessary. When the velocities are too high to use the depth- or point-integrating samplers or when debris makes normal sample collection dangerous or impossible, surface or dip samples may be collected. 
A surface sample is one taken on or near the surface of the water with or without a standard sampler. At some locations stream velocities are so great that even 100-1b samplers cannot penetrate the water more than a short distance before they are dragged downstream and out of the water into an erratic movement. Under such conditions it can be expected that all except the largest particles of sediment will be thoroughly mixed within the flow and therefore a sample near the surface is representative of the entire vertical. Extreme care should be used, however, because often such high velocities occur during floods when large debris is moving, especially on the rising part of the hydrograph. This debris may strike or become entangled with the sampler and thereby damage the sampler, break the sampler cable, or injure the field person. Of course, a full explanation of sampling conditions, including the depth to which the sample was taken, should be noted on the bottle and in the field notes in order that special handling may be given the samples in the laboratory and in computing the records.

Because of the many problems associated with surface and dip sampling, these samples should be correlated to regular depth-integrated samples collected as soon as possible after the high flow recedes enough to allow collection of a full depth-integrated sample. Along with the full depthintegrated sample, a sample should be collected in a manner duplicating the sampling procedure used to collect the surface or dip sample. These samples will be used to adjust the analytical results of the surface or dip sample collected during the higher flow, if necessary, to facilitate the use of these data in sediment-discharge computations and data analyses.

\section{Multivertical}

A depth-integrated sample collected using the procedures outlined in the previous section will accurately represent the discharge-weighted suspendedsediment concentration along the vertical at the time of the sample collection. As mentioned before, the purpose of collecting sediment samples is to determine the instantaneous sediment concentration at a cross section. The question now becomes 'how do we locate the verticals in the cross section so that the end result will be a sample that is representative of the mean discharge-weighted sediment concentration?'

The Geological Survey uses two basic methods to define the location or spacing of the verticals. One is based on equal increments of water discharge (EDI); the second is based on equal increments of stream or channel width (EWI). Both methods are in accordance with American Society for Testing and Materials (ASTM) Standard Guide for Sampling Fluvial Sediment in Motion, D4411 (ASTM, 1987).

\section{The equal-discharge-increment method}

With the EDI method, samples are obtained from the centroids of equal discharge increments (fig. 29). This method requires some knowledge of the distribution of streamflow in the cross section based on a long period of discharge record or on a discharge measurement made immediately prior to selecting sampling verticals. If such knowledge can be obtained, the EDI method can save time and labor (compared to the EWI method, discussed in the next section), especially on the larger streams because fewer verticals are required (Hubbell and others, 1956). 


\section{EXPLANATION}

W Width between verticals (not equal)

Q Discharge in each increment (equal, EDI)

Samples collected

at each centroid

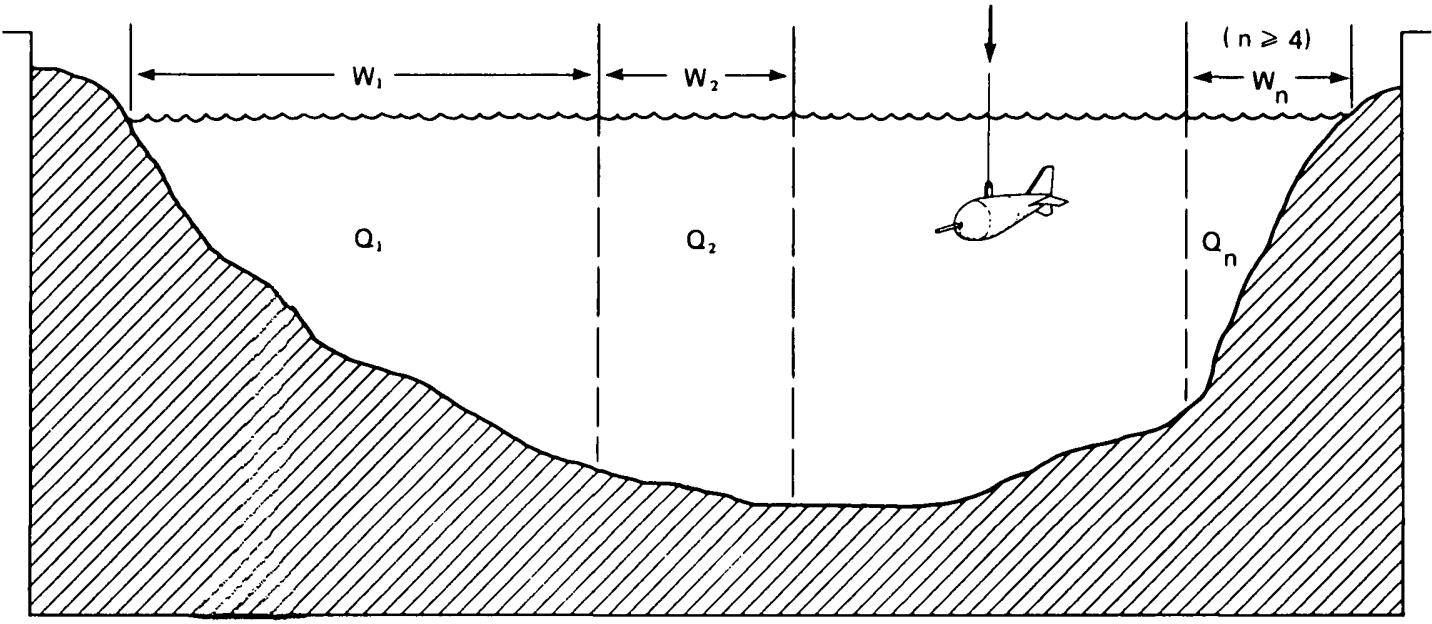

Figure 29.--Equal-discharge increment--samples collected at the centroids of flow of each increment.

To use the EDI method without the benefit of previous knowledge of the flow distribution in the sampling cross section, first measure the discharge of the stream and determine the flow distribution across the channel at the sampling cross section prior to sampling. From the discharge measurement preceding the sampling (fig. 30) or from historic discharge measurement records, equal discharge increments can be determined and centroids at which samples are to be collected can be located. In this example the total discharge is equal to 167 cubic feet per second $\left(\mathrm{ft}^{3} / \mathrm{s}\right)$. For illustration purposes it was determined, by methods to be discussed later, that five verticals would be sampled. The equal increments of discharge (EDI's) are then computed by dividing the total discharge by the number of verticals $(167+5=33.4$ $\left.\mathrm{ft}^{3} / \mathrm{s}\right)$. The first vertical (A) is located at the centroid of the initial EDI or at a point where the cumulative discharge from the left edge of water (LEW) is half of the EDI, in this case $33.4+2=16.7 \mathrm{ft}^{3} / \mathrm{s}$. Subsequent centroids (B, C, etc.) are located by adding the increment discharge to the discharge at the previously sampled centroid; in this example $\mathrm{A}=16.7 \mathrm{ft} / \mathrm{s}, \mathrm{B}=\mathrm{A}+33.4$ $\mathrm{ft}^{3} / \mathrm{s}, \mathrm{C}=\mathrm{B}+33.4 \mathrm{ft}^{3} / \mathrm{s}$, etc. Samples are therefore collected at points where the cumulative discharge relative to the LEW is $16.7,50.1,83.5,116.9$ and $150.3 \mathrm{ft}^{3} / \mathrm{s}$.

A minimum of four and a maximum of nine verticals should be used when using the EDI method. This method assumes that the sample collected at the centroid represents the mean concentration for the subsection. If this assumption is not true, the number of verticals should be increased until it becomes true or the EWI method should be used.

To determine the stationing of the centroids, the field person must include a cumulative discharge column $(\Sigma Q)$ on the discharge-measurement note sheet by adding the discharges shown in the "discharge" column and keeping a running total as shown in figure 31. The next step is to estimate the stationing of the above centroids. Each centroid is located at the station in 


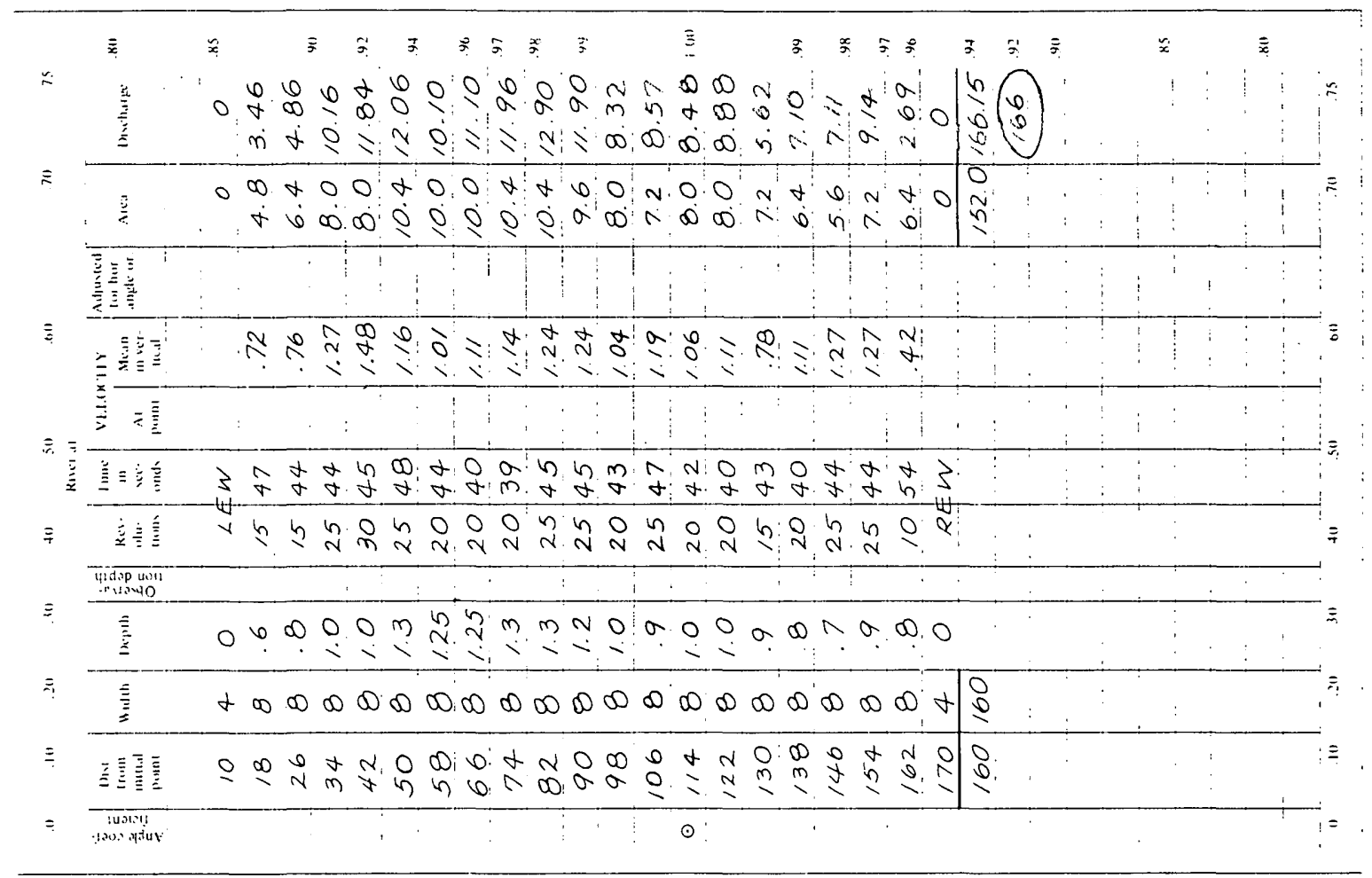

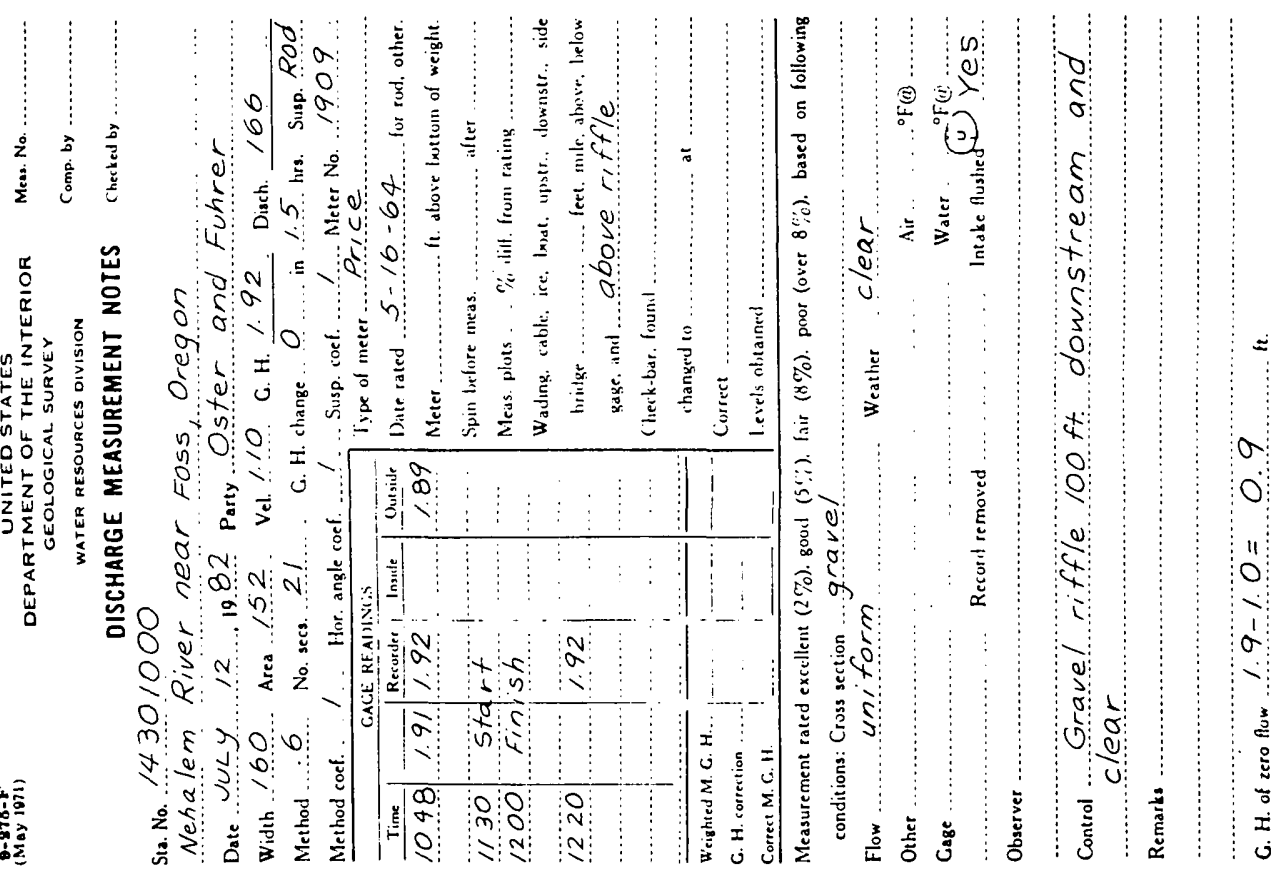

Figure 30.--Discharge-measurement notes for Nehalem River near Foss, Oregon. 
the cross section corresponding to the occurrence of its computed cumulative discharge. As shown in figure 31, the cumulative discharge at station 26 equals $8.32 \mathrm{ft}^{3} / \mathrm{s}$ while station 34 corresponds to $19.2 \mathrm{ft} 3 / \mathrm{s}$. Actually, the cumulative discharge is computed to the point midway between stations (far midpoint, fig. 31). Therefore the point where the cumulative discharge equals $8.32 \mathrm{ft}^{3} / \mathrm{s}$ is located halfway between stations 26 and 34 at station 30 . In like manner the cumulative discharge of $19.2 \mathrm{ft}^{3} / \mathrm{s}$ occurs at the far midpoint between stations 34 and 42 at station 38 . The first centroid would then be located between stations 30 and 38 . Interpolating between these stations, the centroid discharge of $16.7 \mathrm{ft} / \mathrm{s}$ would be located at a station closer to station 38 where 19.2 occurs, in this case near station 36 . Using the same procedure, estimates of centroid stationing yield stations $60,82,110$, and 146 for the four remaining centroids.

If the cross section at the measurement site is stable and the control governing the stage at the measurement cross section is also stable, previous measurements may be used to determine centroids of equal increments of discharge.

By plotting the cumulative discharge versus stations for our example (fig. 32), the stations of the centroids may be read directly from the curve. Their values are 36, 59, 82, 110, and 146, which correspond nicely with our previously estimated values.

A number of these measurements may be plotted on the same sheet (fig. 33) and carried into the field. For discharges that fall between those plotted, the field person can estimate the locations of the centroids by interpolating between the curves.

An alternate method of estimation is to plot cumulative percent of total discharge on the y-axis, instead of cumulative discharge (fig. 34). This method entails one additional step in that the cumulative percent must be calculated; however, it does have the advantage of showing the variation in stations for the same percentage of flow for different discharges. For example, figure 34 shows that for discharges 86 to $200 \mathrm{ft}^{3} / \mathrm{s}$ the 10 -percent centroid (the centroid of the first 20 percent of flow) can range from station 20 to station 50 .

At each centroid, two or more depth-integrated samples are collected. Each bottle collected at a vertical is one of many bottles comprising a complete cross-section sample (set); thus if two bottles are collected representing each centroid, two sets will be produced. The transit rate used to collect sample portions at individual centroids must be unidirectionally constant. However, the transit rate used in traversing the distance from water surface to streambed and back to water surface need not be the same in both directions and can vary among centroids. This technique should facilitate collection of approximately equal sample volumes from each centroid (fig. 35). Equal sample volumes are of primary importance when using the EDI method.

Individual bottles collected as part of an EDI sample set can be analyzed for concentration separately and their concentrations averaged to give the mean discharge-weighted concentration for the set. The advantage of this method is that data describing the cross-sectional variation in concentration is produced. Additionally, a bottle containing an abnormally high concentration compared to others in the set (due to recirculation or to digging the nozzle into the bed) could be excluded from the concentration calculation where it might seriously affect the results. If approximately equal volumes of sample are collected at each vertical, the samples may be composited prior to analysis. 


\begin{tabular}{|c|c|c|c|c|c|c|c|c|c|c|c|c|c|}
\hline \multirow{3}{*}{$\frac{.0}{\bar{c}}$} & .10 & .20 & \multicolumn{2}{|c|}{.30} & .40 & \multicolumn{2}{|c|}{$\begin{array}{r}.50 \\
\end{array}$} & \multicolumn{2}{|l|}{.60} & \multicolumn{2}{|c|}{.70} & \multicolumn{2}{|l|}{.75} \\
\hline & & & & 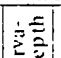 & & \multicolumn{3}{|c|}{\begin{tabular}{l|l}
\multicolumn{2}{c}{ River at } \\
Time & VELOCITY
\end{tabular}} & \multirow{2}{*}{$\begin{array}{l}\text { Adjusted } \\
\text { for hor. } \\
\text { angle or. }\end{array}$} & \multirow[b]{2}{*}{ Areä } & \\
\hline & $\begin{array}{l}\text { from } \\
\text { initial } \\
\text { point }\end{array}$ & Width & Depth & $\mid$ & $\begin{array}{l}\text { Rev- } \\
\text { olu- } \\
\text { tions }\end{array}$ & $\begin{array}{l}\text { in } \\
\text { sec- } \\
\text { onds }\end{array}$ & $\begin{array}{c}\mathrm{At} \\
\text { point }\end{array}$ & $\begin{array}{l}\text { Mean } \\
\text { in ver. } \\
\text { tical }\end{array}$ & & & $Q^{\text {Dischis }}$ & $\sum Q$ & \\
\hline \multicolumn{14}{|c|}{$\begin{array}{l}\text { Far } \\
\text { Mid-Point }\end{array}$} \\
\hline 14 & 10 & 4 & 0 & & \multicolumn{2}{|c|}{$\angle E W$} & & & & 0 & 0 & 0 & .85 \\
\hline 22 & 18 & 8 & 6 & & 15 & 47 & & .72 & & 4.8 & 3.46 & 3.46 & \\
\hline 30 & 26 & 8 & 8 & & 15 & 44 & & .76 & & 6.4 & 4.86 & \multirow{2}{*}{\multicolumn{2}{|c|}{\begin{tabular}{|l|}
8.32 \\
16.60 \\
18.48
\end{tabular}}} \\
\hline \multicolumn{2}{|c|}{$3 \frac{316}{38} 34$} & 8 & 1.0 & & 25 & 44 & & 1.27 & & 8.0 & $\overrightarrow{0.16}$ & & \\
\hline 46 & 42 & 8 & 1.0 & & 30 & 45 & & 1.48 & & 8.0 & 11.84 & \multicolumn{2}{|c|}{30.32 .92} \\
\hline 54 & 50 & 8 & 1.3 & & 25 & 48 & & 1.16 & & 10.4 & 12.06 & \multicolumn{2}{|c|}{42.38} \\
\hline \multicolumn{2}{|c|}{$6 \frac{600}{62} 58$} & 8 & 1.25 & & 20 & 44 & & 1.01 & & 10.0 & 10.10 & \multicolumn{2}{|c|}{$59.80^{.94}$} \\
\hline 70 & 66 & 8 & 1.25 & & 20 & 40 & & 1.11 & & 10.0 & 11.10 & \multicolumn{2}{|c|}{$63.58^{96}$} \\
\hline 78 & 74 & 8 & 1.3 & & 20 & 39 & & 1.14 & & 10.4 & V/.86 & \multicolumn{2}{|c|}{$75.44^{-97}$} \\
\hline \multicolumn{2}{|c|}{86} & 8 & 1.3 & & 25 & 45 & & 1.24 & & 10.4 & 212.90 & $\frac{83.00}{88.34}$ & \\
\hline 94 & 90 & 8 & 1.2 & & 20 & 45 & & 1.24 & & 9.6 & 11.90 & 100.24 & 999 \\
\hline 102 & 98 & 8 & 1.0 & & 20 & 43 & & 1.04 & & 8.0 & 8.32 & 108.56 & \\
\hline 110 & 106 & 8 & .9 & & 25 & 47 & & 1.19 & & 7.2 & $\overrightarrow{8.57}$ & $1 \frac{16.2}{117.13}$ & \\
\hline 18 & 114 & 8 & 1.0 & & 20 & 42 & & 1.06 & & 8.0 & 8.48 & 25.61 & 1.00 \\
\hline 126 & 122 & 8 & 1.0 & & 20 & 40 & & 1.11 & & 8.0 & 8.88 & 134.49 & \\
\hline 134 & 130 & 8 & .9 & & 15 & 43 & & .78 & & 7.2 & 5.62 & 140.11 & \\
\hline 142 & 138 & 8 & .8 & & 20 & 40 & & 1.11 & & 6.4 & 7.10 & 147.21 & .99 \\
\hline 150 & 146 & 8 & 7 & & 25 & 44 & & 1.27 & & 5.6 & $\overrightarrow{7.11}$ & 149.40 & .98 \\
\hline 158 & 154 & 8 & .9 & & 25 & 44 & & 1.27 & & 7.2 & 9.14 & 163.46 & 59 \\
\hline 166 & 162 & 8 & 8 & & 10 & 54 & & $42^{\circ}$ & & 6.4 & 2.69 & 166.15 & .96 \\
\hline 170 & 170 & 4 & 0 & & $R E$ & $E w$ & & & & 0 & 0 & 166.15 & \\
\hline & 160 & 160 & & & & & & & & 152.0 & 166 & .15 & .94 \\
\hline & & & & & & & & & & & 166 & 6 & .92 \\
\hline & & & EOI & cul & nula. & tive & yischd & rge & $\longrightarrow$ & & & & 90 \\
\hline & & & & & & & & & & & & & \\
\hline & & $-E C$ & 1 far & $m$ & $d-p o 1$ & of $\mathrm{ce}$ & itrolo & 1 stat & fionin & & & & \\
\hline & & & & & & & & & & & & & 85 \\
\hline & & & & & & & & & & & & & \\
\hline & & & & & & & & & & & & & \\
\hline & & & & & & & & & & & & & .80 \\
\hline & & & & & & & & & & & & & \\
\hline . & .10 & .20 & .30 & & .40 & .5 & & .60 & & .70 & & .75 & \\
\hline
\end{tabular}

Figure 31.--Discharge-measurement note sheet used to estimate the equal-discharge-increment centroid locations based on cumulative discharge and far-midpoint stationing. 


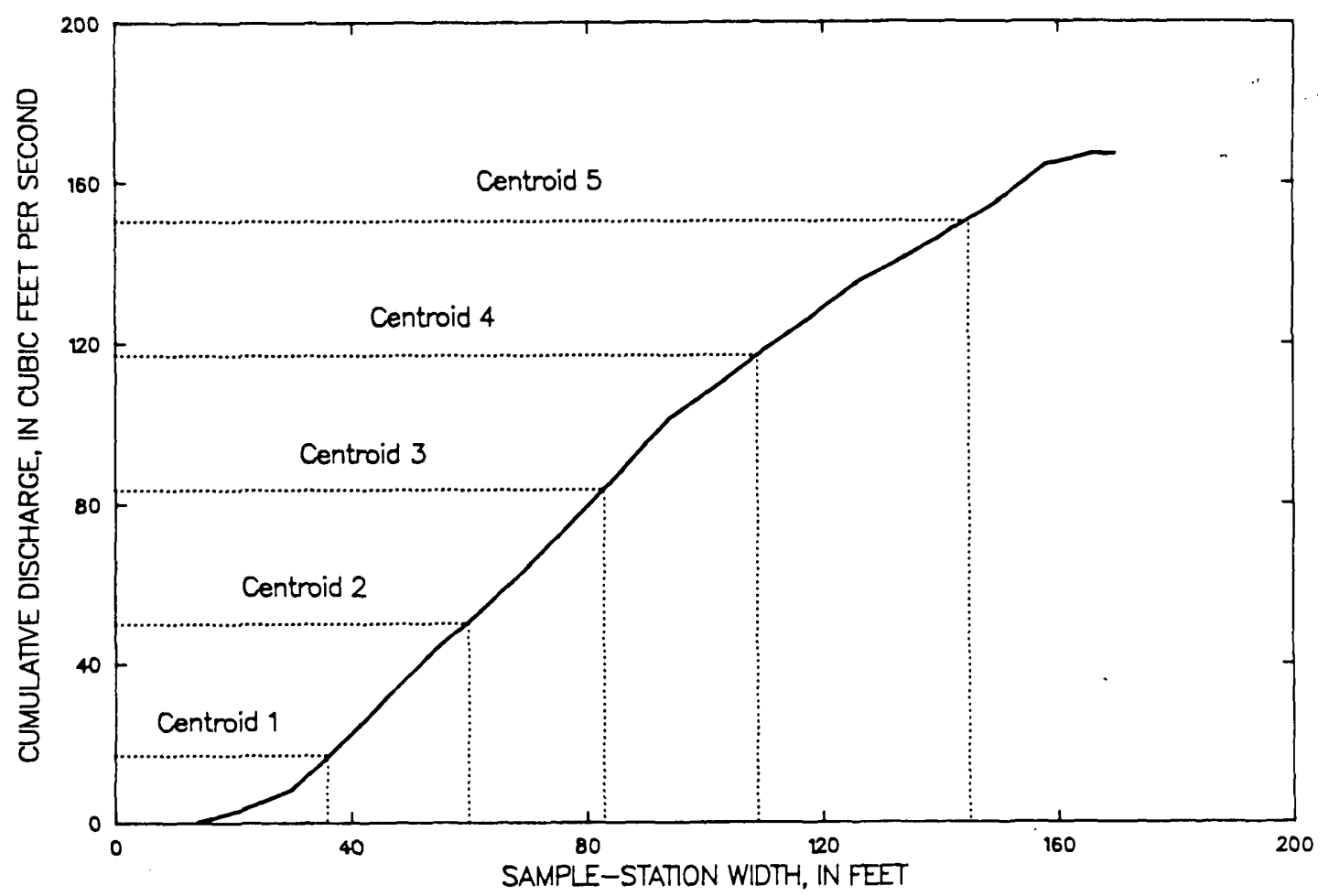

Figure 32.--Cumulative discharge versus stations equal-dischargeincrement centroid determination.

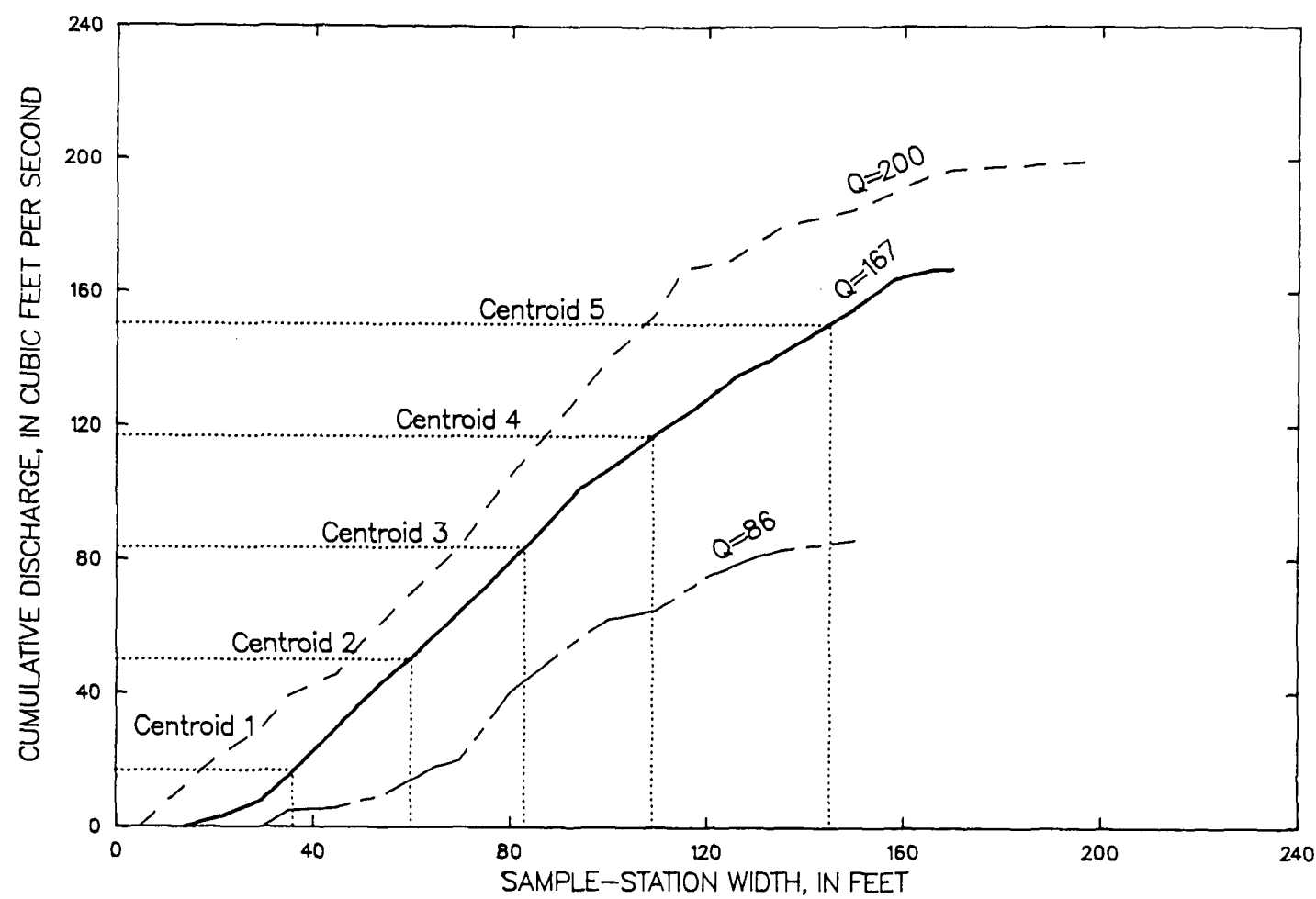

Figure 33.--Three cumulative discharges versus stations equaldischarge-increment centroid determination. 


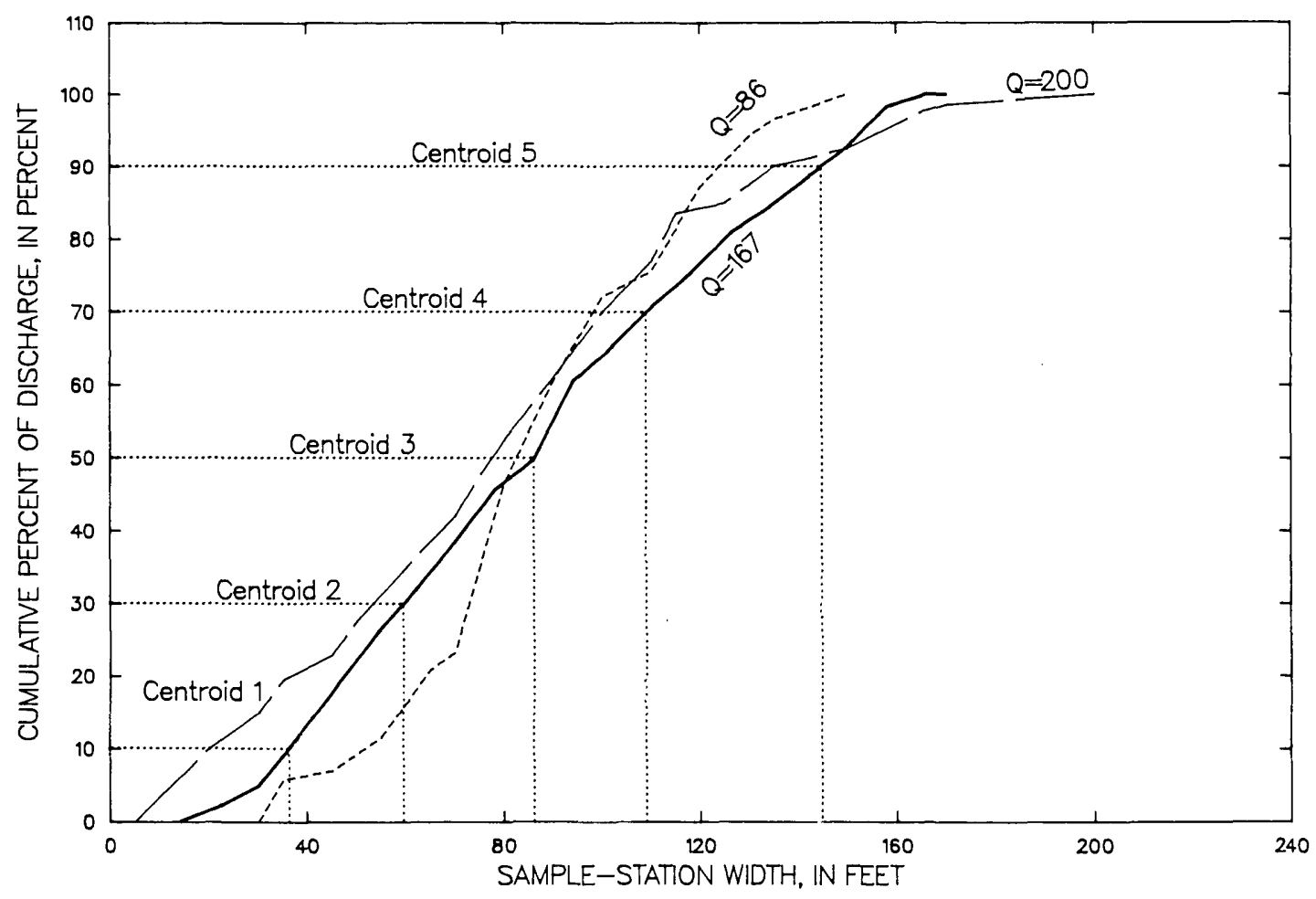

Figure 34.--Three cumulative percent of discharges versus stations equal-discharge-increment centroid determination.

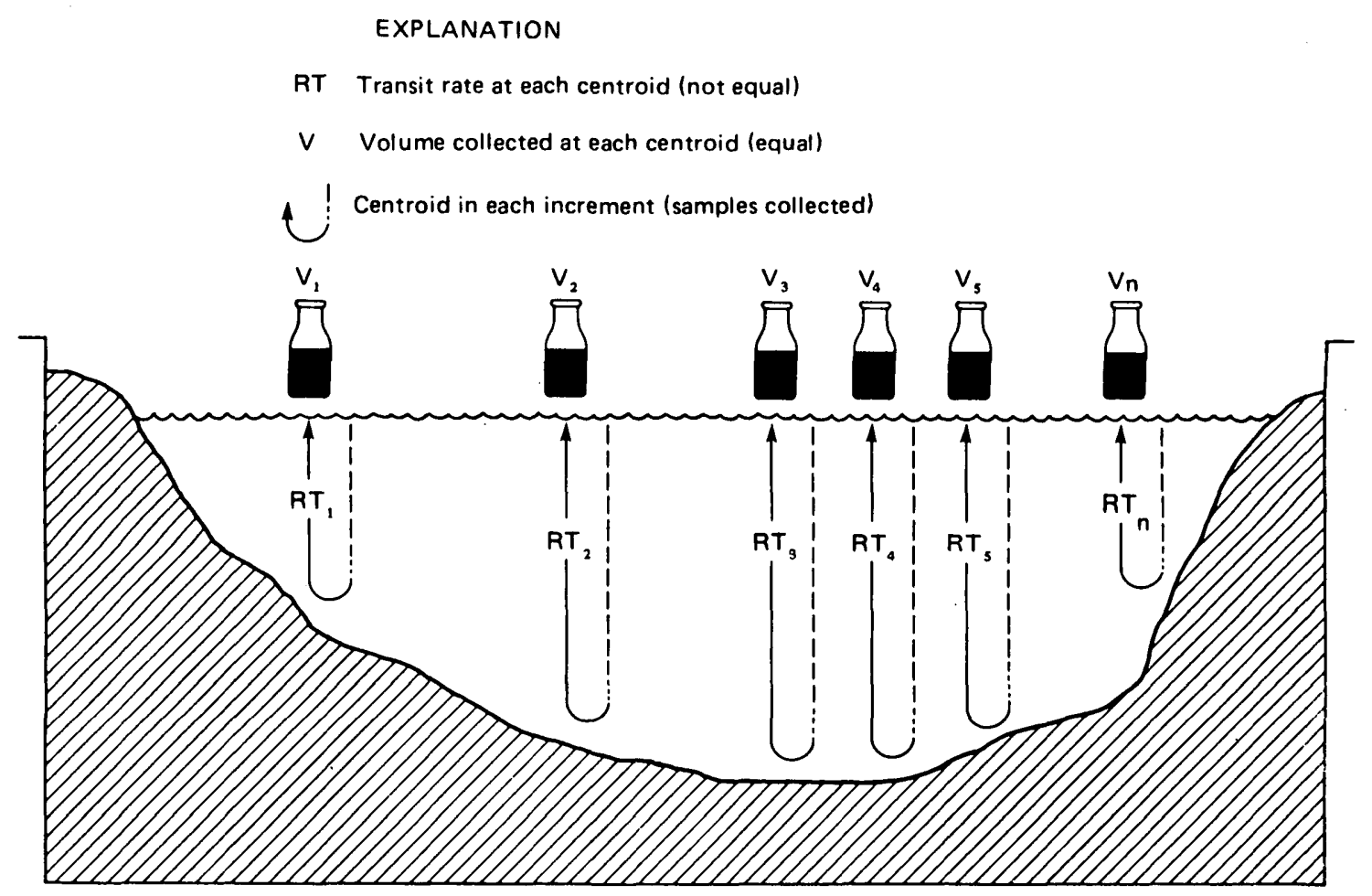

Figure 35.--Vertical transit rate relative to sample volume collected at each equal-discharge-increment centroid. 
The streambed of a sand-bed stream characteristically shifts radically, at single points and across segments of the width, over a period of weeks or in a matter of hours. This not only makes it impossible to establish cumulative discharge or cumulative percentage of discharge versus station curves applicable from one visit to the next, but also makes it impossible to be certain the discharge distribution does not change between the water-discharge measurement and the sediment sampling (see Guy, 1970, fig. 15). In this case the EWI method discussed next should be used. For sand-bed streams and for new sediment-measuring sites, the main disadvantage to the EDI method is that a water-discharge measurement must precede the sediment-discharge measurement.

\section{The equal-width-increment method}

A cross-sectional suspended-sediment sample obtained by the EWI method requires a sample volume proportional to the amount of flow at each of several equally spaced verticals in the cross section. This equal spacing between the verticals (EWI) across the stream and sampling at an equal transit rate at all verticals yields a gross sample volume proportional to the total streamflow. It is important, obviously, to keep the same size nozzle in the sampler for a given measurement. This method was first used by B. C. Colby in 1946 (F.I.S.P., 1963b, p. 41) and is used most often in shallow, wadable streams and (or) sand-bed streams where the distribution of water discharge in the cross section is not stable. It is also useful in streams where tributary flow has not completely mixed with the main stem flow.

The number of verticals required for an EWI sediment-discharge measurement depends on the distribution of concentration and flow in the cross section at the time of sampling as well as on the desired accuracy of the result. On many streams both statistical approaches and experience are needed to determine the desirable number of verticals. Until such experience is gained, the number of verticals used should be greater than necessary. In all cases a minimum of 10 verticals should be used for streams over 5 feet wide. For streams less than 5 feet wide, as many verticals as possible should be used as long as they are spaced a minimum of 3 inches apart to allow for discrete sampling of each vertical and to avoid overlaps. Through general experience with similar streams, field personnel can estimate the required minimum number of verticals to yield a desired level of accuracy. For all but the very wide and shallow streams, a maximum of 20 verticals is usually ample.

The width of the increments to be sampled, or the distance between verticals, is determined by dividing the stream width by the number of verticals necessary to collect a discharge-weighted suspended-sediment sample representative of the sediment concentration of the flow in the cross section (fig. 36). For example, if the stream width determined from the tagline, cableway, or bridge-rail markings at the sample cross section is 160 feet, and the number of verticals necessary is 10 , then the width $(W)$ of each sampled increment would be 16 feet. The sample station within each width increment is located at the center of the increment $\left(\frac{W}{2}\right)$, beginning at a location of 8 feet from

the bank nearest the initial point for width measurement. The verticals are then spaced 16 feet apart, resulting in sample stationing at 8, 24, 40, 56, 72, 88, 104, 120, 136, and 152 feet of width. However, in the event the width increment results in a fractional measurement, the width can be rounded to the nearest integer that will yield a whole numbered station for the initial sample vertical. That is, if the increment computation yields a width of 15.5 feet, the nearest integer width would be 16 feet, and the initial vertical 


\section{EXPLANATION}

W Width between verticals (equal, EWI)

Q Discharge in each increment (not equal)

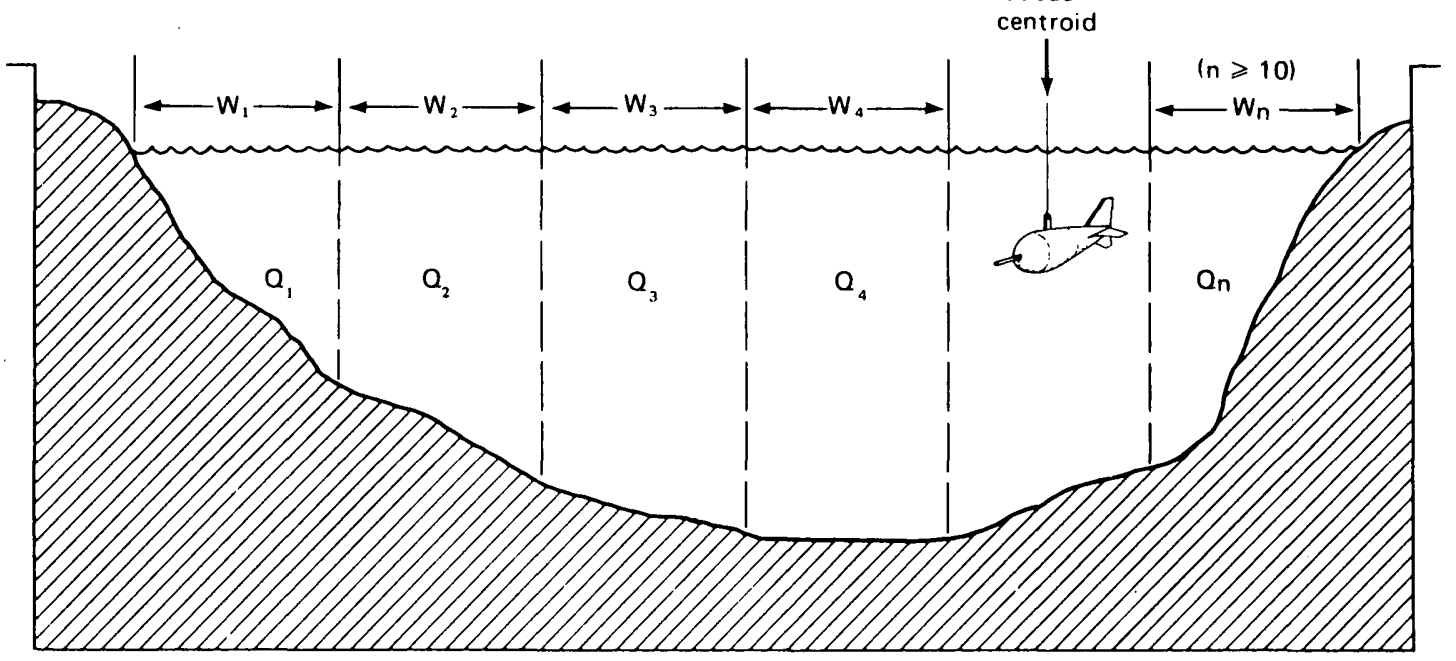

Figure 36.--Equal-width-increment sampling technique.

would be located at 8 feet from the bank; the stationing would be similar to the previous example. Results of samples obtained using this nonideal stationing will not be measurably affected since alterations in width occur in the increments nearest the streambank where flow velocity is normally low compared to midstream increments.

The EWI sampling method requires that all verticals be traversed using the same transit rate (fig. 37). The descending and ascending transit rates must be equal during the sampling traverse of each vertical, and they must be the same at all verticals. By using this equal-transit-rate technique with a standard depth- or point-integrating sampler at each vertical, a volume of water proportional to the flow in the vertical will be collected (fig. 37).

It is often difficult to maintain an equal transit rate when collecting samples while wading. The authors have found the following procedure to be effective in alleviating this difficulty. The field person should hold the sampler at a reference point on the body (for example, the hip) at which level the downward and upward integration is started and finished (even though part of the traverse is in air). The same reference point should be used at each vertical, allowing the same amount of time to elapse during the round trip traverse of the sampler (regardless of the stream depth encountered). In this manner the transit rate will remain constant for the entire cross section. It should be remembered that the reference point at which the sampler traverse is started and stopped must be located above the water surface at the deepest vertical sampled and must be the same for each vertical.

Because the maximum transit rate must not exceed $0.4 V_{m}$, and because the minimum rate must be sufficiently fast to keep from overfilling any of the sample bottles, it is evident that the transit rate to be used for all verticals is limited by conditions at the vertical containing the largest discharge per foot of width (largest product of depth times velocity). A discharge 


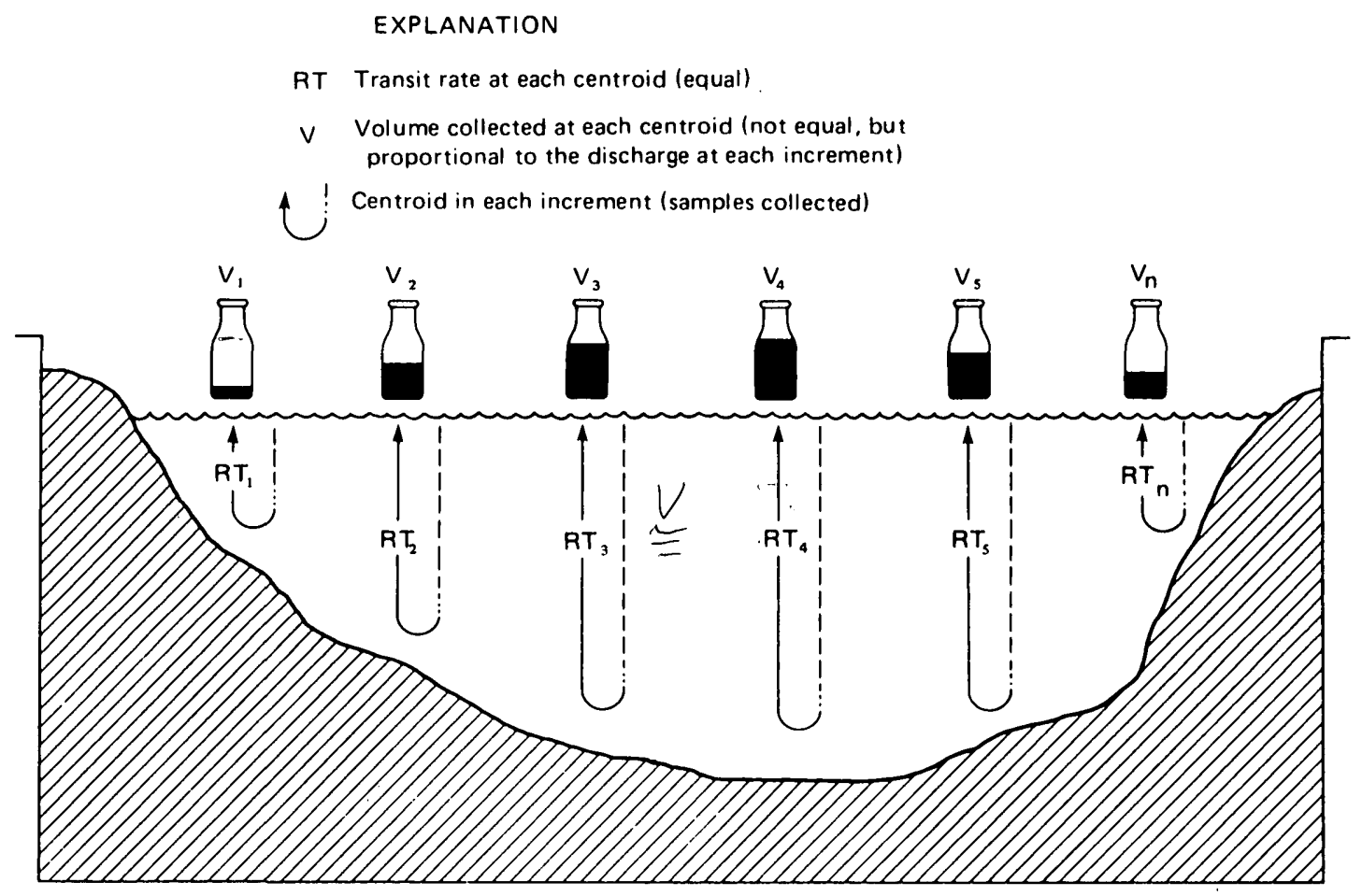

Figure 37.--Equal-width-increment vertical transit rate relative to sample volume that is proportional to water discharge at each vertical.

measurement can be made to determine where this vertical is located, but generally it is estimated by sounding for depth and acquiring a "feel" for the relative velocity with an empty sampler or wading rod. The transit rate required at the maximum discharge vertical must then be used at all other verticals in the cross section and is usually set to fill a bottle to the maximum sample volume in a round trip. It is possible to sample at two or more verticals using the same bottle if the bottle is not overfilled. If a bottle is overfilled, it must be discarded and all verticals previously sampled using that bottle must be resampled using a sufficient number of bottles to avoid overfilling. Note: a sample bottle is "overfilled" when the water surface in the bottle is above the nozzle or air exhaust with the sampler held level.

It is apparent that a water-discharge measurement is not required preceding use of the EWI method. In fact, the method makes it possible to estimate the water-discharge rate for the stream if the vertical spacing, the stream depth at each vertical, the length of time the sampler is in the water, and the volume of sample is recorded. This is possible because the water enters the sample bottles at the ambient stream velocity and thus the gross sample volume is proportional to the integrated velocity in the verticals. Note: at streamflow velocities less than $1 \mathrm{ft} / \mathrm{s}$, the nozzle-entrance velocity will increase as the ambient streamflow velocity decreases, resulting in erroneous stream discharge if this technique is used at stream velocities less than $1 \mathrm{ft} / \mathrm{s}$. The mean velocity of the flow sampled in the vertical or verticals, $V_{m}$ can be determined by the equation 


$$
V_{m}=\frac{V / T_{t}}{A_{n}}
$$

where $V=$ volume of the sample, in cubic feet;

$T_{t}=$ total transit time to obtain sample, in seconds; and

$A_{n}=$ cross-section area of nozzle, in square feet.

The discharge of the stream is then simply the summation of the velocity-area product for each sampled segment of the stream. Note: the same method may be used for the EDI samples, but the volume and time for each bottle must be recorded. Additionally, the EWI method saves analytical time and effort in the laboratory because the sample bottles are composited to give one crosssectional sediment concentration and (or) particle-size gradation (see Guy, 1969). If sample bottles are analyzed separately, the average cross-sectional discharge-weighted sediment concentration in milligrams per liter must be computed by dividing the total mass, in grams, of sediment in all the bottles by the total mass, in grams, of the water-sediment mixture in all the bottles and then multiplying the quotient by $10^{6}$.

Advantages and disadvantages of the equal-discharge-increment method and the equal-width-increment method

Some advantages and disadvantages of both the EDI and EWI methods have been mentioned in the previous discussion. It must be remembered, however, that both methods, if properly used, yield the same results.

The advantages of the EDI method are:

1. Fewer verticals are necessary resulting in a shortened collection time.

2. Sampling during rapidly changing stages is facilitated by the shorter sampling time.

3. Bottles comprising a sample set may be composited for laboratory analysis when equal volumes of sample are collected from each vertical.

4. The cross-sectional variation in concentration can be determined if sample bottles are analyzed individually.

5. Duplicate cross-section samples can be collected simultaneously.

6. A variable transit rate can be used among verticals.

The advantages of the EWI method are:

1. Previous knowledge of flow distribution in the cross section is not required.

2. Variations in the distribution of concentration in the cross section may be better defined due to the greater number of verticals sampled. 
3. Analytical time is reduced as sample bottles are composited for laboratory analysis.

4. This method is easily taught to and used by observers, since the spacing of sample verticals is based on the easily obtained stream width, instead of on discharge.

5. Generally, less total time is required on site if no discharge measurement is deemed necessary and the cross section is stable.

From the previous discussion it is obvious that while both methods have definite advantages, the advantages of one method are in many cases the disadvantages of the other. One major disadvantage of the EWI method that should be noted is the inability to adequately distinguish obviously bad samples in the sample set as illustrated by the following:

Example

\begin{tabular}{|c|c|c|c|c|c|c|}
\hline Vertical/Bottle & 1 & 2 & 3 & 4 & 5 & 6 \\
\hline$=$ of sediment $(\mathrm{g})$ & 0.053 & 0.036 & 0.699 & 0.053 & 0.047 & 0.036 \\
\hline Weight of water/sediment $(\mathrm{g})$ & 350 & 300 & 325 & 330 & 360 & 355 \\
\hline Concentration $(\mathrm{mg} / \mathrm{L})$ & 151 & 120 & 2150 & 161 & 131 & 101 \\
\hline
\end{tabular}

Mean concentration

EWI and EDI Methods (composited)

EDI Method (individual bottles analyzed, concentration averaged)

EDI Method (individual bottles analyzed excluding bottle 3 , concentration averaged)

$=457 \mathrm{mg} / \mathrm{L}$

$=469 \mathrm{mg} / \mathrm{L}$

$=133 \mathrm{mg} / \mathrm{L}$

As this example shows, if the sample was an EWI sample and composited for analysis, the computed mean concentration is $457 \mathrm{mg} / \mathrm{L}$, which is also the mean concentration if the sample was considered as an EDI sample similarly composited for analysis. If, as in the case of the EDI sample, the individual bottles were analyzed, normal computation would result in a mean concentration of $469 \mathrm{mg} / \mathrm{L}$. From the data, bottle 3 appears to have been enriched and is not consistent with the other data points for this cross section. By exercising the flexibility of the EDI method and eliminating the number 3 bottle, the mean concentration of the remaining five bottles is computed to be $133 \mathrm{mg} / \mathrm{L}$, which is probably more consistent with the actual mean concentration in the cross section.

\section{Point Samples}

A point sample is a sample of the water-sediment mixture collected from a single point in the cross section. It may be collected using a pointintegrating sampler.

Point-integrated samples may be collected using one of the pointintegrating samplers previously discussed. Data obtained in this manner may be used to define the distribution of sediment in a single vertical, such as the observer's fixed station, the vertical and horizontal distribution of sediment in a cross section, and the mean spatial sediment concentration.

The purpose for which point samples are to be collected determines the collection method to be used. If samples are collected for the purpose of 
defining the horizontal and vertical distribution of concentration and (or) particle size, samples collected at numerous points in the cross section, with any of the "P" type samplers, will be sufficient. Normally, 5 to 20 verticals are sufficient for horizontal definition. Vertical distribution can be adequately defined by obtaining samples from a number of points between the water surface and the streambed. Specifically, samples should be taken at the surface, from 1 foot above the bed, with the sampler touching the bed, and from 6 to 10 additional points in the vertical above the 1-foot-above-bed point. At each point a sample should be collected and analyzed separately. The results can then be plotted on a cross section relative to their instream location.

If point samples are collected to define the mean concentration in a vertical, 5 to 10 samples should be collected from the vertical. The sampling time for each sample (the time the nozzle is open) must be equal. This will ensure that samples collected are proportional to the flow at the point of collection. These samples are then composited for laboratory analysis. If the EDI method is used to define the stationing of the verticals, the sampling time may be varied among verticals. If the EWI method is used to determine the location of verticals, a constant sampling time for samples from all verticals must be used.

Number of Verticals

The number of suspended-sediment sampling verticals at a measuring site may depend on the kind of information needed in relation to the physical aspects of the river. For example, to determine the distribution of sediment concentration or particle size across the stream, it is necessary to sample at several verticals. The number of verticals necessary to define such a crosssectional distribution depends on the accuracy being sought and on the systematic variation of sediment concentration at different verticals across the stream.

As noted previously, suspended-sediment samplers are designed to accumulate a sample that is directly proportional to the stream discharge or velocity. The accumulated sample may be from a point in the stream cross section, a vertical line between the surface and streambed, or several such vertical lines across the entire stream cross section. Such a sample can then be considered to be representative of some element of cross-sectional flow, whether it be a few square feet adjacent to the point sample, a few square feet adjacent to both sides of a vertical line, or the area of the entire flow summed by several vertical lines. The number of verticals sampled must be adequate to represent the cross section in the sample. The number of sample bottles to be collected will depend on the kind of analysis to be made in the laboratory, and the location of the sampling verticals will depend on the concentration and size distribution of sediment moving through the stream cross section.

Both EDI and EWI methods of sediment-discharge measurement obtain a volume of sample at each vertical, weighted with the water discharge for that vertical. The volumetric sum from all verticals yields a sample volume proportional to the water discharge for the stream. Remember that all or nearly all of the concentration variations at different verticals across the stream will be the result of sand-sized material and that finer sediments are uniformly dispersed throughout the section unless the section is close to a tributary and mixing is not complete. Measuring sections near such tributaries should be avoided. 
Colby (1964) showed that the discharge of sand is approximately proportional to the third power of the mean velocity with constant temperature and a given particle-size distribution for a range of velocity from about 2 to 5 $\mathrm{ft} / \mathrm{s}$ and within some reasonable range of depths. Thus, $q_{s}=k_{1} V^{3}$, in which $q_{s}$ is the discharge of sand per unit width; $k_{1}$ is a constant for a given depth, particle size, and temperature; and $V$ is the mean velocity. The sand discharge can be written as $q_{s}=k_{2} C V D$, in which $k_{2}$ is another constant, $C$ is the mean discharge-weighted concentration in the sampled vertical, and $D$ is the total sampled depth. Solving for $C$ gives

$$
C=\frac{k_{1}}{k_{2}} \frac{V^{2}}{D} .
$$

Thus, the variability of concentration at different sampling verticals should be closely related to the variability of $\frac{V^{2}}{D}$. In order to have a $\frac{V^{2}}{D}$ index useful for comparison among all streams, the compound ratio

$$
\frac{V^{2} / D(\max )}{\bar{V}^{2} / \bar{D}} \text { is suggested, }
$$

where $\left(V^{2} / D(\max )\right)$ is the ratio from the vertical having the maximum $V^{2} / D$, and $\bar{V}^{2} / \bar{D}$ is the ratio of the mean velocity squared to the mean depth of the whole stream cross section. The mean velocity and mean depth are computed and available from water-discharge measurements.

Based on the $V^{2} / D$ index concepts of variability, P. R. Jordan (written commun., 1968) used data from Hubbell and others (1956) to prepare a nomograph (fig. 38) that indicates the number of sampling verticals required for a desired maximum acceptable relative standard error (sampling error) based on the percentage of sand and the $V^{2} / D$ index. In the example illustrated by figure 38, the acceptable relative standard error is 15 percent, the sample is 100-percent sand, the $V^{2} / D$ index is 2.0 , and the required number of verticals is seven. Notice that if the sediment were 50-percent sand, the same results could be obtained with three verticals; or, if seven verticals were used with 50-percent sand, the relative standard error would be about 8 percent. When the discharge of sand-sized particles is of primary interest, the 100-percent line should be used regardless of the amount of fines in the sample.

\section{Transit Rates for Suspended-Sediment Sampling}

The sample obtained by passing the sampler throughout the full depth of a stream is quantitatively weighted according to the velocity through which it passes. Therefore, if the sampling vertical represents a specific width of flow, the sample is considered to be discharge-weighted because, with a uniform transit rate, suspended sediment carried by the discharge throughout the sampled vertical is given equal time to enter the sampler. In previous writings the point was made to keep the transit rate of the samplers constant throughout at least a single direction of travel.

The maximum transit rate used with any depth-integrating. sampler must be regulated to ensure the collection of representative samples. If the transit rate is too fast, the rate of air-volume reduction in the sample container is less than the rate of increase in hydrostatic pressure surrounding the sampler; and water may be forced into the intake or air exhaust. Additionally, an excessive transit rate can result in intake velocities less than the stream 


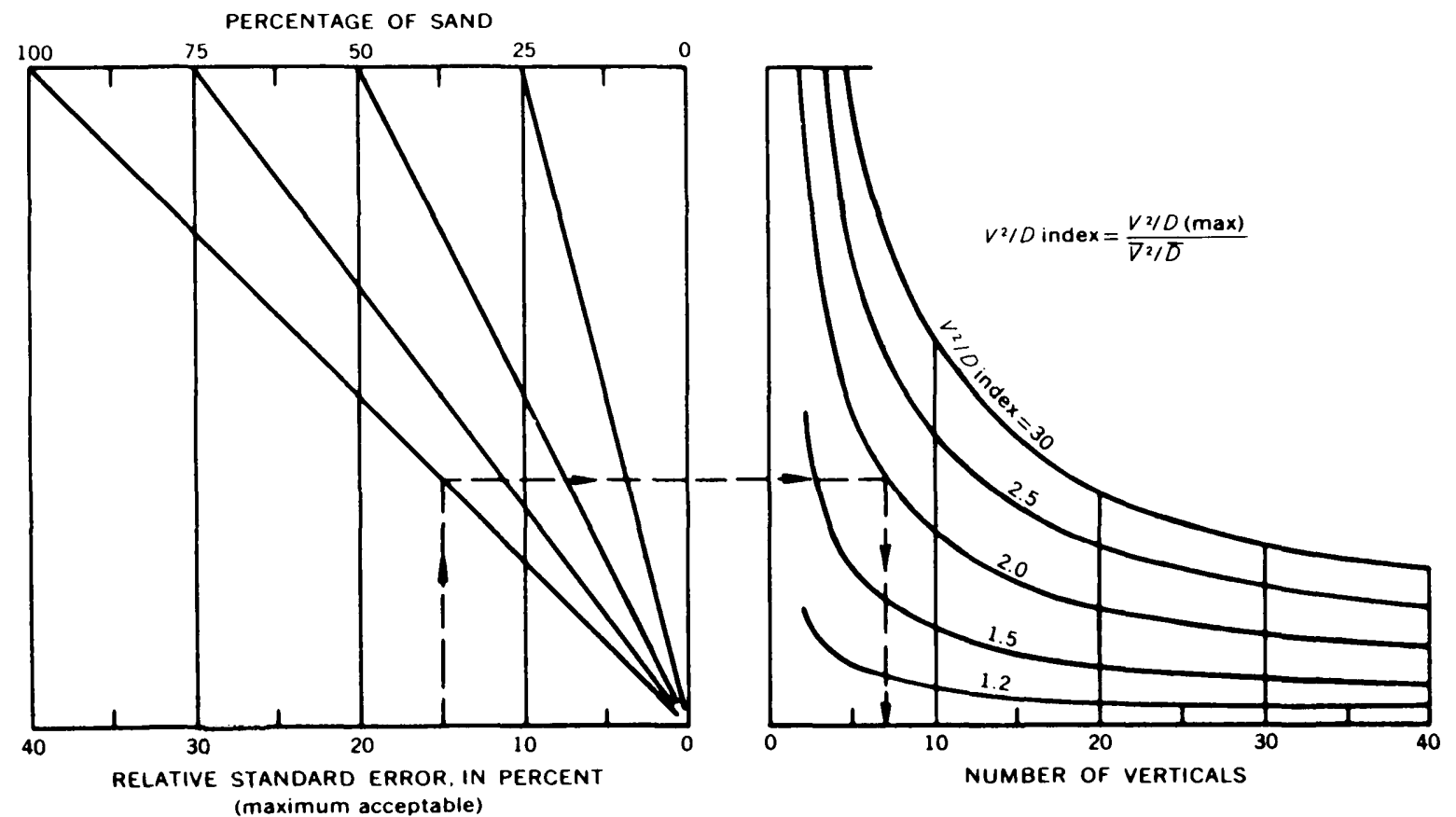

Figure 38.--Nomograph to determine the number of sampling verticals required to obtain results within an acceptable relative standard error.

velocity at the intake due to a large entrance angle between the nozzle and streamflow lines caused by the vertical movement of the sampler in the flow (F.I.S.P. 1952, Report 6). To alleviate these problems, transit rates should never exceed 0.4 of the mean velocity $\left(0.4 V_{m}\right)$ in a vertical. Figures 39, 40, and 41 can be used to determine the appropriate transit rate to be used with a given nozzle-size/sample-container-size combination. These figures show that maximum transit rates vary from about 0.1 mean velocity $\left(0.1 V_{m}\right)$ to the approach angle limit of $0.4 V_{m}$ noted previously. This variation is a function of both nozzle size and sample-container size. The smaller nozzle ( $1 / 8$ inch) is greatly affected by approach angle intake velocity reductions; figures $39 a$, $\mathrm{b}$, and $\mathrm{c}$ and $40 \mathrm{a}, \mathrm{b}, \mathrm{c}$ show that the transit rate $\left(R_{T}\right)$ decreases directly with nozzle size.

Also, by comparison of figures $39 a, b$, and $c$ and $40 a, b$, and $c$, it is obvious that transit rates are inversely affected by sample-container size since an increase in sampler container size produces a decrease in allowable transit rate due to the effects of hydrostatic pressure compressing the air within the container during the downward transit.

Figures 39, 40, and 41 were constructed using the nomenclature and equations from F.I.S.P., Report 6 , Section 8 , as contained in the sampling instructions for the $\mathrm{D}-74$ depth-integrating sampler. 


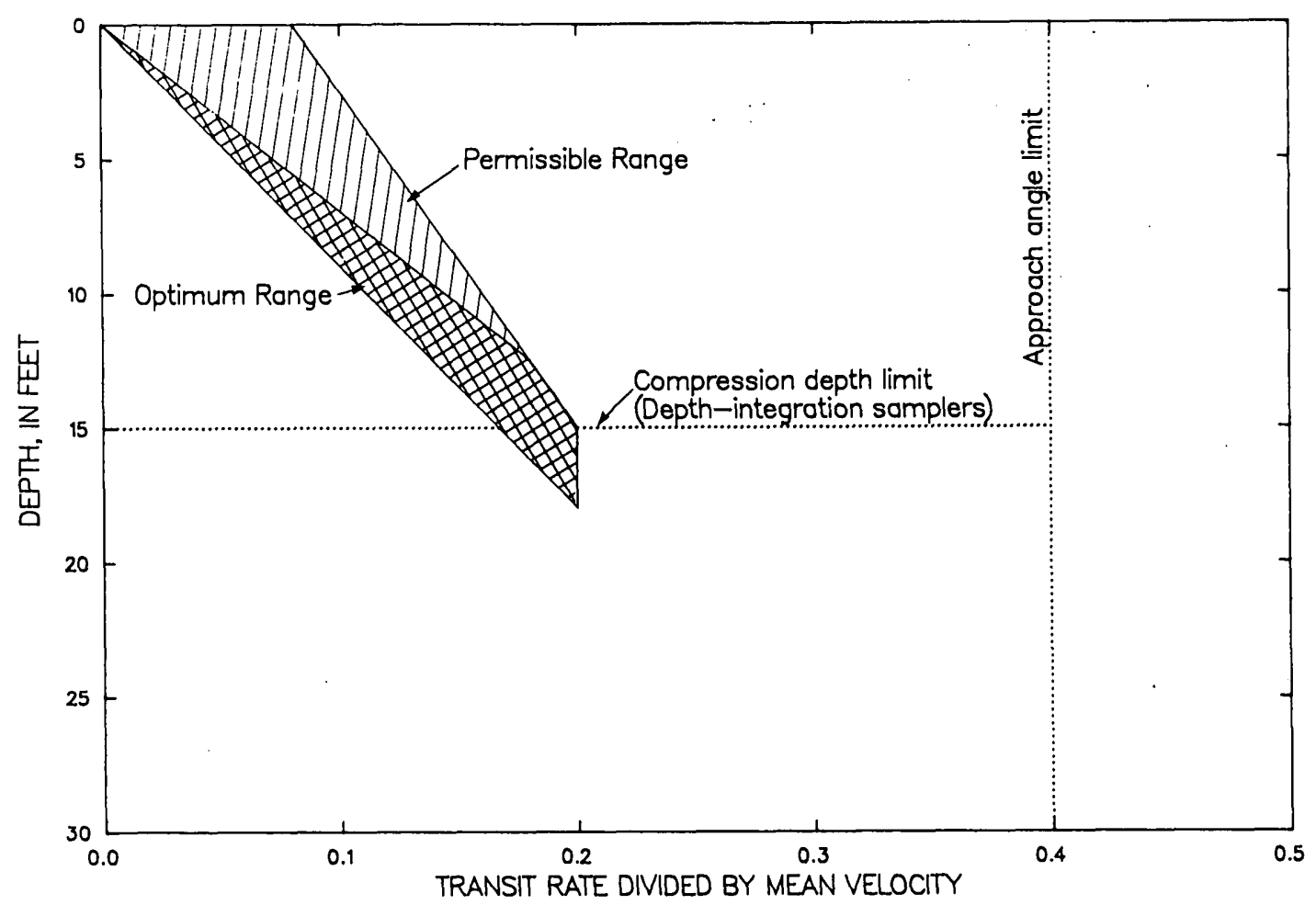

Figure 39a.--Ratio of transit rate $\left(R_{T}\right)$ to mean velocity $\left(V_{m}\right)$ : transit rate determination for 1/8-inch nozzle and pint bottle.

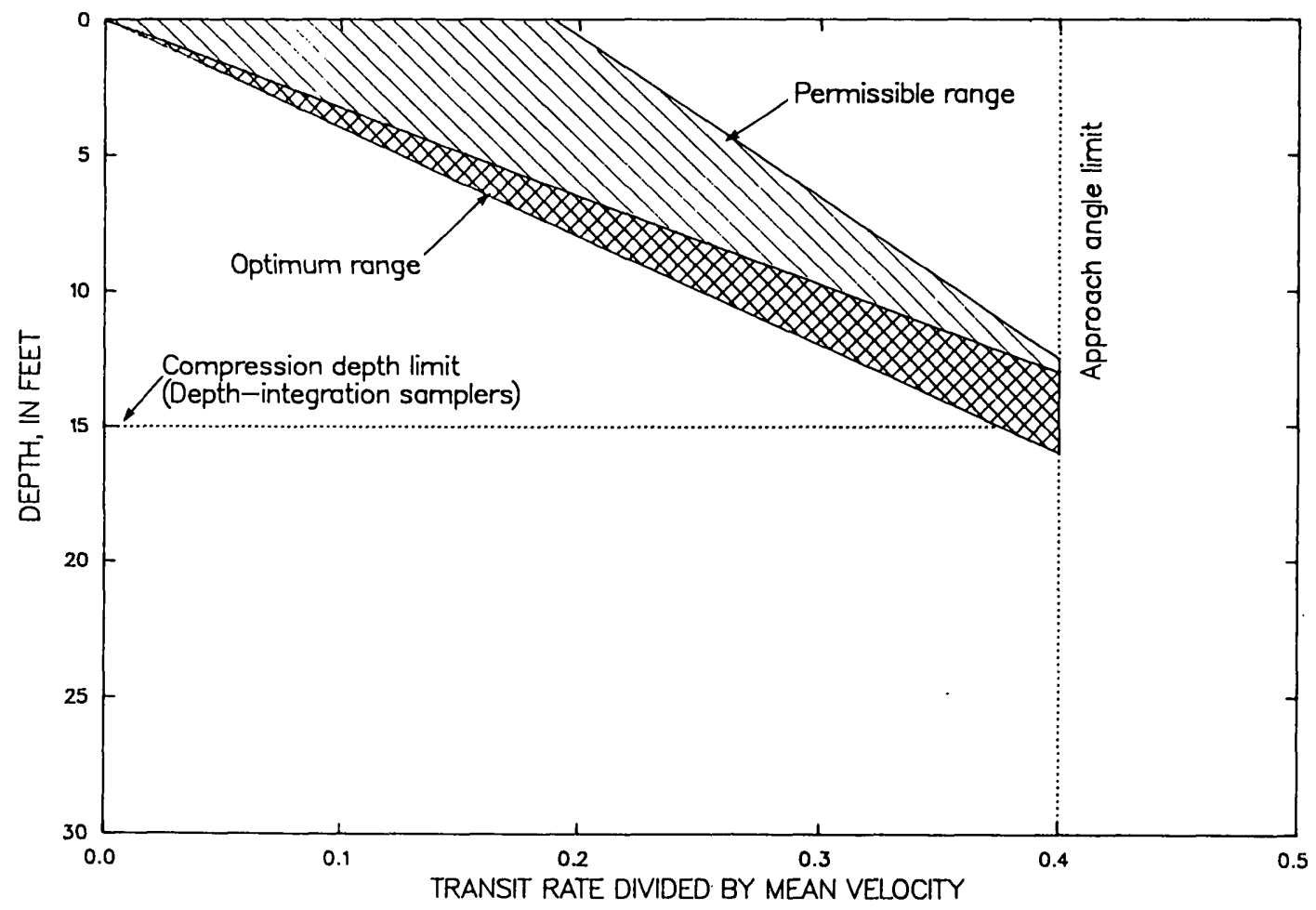

Figure 39b.--Ratio of transit rate $\left(R_{T}\right)$ to mean velocity $\left(V_{m}\right)$ : transit rate determination for 3/16-inch nozzle and pint bottle. 


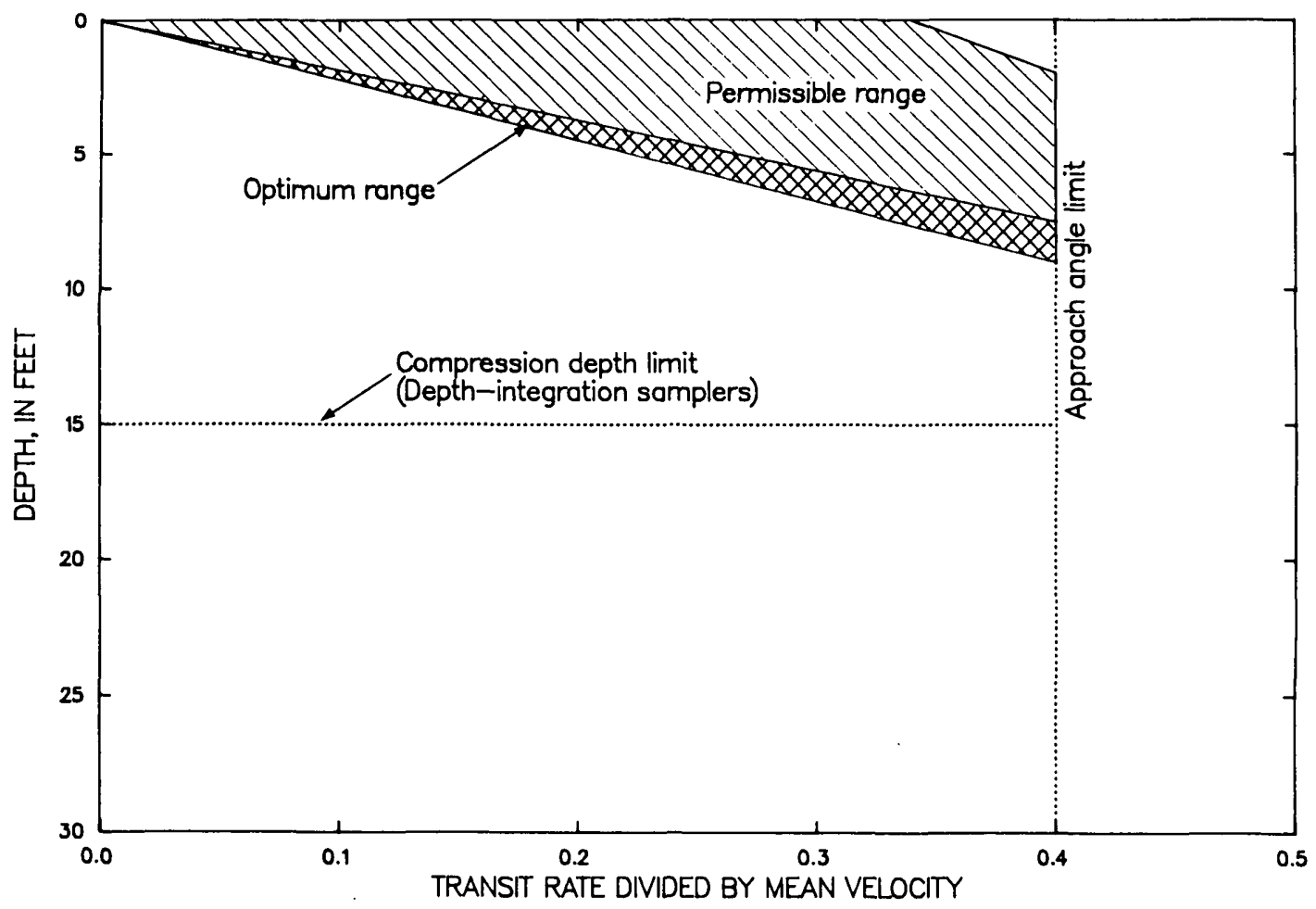

Figure 39c.--Ratio of transit rate $\left(R_{T}\right)$ to mean velocity $\left(V_{m}\right)$ : transit rate determination for 1/4-inch nozzle and pint bottle.

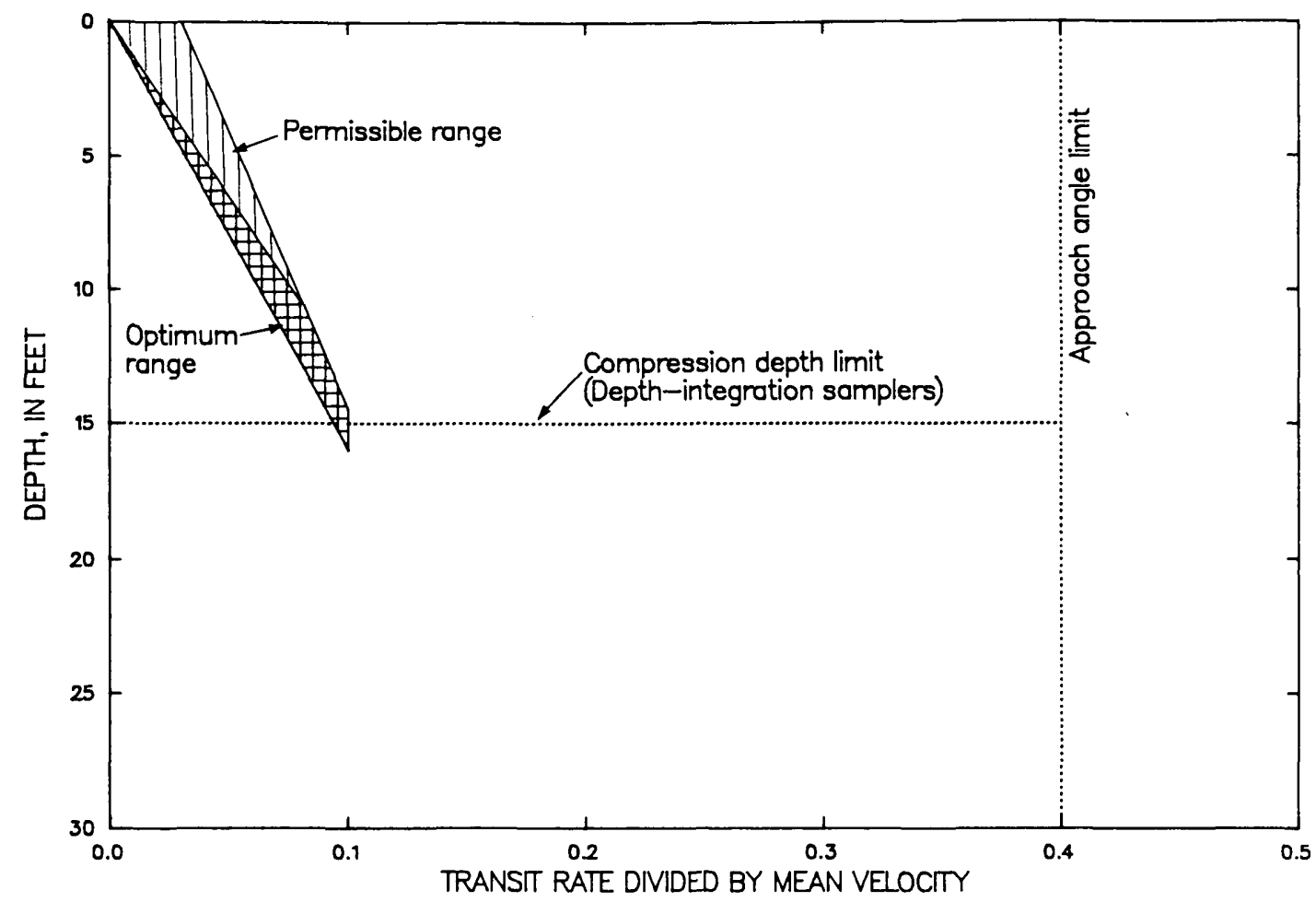

Figure $40 \mathrm{a} .--$ Ratio of transit rate $\left(R_{T}\right)$ to mean velocity $\left(V_{m}\right)$ : transit rate determination for 1/8-inch nozzle and quart bottle. 


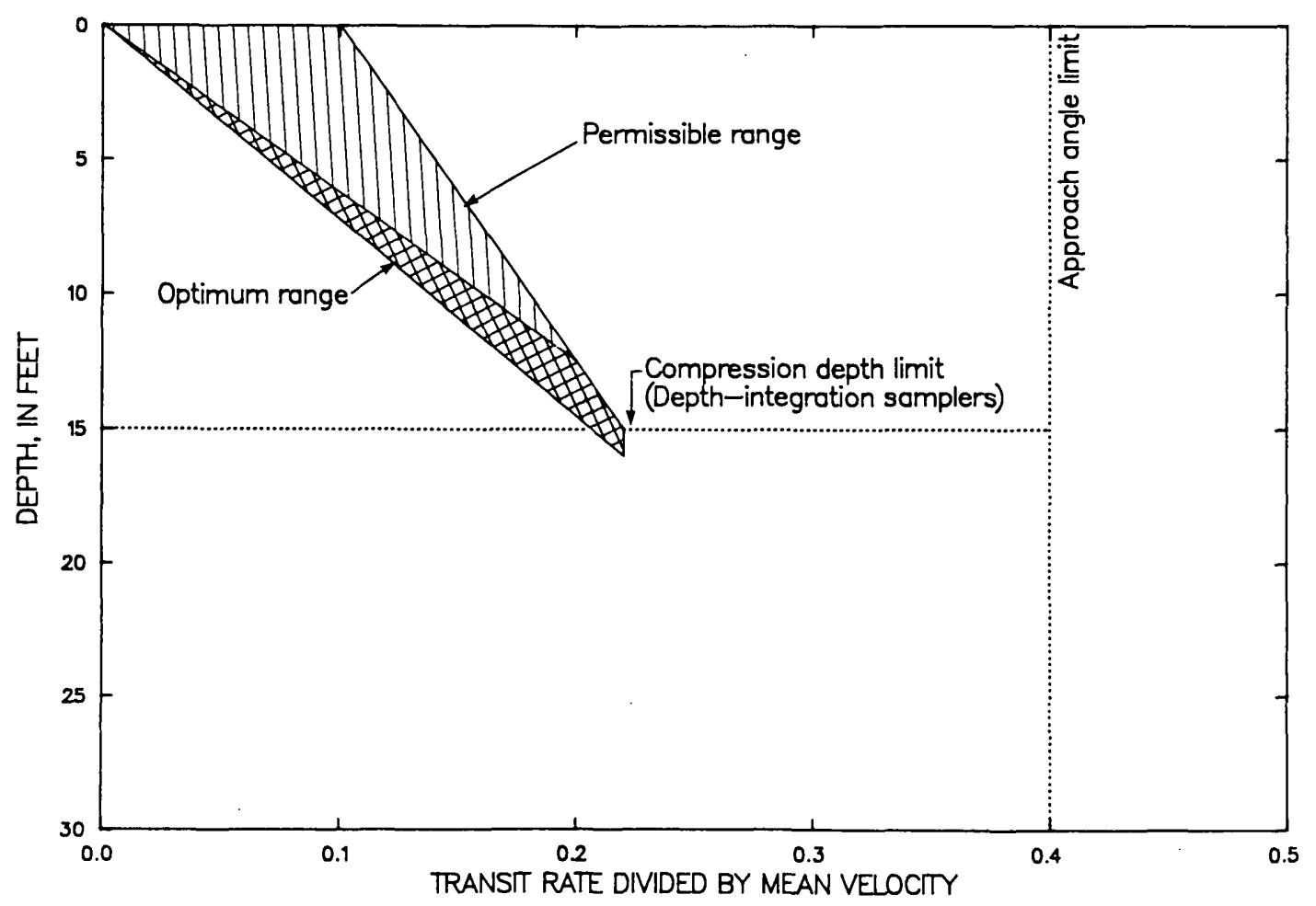

Figure $40 \mathrm{~b}$.--Ratio of transit rate $\left(R_{T}\right)$ to mean velocity $\left(V_{m}\right)$ : transit rate determination for 3/16-inch nozzle and quart bottle.

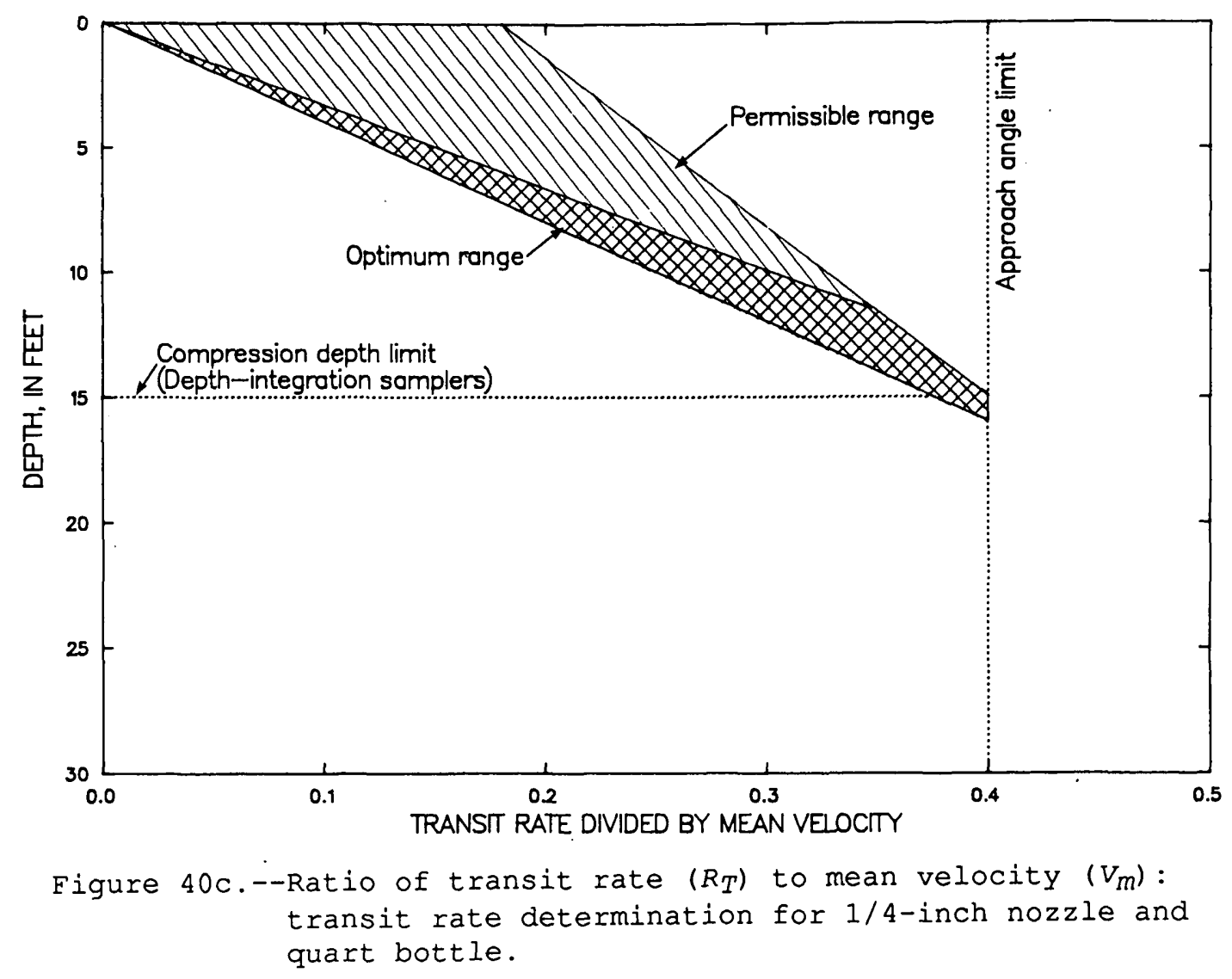




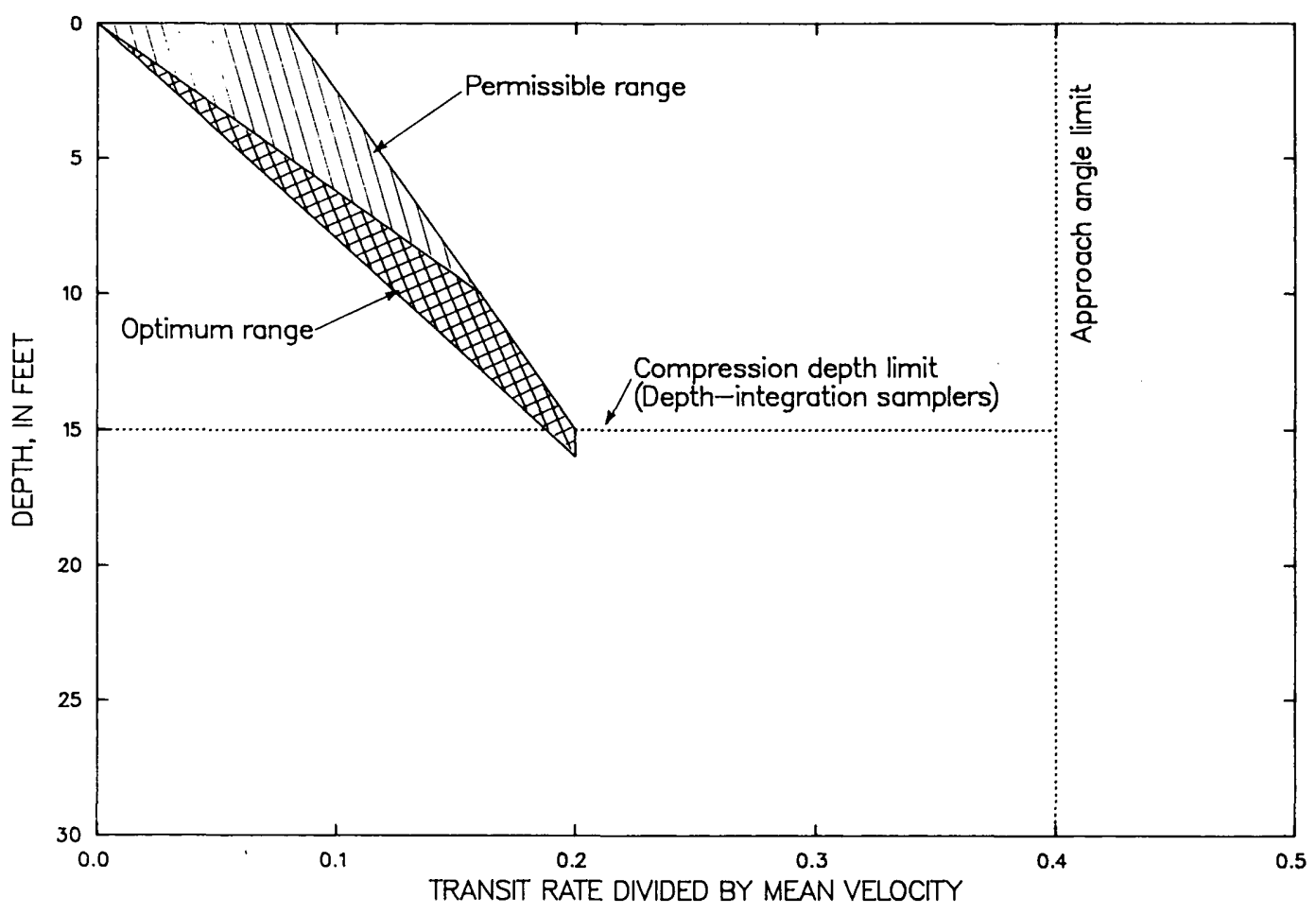

Figure $41 .-$
transit rate determination for $5 / 16$-inch nozzle and
3-liter bottle.

Figure 42 is a graphic presentation of the procedure to be followed when constructing a transit-rate graph like those presented in figures 39,40 , and 41 using the following nomenclature and equations:

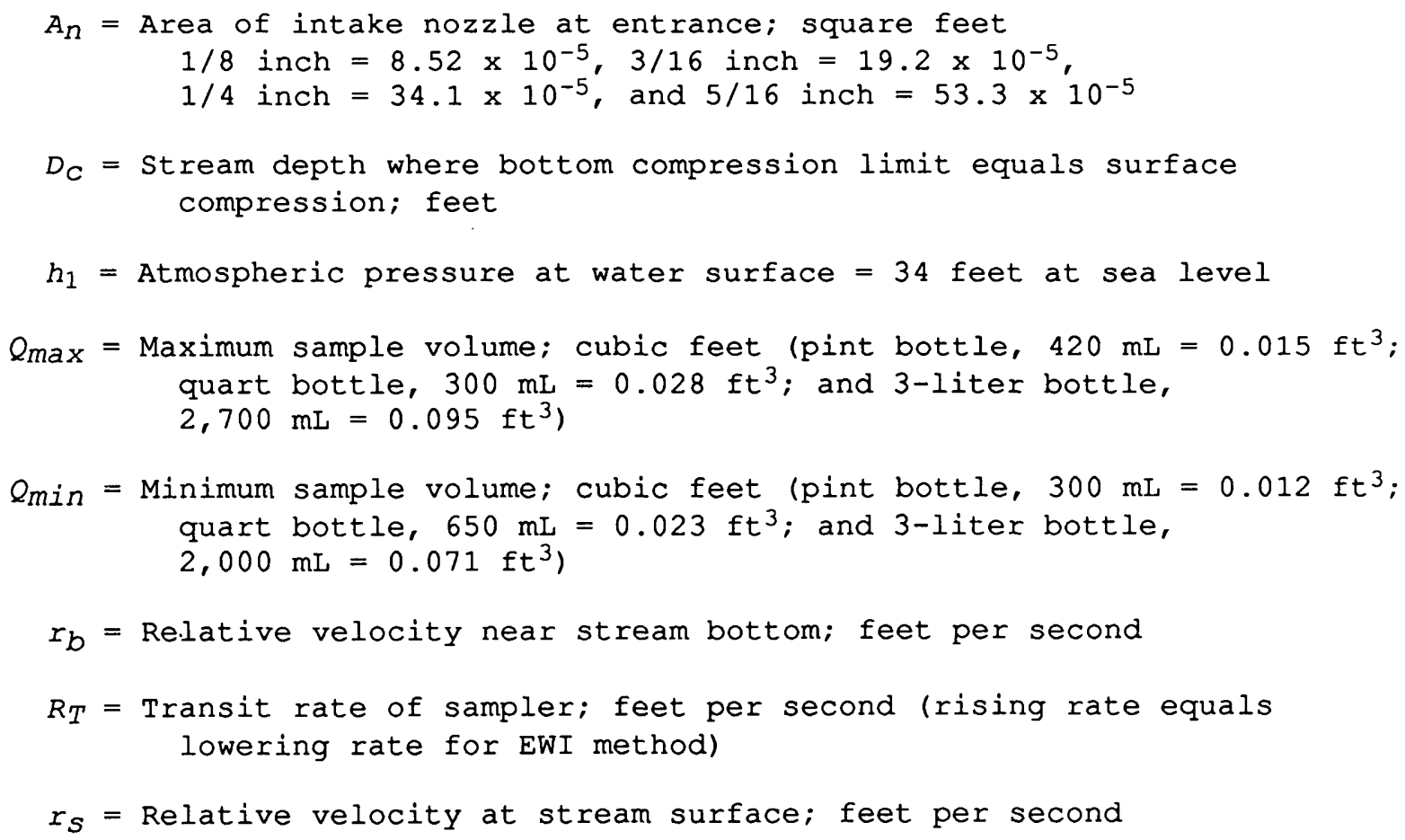




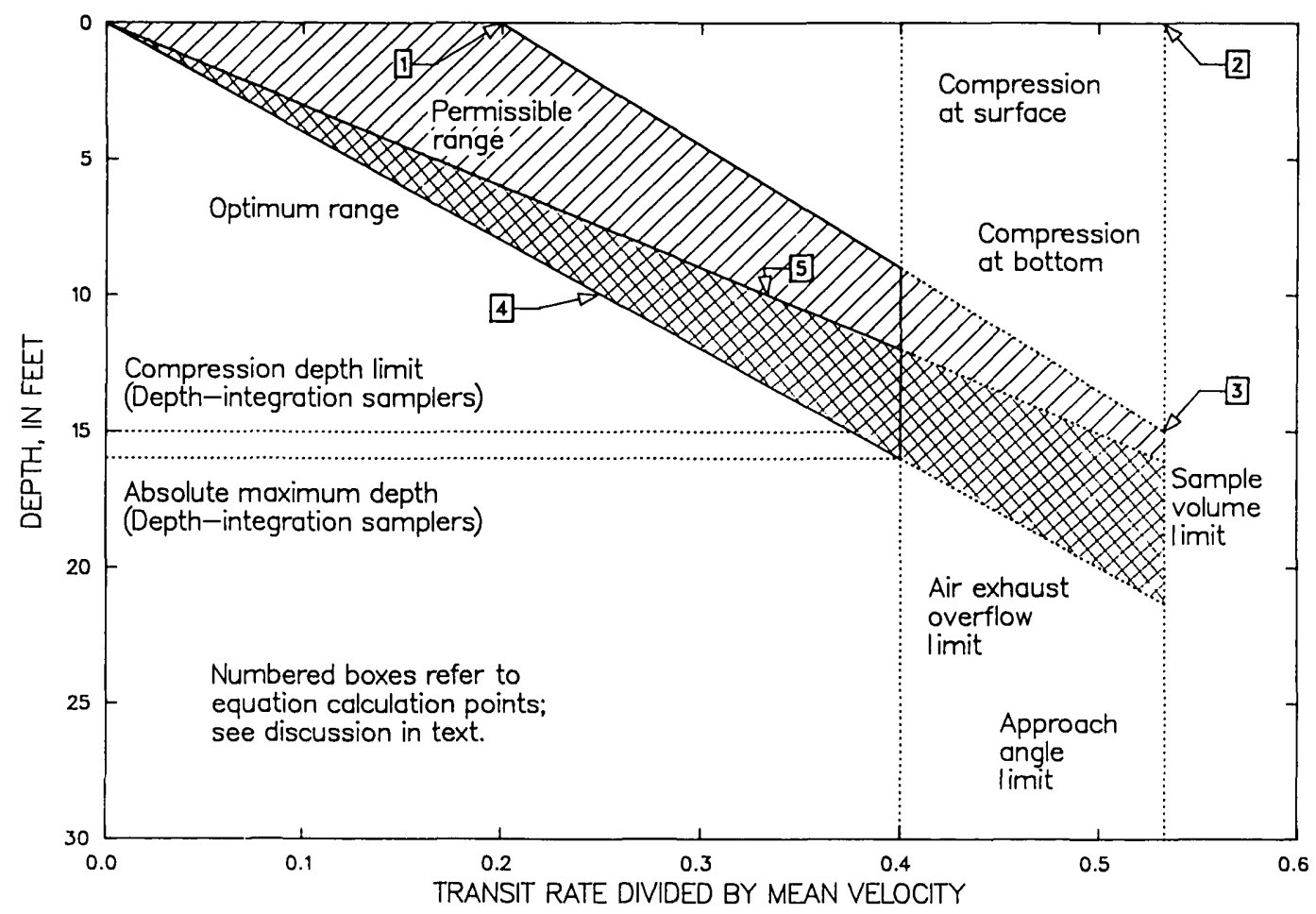

Figure 42.--Construction of a transit rate $\left(R_{T}\right)$ determination graph (see text for explanation of numbered points).

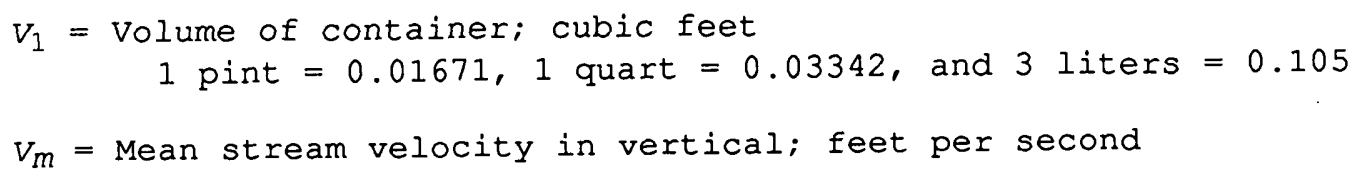

Point $1 \quad \frac{R_{T}}{V_{m}}=\frac{A_{n} r_{b} h_{1}}{V_{1}}$

Point $2 \quad \frac{R_{T}}{V_{m}}=\frac{A_{n} r_{S} h_{1}}{V_{1}}$

Point $3 \quad \frac{D_{C}}{V_{m}}=\frac{h_{1}\left(r_{S}-r_{b}\right)}{r_{b}+1}=15$ feet, for assumed velocity

profile presented below

Point $4 \quad \frac{R_{T}}{V_{m}}=\frac{20 A_{n}}{Q_{\max }}$

Point $5 \quad \frac{R_{T}}{V_{m}}=\frac{20 A_{n}}{Q_{\min }}$ 
For points 4 and 5 , the depth is arbitrarily taken at 10 feet to facilitate plotting. Also, the following sample vertical velocity profile is assumed:

\begin{tabular}{cc} 
Relative depth & $\begin{array}{c}\text { Velocity/mean velocity } \\
\text { in vertical }\end{array}$ \\
\hline 0 surface & 1.16 \\
.1 & 1.17 \\
.2 & 1.16 \\
.3 & 1.15 \\
.4 & 1.10 \\
.5 & 1.05 \\
.6 & 1.0 \\
.7 & .94 \\
.8 & .84 \\
1.0 bottom & .67
\end{tabular}

The technique for use of figures 39, 40, and 41 to determine the transit rate to be used in a given situation depends upon (1) the depth of the sample vertical, (2) the mean velocity of the vertical, (3) the nozzle size being used, and (4) the sample-bottle size used in the sampler. An example of transit rate determination is presented in figure 43. The nozzle size and sample-bottle size must be known so the proper figure can be selected. In this case a 3/16-inch nozzle and 1-pint bottle will be used. The depth and mean velocity of the sample vertical must also be known. For this example a depth of 10 feet and mean velocity of $2 \mathrm{ft} / \mathrm{s}$ are assumed. To determine transit rate for this example: (1) select the depth of the sample vertical (10 feet); (2) draw a line perpendicular to the depth on the vertical scale that terminates at the center of the optimum range; (3) read the value of $R_{T} / V_{m}$ from the horizontal scale corresponding to this point $(0.28) ;$ and (4) multiply the $R_{T} / V_{m}$ value by the mean velocity $\left(V_{m}=2 \mathrm{ft} / \mathrm{s}\right)$ to determine the transit rate $\left(R_{T}=0.56 \mathrm{ft} / \mathrm{s}\right)$. Note that if the same nozzle, depth, and mean velocity were used with a quart sample container in lieu of the pint container (fig. 40b), an $R_{T}$ value of $0.30 \mathrm{ft} / \mathrm{s}$ would be used, reducing the transit rate by almost half.

Use of transit rates determined from the optimum range of figures 39 , 40, or 41 will yield a representative sample of adequate volume to provide for laboratory analysis and avoid overfilling. In some instances, however, sampler operation within the optimum range is not possible. Under these conditions, operation using a transit rate determined from the permissible range is acceptable. In these cases it should be realized that a representative sample can still be obtained, but the sample volume may be less than adequate for laboratory purposes; and, therefore, more integrations may be required at each vertical to obtain the necessary volume of sample.

Additional explanation and qualifications with respect to the transit rate for depth-integrated suspended-sediment sampling include the following:

1. For cable-suspended samplers, the instantaneous actual transit rate, $R_{T a}$, may differ considerably from the computed rate, $R_{T}$, if $V_{m}$ exceeds about $6 \mathrm{ft} / \mathrm{s}$ and if the sampler is suspended from more than 20 feet above the water surface. Under such conditions, the sampler is dragged downstream and the indicated depth is greater than the true depth. Corrections for indicated depth are given by Buchanan and Somers (1969, p. 50-56) for various angles and lengths of sound ing line used for suspension of a weight in deep, swift water. The 


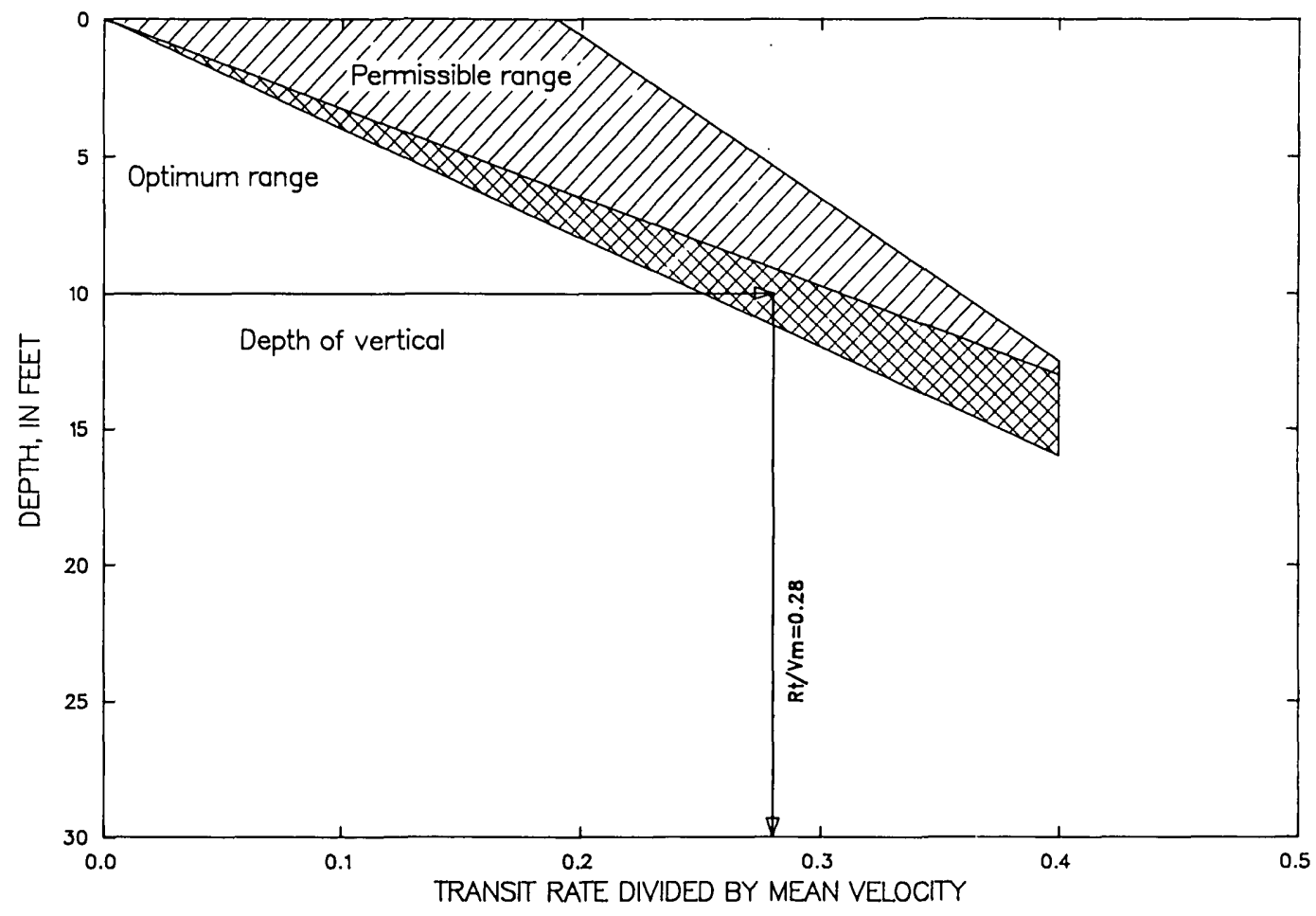

Figure 43.--Example of determining the ratio of transit rate $\left(R_{T}\right)$ to mean velocity $\left(V_{m}\right)$ : transit rate determination for 3/16-inch intake nozzle and a 1-pint sample container.

correct depth would then be used to enter in figures 39, 40, and 41 to determine the appropriate transit rate.

2. In theory, the allowable $R_{T}$ may be greater than $0.4 V_{m}$ and sampling depth thereby increased if the sampler is cable suspended and capable of being tilted somewhat in the direction of vertical move ment (that is, nozzle is slightly down when sampler is lowered and slightly up when sampler is raised, due to the effect of vertical forces on the horizontal tail-fin stabilizer). On the other hand, if the sampler cannot be tilted, the velocity at the bottom of the vertical is much less than $V_{m}$, and there is a heavy concentration of suspended sand near the bed, the use of an $R$ value near the $0.4 V_{m}$ limitation may cause $R_{T}$ to approach or even exceed the actual veloc ity near the bed and thus cause an excessive error in the collection of sand particles. The approach-angle theoretical depth limits will of course be less if either the downward or the upward transit rates, $R_{T d}$ or $R_{T u}$, are different from $R_{T}$. However, determining the attitude of the sampler during actual use is difficult at best and impossible under turbid flow conditions. For this reason, varying either $R_{T}$ or sampling beyond recommended limits is not advisable and probably not necessary, as small errors during descent will probably be cancelled during ascent.

3. The air compression lower limit is based on the assumption that a uniform velocity distribution exists throughout the vertical.

Actually the velocity varies with the depth throughout the vertical. 
Therefore, where the velocity is considerably greater than the mean in the upper part of the vertical, the lower limit could be increased somewhat. In theory, the air compression lower limit could be effectively increased by using a downward transit rate, $R_{T d}$, where $R_{T d}$ is less than $R_{T}$, and compensating for the extra fill ing of the bottle on the downward trip by using an upward transit rate, $R_{T u}$, where $R_{T u}=R_{T}+\left(R_{T}-R_{T d}\right)$. Note: this brief discussion is presented here as an interesting concept and should not be prac ticed in actual field conditions where channel configuration and velocity profiles may not represent the ideal flow conditions found in a controlled flume environment.

4. Because of possible greater deviation from the ideal relation of intake velocity to stream velocity of 1.0 , the $1 / 8$-inch nozzle should not be used if there are significant quantities of sand larger than $0.25 \mathrm{~mm}$ in suspension. The $1 / 8$-inch nozzle is also less reliable than the larger nozzles where small roots and other organic fibers are suspended in the flow.

5. In the event the sampler accommodates other than a pint-sized sample container, the $R_{T}$ should be carefully determined, since the $R_{T}$ for a quart container may be nearly half of that acceptable for a pint container with a given nozzle size. The use of a sample container larger than 1 pint does not, however, increase the sample depth range, due to the air compression depth limit. Therefore, samples should not be taken from greater than about 15 feet with a depthintegrating sampler.

Sometimes when suspended sediment or bedload is sampled for a total-load computation, unusual cross-section and streambed conditions may require a change or break in the transit rate used in an EWI measurement. This may be desirable where a small part of the section carries a large part of the total discharge and where the stream can be divided into two parts and analyzed as "two" streams. Two or more transit rates may also be desirable in a section where there is a marked change in bed-material size from one side to the other or where a braided stream occurs. However, the practice of changing transit rates in the "middle of the stream" is not desirable unless it will improve the resulting data. Bottles and field notes should be labeled with a full explanation of why and how the change was made. Samples should not be composited for analysis if a cross section is sampled with two or more different transit rates while using the EWI method. If varying transit rates are used during collection of an EWI sample, each sample then represents the velocity in the sampled vertical, with no common bond of equal transit rate or equal discharge rate among them. In order to determine the mean sediment concentration for a cross section sampled in this manner, the discharge represented by the samples collected at each transit rate must be determined and the sediment concentrations must be weighted to reflect the discharge they represent. After the sediment concentrations are properly discharge-weighted, the mean sediment concentration for the cross section can be computed as the arithmetic mean of the individual discharge-weighted concentrations.

\section{Observer Samples}

At many sites, collection of suspended-sediment data is required on a frequent basis. To define the sediment-discharge trends, these data could be required once daily or more often (in the case of high-flow events). Frequent suspended-sediment data collection can put extreme pressure on a project's 
fiscal resources as well as on the personnel involved. In order to save money, travel time, and, most importantly, to ensure timely collection of data on a regular basis and during extreme events, local residents are often contracted to work as observers.

Observers usually lack technical background but can be trained to collect cross-section samples using either the EDI or EWI method. However, due to the complexities involved in computing centroids and a lack of expertise in obtaining the stream discharge for the EDI method, this technique is not recommended for observer operated sites.

Observers most often collect samples from an established single vertical in the cross section, as previously mentioned. The best location in the cross section for a single-vertical sediment sample is determined by data collection. Generally each new sediment-record site is carefully investigated by means of several detailed sediment-discharge measurements to determine the concentration of sediment across the stream at different discharges. These sediment data can be collected using either the EDI or EWI method, utilizing the maximum number of sample verticals.

If the single vertical is used to obtain observer collected samples, these data must be treated much the same as point-sample data collected with a pumping sampler. That is, cross-section samples must be taken occasionally for comparison with the observer samples in order to establish adjustment coefficients. Samples should be collected at the observer's single vertical using the observer's equipment, both before and after each cross-section sample is taken. These samples then form the basis for a coefficient that can be used to adjust the concentration of the single vertical samples. This adjustment coefficient, or comparison of the routine single vertical with the cross section, is determined by computing the ratio of the average concentration of cross-section samples to the average concentration of single-vertical samples. This ratio can then be applied to the daily samples taken between sedimentdischarge measurements. If the coefficient is consistently above or below unity, it may be desirable to change the position of the fixed routine sampling installation to a location where the coefficient would be at or near unity. Generally, if the coefficients are within 5 percent of unity, a coefficient of 1.0 is applied, unless they are consistently high or low for long periods of time. Guy (1968) illustrated methods for determining the quality of the coefficient and the number of samples needed in a sample set. Porterfield (1972) gave further details on how coefficients are used in the computation of sediment records.

During high flows, when the depth of the single vertical exceeds the theoretical 15-foot compression-depth limit of the depth-integrating sampler, the observer should try to obtain a sample by altering the technique to collect the most representative sample possible. The best collection technique under these conditions would be to depth integrate 0.2 , of the vertical depth (0.2D), or a 10-foot portion of the vertical. These samples can then be checked and verified by collecting a set of reference samples with a pointintegrating sampler. By reducing the sampled depth during periods of high flow, the transit rate can be maintained at $0.4 \mathrm{~V}$ or less in the vertical; and a partial sample can be collected without overfilling the sample container, even under conditions of higher velocities that usually accompany increases in discharge. 
Sampling Frequency, Sediment Quantity, Sample Integrity, and Identification

Sampling frequency

When should suspended-sediment samples be taken? How close can samples be spaced in time and still be meaningful? How many extra samples are required during a flood period? These are some questions that must be answered because timing of sample observations is as important to record computations (see Porterfield, 1972) as is the technique for taking them. Answering such questions is relatively easy for those who compute and assemble the records because they have the "history" before them and can easily see what is needed. However, the field person frequently has no "record" experience and certainly cannot know what the conditions will be in the future.

Observers should be shown typical hydrographs or recorder charts of their stations or of nearby stations to help them understand the importance of timing their samples so that each sample yields maximum information. The desirable time distribution for samples depends on many factors, such as the season of the year, the runoff characteristics of the basin, the adequacy of coverage of previous events, and the accuracy of information desired or dictated by the purpose for which the data are collected.

For many streams the largest concentrations and 70 to 90 percent of the annual sediment load occur during spring runoff; on other streams the most important part of the sediment record may occur during the period of the summer thunderstorms or during winter storms. The frequency of suspendedsediment sampling should be much greater during these periods than during the low-flow periods. During some parts of these critical periods, hourly or more frequent sampling may be required to accurately define the trend of sediment concentration. During the remainder of the year, the sampling frequency can be stretched out to daily or even weekly sampling for adequate definition of concentration. Hurricane or thunderstorm events during the summer or fall require frequent samples during short periods of time. Streams having long periods of low or intermittent flow should be sampled frequently during each storm event because most of the annual sediment transport occurs during these few events.

During long periods of rather constant or gradually varying flow, most streams have concentrations and quantities of sediment that vary slowly and therefore may be adequately sampled every 2 or 3 days; in some streams, one sampling a week may be adequate. Several samplings a day may occasionally be needed to define the diurnal fluctuation in sediment concentration. Fluctuations in power generation and evapotranspiration can cause diurnal fluctuations. Sometimes daily temperature changes cause snow and ice to melt; thereby a considerable rise and fall in stage may occur each day. Diurnal fluctuations have also been noted in sand-bed streams when water-temperature changes cause a change in flow regime and a drastic change in bed roughness (Simons and Richardson, 1965).

The temporal shape of the hydrograph is an indicator of how a stream should be sampled. Sampling twice a day may be sufficient on the rising stage if it takes a day or more for a stream to reach a peak rate of discharge. During the peak, samples every few hours may be needed. During the recession, sampling can be reduced gradually until normal sampling intervals are sufficient.

The sediment-concentration peak may occur at any time relative to the water discharge; it may coincide with the water-discharge peak or occur 
several days prior to or after it. Hydrographs for large rivers, especially in the midwest, typically show water-discharge peaks occurring several days after a storm event. If the sediment concentration has its source locally, the sediment peak can occur a day or more prior to the water-discharge peak. In this case, the receding limb of the sediment-concentration curve will nearly coincide with the lagging water-discharge peak. In this event, intensive sampling logically should be done prior to the water-discharge peak. Detailed sampling of hydrograph peaks during the initial stages of a monitoring program will help determine when the sediment-sampling frequency should be increased and decreased in order to optimize the sediment-sampling effort relative to peak flow conditions.

Intermittent and ephemeral streams usually have hydrograph traces in which the stage goes from a base flow or zero flow to the maximum stage in a matter of a few minutes or hours, and the person responsible for obtaining the samples frequently does not know when such an event is to occur. Ideally, samples should be obtained as follows. During the rising stage, sample small streams every few minutes and large streams every half hour or hour. After the peak rate of flow passes (if this can be determined), the sampling frequency may be reduced somewhat. During the recession, the sampling rate should gradually be reduced to the normal daily schedule as the preceding base flow is reached or as the flow stops. Generally, adequate coverage of such a peak is obtained if samples on the rising limb are four times as frequent as samples needed to define the recession limb; thus if the recession is best sampled on a bihourly basis, the rising limb should be sampled every half hour.

Elaborate and intensive sampling schedules are not required for each and all events on small streams that drain basins of rather uniform geologic and soil conditions because similar runoff conditions will yield similar concentrations of sediment for the different runoff events. Once a concentration pattern is established, samples collected once or twice daily may suffice, even during a storm period (Porterfield, 1972).

Streams draining basins with a wide variety of soils and geologic conditions and receiving uneven distributions of precipitation cannot be adequately sampled by a rigid, predetermined schedule. Sediment concentration in the stream depends not only on the time of year, but also on the source of the runoff in the basin. Thus each storm or chânging flow event should be covered as thoroughly as possible, in a manner similar to that described for intermittent and ephemeral streams.

The accuracy needed in the sediment information also dictates how often a stream should be sampled. The greater the required accuracy and the more complicated the flow system, the more frequently it will be necessary to obtain samples. This increase in sampling frequency--with the added costs of laboratory analysis--greatly increases the cost of obtaining the desired sediment information. Often, however, the record may actually cost less when adequate samples are collected than when correlation and other synthetic means must be used to compute segments of a record because of inadequate sampling.

Stream-sediment stations may be operated or sampled on a daily, weekly, monthly, or on an intermittent or miscellaneous schedule. Usually those operated on a daily basis are considered adequate to yield the continuous record. one should be mindful that each sample at a specific station costs about the same amount of money, but the amount of additional information obtained often decreases with each succeeding sample after the first few samples are taken. Sometimes samples obtained on a monthly basis yield more information for the money than those from a daily station, though there is a danger that too 
little information may be of no value or even may be misleading. For a given kind of record, the optimum number of samples should be a balance between the cost of collecting additional samples and the cost of a less precise record.

The frequency of collection of bed-material samples depends upon the stability of the streambed at the sample site. In many cases seasonal samples may be adequate to characterize the distribution among particles comprising the bed. However, samples should be obtained whenever possible during highflow events in order to describe the composition of bed material as compared to its composition during periods of normal or low flow. Particularly important is the collection of bed-material samples following high flows that have inundated the floodplain and greatly altered the streambed configuration.

\section{Sediment quantity}

Previous sections discussed the number of sampling verticals required at a station to obtain a reliable sediment-discharge measurement or a sample of the cross-sectional concentration. The number of cross-sectional samples required to define the mean concentration within specific limits has also been discussed. The requirements in terms of quantity of sediment for use in the laboratory to determine particle-size gradation at times may exceed the other requirements for concentration. The size range and quantity of sediment needed for the several kinds of sediment analyses in the laboratory are given in table 3. The desirable minimum quantity of sediment for exchange capacity

Table 3.--The desired quantity of suspended sediment required for various sediment analyses

\begin{tabular}{|c|c|c|c|}
\hline Analysis & $\begin{array}{r}\text { Size } \\
(\end{array}$ & $\begin{array}{l}\text { range } \\
\text { (mm) }\end{array}$ & $\begin{array}{c}\text { Desirable minimum } \\
\text { quantity of } \\
\text { sediment }(\mathrm{g})\end{array}$ \\
\hline \multicolumn{4}{|l|}{ Size: } \\
\hline \multicolumn{4}{|l|}{ Sieves: } \\
\hline Fine & 0.062 & -0.5 & 0.07 \\
\hline Medium & .25 & -2 & .5 \\
\hline Coarse & 1.0 & -16 & 20 \\
\hline \multicolumn{4}{|l|}{ VA tube: } \\
\hline Smallest & .062 & $-\quad .5$ & .05 \\
\hline Largest & .062 & -2 & 5 \\
\hline Pipette & .002 & $-\quad .062$ & $.8^{a}$ \\
\hline $\mathrm{BW}$ tube & .002 & .062 & $.5^{a}$ \\
\hline \multicolumn{4}{|l|}{ Exchange capacity: } \\
\hline Fine & & .002 & 1 \\
\hline Medium & .002 & -.062 & 2 \\
\hline Coarse & .062 & -2 & 10 \\
\hline \multicolumn{4}{|l|}{ Mineralogical: } \\
\hline Fine & & .002 & 1 \\
\hline Medium & .002 & $-\quad .062$ & 2 \\
\hline Coarse & .062 & -2 & 5 \\
\hline
\end{tabular}

apouble the quantities shown if both native and dispersed media are required. 
and mineralogical analyses is based on the requirements for radioactive cesium techniques described by Beetem and others (1962).

To estimate visually the quantity of sediment entrained in a sample or series of sample bottles requires considerable experience. It is also difficult to determine what portion of the total sample is sands $(>0.062 \mathrm{~mm})$

because the proportion can be different from stream to stream and from time to time in the same stream. To aid in estimating such sediment quantities, it is helpful to have in the office or laboratory reference bottles with various known quantities and concentrations for visual inspection. The number of bottles of sample, the amount of sand, and sample concentration needed for a given kind of analysis are shown in figure 44 (Porterfield, written commun., 1968).

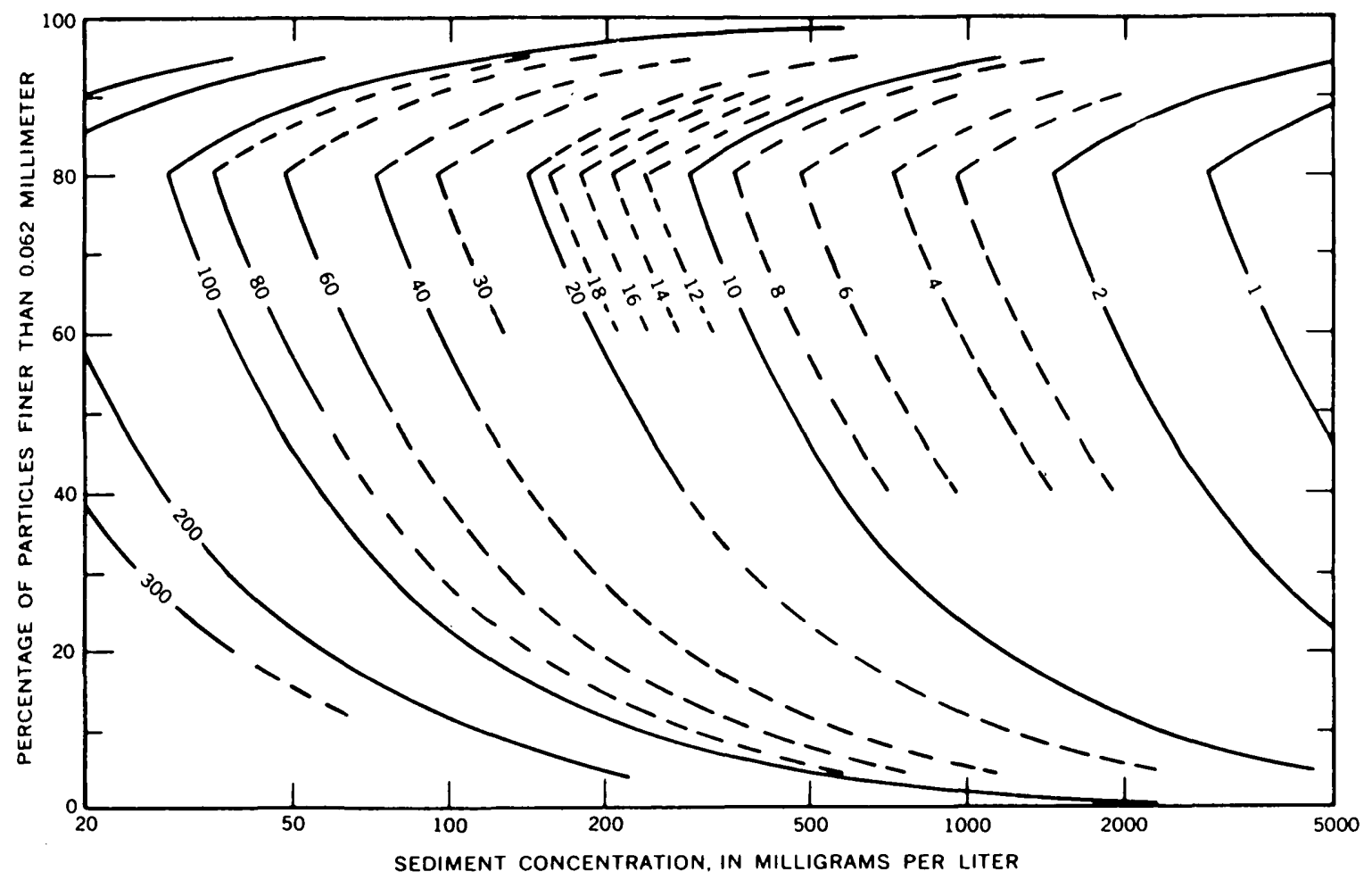

Figure 44.--Minimum number of bottles of samples needed to yield sufficient sediment for size analyses. From Porterfield (1972).

Though it is possible to conduct the laboratory operation for particlesize analysis in a manner that will also give the sediment concentration, it is best to obtain separate samples for size analysis and concentration analysis. Such "special" samples should be plainly labeled. Generally, it is desirable to instruct the observer to collect additional samples for particlesize analysis. 
Every sample taken by a field person should be--as previously indicated--the best sample possible considering the stream conditions, the available equipment, and the time available for sampling. Because sampling errors on sand-bed streams frequently occur in the dune regime where the nozzle of the sampler can accidentally pick up sand from the downstream side of a dune, each sample bottle must be inspected in the field immediately after removing it from the sampler. The cost of the field and laboratory work, to say nothing of the embarrassment of a bad record, is sufficient incentive to make this simple check and, if necessary, to collect another sample.

After the first bottle is taken, it can be checked by swirling the contents of the bottle, then holding the bottle where the sand on the bottom can be seen moving. A mental note is made of the quantity of sand contained in the bottle. The second and remaining bottles can then be examined and compared with the previous bottles. Any vertical or verticals where a bottle or bottles contain a significantly different quantity of medium and coarse sand should be carefully resampled. If the "check" sample also contains a noticeably different amount of sand in comparison to others in the set, retain both bottles and note that the high or low concentration of sand is consistent at the vertical or verticals in question. If the check sample contains a smaller or more representative amount of sand, or if the quantity of sand is different from the first but still not "normal," it may be desirable to wait several minutes to take a third bottle on the assumption that the dune face would move beyond the sample vertical.

A more subtle error in sample concentration may occur when a bottle is overfilled. This error also results in too high a concentration. The error caused by overfill may occur whenever the bottle is filled to less than 1-1/2 to 2 inches from the top. Such a sample should be discarded and another sample obtained using an increased transit rate. If the transit rate or the nozzle must be changed to avoid overfilling during an EWI measurement, then it is best to discard any previous samples and resample in clean bottles. The computations required to make use of an EWI measurement having two transit rates are more costly and error prone than the minor expense of discarding samples.

\section{Sample identification}

Although most of the information needed on sample bottles is indicated by figure 27, other information may be helpful in the laboratory and in records processing. The field person will need to keep the requirements for such processing in mind so that other explanatory notes can be recorded on the sample or inspection sheets (fig. 45). Such notes, some of which have been mentioned previously, may include:

1. Time--Sometimes operations cross zone boundaries or the use of daylight time may cause confusion.

2. Method or location--Routine vertical, EDI, or EWI cross-section sample.

3. Stationing--Is it one location or sampling vertical, or is the sample an accumulation of several verticals at different locations? 


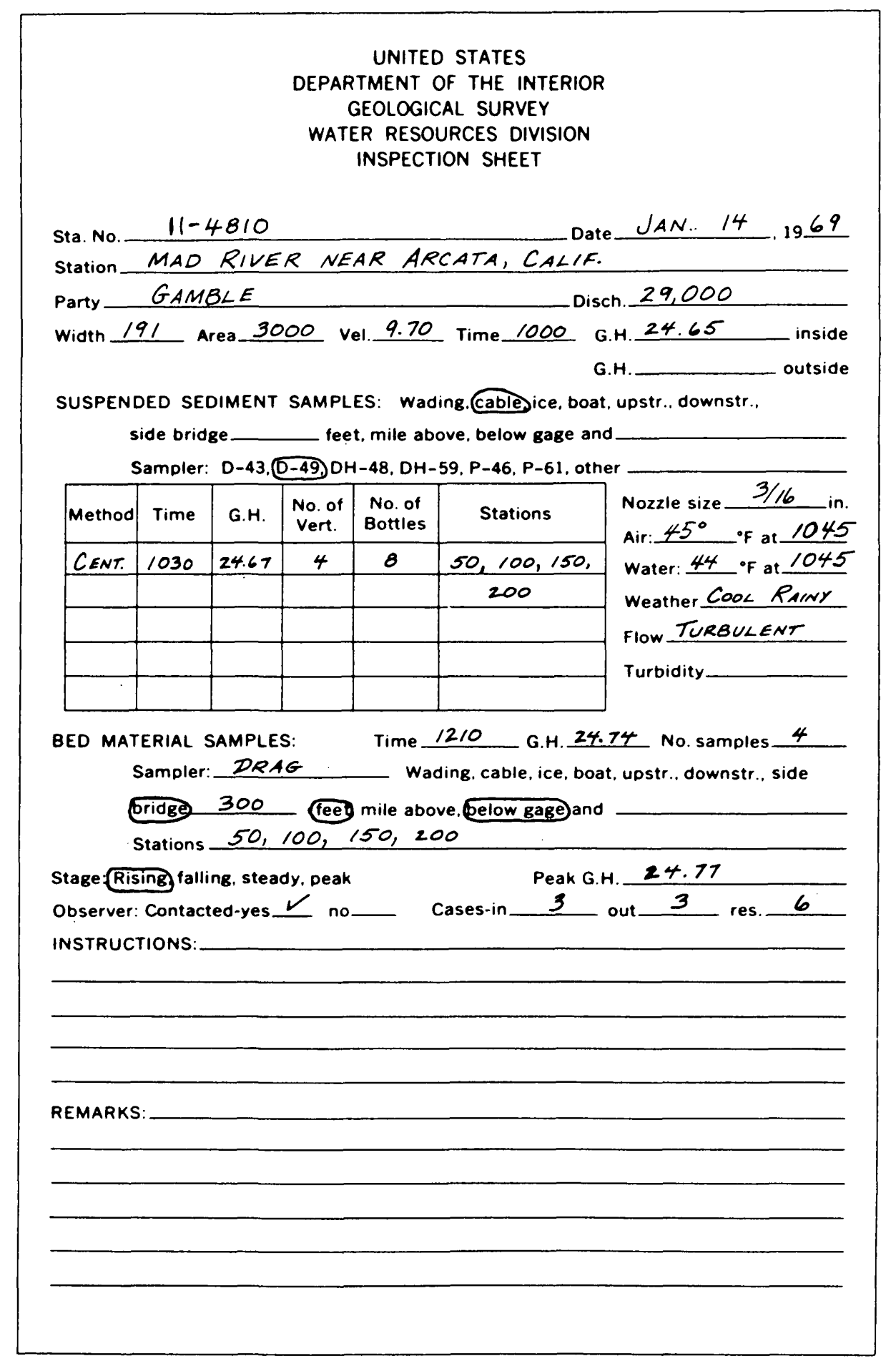

Figure 45.--Example of inspection sheet for use by field person to record the kinds of measurements made and the stream conditions observed during a visit to a sediment-measurement site. 
4. Unusual sample conditions--Consistent sampling of sand at this loca tion, surface sample, or dip sample.

5. Variation of desired technique--Such as change of transit rate, change of sampling vertical location, depth somewhat beyond capacity of instrument, or transit rate may have exceeded $0.4 \mathrm{~V}$.

6. Condition of stream--Such as boils noted on water surface, soft dune bed, swift smooth water, braided stream, sandbar in cross section, or slush ice present.

7. Location in the vertical--If a point sampler is used for one way integration, mention which direction the sampler was moving, the depth dividing the integrated portions, and the total depth.

8. Gage height--Note if the inside or outside gage was used. Note any unusual conditions that may. affect the reading.

9. Collector's name.

\author{
Sediment-Related Data
}

Water temperature

Water-temperature data may seem unimportant in comparison with the sediment data. However, it has a growing list of uses besides the need to help evaluate the sediment-transport characteristics of the stream. The temperature or viscosity of the flow affects sediment suspension and deposition and may affect the roughness of a sand-bed stream.

The best or preferred method to obtain the correct water temperature is to submerge the thermometer while wading some distance out in the stream. The thermometer is held beneath the water for sufficient time (about one-half minute) to allow the temperature of the thermometer to equalize with the water temperature. The stem or the scale of the thermometer is raised out of the water and held so that the etched scale on the stem is at right angles to the line of sight; the temperature should then be read to the nearest one-half degree. The bulb of the thermometer should always remain in the water until after the reading is obtained. The reading of a wet thermometer when exposed to the air may decrease several degrees in a matter of seconds because of evaporation if the air is dry or the wind is blowing. Be certain that the location in the stream where the temperature is taken is not affected by the inflow from a spring or tributary.

When it is not possible to wade out into a stream, the water temperature may be taken from a sample bottle. The thermometer should be inserted first into a bottle from near midstream to let the thermometer adjust to the approximate temperature. Then, immediately after removing the next bottle from the sampler, transfer the thermometer from the previous bottle and allow about 15 seconds for the temperature to stabilize. The thermometer should be read while the bulb of the thermometer is submerged. When removing the thermometer from a bottle, lift the thermometer about 2 inches from the bottom and shake slightly to remove sediment from the case of the thermometer. Most "fresh" waters freeze at zero degree Celsius; therefore, if a negative reading is obtained, an error is indicated. Brackish and brine waters freeze at temperatures somewhat less than zero degree Celsius, depending on the kind and concentration of ions present. 
As with temperature, stream-stage data may seem insignificant but in reality can be very important. The data may be used to construct missing gage-height records for periods of recorder failure or to verify time of sampling. Gage heights may also serve to indicate whether the observer actually obtained a sample at the time and in the manner indicated by available notes.

Remember that the gage height is defined as the water surface elevation referred to some arbitrary gage datum. For the gage height to be considered correct, the observer or field person should always note which gage is read. The streamflow and sediment records are computed on the basis of the inside or recording gage. The observer is usually instructed to read only the outside or reference gage. Because of differences in location and the effect of velocity head, it is not expected that both gages will read the same at a given time, though some relationship may exist between them as the stage changes (Buchanan and Somers, 1968; and Carter and Davidian, 1968). The field person should record all stream-stage information on the inspection sheet (fig. 45).

The outside reference gage may be one of two types. The most common of those exposed continuously to the flowing stream are the staff gage and the slope gage. Under turbulent flow conditions these exposed gages should be read by noting the average of several "high" and "low" readings that may occur within a period of 10 or 15 seconds. It is necessary to make certain that the observer understands that the scale is divided into hundredths of a foot and not feet, inches, and fractions of an inch, and that he understands the divisions of the metric system if that is used. The other type of outside gage is the wire-weight gage or chain gage that is usually attached to a bridge railing. The weight from this type of gage is lowered so that its bottom breaks the water surface about half the time when there are water waves or ripples. For the wire-weight gage, the gage height is read on the scale of the drum at the pointer. For the chain gage, the reading is obtained by reference to the scale provided.

The inside gage height is usually referenced by tape from a float in a stilling well to a pointer. The stilling well is connected hydraulically to the flow of the stream. The inside reference gage should correspond to the gage height being recorded, but, as mentioned previously, it may vary somewhat from the outside gage. If the variance between inside and outside gages is unusually large and the inside gage is lagging the actual gage height of the stream, the intake should be flushed to remove any obstruction caused by sediment accumulation.

The field person should record the inside gage reading at least once each visit to ensure that the gage is working properly. Also, if the observer uses the outside gage, the field person should record the readings from both the outside and the inside gages.

\section{Cold weather Sampling}

Subfreezing temperatures can cause surface ice, frazil ice, and anchor ice to form on or in a stream and create many difficulties with regard to suspended-sediment sampling. The surface ice usually forms at the edges of the stream first and covers the midstream part last. If it is necessary to use surface ice for support to make holes for sampling, extreme caution should be exercised because the strength of such ice can be deceiving, especially if 
weakened during alternating freezing and warm periods. If these auger holes are to be reused later, a cover of wood or some other low-cost insulating material can be used to protect them from refreezing. However, it should be realized that covers of this type may be lost if the weather warms sufficiently for the ice to break up. In some cases (to avoid walking out on the ice or if a warming trend is expected) it may be possible to prevent loss by attaching the cover to a line or to the sampler cable to allow its easy removal. If the sampler cable is used for this purpose, however, the sampler should be secured to or removed from the sampler shelter to avoid its loss by falling through the open bottom of the shelter. Suspended-sediment samplers should never be used to break through seemingly thin ice by dropping the sampler more than 3 or 4 inches since the sampler and nozzle can be damaged by the force of the drop. If the ice will not break by the sheer weight or very gentle drop of the sampler, a hole must be opened by some other means.

If the ice is too thin to safely support a person's weight, it is best not to obtain a sample for 1 or more days because winter samples are generally low in sediment concentration and are therefore most certainly not worth the chance of an accident. When the spring breakup occurs, the large slabs of floating ice can easily cause damage to the sampler, the support equipment, or the operator. Under these conditions a surface sample may be all that can be obtained between cakes of floating ice. Every effort should be made to obtain such a surface sample because the sediment concentration can and usually does change considerably under such conditions.

Frazil ice is composed of the small ice crystals formed at the surface in the turbulent part of the stream. The crystals are formed in a variety of shapes, from slender needles to flat flakes. They do not freeze together because of the swift current but may bunch together to form a soft mass. This kind of ice may partly or completely clog the intake nozzle of the sampler. Sampling may be best accomplished by moving the sampler swiftly through the layer of frazil ice and then using a normal transit rate to sample the relatively ice free region below. Often when such ice obstructs the nozzle, it will remove itself when the sampler is brought out of the water; and the only indication that the sample is in error would be that the quantity of water in the bottle is significantly less than would be expected under normal circumstances.

Anchor ice is formed on the bottom of shallow streams by radiation of heat during the colder nighttime hours. Incoming radiation and the warmer temperatures during the day allow this ice to break loose from the bottom and float to the top to mix with the frazil ice. Sometimes when the nozzle contains frazil or small pieces of anchor ice as the sampler is brought out of the water, a subfreezing air temperature will cause the ice to freeze tight in the nozzle. If the ice freezes tight to the nozzle or if the sample bottle freezes to the sampler casing, it will be necessary to heat the sampler by using the heater in the field vehicle, soaking the sampler in a container of warm water, or heating the nozzle and sampler head with a small propane torch. Care must be taken when employing the torch method because the nozzles and gaskets in the sampler head can be damaged by the open flame. Some of these problems can be avoided by the use of two samplers; while one sampler is thawing, the other can be used to sample.

If the sampler or samplers are kept beneath the heater in the field vehicle while the observer drives to the station or from one station to another, the first one or two verticals can be more easily sampled. The observer should be advised and encouraged to remove the nozzle from the sampler and leave the sampler head in the open position after completing the 
sampling. This will allow the gasket, nozzle, and air vent to dry more completely and may avoid a frozen sampler nozzle or sampler head frozen shut on the next visit.

Aside from the problems with plugged sampler nozzles, a very cold sampler may cause freezing of water between the sample bottle and the inside of the sampler. This problem can be minimized by removing the bottle as quickly as possible from the sampler after the integration is complete; otherwise it may be necessary to heat the sampler as described above. It should also be obvious that samples in glass bottles must be protected from freezing after the measurement and during transport to the laboratory. Freezing itself does not harm a sample for sediment analysis, but a broken bottle will obviously result in loss of the sample.

If an extensive sampling program is to be carried out during the winter months in areas of extreme cold, it is advisable for the investigator to obtain DH-75 and D-77 samplers. These samplers are designed to be used in freezing conditions as previously discussed. Several sample bottles and nozzle and cap assemblies can be taken to the site where they can be changed easily if nozzle or air exhaust freeze-ups occur during sampling.

\section{Bed-Material Sampling}

Data on the size of material making up the streambed (across the entire channel, including floodplains) are essential for the study of the long range changes in channel conditions and for computations of unmeasured or total load. Research studies also require information on bed material, but the purpose for such information is specialized relative to the study for which it is collected.

\section{Materials Finer than Medium Gravel}

The selection of a suitable bed-material sampler is primarily.dependent on stream depth and velocity. When a stream can be waded, the most practical of the standard samplers is the $\mathrm{BMH}-53$ or $\mathrm{BMH}-80$. Use of these samplers can be extended somewhat to about 4 feet of depth by use of a boat.

In use the BMH-53 is placed in a vertical position on the streambed with the piston extended to the open end of the cylinder. The cylinder is then pushed a full 8 inches into the bed while the piston is held at the bed surface. Complete filling of the cylinder will help ensure a minimum of disturbance of the top 1 or 2 inches when the sampler is raised through the flow. When coarse sand or gravel material is being sampled, it is often necessary to pull on the piston rod while pushing on the cylinder. By pulling on the piston, a partial vacuum is created above the sample, which helps draw the sample into the cylinder. The sampler is then withdrawn from the bed and held in an inclined position above the water with the cylinder end highest. For most purposes only the upper inch of material nearest the surface of the streambed is desired or needed in an analysis. This is obtained by pushing on the piston while the sampler is still inclined until only 1 inch of material remains in the tube. Any excess material is removed by smoothing off the end of the cylinder with a spatula or a straight pencil. The material left in the sampler is ejected into a container (usually a paper or plastic carton). An experienced field person can composite, into just a few cartons, samples or observations from the entire cross section, as indicated by differences in flow conditions and differences in bed-material size and composition. The 
inexperienced field person would do well to use a separate container for each vertical. Before storing the sampler, it should be rinsed by stroking the piston a few times in the stream to remove sediment particles from the cylinder and piston seal.

The BMH-80 is used in a manner similar to that of the BMH-53. The sampler is extended to the streambed with the bucket in the open position. After the sampler contacts the bed material, the field person should keep a firm downward pressure on the sampler while closing the sample bucket, thus trapping a shallow sample of the streambed. This sampling procedure should be repeated until the streambed has been representatively sampled.

If the stream is too deep or swift for the BMH-53 or BMH-80, the BMH-60 or the BM-54 can be used. The $30-1 \mathrm{~b}$ BMH-60 is easiest to use when stream velocities are under 2 or $3 \mathrm{ft} / \mathrm{s}$ and depths are less than about 10 feet. To use the BMH-60, suspend the entire weight of the sampler by the hanger rod and cock the bucket in the open position with the allen wrench provided. The energy thus imparted to the spring and the sharp edge of the bucket make it obvious that one must keep hands away from the bucket opening at all times. If necessary, the safety yoke may be fastened around the hanger bar while opening and cocking the bucket. After the safety yoke is removed and fastened to the tail, the sampler can then be lowered by hand or by cable and reel to the surface of the streambed. Any jerking motions made while lowering the sampler that would cause the cable to slack may release the catch and allow the bucket to close prematurely. This can happen if the water surface is struck too hard. After the cocked sampler touches the streambed and tension is released on the line, the sampler should be lifted slowly from the bed so the bucket will scoop a sample.

To remove the sample from the bucket, a carton or container is positioned under the sampler and the bucket is opened with the allen wrench. The sampler need not be held by the hanger bar during sample removal unless considerable material is clinging to the flat plate within the bucket cavity. If removal of such material is required, the bucket should be cocked in the open position and the sample brushed into the container with a stick or small brush. When moving the sampler between verticals and when storing it in the vehicle, the bucket should be in the closed position to avoid an accidental closing and to reduce the tension on the spring. If the bucket is closed for transport as suggested, a stick, a piece of tire, or similar material should be used to cushion the force of the bucket when it is closed because the closing force is sometimes great enough to break welded joints in the mechanism (John Skinner, F.I.S.P., written commun., 1985).

The 100-1b BM-54 is needed for velocities that are above 2 or $3 \mathrm{ft} / \mathrm{s}$ and depths that are greater than about 10 feet. The BM-54 sampling action, described previously, is similar to the BMH-60 except that the bucket opens front to back. It is used only with a reel-and-cable suspension and is rather awkward to handle when removing the sample. The techniques for taking a sample with the BM-54 are essentially the same as for the BMH-60. One important difference in operation is the use of a safety bar on the BM-54 to hold the bucket in an open position--instead of the safety yoke as on the BMH-60. As noted earlier, the sampler should be stored with the bucket in a closed position; and, if extended storage is anticipated, the tension on the spring should be further reduced.

When extremely high velocities are encountered and samples are unobtainable with the BM-54, there may be another alternative. A C-type weight placed on the hanger bar above the BM-54 can increase its usefulness. If additional 
weights are required with the BM-54, extreme care should be taken to avoid bending and possibly breaking the hanger bar between the sampler and the Ctype weight.

For sampling conditions requiring a sampler larger than the BM-54, there is no available equipment at this time. However, personnel of F.I.S.P. are working to develop a heavy bed-material sampler (the BM-84, which weighs about $160 \mathrm{lb})$. The body of a P-61 point-integration sampler is used to provide a large mass. The streamlined body configuration is fitted with a spring driven sample scoop that is activated by a solenoid system similar to that used on point samplers. Otherwise the sampler is similar to, and performs the same function as, the BM-54. The design is an attempt to cope with bed-material sampling problems encountered in the vicinity of Mount St. Helens volcano (John Skinner, F.I.S.P., oral commun., 1984). The weight of this configuration is increased by filling void space within the sampler body to increase the cross-sectioned density of the sampler, thus increasing its stability in deep, high-velocity conditions.

As previously discussed, other sampling equipment is available commercially--for example, the ponar sampler and core samplers such as the vibracore unit and gravity corer. These samplers can be very useful; however, careful planning of the proposed sampling project and analytical methods is essential to obtaining a representative sample and reliable data.

\section{Materials Coarser than Medium Gravel}

Gravels in the 2- to $16-\mathrm{mm}$ range can be analyzed by mechanical dry sieving; in order to obtain a representative particle-size distribution, the size of the sample to be collected must be increased with particle size. Large sediment sizes $(>16 \mathrm{~mm})$ are difficult both to collect and to analyze. The method now used for size determination of these very large particles involves a "pebble count," in which at least 100 pebbles from a wadable streambed are manually collected and measured. A fixed grid pattern locating the sampling points can be paced, outlined by surveys, or designated by small floats. At the intersections of the fixed grid pattern, a particle is retrieved and a measurement is made of the long, intermediate, or short diameters, or all three. The measurements are tabulated as to size interval and the percentage of the total of each interval is then determined (Wolman, 1954).

Because the pebble-count method entails the measurement of the dimensions of randomly selected particles in the field, it is laborious and usually limits the number of particles counted. Too often this results in an inadequate sample of the population.

Another method for analyzing coarse particles involves the use of an instrument known as the Zeiss Particle Size Analyzer (Ritter and Helley, 1968). For the zeiss technique, a photograph of the streambed is made during low flow with a 35-mm camera supported by a tripod about 6 feet above the streambed--the height depends on the size of the bed material. A reference scale, such as a steel tape or surveyor's rod, must appear near the center of the photograph to provide a size reference.

In the laboratory particle diameters are registered cumulatively or individually on exponential or linear scales of size ranges (Guy, 1969). After the data are tabulated, the sizes registered on the counter of the particle-size analyzer must be multiplied by the reduction factor of the photograph, which is calculated from the reference scale in the photograph. 
In nonwadable streams a pipe dredge is useful in sampling these large particles. However, this method entails the use of equipment capable of handling extremely heavy loads and requires special attention to safety during operation.

\section{Location and Number of Sampling Verticals}

Bed-material samples are often collected in conjunction with a discharge measurement and (or) a set of suspended-sediment samples. If the discharge measurement and (or) the suspended samples are taken first, the bed-material samples should be collected at the same stations but not necessarily from the same number of stations. By taking them at the same stationing points, any change in bed material or radical change in discharge across the stream that would affect the sediment-discharge computations can be accounted for by subdividing the stream cross section at one or between two of the common verticals.

To avoid collection of bed-material samples from an excessively disturbed streambed, it is best to obtain the bed-material samples prior to making other measurements, especially in wadable streams. Also, by taking the bed material first, radical changes across the section in bed-material size and water discharge can be used as a basis for choosing desirable verticals for other measurements.

Most results from bed-material samples will not be noticeably affected, but it should be remembered that the sample taken with the BMH-53 or other core sampler is different from that taken with the BMH-60, BMH-80; and the BM-54. The cross section of the BMH-53 or other core sampler is constant with depth so that each increment of sample with depth is equally represented by volume. The curved buckets of the BMH-80, BMH-60, and BM-54 do not sample equal volumes of material with depth; instead, the bottom half inch of the 2-inch-deep bucket contains only 15 percent of the total sample, whereas the upper half inch contains 33 percent of the sample.

The number and location of bed-material samples required at a cross section must be adequate to provide a representative statistical population. This population should include samples collected from the entire cross section--consisting of the floodplain and the active stream channel. To obtain this population the logical procedure is to use the results from a rather detailed set of 10 to 20 uniformly spaced bed-material samples taken from the entire cross section.

When spacing these sampling verticals, the field person must not ignore practical considerations, such as the need to avoid sample collection from slack water areas behind sand bars or bridge piers. If sand bars or islands split the flow within the cross section, the active channel should be treated as two or more streams allowing for samples to be collected across the sand bars and from the floodplain areas of the islands.

\section{Sample Inspection and Labeling}

As samples are obtained across the stream, the field person should visually check and compare each sample with the previous samples to see if the material varies considerably in size from one location to the next. Samples of different sizes and (or) weight should not be composited. If a given sample does contain considerable coarser or finer material, another sample 
should be obtained about a foot from the original location. If after two or three tries in the vicinity of the the first sample no appreciable difference is noted, the first sample should be retained. Small deposits of material that is coarser or finer than most of the bed material are not considered representative of the bed-material size for the stream cross section.

Proper labeling of bed-material samples is not only necessary for future identification but also provides important information useful in the laboratory analysis and the preparation of records. Information desired on each bed-material sample carton should include:

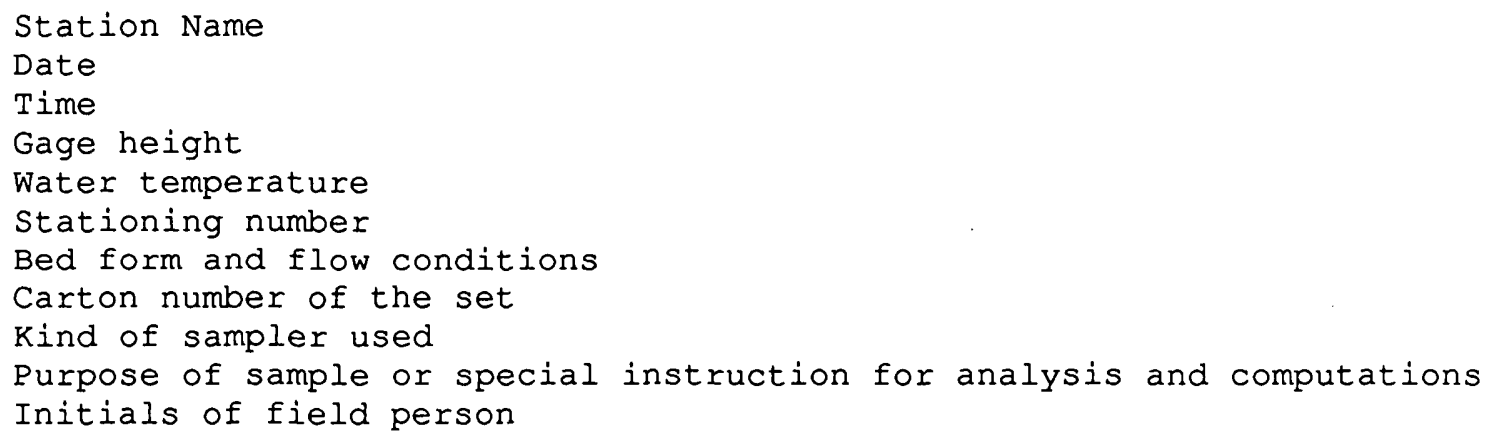

Bedload Sampling. Technique

The sediment moving in the unsampled zone (fig. 1) is comprised of suspended sediment and bedload. Bedload is the sediment that moves by sliding, rolling, or bouncing along on or within a few grain diameters of the streambed.

Although many investigations, especially those of William Emmett and David Hubbell of the Geological Survey, have provided extensive knowledge in the areas of how bedload moves in a channel and how pressure-differential bedload samplers operate, a great deal more work in these areas is needed. The following paragraph, taken from Hubbell (1964, p. 2) is still appropriate today (1986):

In the past, attempts have been made to determine the bedload discharge in three general ways: by direct measurement with some type of apparatus, by definition of physical relations from which the bedload could be estimated, and by quantitative measurements of the results of some sedimentation process such as erosion or deposition. Unfortunately, direct-measuring apparatus have been useful for only a very limited range of sediment and hydraulic conditions; the definition of physical relations has not been complete enough to estimate precisely the bedload discharge; and the quantitative measurements have supplied information only on the characteristics of the reach that was studied. As a result, no single apparatus or procedure, whether theoretical or empirical, has been universally accepted as completely adequate for the determination of bedload discharge over the wide range of sediment and hydraulic conditions in nature.

Despite these difficulties, the hydrologist is often called upon to provide estimates of bedload transport from measurements. The purpose of this section is not only to outline instructions governing the collection of bedload samples, but also to present a discussion of variations in bedload 
discharge, problems involved in collecting samples, and considerations in the design and development of a sampling program to measure bedload movement.

Bedload discharge can be extremely variable. Variations can occur both spatially and temporally during steady-flow conditions, as well as with changes in stream discharge. In order to collect a sample which represents the mean bedload discharge, all variations must be taken into account.

Even for constant flow conditions, the temporal variation of bedload transport rates at a given point in a cross section often is quite large. When dunes are present, bedload discharges are zero, or near zero, in the troughs, increase progressively along the upstream side of the dune, and are maximum at the crest. Even in streams with gravel beds, the bedload appears to move in waves and pulses. Recently these variations have been measured in the laboratory flume by Hubbell and others (1981) and in the field by Emmett (1975) and Carey (1985; fig. 46).

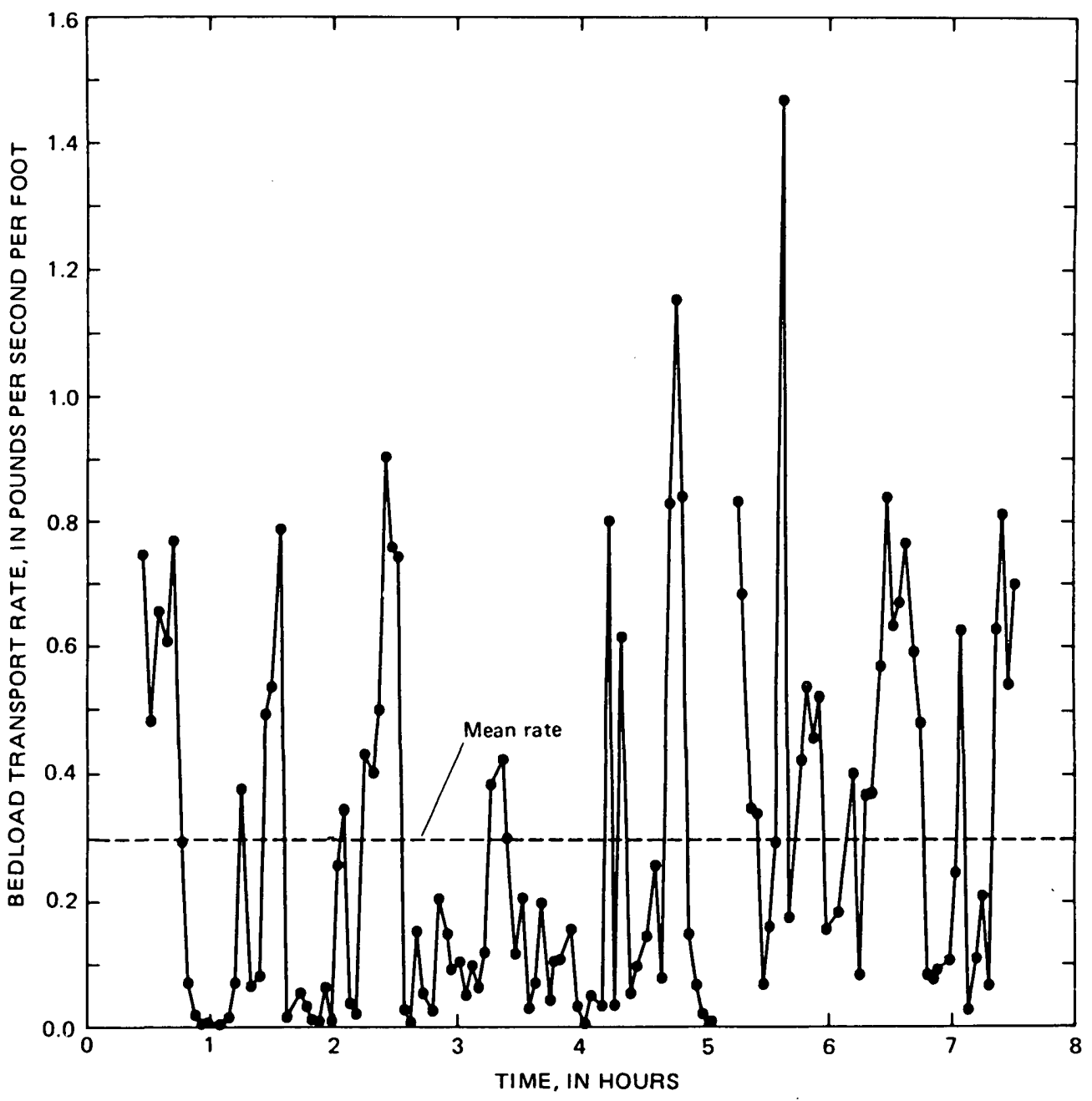

Figure 46.--Temporal variation of bedload transport rates for 120 consecutive bedload samples from a stream with constant water discharge (Carey, 1985). 
Temporal variation in sampled bedload rates collected at steady flow conditions at a single vertical are primarily dependent upon the ratio of sampling time to the time it takes one dune, cycle, or slug to pass by the sampling point. If the sampling time were equal to the cycle period or several times greater than the cycle period, the temporal variation at a single sampling point would be relatively small. However, as the sample time becomes short with respect to the cycle period, the temporal variation increases and can become large.

Einstein (1937) and Hamamori (1962) both developed theoretical frequency distributions to describe the temporal distribution of bedload transport rates at a vertical. Einstein based his distribution on the assumption that bedload particles move in a random series of alternate steps, lengths, and rest periods, with the particles generally resting a much longer period of time than they are moving. Hamamori's distribution was derived to define the temporal variation when ripples and dunes are present on the bed. Figure 47 shows a comparison of Einstein's and Hamamori's distributions. Einstein's $T$ is defined as the nondimensional sampling time measured in terms of the average rest period. For Einstein's $T=2$ (sample time equals the length of two average rest periods), the distributions are nearly identical. As $T$ increases (sampling time increases), the two theoretical distributions depart from one another and Einstein's distribution indicates reduced variability.

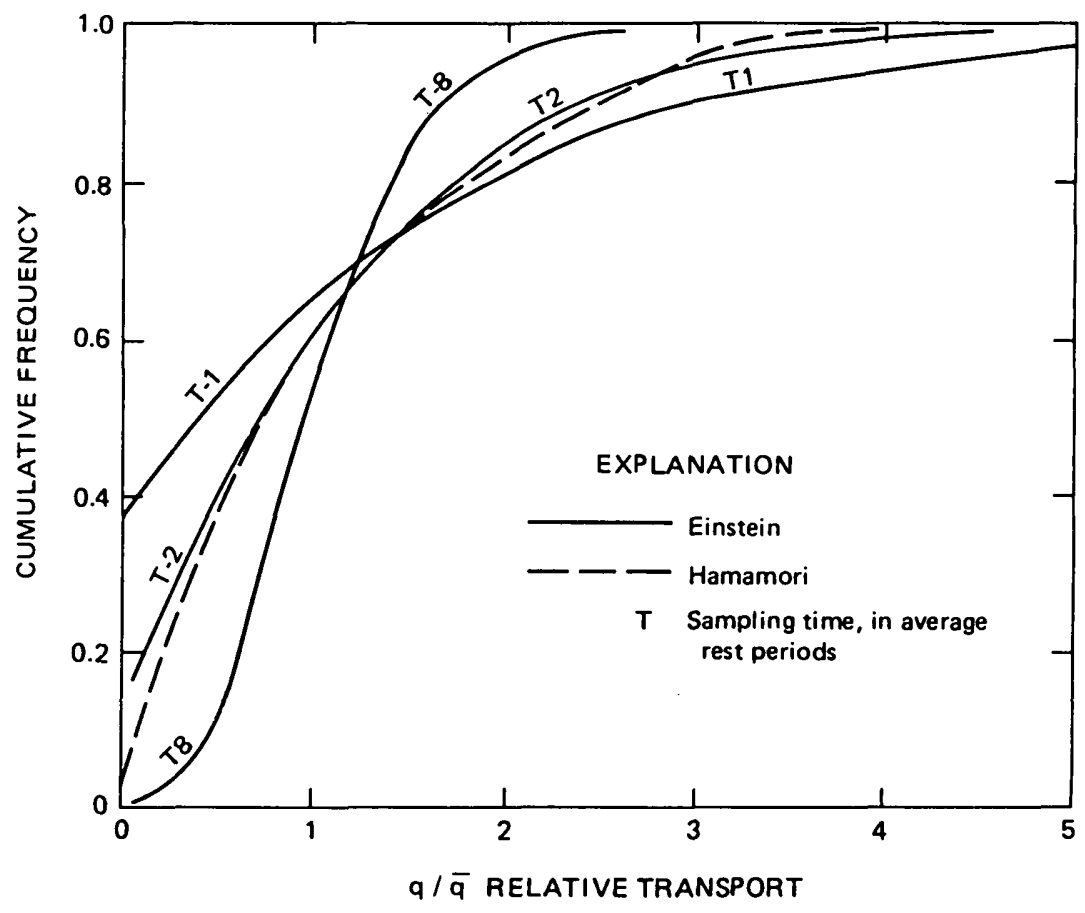

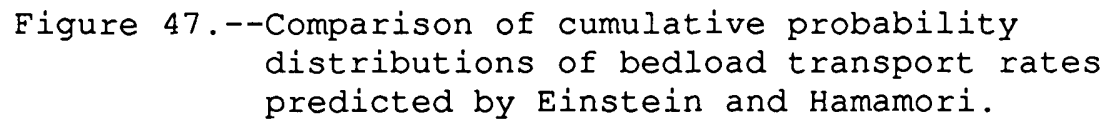

The temporal variations in bedload transport rates measured by Carey (1985) at a single vertical in a stream in Tennessee are shown in figure 46. The cumulative probability distribution of bedload transport rates measured by 
Carey fit the theoretical distribution developed by Hamamori. As indicated in the figure, even for a constant flow condition, the rate determined from a sample taken from a single vertical at a point in time may differ considerably from the mean bedload transport rate at that vertical. This extreme temporal variability in bedload transport rates has been known since at least 1931 (Hubbell, 1964). Many samples may be needed to accurately estimate the mean rate.

The spatial or cross-channel variation in bedload transport rate is also usually significant. Bedload transport rates often vary from zero or a small value near banks to larger values toward midstream, such as observed on the Snake River in Idaho (Emmett and Seitz, 1974), the East Fork River in Wyoming (Leopold and Emmett, 1977), and the Eel River and Redwood Creek in California (Glysson, oral commun., 1987). The mean cross-channel distribution of transport rate may vary uniformly (fig. 48a), may be uniformly consistent (fig. 48b), may be erratic with tongues and stringers (fig. 48c), or may be an unpredictable combination of varying tendencies (fig. 48d). Each river is likely to have a unique combination; adjacent reaches of the same river may have different lateral distributions, and these distributions are likely to change with changing flow conditions (stages). There is little proven basis for predicting spatial variability.

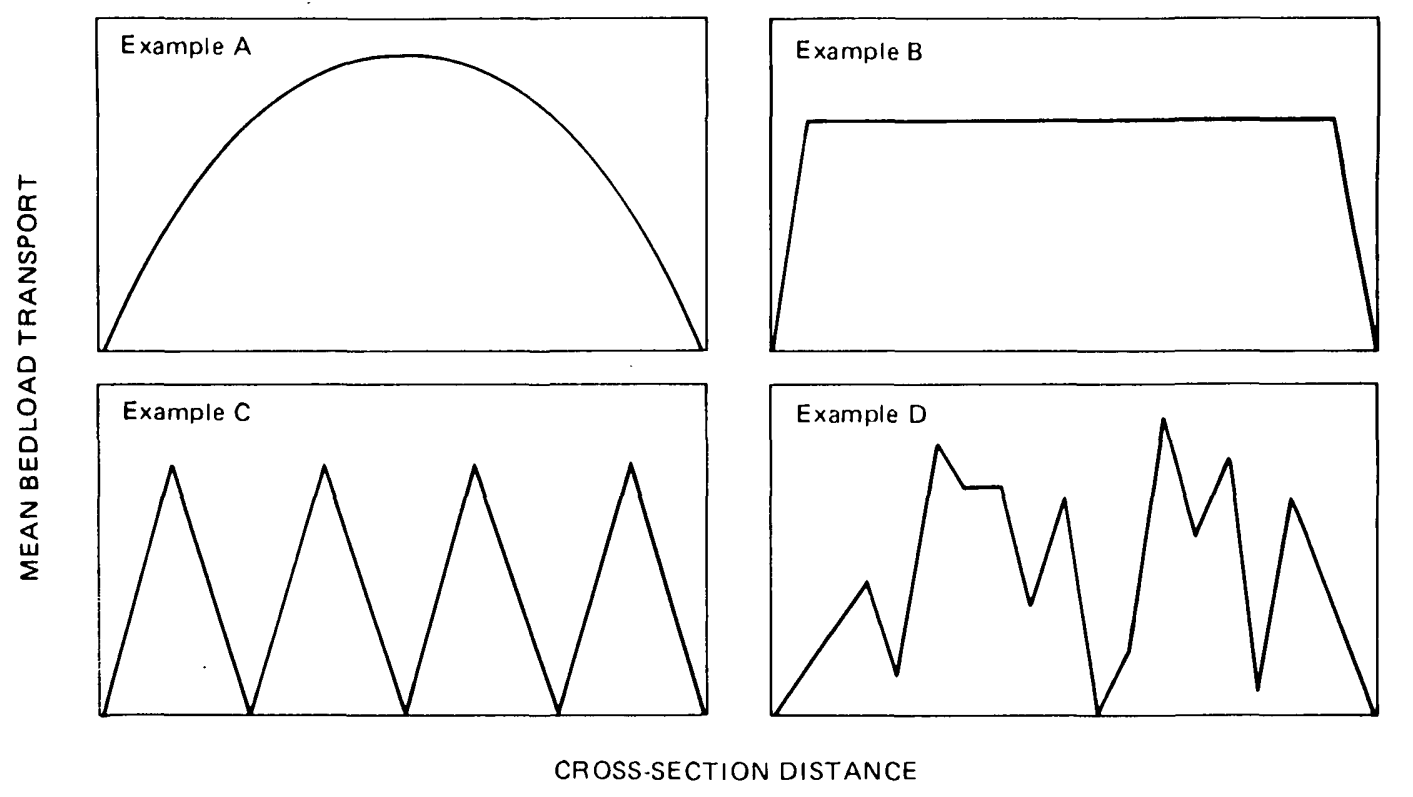

Figure 48.--Examples of possible distribution of mean bedload
transport rates in a cross section.

The temporal and spatial variations in transport rates of bedload discharge that occur under steady flow conditions are amplified when the stage changes rapidly. Because of these temporal and spatial variations, many samples have to be collected at many verticals in the cross section to assure an accurate estimate of the mean bedload transport rate. The samples also would have to be collected over a short enough period of time to avoid any change in transport rates due to changing stage. In most field sampling programs, the number of samples collected must represent a comprise between accuracy and economic or physical feasibility. 
Another problem encountered in bedload sampling is that of collecting a representative sample. Ideally, the sampler should (1) trap, during the sampling period, all bedload particles that would normally have passed through the width occupied by the sampler, and (2) reject all particles that normally would not have passed through the width during the same period. The degree to which this is accomplished is termed the "sampling efficiency," which is defined as the ratio of the mass of bedload collected to mass of bedload that would have passed through the sampler width in the same time period had the sampler not been there (Hubbell, 1964). For perfect sampling the sampling efficiency should be 1.0 (or 100 percent) for all sizes of bedload particles in transport at the sampling point during the sampling period. To collect a representative sample, the sampler must have a defined sampling efficiency over the full range of transport rates and particle sizes sampled.

Currently, the most commonly used bedload sampler is the Helley-Smith sampler. More than 3,000 of these samplers have been placed in use since the model was introduced in the early 1970's. It should be understood that the Helley-Smith is not a true bedload sampler because it collects some particles moving in suspension. As previously noted, bedload moves on or very near the streambed. Depending on the size of the unsampled zone, the Helley-Smith has the potential to collect a sample from the entire unsampled zone. Even if the Helley-Smith sampler has a sampling efficiency of 1.0, the total sediment discharge cannot necessarily be calculated by simply summing the measured suspended-sediment discharge and the measured bedload discharge. This is due to the fact that the measured suspended-sediment discharge is computed in such a way that it inherently accounts for some of the suspended-sediment discharge in the unsampled zone.

Hubbell (1964) gives the following formula for determining the total sediment discharge of a given size range from the measured suspended-sediment discharge and the discharge measured with any type of bedload apparatus (see fig. 49):

$$
T=\frac{D}{e}+Q_{S m}+Q_{u s m_{1}}-F Q_{S m}+(1-E / e) Q_{t s 2}
$$

where $T$ = total sediment discharge of the size range.

$$
\begin{aligned}
D= & \text { discharge of the size range as measured with the bedload apparatus. } \\
& \text { If the apparatus measures more than the bedload discharge, as does } \\
& \text { the Helley-Smith, } D \text { includes some of the suspended-sediment } \\
& \text { discharge. } \\
e= & \text { efficiency of the bedload apparatus in measuring bedload discharge } \\
& \text { of the size range. } \\
Q_{s m}= & \text { measured suspended-sediment discharge of the size range } \\
& \left(Q_{s m}=Q_{w t} \cdot C_{m} \cdot k\right) . \\
Q_{u s m 1}= & \text { unmeasured suspended-sediment discharge of the size range in the } \\
& \text { zone between the lowest point measured by the suspended-sediment } \\
& \text { sampler and the highest point measured by the bedload apparatus. } \\
& \text { It equals the product of the water discharge in this zone and the } \\
& \text { difference between the velocity-weighted concentration in this zone } \\
& \text { and in the sampled zone (Qusm } \left.=Q_{w u m} \cdot C_{u s m} \cdot k\right) \text {. }
\end{aligned}
$$



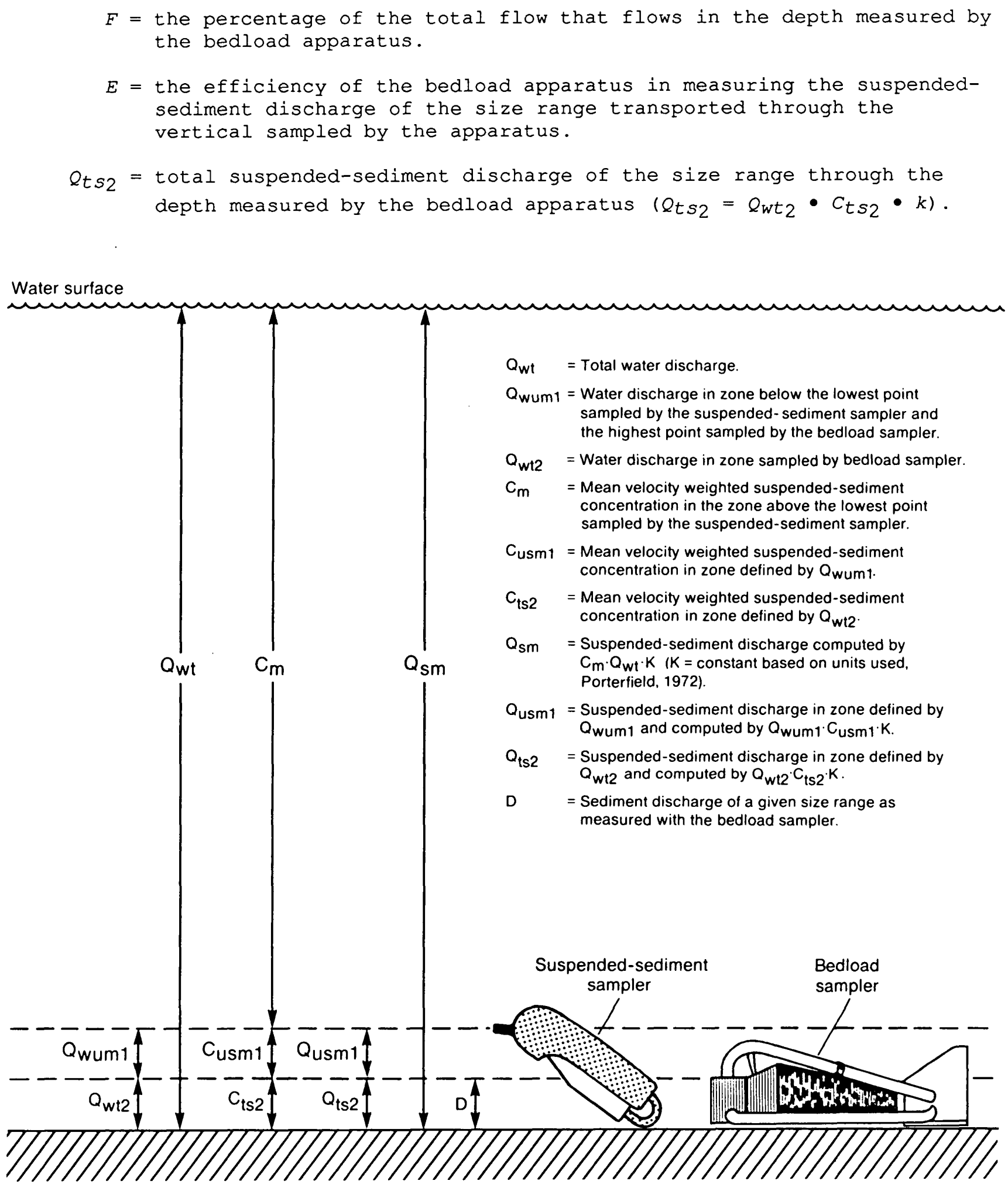

Figure 49.--Zones sampled by suspended-sediment and bedload samplers and the unmeasured zone. 
A more detailed explanation of how to compute the total sediment from measured suspended-sediment discharge and bedload discharge measured with a bedload measuring apparatus is given by Hubbell (1964, p. 7-9). If the efficiency of the bedload sampler is 100 percent for both bedload and suspended-sediment load and if the bedload sampler samples the entire unsampled zone, then the above equation is much simpler. Using these assumptions and the above equation, Carey developed figure 50 that shows the percent error involved in computing total sediment discharge for a particular size range by summing the measured suspended-sediment discharge $\left(Q_{s m}\right)$ and the bedload discharge measured with a Helley-Smith sampler (D) for that particular size range.

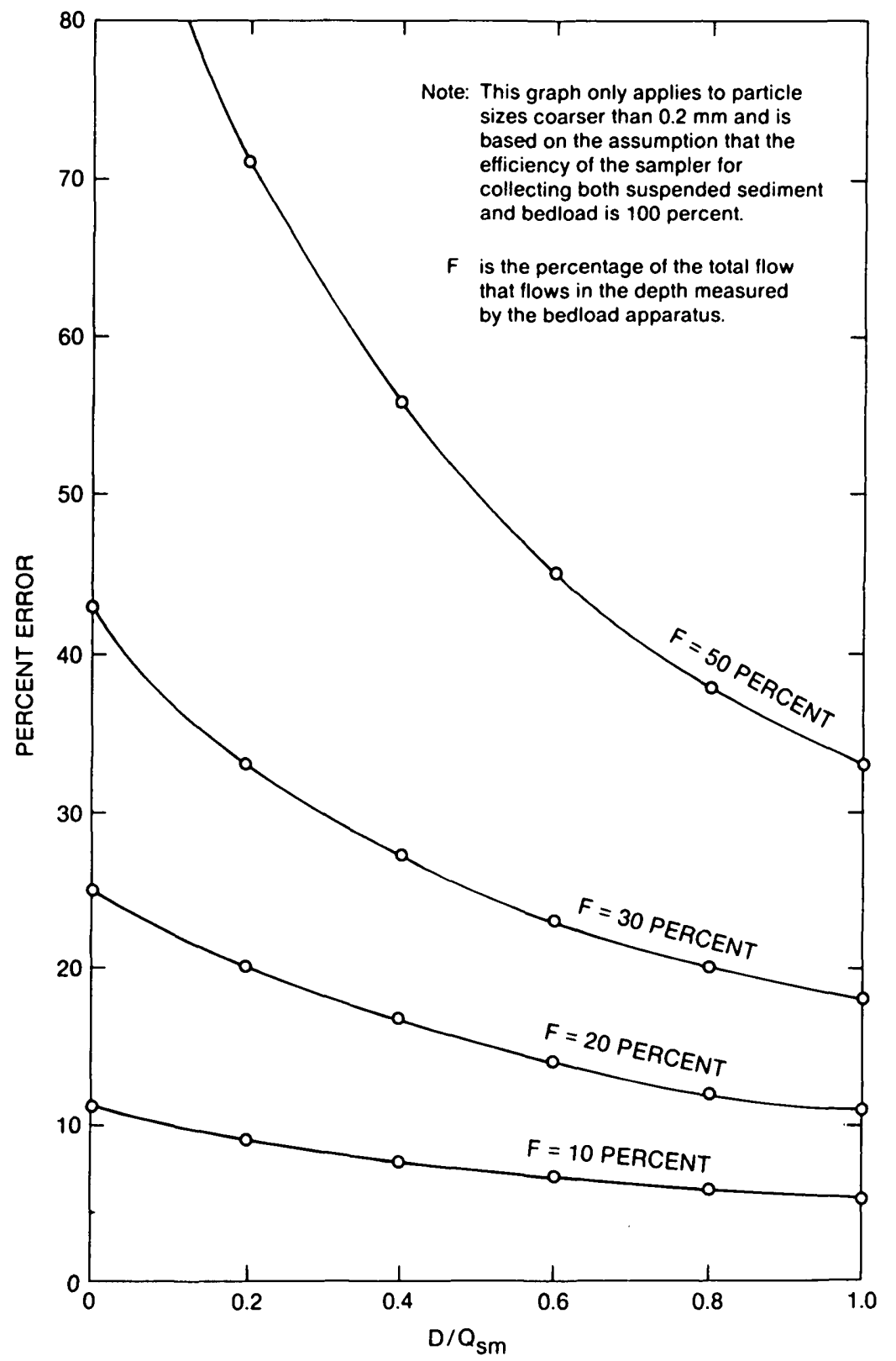

Figure 50.--Percent error due to computing total sediment discharge of a size range by summing measured suspended-sediment discharge $\left(Q_{S m}\right)$ and discharge measured with a Helley-Smith sampler (D). 
In order to make bedload sampling practical, methods must be used that minimize the number of samples required to obtain a reasonable estimate of the mean cross-sectional bedload discharge. Field experience has shown that the collection of about 40 individual bedload transport rate measurements per cross-section sample is, in most cases, practical and economically feasible (Emmett, 1980a). The following general methods can be used to collect the samples.

1. Starting at one bank and proceeding to the other, collect one sample per vertical at 20 evenly spaced verticals in the cross section, return to the bank, and repeat the process. We will refer to this. method as the single equal width increment (SEWI) method (fig. 51). The time the sampler is left on the bottom should be equal for all verticals in a given cross section. The time the sampler is left $O$. the bottom need not be the same for both cross sections collected. This procedure was first introduced by Emmett (1980a) and is widely? used. The samples are collected at the midpoint of the evenly . spaced inckiements.

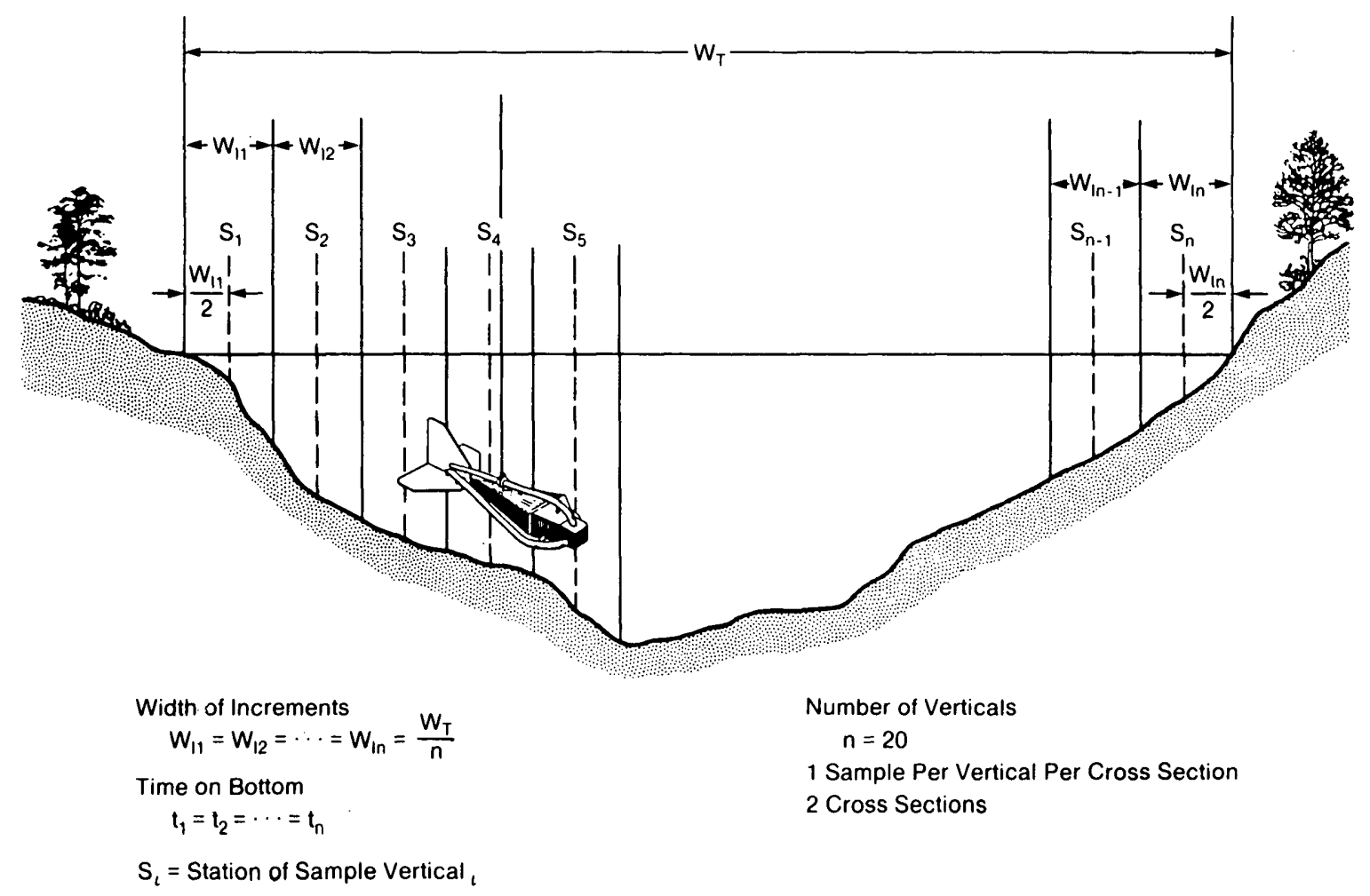

Figure 51.--Single equal width increment (SEWI) bedload sampling method.

2. Starting at one bank and proceeding to the other, collect one sample at 4 to 5 evenly spaced verticals, return to the starting bank, and repeat the process 8 to 10 times until a total of 40 samples are collected. We will refer to this method as the multiple equal width increment (MEWI) method (fig. 52). If the sample collected at each vertical is bagged separately, the time the sampler is left on the 
bottom need not be equal at all verticals. If samples collected in a cross section are to be composited, sample times at each vertical in the cross section must be equal. As in the SEWI method, samples are collected at the midpoint of the evenly spaced increments.

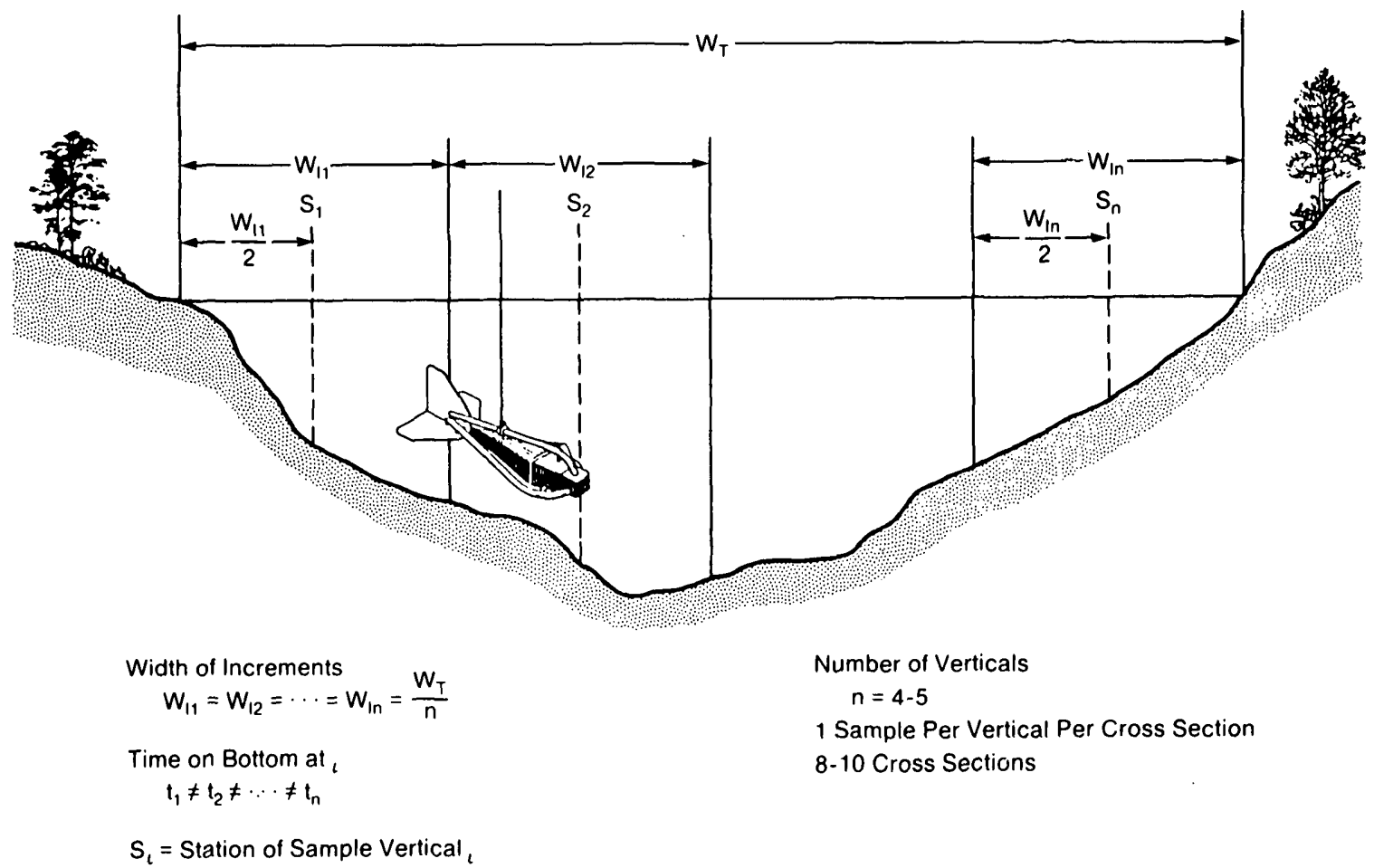

Figure 52.--Multiple equal width increment (MEWI) bedload sampling method.

3. Starting at one bank and proceeding to the other, collect one sample from 4 to 10 unevenly spaced verticals, return to the starting bank, and repeat the processes until a total of 40 samples are collected. We will refer to this method as the unequal widths increment (UWI) method (fig. 53). This method would require some prior knowledge of the depths and velocities across the section. The selection of where to place the verticals in the UWI method depends, to a certain extent, on which method is to be used to calculate the bedload discharge. If the midsection method is used (see calculations of Bedload Discharge Measurements section for explanation of calculation methods), the sampling verticals should be spaced unevenly in an attempt to delineate equal portions of the cross-section bedload discharge. To the extent possible, samples should be collected midway between breaks in the lateral bed slope and closer together in segments of high velocity and changing lateral bed slope. If the mean-section method is used to calculate the bedload discharge, sample verticals should be placed at the break points in the lateral cross-sectional distribution curve of mean bedload transport rate where the rate changes from one "trend" to another (that is, breakin slope). At most sections the lateral distribution in mean rates, once defined, can be related to velocity and lateral bed topography. 


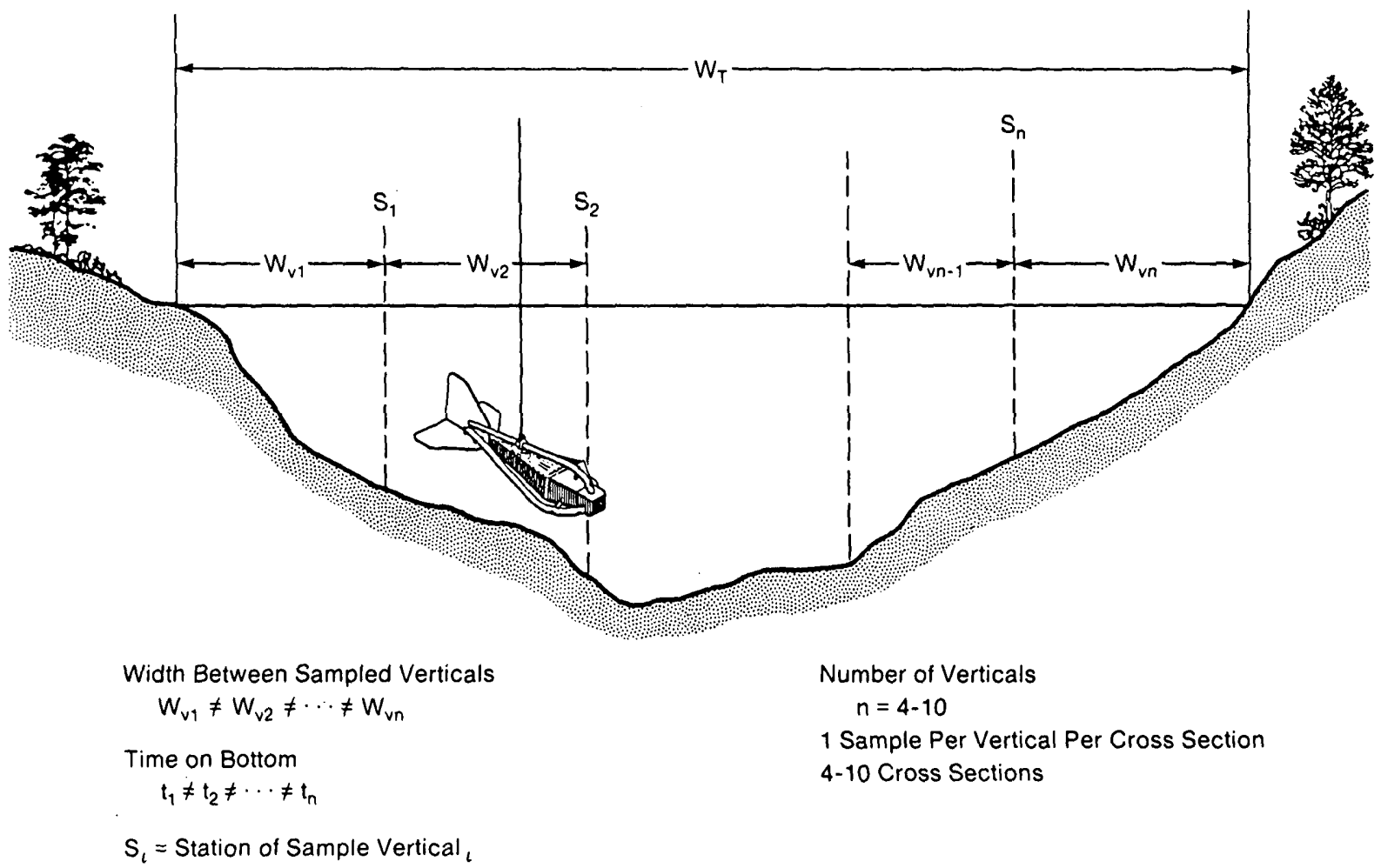

Eigure 53.--Unequal width increment (UWI) bedload sampling method.

To quantify the approximate magnitude of sampling errors that could result from various sampling situations, Hubbell and Stevens (1986) developed a bedload transport simulation model. They used Hamamori's (1962) distribution to simulate temporal variations at the equally spaced sampling verticals and assumed that the sampler used had a 100-percent sampling efficiency. The results of test runs using two different spatial variations are shown in figure 54. In the first case the lateral distribution of mean bedload transport rates is fairly uniform across the cross section, and in the second case it is skewed. If these results were used to estimate maximum possible error for using the SEWI and MEWI methods, in the first case the MEWI method would give a lower maximum possible error ( 35 percent) than would the SEWI method ( 50 percent). In the second case, however, using the SEWI method would result in a maximum error of 80 percent and using the MEWI method would result in a maximum error of 120 percent. The maximum probable error with the UWI method cannot be evaluated from figure 54.

One can see from the previous discussion that no one method works best in all situations and that no one standard sampling protocol can be used at all stations. This should come as no surprise. There are two acceptable methods for collecting suspended-sediment samples (EWI and EDI). Both work equally as well as the other, but are better suited to different stream conditions and cross-sectional sediment distributions. Likewise, a unique sampling protocol must be derived for each site at which bedload discharge data is to be collected. Probably the best way to start sampling at a site is to do multiple sets of complete SEWI and MEWI or UWI measurements each time the site is visited and over as many flow ranges as possible. Unfortunately, manpower 

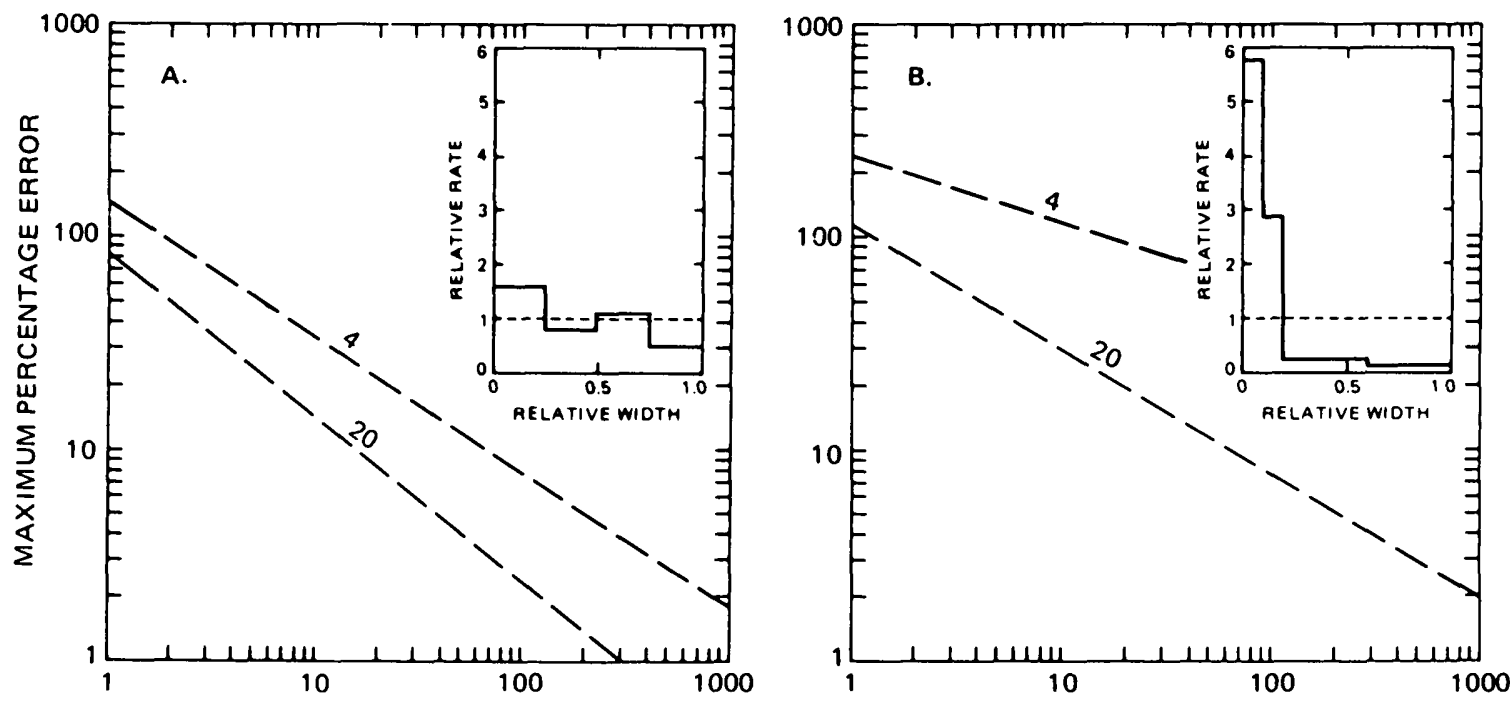

NUMBER OF TRAVERSES

Figure 54.--Variation in maximum probable errors with number of sampling traverses at 20 and 4 equally spaced verticals at cross sections with different bedload transport rates (99-percent confidence level). Modified from Hubbell and Stevens, 1986.

and budget restrictions, as well as hydrologic conditions, may prevent multiple or even single SEWI, MEWI, or UWI type cross-sectional measurements. If it is not possible or feasible to collect full SEWI, MEWI, and (or) UWI type samples, the approach listed below can be used as a minimum protocol to follow when first starting to collect bedload data at a site. Caution should be used, however, because the modified SEWI, MEWI, or UWI methods will not supply as much information as would the complete method. Therefore, more sets of samples may be needed to acquire sufficient knowledge of the cross section to design an efficient sampling protocol. (Note: The SEWI method helps define cross-sectional variations in bedload transport rates whereas the MEWI and UWI methods are more effective in defining temporal variations at individual verticals.)

1. Using the SEWI method, collect samples at approximately 20 equally spaced verticals in the cross section. The spacing and location of the verticals should be determined by the sampling procedure used in the EWI method. For very wide sections where large variations in bedload rates are suspected, sampling stations should not be spaced more than 50 feet apart. For narrow cross sections, sampling stations need not be closer than 1 foot apart.

2. Lower the sampler to the streambed and use a stopwatch to measure the time interval during which the sampler is on the streambed. The sampling time interval should be the same for each vertical sampled in the cross section. The time required to collect a proper sample can vary from 5 seconds or less to several hours or more. Generally a sampling time that does not exceed 60 seconds is preferred. Because of the temporal variations in bedload transport rates, there is no easy way to determine the appropriate sampling time. Several test samples, as many as 10 or more collected sequentially at a vertical with a suspected high transport rate, may be needed in 
order to estimate the proper sampling-time interval to be used. The sample time should be short enough to allow for the collection of a sample from the section with the highest transport rate, without filling the sample bag more than about 40 percent full. The sample bag may be filled to 40 percent full with sediment coarser than the mesh size of the bag without reducing the hydraulic efficiency of the sampler (Druffel and others, 1976). Sediment that is approxi mately equal to the mesh size may clog the bag and cause a change in the sampling efficiency of the sampler.

3. One sample should be collected at each vertical, starting at one bank and proceeding to the other. It is recommended that during this initial data gathering stage, a minimum of one transect using the SEWI method be used. The samples should be placed in separate bags for individual analysis and labeled with the vertical's station number. They may be composited into one or several sample bags for a composite analysis, but if composited, no information on crosssectional variability can be obtained from the data.

4. A second transect should be collected using the UWI or MEWI method. Four or five verticals should be sampled four or five times each, obtaining a total of 20 samples. Samples should be collected using the same procedure as described in number 2 above except that the sample time for each sample need not be the same. All samples should be bagged and tagged for separate analysis.

5. The following data must be recorded on a field note sheet for each cross-section sample:

Station name/number

Date

Cross-section sample starting and ending times

Gage height at the start and end of sample collection

Total width of the cross section including stations of both banks Width between verticals (SEWI method)

Number of verticals sampled (SEWI method)

Station of verticals sampled (UWI or MEWI method)

Time sampler was on the bottom at each vertical

Type sampler used

Name of person collecting sample

In addition, the following information should be recorded on each sample container:

Station name

Date

Designation of cross-section sample to which the container belongs (that is, if two cross-section samples were collected, one would be "A" and the other "B")

Number of containers for that cross section (for example, "1 of 2" or "2 of 2 ")

Station(s) of the vertical(s) the sample was collected from

Time sampler was on the bottom and at the vertical station

clock time the sample was collected (start and finish if composite)

Collector's initials

Analysis of the first transect (SEWI method) will give some indication of the cross-sectional variability if individual verticals are analyzed 
separately. Analysis of the second set of transects (UWI or MEWI method) will give some indication of temporal variability. As stated before, the procedure described above should be considered the minimum to be followed when first collecting bedload data at a site. Additional samples and transects will help define the temporal and spatial variation at the site for all. flow ranges. After a cross section has been sampled several times at different flow ranges using the above procedure, it should be possible to develop a sampling protocol that fits the site better and will require only 40 samples or less.

\section{Computation of Bedload Discharge Measurements} equation

The bedload transport rate at a sample vertical may be computed by the

$$
R_{i}=\frac{K M_{i}}{t_{i}}
$$

where $R_{i}=$ bedload transport rate, as measured by bedload sampler, at vertical $i$, in tons per day per foot;

$M_{i}=$ mass of the sample collected at vertical $i$, in grams;

$t_{i}=$ time the sampler was on the bottom at vertical $i$, in seconds; and

$K=$ a conversion factor used to convert grams per second per foot into tons per day per foot. It is computed as:

$1 \quad K=\left(86,400 \frac{\mathrm{sec}}{\mathrm{day}}\right) \quad\left(\frac{\text { tons }}{907,200 \mathrm{grams}}\right) \quad\left(\frac{12 \text { inches }}{\mathrm{NW}}\right)$

where $N W$ is the width of the sampler nozzle in inches. For a 3-inch nozzle, $K=0.381$; for a 6 -inch nozzle, $K=0.191$.

The cross-sectional bedload discharge measured by the Helley-Smith sampler may be computed using the total cross-section, midsection, or the mean-section method. The simplest method of calculating bedload discharge from a sample collected with a Helley-smith type bedload sampler is the total cross-section method (fig. 55). This method should only be used if the following three conditions are met:

1. the sample times $\left(t_{i}\right)$ at each vertical are equal;

2. the verticals were evenly spaced across the cross section (that is, SEWI or MEWI method used); and

3. the first sample was collected at one half the sample width from the starting bank.

If these conditions are met, then

$$
Q_{B}=K \frac{W_{T}}{T} M_{T}
$$

where $Q_{B}=$ bedload discharge, as measured by bedload sampler, in tons per day;

$W_{T}=$ total width of stream from which samples were collected, in feet, and is equal to the increment width $\left(W_{I}\right)$ times $n$ ( $n=$ total number of vertical samples); 


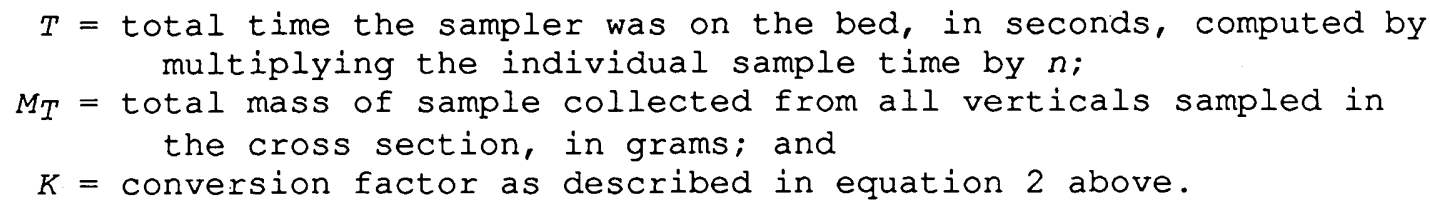

If any of the four conditions stated above are not met, then either the midsection or mean-section method should be used. Mathematically, the two methods, if used with no modifications, will produce identical answers. However, as indicated under the discussion of the UWI method, the placement of the sampling verticals with respect to breaks in the lateral cross-sectional distribution curve of mean bedload transport rate will somewhat dictate which method should be used.

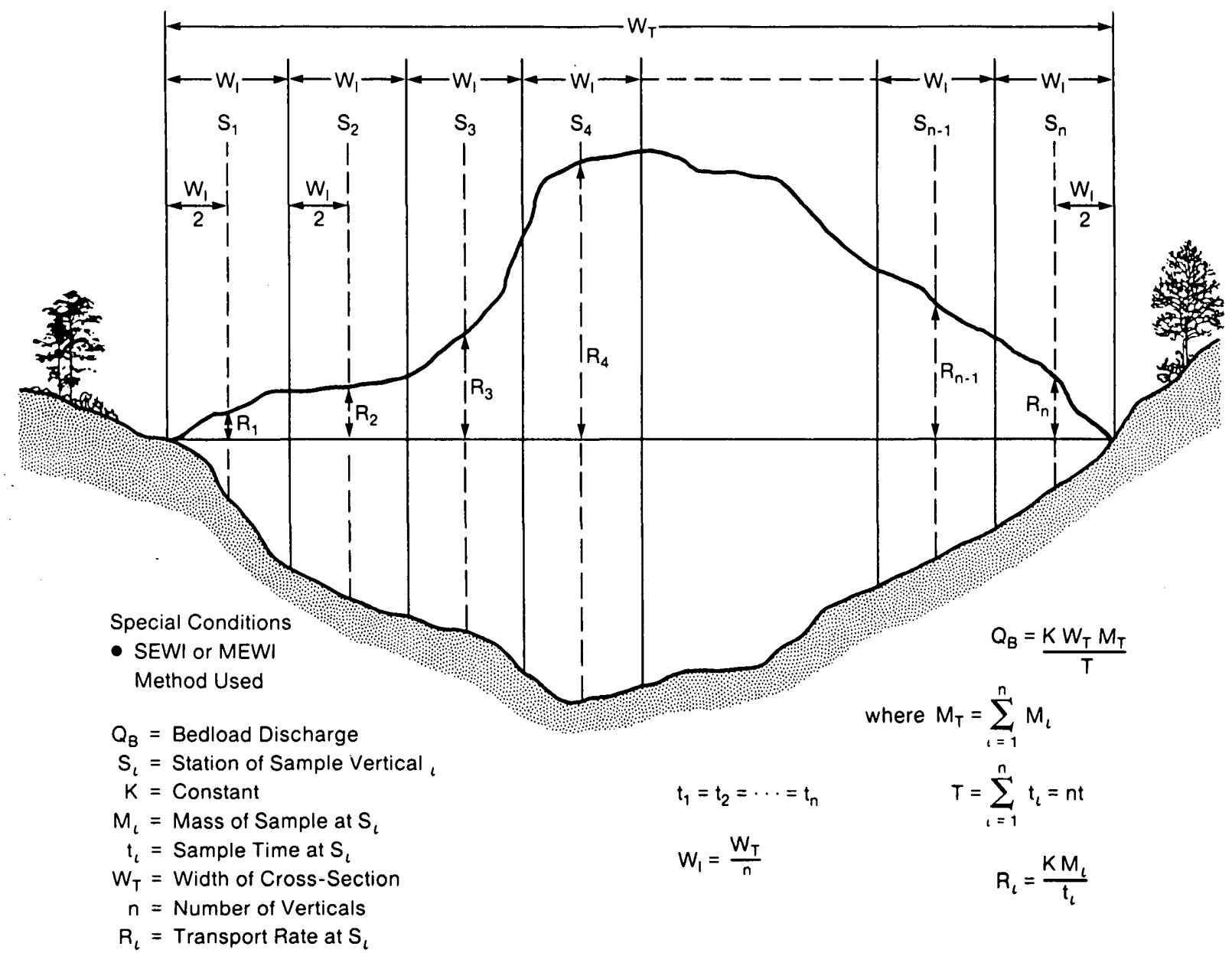

Figure 55.--Total cross-section method for computing bedload discharge from samples collected with a Helley-Smith bedload sampler. 
The midsection method (fig. 56) is computed using the following equation:

$$
Q_{B}=\frac{R_{1} W_{V 2}}{2}+\sum_{i=2}^{n-1} R_{i} \quad\left[\frac{\left(S_{i}-S_{i-1}\right)}{2}+\frac{\left(S_{i+1}-S_{i}\right)}{2}\right]+\frac{R_{n} W_{V n-1}}{2}
$$

where $W_{V_{i}}=$ width between sampling verticals $i$ and $i+1$, in feet;

$S_{i}=$ station of the vertical (i) in the cross section measured from some arbitrary starting point, in feet; and

$Q_{B}, n, R$, and $K$ have previously been defined.

You will note that equation 4 is very similar to the equation used to compute a surface-water discharge measurement. This method corresponds to the midpoint method discussed by Buchanan and Somers (1969) and is the method currently used to compute surface-water discharge measurements.

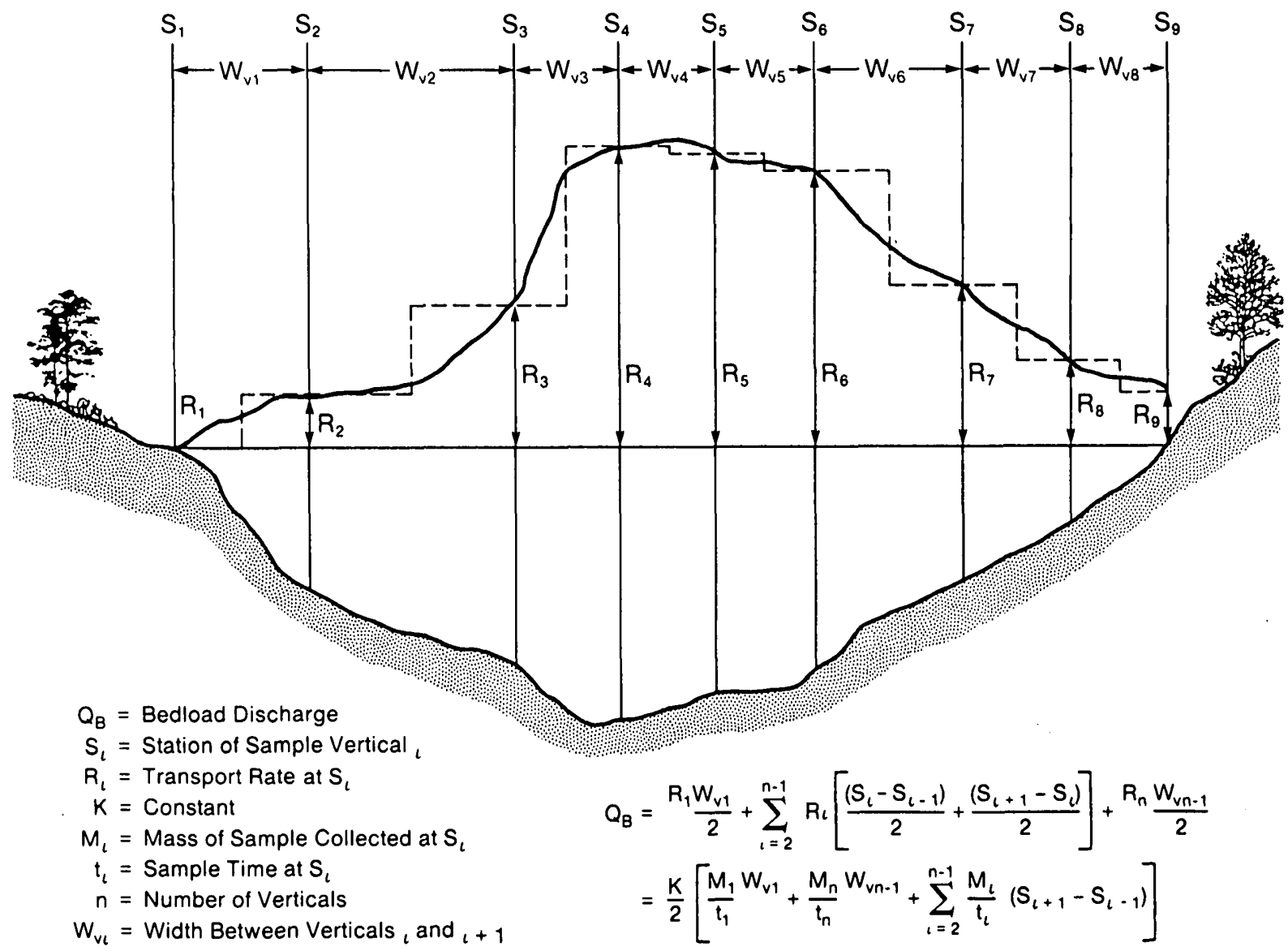

Figure 56.--Midsection method for computing bedload discharge from samples collected with a Helley-Smith bedload sampler. 
By combining equations 1 and 4 and rearranging terms:

$$
Q_{B}=\frac{K}{2}\left[\frac{M_{1} W_{V 1}}{t_{1}}+\frac{M_{n} W_{V n-1}}{t_{n}}+\sum_{i=2}^{n-1} \frac{M_{i}}{t_{i}}\left(s_{i+1}-s_{i-1}\right)\right]
$$

One advantage to using the midsection method is that the distance $W_{V}$ need not necessarily be equal to the distance between sampling verticals. At times it may become apparent, due to local conditions, that a particular $R_{i}$ should not be applied over a width equal to halfway back to the last station and halfway forward to the next, but applied to some other width. This width, sometimes referred to as the effective width, is decided upon by the user. Bridge piers, large boulders, abrupt changes in velocity or lateral bed topography, or other conditions that may obstruct or cause sudden changes to bedload transport rate will affect the selection of the effective width.

The third method, the mean-section method (fig. 57), is computed using the following equation:

$$
Q_{B}=\sum_{i=1}^{n-1} W_{V i} \frac{\left(R_{i}+R_{i+1}\right)}{2}
$$

which is equivalent to:

$$
Q_{B}=\frac{K}{2} \sum_{i=1}^{n-1} W_{V i}\left(\frac{M_{i}}{t_{i}}+\frac{M_{i+1}}{t_{i+1}}\right)
$$

All the above terms are the same as used in the midsection method. This method averages the two adjoining rates and applies the average rate over the distance between them. For this reason it is important to try to place the sampling verticals at points where the trends in lateral mean bedload transport rate change. Under most field conditions, this might be difficult.

For situations where the total cross-section method cannot be used, it is recommended that the midsection method be used. This recommendation is made because of its similarity to the surface-water discharge measurement method, which most field personnel are familiar with, and the flexibility in using the effective width concept.

Collecting bedload samples will generate 40 or more samples, creating a potential problem regarding transportation and analyses of so many samples. Carey (1984) adapted a procedure for measuring the submerged weight of bedload samples in the field and converting that measurement to dry weight from a laboratory procedure used by Hubbell and others (1981). The method uses the basic equation

$$
W_{d S}=\frac{S G_{S}}{S G_{S-1}} W_{S S}
$$

where $W_{d S}=$ dry weight of the sediment;

$S G_{S}=$ specific gravity of the sediment; and

$W_{S S}=$ submerged weight of the sediment. 


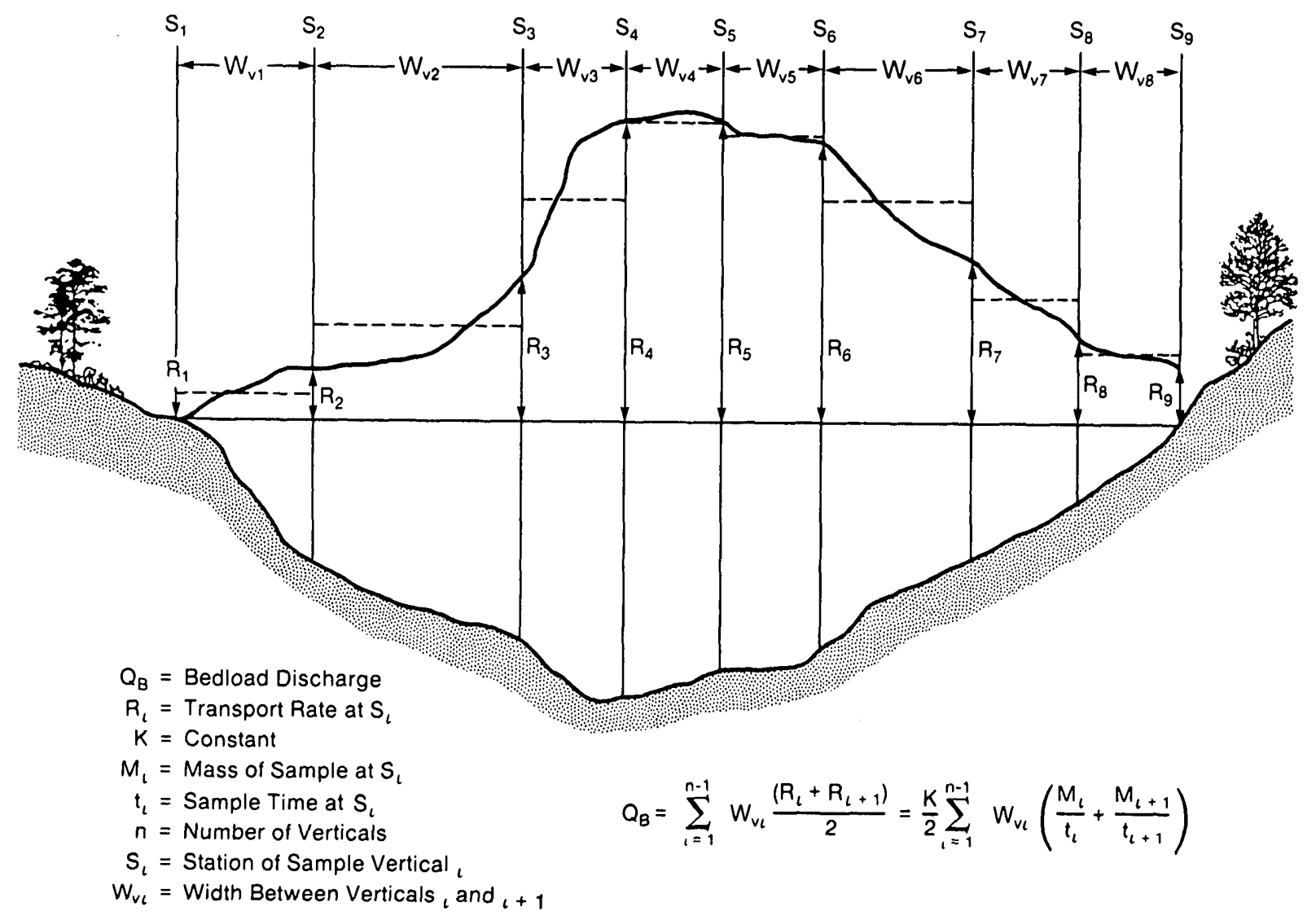

Figure 57.--Mean-section method for computing bedload discharge from samples collected with a Helley-Smith bedload sampler.

\section{MEASUREMENTS FOR TOTAL SEDIMENT DISCHARGE}

Total sediment discharge is the mass of all sediment moving past a given cross section in a unit of time. It can be defined as the sum of the (1) measured and unmeasured sediment discharges, (2) suspended-sediment discharge and bedload discharge, or (3) fine-material discharge (sometimes referred to as the washload) and coarse-material or bed-material discharge.

There are some sandbed streams with sections so turbulent that nearly all sediment particles moving through the reach are in suspension. Sampling the suspended sediment in such sections with a standard suspended-sediment sampler represents very nearly the total load. Several streams with turbulent reaches are described in Benedict and Matejka (1953). Further discussion concerning total-load measurement can also be found in Interagency Report 14 (F.I.S.P., 1963b, p. 105-115). Turbulence flumes or special weirs can be used to bring the total load into suspension. Total load can usually be sampled with suspended-sediment samplers to a high degree of accuracy where the streambed consists of an erosion-resisting material, such as bedrock or a very cohesive clay. In such situations the majority if not all the sediment being discharged is in suspension (or the bed would contain a deposit of sand). 
Benedict and Matejka (1953) and Gonzales and others (1969) have described some structures used for artificial suspension of sediment to enable total-load sampling. However, most total-load sampling is usually accomplished at the crest of a small weir, dam, culvert outlet, or other place where the sampler nozzle integrates throughout the full depth of flow from the surface to the top of the weir.

Where such conditions or structures are not present, the unmeasured load must be computed by various formulas. The unmeasured load can be approximated by use of a bedload formula such as that of Meyer-Peter and Muller (1948), Einstein (1950), Colby and Hembree (1955), or Chang and others (1965). However, these computational procedures can give widely varying answers. The colby and Hembree method (modified Einstein) determines the total load in terms of the amount transported for different particle-size ranges. Colby and Hubbell (1961) later simplified the modified Einstein method to include the use of four nomographs in lieu of a major computational step. The essential data required for the Colby and Hubbell technique at a particular time and location are listed here:

1. stream width, average depth, and mean velocity;

2. average concentration of suspended sediment from depth-integrated samples;

3. size analyses of the suspended sediment included in the average concentration;

4. average depth of the verticals where the suspended-sediment samples were collected;

5. size analyses of the bed material; and

6. water temperature.

Stevens (1985) has developed two computer programs for the computation of total sediment discharge by the modified Einstein procedure. One program is written in FORTRAN 77 for use on the PRIME computer; the other program is in BASIC and can be used on most microcomputers.

\section{RESERVOIR-TRAP EFFICIENCY}

The efficiency with which a reservoir traps sediment depends mostly on its size with respect to the rate of inflow. Other factors may include the reservoir shape, its operation, the water quality, and the size and kind of inflowing sediment. Except for small detentions with bottom outlets, all of the sand-sized and much of the silt-sized particles would be expected to be trapped. An evaluation of reservoir-trap efficiency must involve measurements of the quantity and size characteristics of the sediment entering and leaving the reservoir (Mundorff, 1964, 1966). Sometimes measurements of sediment accumulation in the reservoir plus the sediment output are used as a practical method of evaluating the sediment yield of the drainage basin. 


\section{Inflow Measurements}

On many reservoirs, trap efficiency cannot be evaluated in sufficient detail from measurements of accumulation and sediment outflow. For such reservoirs, it is necessary to measure the sediment discharge and particle size entering the reservoirs. This measurement requires that stations be operated daily or continuously on streams feeding into the reservoir. Trap efficiency on a storm-event basis can be determined if several samples adequately define the concentration of the inflow and outflow hydrographs. For small detention reservoirs, it may be difficult or impractical to measure the inflow on a daily basis. If a continuous record is not possible, the objective should be to obtain observations sufficient to define the conditions for several inflow hydrographs so that a storm-event sediment-transport curve can be constructed for use in estimating the sediment moved by the unsampled storms (GuY, 1965).

If it is impractical to obtain sufficient data to define the sediment content of several storm events, the least data for practical analysis should include 10 or 15 observations per year so that an instantaneous sedimenttransport curve can be constructed (Miller, 1951). It is expected that the instantaneous curve will yield less accurate results than the storm-event curve, which in turn will be less accurate than the continuous record. Each of the transport-curve methods may require data for a range of conditions so that adjustments can be determined for the effect of time of year, antecedent conditions, storm intensity, and possibly for the storm location in the basin (Colby, 1956; Jones, 1966).

As for most new sediment stations, particle-size analysis should be made on several of the inflow observations during the first year. These particlesize observations will then form a base, which may make it possible to reduce the number of analyses required in future years.

\section{Qutflow Measurements}

The outflow from a reservoir is drastically different from the inflow because of the attenuating effect of the flow through the reservoir or because of possible willful control in the release of water (Carter and Godfrey, 1960; Mitchell, 1962). Logically, the smaller reservoirs, which are likely to have fixed outlets and the poorest trap efficiencies, require the most thorough outflow-measurement schedules. If an inflow-outflow relation for sediment discharge can be constructed, such a relation may change considerably in the direction of greater sediment output (lower trap efficiency) as the reservoir fills with sediment.

Normally, the particle size of sediment outflow is expected to be finer than for the inflow; therefore, the concentration of outflowing sediment should not fluctuate as rapidly as that of the inflow. The normal slowly changing outflow concentration may not occur if the outflow is from the vicinity of the interface involving a density current.

A desirable sampling schedule for outflow may vary from once a week for the large reservoir to several observations during a storm event for a small reservoir. The need for outflow particle-size data will also depend on the scale of the stream and reservoir system, the trap efficiency, and how well the inflow is defined. With respect to quality control, if the trap efficiency of a reservoir is expected to be more than 95 percent and if the sediment inflow can only be measured to the nearest 10 or 15 percent of its 
expected true value, it is not necessary to measure the sediment outflow in great detail unless there is a need to accurately define the amount of sediment in the flow downstream from the reservoir.

\section{Sediment Accumulation}

The small reservoir or detention basin can be used--if trap efficiency can be estimated or measured--to provide a measure of the average annual sediment yield of a drainage basin. This method is useful in very small basins where the inflow is difficult to measure and where the amount of water-inflow and sediment-concentration data are not important.

For small catchment basins or reservoirs on ephemeral streams (those that are dry most of the time), the determination of sediment accumulation involves a plane table or other detailed survey of the reservoir from which stage-capacity curves can be developed--usually 1-foot contours for the lower parts of the reservoirs and 2- to 5-foot intervals for the upper parts, depending on the terrain and size of the reservoir (Peterson, 1962). The accretion of sediment can then be measured either by monumented range lines in the reservoir or by resurvey for a new stage-capacity curve.

For reservoirs not dry part of the time, the sediment accumulation is usually measured by sounding on several monumented range lines spaced to provide a representative indication of the sediment accumulation between measurements. Methods for reservoir surveys are described by Heinemann (1961), Porterfield and Dunnam (1964), Vanoni (1975), and Randle and Blanton (1986). A summary of reservoir sediment deposition surveys made in the United States through 1975 was compiled by Dendy and Champion (1978). The period from 1976 to 1980 has been covered by the Interagency Advisory Committee on Water Data's Subcommittee on Sediment (1983).

In order to convert the measurements of sediment volume found in reservoirs to the usual expression of mass of sediment yield, it is necessary that the sedimentation surveys of reservoirs include information on the volume mass of sediment. Heinemann (1964) reports that this was accomplished in Sebetha Lake, Kansas, using a gamma probe and a piston sampler. From his data obtained at 41 locations, he found that the best equation for predicting volume mass is

$$
V_{m}=1.688 \mathrm{D}-0.888 \mathrm{C}+98.8
$$

where $V_{m}$ is the dry unit volume mass in pounds per cubic foot, $D$ is the depth of sample from the top of the deposit, and $C$ is the percentage of clay smaller than $0.002 \mathrm{~mm}$.

On the basis of 1,316 reservoir deposit samples, Lara and Pemberton (1965) found the unit volume mass to vary according to changes in reservoir operation and to the fraction of clay, silt, and sand. Guy (Office of Water Data Coordination, 1978) reported that refinements based on reservoir operation, sediment size, and compaction could be made to the estimates made by Lara and Pemberton (1965) and Lane and Koelzer (1943). The following formula, along with factors listed in table 4, may be used to estimate dry unit volume mass:

$$
v_{m}=v_{t c p_{C}}+v_{t m p_{m}}+v_{t s} p_{s}
$$


where $V_{m}=$ dry unit volume mass, in pounds per cubic foot;

$V_{t}=$ dry unit volume mass as computed in equation 8 , in pounds per cubic foot;

$c=$ clay size material;

$m=$ silt size material;

$s=$ sand size material;

$p=$ percent of total sample, by weight, in size class (clay, silt, sand); and

$$
v_{t}=V_{i}+0.43 K\left[\frac{T}{T-1}(\log T)-1\right]
$$

where $V_{i}=$ initial unit volume mass, in pounds per cubic foot from table 4;

$K=$ Lane and Koelzer factors from table 4, in pounds per cubic foot; and

$T=$ time after deposition in years.

Table 4.--Initial dry unit volume mass $\left(V_{i}\right)$ and $K$ factors for computing dry unit volume of sediment deposits in pounds per cubic foot (Guy, Office of water Data Coordination, 1978)

\begin{tabular}{|c|c|c|c|c|c|c|}
\hline \multirow[b]{2}{*}{ Type of reservoir operation } & \multicolumn{3}{|c|}{$V_{i}$} & \multicolumn{3}{|c|}{$K$} \\
\hline & Clay & silt & Sand & Clay & silt & Sand \\
\hline 1. Sediment submerged & 26 & 70 & 97 & 16 & 5.7 & 0 \\
\hline $\begin{array}{l}\text { 2. Moderate to considerable } \\
\text { annual drawdown }\end{array}$ & 35 & 71 & 97 & 8.4 & 1.8 & 0 \\
\hline 3. Normally empty & 40 & 72 & 97 & 0 & 0 & 0 \\
\hline 4. River sediments & 60 & 73 & 97 & 0 & 0 & 0 \\
\hline
\end{tabular}

\section{SUMMARY}

In retrospect, it must be emphasized that field methods for fluvialsediment measurements must be coordinated with methods for other hydrologic and environmental measurements. With the ever-increasing requirements of a thorough data acquisition system, together with advances in technology, it must be expected that methods will continue to change in the future. For example, because there is a foreseeable need for increasing water-pollution surveillance studies with respect to stream-quality standards, it is apparent that a continuous recording of some indicator of sediment conditions is badly needed at a very large number of sites. Consequently, the F.I.S.P. has undertaken the development of sensors and automatic pumping-type samplers with a view toward continuously recording the concentration of sediment that moves in streams. The development of such automatic equipment is likely to enhance rather than detract from the need for conventional "manual" observations.

The authors sincerely hope that the material regarding the equipment and techniques for sampling presented herein will stimulate the ongoing development of better equipment and techniques for the future and at the same time help to "standardize" and make more efficient the day-to-day operations. 
The opportunity certainly exists at the field level for many innovations for improving the end product or the sediment record. Some field people, for example, may like to carry a copy of the station stage-discharge rating curve, on which all particle-size analyses are recorded, showing date and kind of sample for each measuring site. As communications and river forecasting become more sophisticated, it may be possible to have better dialogue between the office and the field people or local observers who are trying to obtain the maximum information at many sampling sites. Such communication is especially critical during periods of flooding when timely data are most important.

In addition to increasing coordination of sediment-data activities with other related measurements, it is important to stress that adequate notes be obtained (including pictures) so that those involved in the laboratory analysis of the samples, those responsible for preparing the record, and especially those responsible for interpreting the data can properly "read" what happened at the sample site. The amount of new information to be obtained from data interpretation is seriously affected by the quality of the information with respect to timing and representativeness of the sediment measurements.

It also seems desirable in this summary to further emphasize the need for a concerted and continuing effort with respect to safety in the measurement program. Aside from the hazards of highway driving, the work usually involves the use of heavy equipment during floods or other unusual natural events, often in darkness and under unpleasant weather conditions. Even though the hazards of working from highway bridges and cableways are mostly self-evident, there are many opportunities for the "unusual" to happen; and, therefore, a great deal of effort must be expended to ensure safety. Such effort, of course, must be increased when it is necessary to accomplish the work in a limited amount of time and with a reduced work force.

\section{SELECTED REFERENCES}

American Society for Testing and Materials, 1987, Annual Book of American Society for Testing and Materials Standards: Water and Environmental Technology, Section 11, v. 11.02, 1,083 p.

Beetem, W. A., Janzer, V. J., and Wahlberg, J. S., 1962, Use of cesium-137 in the determination of cation exchange capacity: U.S. Geological Survey Bulletin 1140-B, $8 \mathrm{p}$.

Benedict, P. C., and Matejka, D. Q., 1953, The measurement of total sediment load in alluvial streams: in Proceedings of the Fifth Iowa Hydraulics Conference, Engineering Bulletin 34, Iowa University, Iowa City, Iowa, p. 263-286.

Buchanan, T. J., and Somers, W. P., 1968, Stage measurement at gaging stations: U.S. Geological Survey Techniques of Water-Resources Investigations, Book 3, Chapter A7, $28 \mathrm{p}$.

1969, Discharge measurements at gaging stations: U.S. Geological Survey Techniques of Water-Resources Investigations, Book 3, Chapter A8, 65 p.

Carey, W. P., 1984, A field technique for weighing bedload samples: Water Resources Bulletin, American Water Resources Association, v. 20, no. 2, p. 261-265. 
1985, Variability in measured bedload-transport rates: Water Resources Bulletin, American Water Resources Association, v. 21, no. 1, p. 39-48.

Carter, R. W., and Davidian, Jacob, 1968, General procedure for gaging streams: U.S. Geological Survey Techniques of Water-Resources Investigations, Book 3, Chapter A6, $13 \mathrm{p}$.

Carter, R. W., and Godfrey, R. G., 1960, Storage and flood routing: U.S. Geological Survey Water-Supply Paper 1543-B, p. 102-104.

Chang, F. M., Simons, D. B., and Richardson, E. V., 1965, Total bed-material discharge in alluvial channels: U.S. Geological Survey Water-Supply Paper 1498-I, $23 \mathrm{p}$.

Colby, B. R., 1956, Relationship of sediment discharge to streamflow: U.S. Geological Survey Open-File Report, $170 \mathrm{p}$.

1963, Fluvial sediments--a summary of source, transportation, deposition, and measurement of sediment discharge: U.S. Geological Survey Bulletin 1181-A, $47 \mathrm{p}$.

1964, Discharge of sands and mean-velocity relationships in sand-bed streams: U.S. Geological Survey Professional Paper 462-A, 47 p.

Colby, B. R., and Hembree, C. H., 1955, Computations of total sediment discharge, Niobrara River near Cody, Nebraska: U.S. Geological Survey Water-Supply Paper 1357, $187 \mathrm{p}$.

Colby, B. R., and Hubbell, D. W., 1961, Simplified methods for computing total sediment discharge with the modified Einstein procedure: U.S. Geological Survey Water-Supply Paper 1593, 17 p.

Culbertson, D. M., Young, L. E., and Brice, J. C., 1967, Scour and fill in alluvial channels, with particular reference to bridge sites: U.S. Geological Survey Open-File Report, $58 \mathrm{p}$.

Dendy, F. E., and Champion, W. A., 1978, Sediment deposition in United States Reservoirs, summary of data reported through 1975: U.S. Department of Agriculture, Agricultural Research Service, Miscellaneous Publication $1362,84 \mathrm{p}$.

Druffel, Leroy, Emmett, w. W., Schneider, V. R., and Skinner, J. V., 1976, Laboratory hydraulic calibration of the Helley-Smith bedload sediment sampler: U.S. Geological Survey Open-File Report 76-752, 63 p.

Einstein, H. A., 1937, Die Eichung des im Rhein verwenderen Geschiebefangers [Calibrating the bedload trap as used in the Rhine]: Schweizer, Bauzeitung, v. 110, no. 12, p. 29-32.

1950, The bed-load function for sediment transportation in open channel flows: U.S. Department of Agriculture Technical Bulletin 1026, $70 \mathrm{p}$.

Emmett, W. W., 1975, The channels and waters of the upper Salmon River area, Idaho: U.S. Geological Survey Professional Paper 870-A, P. A1-A116 and i-viii. 
1980a, A field calibration of the sediment-trapping characteristics of the Helley-Smith bedload sampler: U.S. Geological Survey Professional Paper $1139,44 \mathrm{p}$.

1980b, Bedload sampling in rivers: International Symposium on River Sedimentation, Beijing, China, p. 991-1017.

Emmett, W. W., Leopold, L. B., and Myrick, R. M., 1983, Some characteristics of fluvial processes in rivers: in Proceedings of the Second International Symposium on River sedimentation, Nanjing, China, 29 p.

Emmett, W. W., and Seitz, H. R., 1974, Suspended and bedload sediment transport in the Snake and Clearwater Rivers in the vicinity of Lewiston, Idaho - July 1973 through July 1974: U.S. Geological Survey basic-data report, $76 \mathrm{p}$.

Federal Interagency Sedimentation Project, 1941, Laboratory investigation of suspended-sediment samplers--Interagency Report 5: Iowa City, Iowa University Hydraulics Laboratory, $99 \mathrm{p}$.

1951, Field tests on suspended-sediment samplers, Colorado River at Bright Angel Creek near Grand Canyon, Arizona--Interagency Report $\mathrm{F}$ : Iowa City, Iowa University Hydraulics Laboratory, $119 \mathrm{p}$.

1952, The design of improved types of suspended-sediment samplers-Interagency Report 6: Minneapolis, Minnesota, St. Anthony Falls Hydraulics Laboratory, $103 \mathrm{p}$.

1958, Operating instructions for US DH-48 suspended-sediment hand sampler--Interagency Report J: Minneapolis, Minnesota, St. Anthony Falls Hydraulics Laboratory, $5 \mathrm{p}$.

1959, Sedimentation instruments and reports--Interagency Report $A A$ : Minneapolis, Minnesota, St. Anthony Falls Hydraulics Laboratory, 38 p.

1961, The single-stage sampler for suspended-sediment--Interagency Report 13: Minneapolis, Minnesota, st. Anthony Falls Hydraulics Laboratory, $105 \mathrm{p}$.

1963a, A summary of the work of the Federal Interagency Sedimentation Project--Interagency Report S: Minneapolis, Minnesota, St. Anthony Falls Hydraulics Laboratory, 29 p.

1963b, Determination of fluvial sediment discharge--Interagency Report 14: Minneapolis, Minnesota, St. Anthony Falls Hydraulics Laboratory, $151 \mathrm{p}$.

1964, Operation and maintenance of US-BM-54 bed-material sampler-Interagency Report M: Minneapolis, Minnesota, St. Anthony Falls Hydraulics Laboratory, $16 \mathrm{p}$.

1965, Instructions for sampling with depth-integrating suspendedsediment samplers, US D-49 and DH-59--Interagency Report O: Minneapolis, Minnesota, St. Anthony Falls Hydraulics Laboratory, $7 \mathrm{p}$. 1966, Laboratory investigation of pumping-sampler intakes--Interagency Report T: Minneapolis, Minnesota, St. Anthony Falls Hydraulics Laboratory, $59 \mathrm{p}$. 
1974, An investigation of a device for measuring the bulk density of water-sediment mixtures--Interagency Report U: Minneapolis, Minnesota, St. Anthony Falls Hydraulics Lab, $35 \mathrm{p}$.

1976, Instructions for sampling with depth-integrating, suspendedsediment samplers, D-74, D-74 AL, D-74 TM, and D-74 AL-TM--Interagency Report: Minneapolis, Minnesota, St. Anthony Falls Hydraulics Laboratory, $13 \mathrm{p}$.

1981a, Instruments and reports for fluvial sediments investigations-Interagency Report Catalog: Minneapolis, Minnesota, St. Anthony Falls Hydraulics Laboratory, $134 \mathrm{p}$.

1981b, Test and design of automatic fluvial suspended-sediment samplers-Interagency Report W: Minneapolis, Minnesota, St. Anthony Falls Hydraulics Laboratory, $53 \mathrm{p}$.

1982, A fluid-density gage for measuring suspended-sediment concentration--Interagency Report X: Minneapolis, Minnesota, St. Anthony Falls Hydraulics Laboratory, $125 \mathrm{p}$.

1982, Development of a bag-type suspended-sediment sampler--Interagency Report Y: Minneapolis, Minnesota, St. Anthony Falls Hydraulics Laboratory, $32 \mathrm{p}$.

1982, Theory and operation manual for the auto pipet semiautomatic pipet withdrawal apparatus--Interagency Report Z: Minneapolis, Minnesota, St. Anthony Falls Hydraulics Laboratory, $71 \mathrm{p}$.

1983, Operator's manual, PS-82 automatic pumping sampler--Interagency Draft Report: Minneapolis, Minnesota, St. Anthony Falls Hydraulics Laboratory, $34 \mathrm{p}$.

Gonzales, D. D., Scott, C. H., and Culbertson, J. K., 1969, Stage-discharge characteristics of a weir in a sand-channel stream: U.S. Geological Survey Water-Supply Paper 1898-A, 29 p.

Guy, H. P., 1965, Residential construction and sedimentation at Kensington, Maryland, in Proceedings of the Federal Interagency Sedimentation Conference, Jackson, Mississippi, 1963: U.S. Department of Agriculture, Agriculture Research Service, Miscellaneous Publication 970, p. 30-37.

1968, Quality control of adjustment coefficients, in Geological survey Reseärch 1968: U.S. Geological Survey Professional Paper 600-B, p. B165-B168.

1969, Laboratory theory and methods for sediment analysis: U.S. Geological Survey Techniques of Water-Resources Investigations, Book 5, Chapter C1, $58 \mathrm{p}$.

1970, Fluvial sediment concepts: U.S. Geological Survey Techniques of Water-Resources Investigations, Book 3, Chapter C1, 52 p.

Guy, H. P., and Simons, D. B., 1964, Dissimilarity between spatial and velocity-weighted sediment concentrations, in Short papers in Geology and Hydrology: U.S. Geological Survey Professional Paper 475-D, P. D134-D137. 
Guy, H. P., Simons, D. B., and Richardson, E. V., 1966, Summary of alluvial channel data from flume experiments, 1956-61: U.S. Geological Survey Professional Paper 462-I, $96 \mathrm{p}$.

Hamamori, A., 1962, A theoretical investigation on the fluctuations of bedload transport: Delft Hydraulics Laboratory, Report R4, 21 p.

Heinemann, H. G., 1961, Sediment distribution in small floodwater-retarding reservoirs in the Missouri Basin Loess Hills: U.S. Department of Agriculture, ARS $41-44,37 \mathrm{p}$.

1964, Volume-weight of reservoir sediment: American Society of Cịvil Engineers Transactions, v. 129, p. 64-66.

Helley, E. J., and Smith, Winchell, 1971, Development and calibration of a pressure-difference bedload sampler: U.S. Geological Survey Open-File Report 8037-01, $18 \mathrm{p}$.

Hubbell, D. W., 1960, Progress report no. 2, Investigations of some sedimentation characteristics of sand-bed streams: U.S. Geological Survey Open-File Report, $54 \mathrm{p}$.

1964, Apparatus and techniques for measuring bedload: U.S. Geological Survey Water-Supply Paper 1748, $74 \mathrm{p}$.

Hubbell, D. W., and others, 1956, Progress report no. 1, Investigations of some sedimentation characteristics of a sand-bed stream: U.S. Geological Survey Open-File Report, $78 \mathrm{p}$.

Hubbell, D. W. and Stevens, H. H., 1986, Factors affecting accuracy of bedload sampling: Proceedings of the Fourth Federal Interagency Sedimentation Conference, v. 1 , p. 4-20 to 4-29..

Hubbell, D. W., Stevens, H. H., Skinner, J. V., and Beverage, J. P., 1981, Recent refinements in calibrating bedload samplers: Proceedings of the Specialty Conference, Water Forum 1981, American Society of Civil Engineers, San Francisco, California, v. 1, $13 \mathrm{p}$.

1985, New approach to calibrating bedload samplers: American Society of Civil Engineers Journal of Hydraulic Engineering, v. III, no. 4, p. 677694 .

Interagency Advisory Committee on Water Data, Subcommittee on Sediment, 1983, Sediment deposition in U.S. Reservoirs, Summary of data reported through 1976-80: U.S. Geological Survey, Office of Water Data Coordination, 32 p.

Jones, B. L., 1966, Effects of agricultural conservation practices on the hydrology of Corey Creek basin, Pennsylvania, 1954-60: U.S. Geological Survey Water-Supply Paper 1532-C, 55 p.

Kellerhals, Rolf, 1967, Stable channels with gravel paved beds: Waterways and Harbors Division Journal, American Society of Civil Engineers Proceedings, v. 93, no. WW1, p. 63. 
Lane, E. W., and Carlson, E. J., 1953, Some factors affecting the stability of canals constructed in coarse granular materials: Minneapolis, Minnesota, International Association for Hydrologic Research.

Lane, E. W., and Koelzer, V. A., 1943, Density of sediments deposited in reservoirs: Federal Interagency Sedimentation Project Report No. 9, Iowa City, Iowa University Hydraulics Laboratory, 60 p.

Lara, J. M., and Pemberton, E. L., 1965, Initial unit weight of deposited sediments, in Proceedings of the Federal Interagency Sedimentation Conference, Jackson, Mississippi, 1963: U.S. Department of Agriculture, Agriculture Research Service, Miscellaneous Publication 970, p. 818-845.

Leopold, L. B., and Emmett, W. W., 1977, 1976 bedload measurement, East Fork River, Wyoming: Proceedings of the National Academy of Sciences, v. 74, no. 7, p. 2644-2648.

Leopold, L. B., Wolman, M. G., and Miller, J. P., 1964, Fluvial processes in geomorphology: W. H. Freeman and Company, San Francisco, California, $522 \mathrm{p}$.

Mclean, D. G., and Tessone, B., (in press), Discussion of bedload sampling and analysis, by David $W$. Hubbell, in Problems of sediment transport in gravel-bed streams (C. R. Thorne and others, eds.): Sussex, England, John Wiley.

Meyer-Peter, E., and Muller, R., 1948, Formulas for bed-load transport: International Association of Hydraulic Structures Research, 2d meeting, Stockholm, Sweden, p. 39-64.

Miller, C. R., 1951, Analysis of flow-duration, sediment rating curve method of computing sediment yield: U.S. Bureau of Reclamation Report, $15 \mathrm{p}$.

Mitchell, W. D., 1962, Effect of reservoir storage on peak flow: U.S. Geological Survey Water-Supply Paper 1580-C, 25 p.

Mundorff, J. C., 1957, A handline suspended-sediment sampler: U.S. Geological Survey Open-File Report, 2 p.

1964, Fluvial sediment in Kiowa Creek basin, Colorado: U.S. Geological Survey Water-Supply Paper 1798-A, $70 \mathrm{p}$.

1966, Sedimentation in Brownell Creek sub-watershed No. 1, Nebraska:

U.S. Geological Survey Water-Supply Paper 1798-C, 49 p.

Office of Water Data Coordination, 1978, National Handbook of Recommended Methods for Water-Data Acquisition: U.S. Geological Survey, Chapter 3 Sediment, $100 \mathrm{p}$.

Peterson, H. V., 1962, Hydrology of small watersheds in western states: U.S. Geological Survey Water-Supply Paper 1475-I, p. 223-227.

Porterfield, George, 1972, Computation of fluvial sediment discharge: U.S. Geological Survey Techniques of Water-Resources Investigations, Book 3, Chapter C3, 66 p. 
Porterfield, George, and Dunnam, C. A., 1964, Sedimentation of Lake Pillsbury, Lake County, California: U.S. Geological Survey Water-Supply Paper $1619-\mathrm{EE}, 46 \mathrm{p}$.

Prych, E. A., and Hubbell, D. W., 1966, A sampler for coring sediments in rivers and estuaries: Geological Society of America Bulletin, v. 77, p. 549-556.

Randle, T. J., and Blanton, J. O., III, 1986, Underwater mapping river channels and reservoirs: in Proceedings of the Fourth Federal Interagency Sedimentation Conference, v. 1, p. 1-79 to 1-88..

Simons, D. B., and Richardson, E. V., 1965, A study of variables affecting flow characteristics and sediment transport in alluvial channels, in Proceedings of the Federal Interagency Sedimentation Conference, Jackson, Mississippi, 1963: U.S. Department of Agriculture, Agriculture Research Service, Miscellaneous Publication 970, p. 193-207.

1966, Resistance to flow in alluvial channels: U.S. Geological Survey Professional Paper 422-J, $61 \mathrm{p}$.

Skinner, J. V., 1982, Proposed practice for sampling fluvial sediment in motion: Published for information only. Annual Book of American Society for Testing and Materials Standards, Part 31, 24 p.

Stevens, H. H., Jr., 1985, Computer program for the computation of total sediment discharge by the modified Einstein procedure: U.S. Geological Survey Water-Resources Investigations Report 85-4047, 76 p.

Thornbury, W. D., 1969, Principles of geomorphology, (2d ed.): New York, John wiley, $594 \mathrm{p}$.

Vanoni, V. A., ed., 1975, Sedimentation Engineering: American Society of Civil Engineers Manuals and Reports on Engineering Practice No. 54, 745 p.

Winterstein, T. A., and Stefan, H. E., 1983, Suspended-sediment sampling in flowing water: Laboratory study of the effects of nozzle orientation withdrawal rate and particle size: St. Anthony Ealls Hydraulic Laboratory External Memorandum No. M-168, University of Minnesota, Minneapolis, Minnesota, $97 \mathrm{p}$.

Wolman, M. G., 1954, A method of sampling coarse river bed material: American Geophysical Union Transcript, v. 35, no. 6, p. 951. 